Daniela Munhoz Rossoni

\title{
Integração morfológica craniana em morcegos da Família Phyllostomidae
}

\author{
Morphological integration on phyllostomid bat skulls \\ (Chiroptera: Phyllostomidae)
}

Orientador: Prof. Dr. Gabriel Marroig 



\title{
Daniela Munhoz Rossoni
}

\section{Integração morfológica craniana em morcegos da Família Phyllostomidae}

\author{
Morphological integration on phyllostomid bat skulls \\ (Chiroptera: Phyllostomidae)
}

Tese apresentada ao Instituto de Biociências da Universidade de São Paulo, para obtenção de título de Doutora em Genética e Evolução, na área de Biologia/Genética.

Orientador: Prof. Dr. Gabriel Marroig 


\section{Ficha Catalográfica}

Rossoni, Daniela Munhoz

Integração morfológica craniana em morcegos da Família Phyllostomidae

234 páginas

Tese (Doutorado) - Instituto de Biociências da Universidade de São Paulo. Departamento de Genética e Biologia Evolutiva.

1. Integração morfológica 2. Modularidade 3. Evolução Morfológica 4. Phyllostomidae I. Universidade de São Paulo. Instituto de Biociências. Departamento de Genética e Biologia Evolutiva.

\section{Comissão Julgadora:}

Prof. Dr(a)

Prof. Dr.(a)

\begin{tabular}{c}
\hline Prof. Dr(a) \\
\hline Prof. Dr.(a)
\end{tabular}

Prof. Dr. Gabriel Marroig

Orientador 
Aos meus pais e à minha irmã, com carinho:

Vera Sílvia Munhoz Rossoni (in memoriam)

Daneu Rossoni

Fabiane M. Rossoni Bauab 
“... It is strange how absorbing this work is. We forget the outside world. It was walking along one day with a light step feeling young and happy when the wind blew a wisp of white hair across my eyes and reminded me!"

Annie Montague Alexander 


\section{AGRADECIMENTOS}

Meus mais sinceros agradecimentos ao Dr. Gabriel Marroig pela orientação, confiança e ensinamentos ao longo desses anos. Obrigada por estar sempre presente, pelas ricas discussões e por transmitir no seu vasto conhecimento o prazer de se fazer ciência com primor. Você é sem dúvida um exemplo prá mim! E, além de um grande orientador, você é meu amigo.

À Dra. Elizabeth Dumont pela co-orientação durante a minha permanência nos Estados Unidos, e pelas colaborações presentes e futuras.

Ao Dr. Norberto Giannini pelo grande auxílio na definição dos marcadores anatômicos nos morcegos filostomídeos, sem dúvida o maior desafio desse trabalho.

À FAPESP e à CAPES pelas bolsas concedidas e pelo apoio financeiro à esta pesquisa.

Aos curadores e técnicos administradores das coleções científicas que visitei no Brasil e nos Estados Unidos, meu muito obrigada por garantirem o bom andamento da minha coleta de dados: Mário de Vivo e Juliana Gualda (Museu de Zoologia da Universidade de São Paulo, MZUSP); Eliana Morielle Versute (Coleção de Chiroptera na UNESP de São José do Rio Preto, DZSJRP); João Alves e Stella Franco (Museu Nacional, MN); Sueli Marques Aguiar e José de Souza Júnior (Museu Paraense Emílio Goeldi, MPEG); Bruce Patterson, Lawrence Heaney e Bill Stanley (Field Museum of Natural History, FMNH); Kristofer Helgen, Darrin Lunde, Marissa Atmann e Suzanne Peurach (National Museum of Natural History, NMNH); Nancy Simmons, Robert Voss e Eileen Westwig (American Museum of Natural History, AMNH); Robert Baker e Heath Garner (Museum of Texas Tech University, TTU); Jim Patton, Eileen Lacey e Chris Conroy (Museum of Vertebrate Zoology, MVZ).

Aos amigos pesquisadores do Laboratório de Evolução de Mamíferos pelo prazer do convívio e pelo aprendizado diário que vocês me proporcionam. Queridas (os): Ana Paula Assis (Paulinha), Alex Hube, Anna Penna (Papete), Ana Carolina Pavan (Aninha), Diogo Melo (Ogro), 
Bárbara Costa (Tafinha), Guilherme Garcia (Pato), Monique Simon, Thiago Zahn (Wally), Fábio Machado (Lugar), Edgar Alvarenga e a mais nova integrante Janaína Serrano (muito bem vinda!).

Agradeço em especial à querida Ana Paula Assis por me acolher em São Paulo no processo de mudança prá cá, por ser uma amiga tão presente e tão admirável. Pela sua presença leve e adorável e pela imensa ajuda ao longo dos anos e nessa reta final!

Agradeço em especial ao Diogo Melo pela grande ajuda decisiva nas análises dos dados, pela sua objetividade e clareza com as rotinas de programação no $\mathrm{R}$ em todos os momentos que precisei.

Aos amigos que passaram pelo LEM e tanto me ensinaram transmitindo suas experiências: Harley Sebastião, Roberta Paresque, Arthur Porto, Felipe Bandoni (Fino) e Leila Shirai. Ao Fino pela gentileza da primiera conversa sobre os trabalhos desenvolvidos no LEM, quando ainda estava definindo o meu grupo de estudos. Essa conversa foi muito importante prá mim. Ao Arthur pelo grande auxílio e paciência ao me apresentar os marcadores cranianos, pelas discussões e análises iniciais dos dados.

Ao meu querido amigo David Canabarro Santana, que nos acolheu com tanto carinho e paciência em Washington DC. Obrigada pela sua presença nessa etapa tão importante da minha vida. Aprendo muito com você meu amigão!

Ao amigo Paul Velazco e sua esposa Kerry Kline por nos acolher em NY com tanto carinho. Ao Paul Velazco mais uma vez pelo grande auxílio nas decisões taxonômicas, por me fornecer a árvore filogenética antes que fosse pulicada, e pela grande ajuda durante a minha coleta de dados no AMNH.

À Valéria Tavares pelas contribuições durante o estabelecimento dos marcadores cranianos em filostomídeos. 
À Cibele Sotero-Caio, Maria Sagot e Liz Siles por me receberem de braços abertos com carinho na casa de vocês durante minha coleta de dados em Lubbock.

Paulo Chaves e Simone Lóss muito obrigada pela grande amizade e por nos ajudar a encontrar um lugar para ficar em NY.

Às pessoas que reencontrei e as que conheci ao longo da coleta de dados nas coleções brasileiras e norte americanas e que contribuíram de diversas formas para esse trabalho: Caleb Phillips, Kate McGrath, Elizabeth Grace, Lauren Helgen, Eliécer Gutiérrez, Bruno Fernando Simões, Cristiano Moreira, Fernando Perini, Adam Ferguson, Molly McDonough, Ruan Carrera, Nicte Ordonez-Garza, Luisa Matos, Hanneke Meijer, David Flores, Valentina Segura, Ricardo Moratelli, Mary Anne, Pedro Peloso, Silvia Pavan, Miriam Tsuchiya, Sandra Schachat.

Aos queridos amigos de todos os momentos: Dani Prioli, Paula Pedrosa, Harley Silva, Thiago Fernandes, Guilherme Borba, Karin Botteon, Thiago André, Chistine Bressan, Fernado Jerep, Jú Leoni, Amanda Tuma, Neto, Gabi, Marcelinha, Bê, Dani, Juzinha, Carol, July, Dé, Ricardo.

À aquipe da coleção de masto do MZUSP, onde iniciei meus primieros passos na coleta de dados, pela companhia e ajuda de vocês: Juliana Gualda (Jú), Carol Aires, Marcos Brandão, Fábio Nascimento, Carla Aquino e Guilherme Garbino.

Aos funcionários do Departamento e da Seção da Pós de Genética e Biologia Evolutiva, em especial à Shirlene Barros, Deisy, Helder e Érika. À Coordenadora da Pós Regina Netto pelo auxílio na solicitação de financiamento para apresentação de trabalho no exterior.

Aos meus pais Vera Sílvia Munhoz Rossoni (in memorian) e Daneu Rossoni pelo amor e incentivo. Como grandes educadores vocês sempre souberam elogiar e confiar. Pai, agradeço pelo apoio total desde sempre, pela amizade, carinho e pelo exemplo de pessoa que é. Você 
dedicou grande parte da sua vida à academia, e sabe exatamente o que essa conquista representa prá mim.

À minha querida irmã Fabiane M. R. Bauab, pela importância imensurável e presença positiva que tem na minha vida. Tenho muito orgulho de você! Obrigada por me dar um novo irmão, Rogério Bauab.

Aos meus familiares queridos que estiveram presentes e me apoiaram nessa caminhada: Elídea Tamborelli Rossoni (por todo carinho de sempre e pela culinária maravilhosa), Paula Tamborelli, Amélia Lembi, Rogério Bauab e Rodolfo Tanno.

À toda a família Costa por todo o apoio e carinho recebido nos últimos anos.

À Bárbara Costa, meu amor, muito obrigada pela sua presença, compreensão e carinho ao longo de todos esses anos juntas. Sou muito feliz por ter você ao meu lado! 



\section{ÍNDICE}

RESUMO

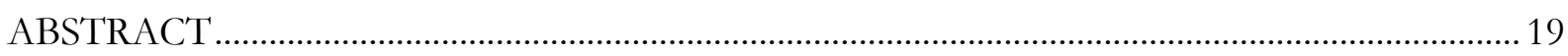

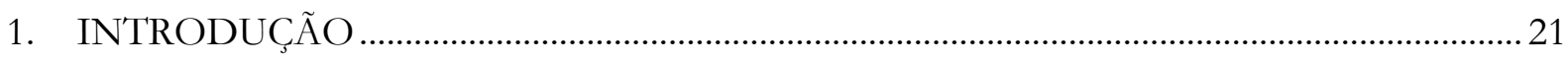

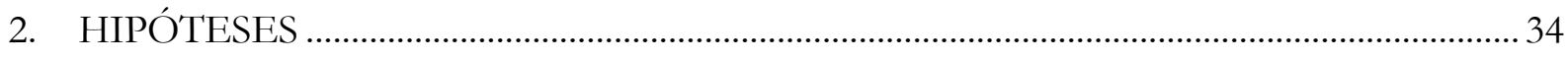

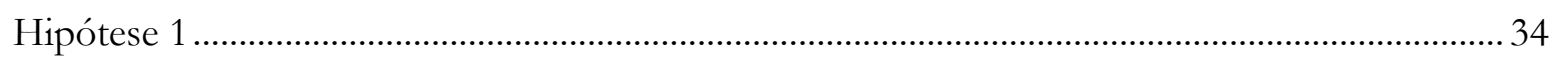

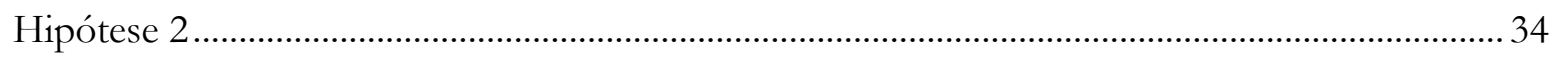

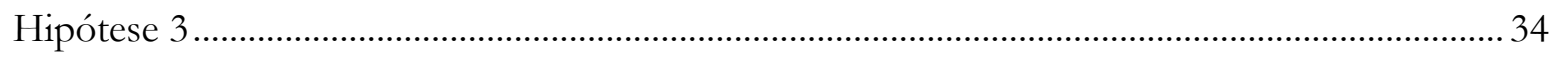

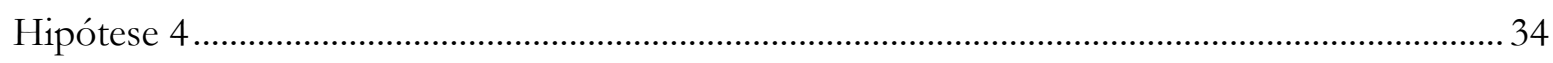

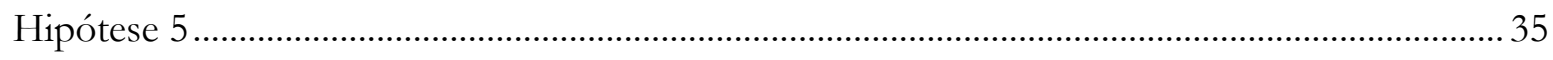

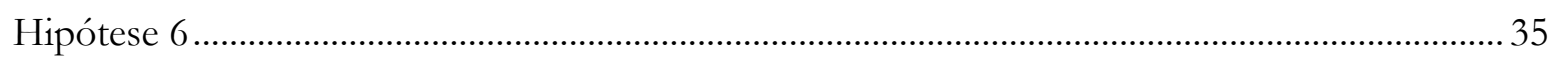

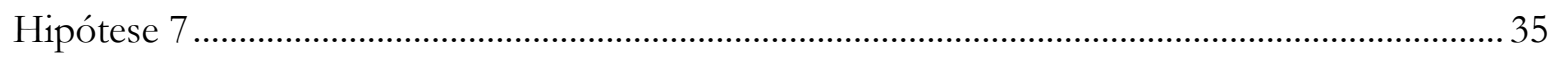

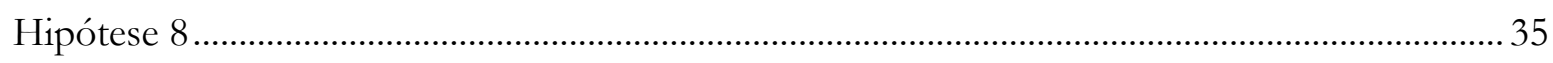

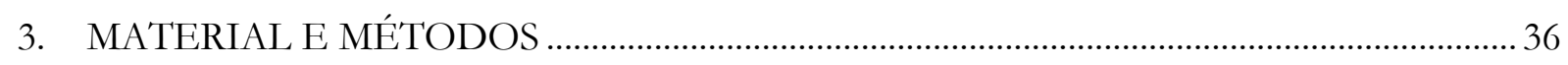

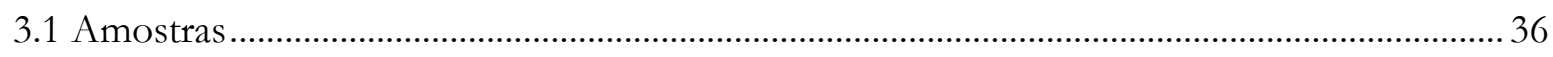

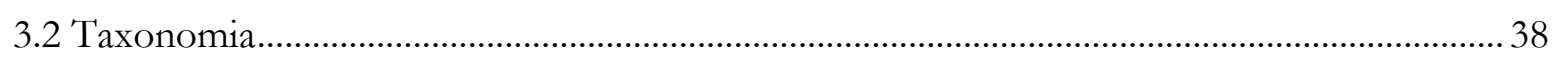

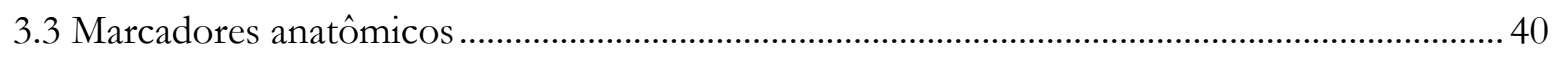

3.4 Padronização dos marcadores anatômicos em Phyllostomidae ............................................... 44 
3.5 Repetibilidade das medidas

3.6 Estimativas das matrizes de correlação e de covariância ............................................................. 47

3.6.1 Controle para variação geográfica e dimorfismo sexual.

3.7 Comparação de padrões entre as matrizes fenotípicas 50

3.7.1 Matrizes de correlação: Krzanowski (KRZ).....

3.7.2 Matrizes de covariância: Random Skewers (RS) e Krzanowski (KRZ)..... 51

3.8 Detectando caracteres similares e dissimilares entre as matrizes 52

3.9 Repetibilidade e ajuste das matrizes.

3.10 Magnitudes de integração .56

3.11 Fator ecológico: Dieta 57

3.12 Fator histórico: Distâncias Filogenéticas .58

3.13 Outros fatores: Distâncias morfológicas 59

3.14 Hipóteses de modularidade...

3.15 Flexibilidade evolutiva e Restrição 61

3.16 Variação devida ao tamanho 63

3.17 Morcegos filostomídeos no contexto dos demais mamíferos .65

4. RESULTADOS .66

4.1 Repetibilidade das medidas. 66

4.2 Similaridade estrutural das matrizes fenotípicas 68 
4.3 Magnitudes de integração

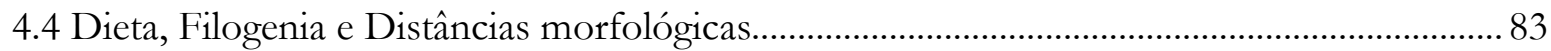

4.5 Detectando caracteres similares e dissimilares entre as matrizes 86

4.6 Modularidade no crânio de morcegos filostomídeos. 93

4.7 Flexibilidade evolutiva e Restrição

4.8 Variação devida ao tamanho 106

4.9 Morcegos filostomídeos no contexto dos demais mamíferos 112

5. DISCUSSÃO

5.1 Similaridade estrutural das matrizes fenotípicas 126

5.2 Magnitudes de integração

5.3 Associação entre os índices de magnitude geral de integração $\left(\mathrm{r}^{2}\right.$ e ICV)..... 134

5.4 Dieta, Filogenia e Distância morfológica. 136

5.5 Estabilidade com divergência? Caracteres similares e dissimilares entre as matrizes.

5.6 Modularidade no crânio de morcegos filostomídeos

5.7 Uma abordagem histórica e funcional na compreensão dos módulos

5.8 Variação devida ao tamanho e a sua relação com os demais índices

5.9 Flexibilidade evolutiva e Restrição

6. CONCLUSÕES 


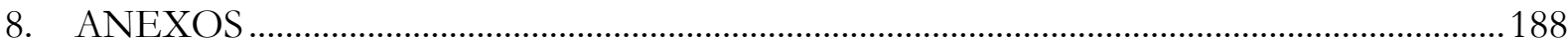

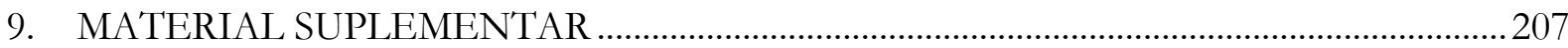




\section{LISTA DE TABELAS}

Tabela 3.1- Lista de espécies de morcegos da Família Phyllostomidae utilizadas no presente estudo. O número de indivíduos por espécies está destacado entre parênteses. Ao todo são 2665 indivíduos distribuídos em 48 espécies, representando 11 subfamílias. Utilizei a classificação taxonômica de subfamília proposta por Baker, (2003) e Baker et al., (2012). 37

Tabela 3.2- Descrição dos marcadores anatômicos mensurados com auxílio do digitalizador Microscribe MX. Apresento também os ossos e as suturas cranianas envolvidas para cada marcador em morcegos da família Phyllostomidae. A descrição dos ossos e das suturas cranianas são baseadas na literatura de Evans \& Evans, (1993) e Giannini et al., (2006).

Tabela 3.3- 35 medidas cranianas lineares (distâncias entre os marcadores) e a classificação dos caracteres nos seis grupos funcionais/de desenvolvimento e nas duas regiões do crânio

Tabela 3.4- Fontes de variação controladas durante a estimativa das matrizes de correlação e covariância fenotípicas para cada uma das 48 espécies de morcegos da Família Phyllostomidae contempladas neste estudo. É possível observar também o tamanho amostral e o número de indivíduos para fêmeas e machos.

Tabela 4.1- Repetibilidade das 35 medidas cranianas em morcegos da Família Phyllostomidae. Médias e desvios padrões estão na parte inferior da tabela.

Tabela 4.2- Similaridade entre as matrizes de correlação determinada por Krzanowski. A diagonal, em negrito, contém a repetibilidade das matrizes. Comparações observadas estão na metade superior e as ajustadas na metade inferior. 
Tabela 4.3- Similaridade entre as matrizes de covariância, determinada por Kræanowski. A diagonal, em negrito, contém a repetibilidade das matrizes. Comparações observadas estão na metade superior e as ajustadas na metade inferior. 72

Tabela 4.4- Similaridade entre as matrizes de covariância, determinada por Random Skewwers. A diagonal, em negrito, contém a repetibilidade das matrizes. Comparações observadas estão na metade superior e as ajustadas na metade inferior. .73

Tabela 4.5- Estatística básica calculada a partir dos valores de similaridade média observados das matrizes de correlação (Krzanowski; Kry) e covariância (Krz̧anowski ; Krz e Ramdom Skewwers; RS)... 77

Tabela 4.6- Estatística básica calculada a partir dos valores de similaridade média ajustados das matrizes de correlação (Kræanowski; Krz) e covariância (Kræanowski ; Krz e Ramdom Skewers; RS)... 77

Tabela 4.7- Estatística básica calculada a partir dos valores de repetibilidade das matrizes de correlação (Krzanowski; Krr) e covariância (Krzanowski; Krž e Ramdom Skewers; RS) 79

Tabela 4.8- Resultados de estatística básica para os índices de magnitiude geral de integração: $\mathrm{r}^{2}$ (obtido a pertir da matriz de correlação) e ICV (obtido a partir da matriz de covariância) 81

Tabela 4.9- Resultados das correlações entre a similaridade observada nos padrões de correlação e covariação (observadas à esquerda e ajustadas à direita) e as matrizes de dieta, filogenia e distâncias morfológicas. Valores destacados em negrito, itálico e sublinhado são significativos $(\mathrm{p}<0.05)$ 84

Tabela 4.10- Correlações par a par entre as matrizes de dieta, filogenia, distâncias morfológicas e diferenças na magnitude de integração $\left(\mathrm{r}^{2}\right)$. Valores destacados em negrito, itálico e sublinhado são significativos $(\mathrm{p}<0.05)$. 84

Tabela 4.11- Resultados da correlação entre a similaridade observada e ajustada nos padrões de correlação e covariação e as matrizes residuais de dieta removendo o efeito da filogenia (dieta - 
filogenia) e da filogenia removendo-se o efeito da dieta (filogenia - dieta). Valores destacados em negrito, itálico e sublinhado são significativos $(\mathrm{p}<0.05)$.

Tabela 4.12- Resultados das correlações entre as matrizes de dieta residual (Dieta - Filogenia) e filogenia residual (Filogenia - Dieta) com as matrizes de distâncias morfológicas e de diferenças na magnitude de integração $\left(\mathrm{r}^{2}\right)$. Valores destacados em negrito, itálico e sublinhado são significativos $(\mathrm{p}<0.05)$ .86

Tabela 4.13- Divergência total dos caracteres cranianos em morcegos filostomídeos, obtida a partir do método de SRD.

Tabela 4.14- Resultados de correlação entre as 35 matrizes de distâncias (utilizando os valores médios do SRD) e a matriz de dieta. Caracteres destacados em negrito, itálico e sublinhado são significativos $(\mathrm{p}<0.05)$.

Tabela 4.15- Caracteres significativos da correlação entre 35 matrizes de distâncias (utilizando os valores médios do SRD) e a matriz de dieta.

Tabela 4.16- Razão entre a magnitude da correlação entre caracteres integrados (avg+) e não integrados (avg-) para cada hipótese teórica de integração (razão avg+/avg-, ou índice de modularidade). Valores em negrito, itálico e sublinhados indicam correlações significativas $(\mathrm{p}<0.05)$, e valores somente em negrito indicam correlações marginalmente significativas $(0.05<\mathrm{p}<0.1)$, para os testes de Mantel de integração morfológica.

Tabela 4.17- Número de correlações significativas, marginalmente significativas e totais considerando as hipóteses de modularidade cranianas para os morcegos da Família Phyllostomidae. .98

Tabela 4.18- Resultados de correlação incluindo todas as espécies, retirando A. geoffroyi e retirando $A$. geoffroyi e $P$. falcatus. Destacados em cinza estão os modelos selecionados para a 
elaboração gráfica da associação entre a magnitude de integração geral e o índice de modularidade $(\operatorname{avg}+/ \operatorname{avg}-)$

Tabela 4.19- Resultados da correlação entre os índices de magnitude geral de integração $\left(r^{2}\right.$ e ICV) e os índices de flexibilidade e restrição; variação no primeiro componente principal (extraído da matriz de covariância) e a variação relativa relacionada ao tamanho. 106

Tabela 4.20- Conjunto de dados representando a dieta, o índice de magnitude geral de integração $\left(\mathrm{r}^{2}\right)$, índices de flexibilidade e restrição evolutivas, quantidade de variação no primeiro componente principal (PC1), quantidade relativa de tamanho (iso relativa) e em qual componente tamanho foi detectado(tamanho)

Tabela 4.21- Resultados da correlação entre os índices de flexibilidade e restrição e a quantidade de variação explicada pelo primeiro componente principal (extraído da matriz de covariância) e a variação relativa relacionada ao tamanho.

Tabela 4.22- Estatísticas básicas calculadas para os índices de magnitude de integração $\left(\mathrm{r}^{2}\right.$ e ICV), apresentadas comparativamente entre os morcegos filostomídeos que fazem parte deste estudo e os demais grupos de mamíferos examinados por Marroig et al., (2009).

Tabela 4.23 - Estatísticas básicas calculadas para o índices de flexibilidade evolutiva, apresentadas comparativamente entre os morcegos filostomídeos que fazem parte deste estudo e os demais grupos de mamíferos examinados por Marroig et al., (2009).

Tabela 4.24- Estatísticas básicas calculadas para o índices de restrição evolutiva, apresentadas comparativamente entre os morcegos filostomídeos que fazem parte deste estudo e os demais grupos de mamíferos examinados por Marroig et al., (2009).

Tabela 4.25- Estatísticas básicas calculadas para a porcentagem total de variação no primeiro componente principal (obtidas a partir das matrizes de covariância); e apresentadas 
comparativamente entre os morcegos filostomídeos que fazem parte deste estudo e os demais grupos de mamíferos examinados por Marroig et al., (2009).

Tabela 4.26- Correlação entre os índices de flexibilidade, restrição, $r^{2}$, ICV, quantidade de variação no primeiro CP e avg+/avg- considerando-se integração total e neuroface. Os resultados são todos significativos $(\mathrm{p}<0.001)$ e apresentados para os morcegos da Família Phyllostomidae que compõem o presente estudo. 116

Tabela 4.27- Correlação entre os índices de flexibilidade, restrição, $r^{2}$, ICV, quantidade de variação no primeiro CP e avg+/avg- considerando-se integração total e neuroface. Os resultados são todos significativos $(\mathrm{p}<0.001)$ e apresentados para o grupo dos demais mamíferos investigados por Marroig et al., (2009).

Tabela 4.28- Correlação entre os índices de flexibilidade, restrição, $\mathrm{r}^{2}, \mathrm{ICV}$, quantidade de variação no primeiro CP e avg+/avg- considerando-se integração total e neuroface. Os resultados são todos significativos $(\mathrm{p}<0.001)$ e apresentados conjuntamente para os morcegos da Família Phyllostomidae e para o grupo dos demais mamíferos investigados por Marroig et al., (2009)...117 


\section{LISTA DE FIGURAS}

Figura 1.1- Representação da ação de seleção natural sobre dois caracteres, A e B. Os círculos pretos representam as médias das populações antes e depois da seleção, enquanto que a elipse em torno da média representa a dispersão dos dois caracteres na população. Na situação à esquerda, os dois caracteres não estão correlacionados; nessa situação, a seleção sobre A (SA) leva a média da população de A1 para A2, sem modificar a média de B (a média do caráter B se mantém constante antes e depois da ação da seleção, ou seja, B1=B2). Na situação à direita, os dois caracteres estão correlacionados e, quando a seleção atua em A exatamente da mesma maneira, observa-se evolução também na média de B (B1キB2). Modificado a partir de Cheverud, (2004).

Figura 1.2 -Tabela de correlações entre quatro medidas cranianas de duas espécies hipotéticas, A e B, e suas respectivas representações gráficas. Também são apresentados os quatro primeiros componentes principais e os autovalores para cada espécie, bem como o índice (taxa) de modularidade que mede o grau de distinção dos módulos. Este índice examina se a média das correlações entre os caracteres integrados (avg+), é maior que a média dos caracteres não integrados (avg-). Neste caso, as espécies têm exatamente o mesmo padrão de relação entre os caracteres, porém diferem na magnitude de suas correlações. A espécie A apresenta magnitude de integração maior do que a espécie B. Note que os caracteres estão mais fortemente associados em A do que em B. 26

Figura 1.3- Crânios de 12 gêneros representando as 11 subfamílias de Phyllostomidae (sensu Baker et al., 2003; Baker et al., 2012). A imagem ilustra as diversas morfologias cranianas presentes na família. A figura foi adaptada de Baker et al., 2012. Os crânios de cima para baixo representam: Macrotus waterhousii, Lampronycteris brachyotis, Diaemus youngi, Lonchorbina orinocensis, Vampyrum 
spectrum, Choeronycteris mexicana, Lonchophylla robusta, Carollia brevicauda, Trinycteris nicefori, Rhinophylla pumilio, Vampyrodes major e Centurio senex. Imagens dos crânios: Dani Rossoni, com exceção de $M$. waterhousii e C. brevicauda que foram extraídos do Animal Diversity Web.

Figura 3.1- Perspectiva filogenética da variação craniana em espécies atuais (ramos terminais) a partir de um ancestral semelhante à Macrotus-Micronycteris-Glyphonycteris (crânio desenhado). A figura foi adaptada de Baker et al., 2012. Desenhos ao lado dos crânios representam a dieta principal de cada espécie (insetivoria, hematofagia, carnivoria, nectarivoria e frugivoria). Os crânios de cima para baixo representam: Macrotus waterhousii, Lampronycteris brachyotis, Diaemus youngi, Lonchorbina orinocensis, Vampyrum spectrum, Choeronycteris mexicana, Lonchophylla robusta, Carollia brevicauda, Trinycteris nicefori, Rhinophylla pumilio, Vampyrodes major e Centurio senex.

Figura 3.2- Marcadores cranianos em Chrotopterus auritus (A-E; MZUSP 3077) e Phyllostomus hastatus (F-G; MZUSP 18348). A e B - vista lateral. C - vista oblíqua dorsolateral com detalhe do osso jugal. D - vista oblíqua do occipital. E - vista ventral. F - vista dorsal. G - vista dorsal com detalhe dos ossos nasais e frontais. Escala $=5 \mathrm{~mm}$

Figura 3.3- Vista ventral do crânio de um indivíduo jovem de Artibeus lituratus (MZUSP 27794). Nesta imagem é possível observar a sincondrose esfeno-occipital (synchondrosis sphenoccipitalis), que delimita os ossos basiesfenóide e basioccipital. Escala: 5mm. Foto: Dani Rossoni. 44

Figura 4.1- Similaridade média dos valores observados (esquerda) e ajustados (direita) entre os morcegos da Família Phyllostomidae, baseada em comparações de matrizes de correlação (método Kræanowski). 74

Figura 4.2- Similaridade média dos valores observados (esquerda) e ajustados (direita) entre os morcegos da Família Phyllostomidae, baseada em comparações de matrizes de covariância (método Krzanowski). 75 
Figura 4.3 - Similaridade media dos valores observados (esquerda) e ajustados (direita) entre os morcegos da Família Phyllostomidae, baseada em comparações de matrizes de covariância (método Random Skewers). 76

Figura 4.4- Correlação entre o número de indivíduos e a similaridade média observada $(\mathrm{r}=0.33$, $\mathrm{p}=0.02)$ e ajustada $(\mathrm{r}=0.29, \mathrm{p}=0.05)$ das matrizes de covariância estimadas por Krzanowski. Os números que representam as espécies nos gráficos equivalem àqueles utilizados nas matrizes (tabela 4.2 p.ex.). 78

Figura 4.5- Correlação entre o número de indivíduos e a similaridade média observada $(\mathrm{r}=0.34$, $\mathrm{p}=0.02)$ e ajustada $(\mathrm{r}=0.33, \mathrm{p}=0.02)$ das matrizes de correlação estimadas por Krz̧anowski. Os números que representam as espécies nos gráficos equivalem àqueles utilizados nas matrizes (tabela 4.2 p.ex.). 78

Figura 4.6- Correlação entre o número de indivíduos e a similaridade média observada ( $\mathrm{r}=0.40$, $\mathrm{p}<0.01)$ e ajustada $(\mathrm{r}=0.30, \mathrm{p}=0.03)$ das matrizes de covariância estimadas por Random Skewers. Os números que representam as espécies nos gráficos equivalem àqueles utilizados nas matrizes (tabela 4.2 p.ex.). 79

Figura 4.7 Correlação entre o número de indivíduos e os valores de repetibilidade da matriz de correlação $(\mathrm{r}=0.40, \mathrm{p}<0.01)$. Os números que representam as espécies nos gráficos equivalem àqueles utilizados nas matrizes (tabela 4.2 p.ex.). 80

Figura 4.8- Índice de magnitude geral das correlação entre caracteres para cada espécie de morcego filostomídeo, e os respectivos intervalos de confiança de $95 \%$ 82

Figura 4.9- Comparação entre as matrizes de covariância fenotípicas de Trachops cirrhosus e Trinycteris nicefori através do método SRD. À esquerda, estimativas de valores médios de SRD para as 35 distâncias euclidianas com seus respectivos intervalos de confiança de $95 \%$. À direita, a relação entre média e desvio padrão centralizados destes escores. Círculos abertos indicam 
caracteres cujos valores nestes dois parâmetros são significativamente menores que o valor médio para $\mathrm{p}<0.025$

Figura 4.10- Comparação entre as matrizes de covariância fenotípicas de Mesophylla macconnelli e Vampyressa thyone através do método SRD. À esquerda, estimativas de valores médios de SRD para as 35 distâncias euclidianas com seus respectivos intervalos de confiança de 95\%. À direita, a relação entre média e desvio padrão centralizados destes escores. Círculos abertos indicam caracteres cujos valores nestes dois parâmetros são significativamente menores que o valor médio para $\mathrm{p}<0.025$

Figura 4.11- Relação do índice de integração morfológica (logarítimo de $\mathrm{r}^{2}$ ) com o índice de modularidade correspondente à hipótese de integração oral. O gráfico na parte superior representa as espécies e o inferior as suas respectivas dietas.

Figura 4.12- Relação do índice de integração morfológica (logarítimo de $\mathrm{r}^{2}$ ) com o índice de modularidade correspondente à hipótese de integração da abóbada craniana. O gráfico na parte superior representa as espécies e o inferior as suas respectivas dietas 100

Figura 4.13- Relação do índice de integração morfológica (logarítimo de $\mathrm{r}^{2}$ ) com o índice de modularidade correspondente à hipótese de integração do neurocrânio. O gráfico na parte superior representa as espécies e o inferior as suas respectivas dietas 101

Figura 4.14- Relação do índice de integração morfológica (logarítimo de $\mathrm{r}^{2}$ ) com o índice de modularidade correspondente à hipótese de integração da neuroface. O gráfico na parte superior representa as espécies e o inferior as suas respectivas dietas.

Figura 4.15- Relação do índice de integração morfológica (logarítimo de $\mathrm{r}^{2}$ ) com o índice de modularidade correspondente à hipótese de integração total. O gráfico na parte superior representa as espécies e o inferior as suas respectivas dietas. 
Figura 4.16- Gráfico resultante da análise discriminante considerando os índices de modularidade (avg+/avg-) para todas as regiões e subregiões cranianas e as respectivas dietas em filostomídeos.

Figura 4.17 - Relação entre o índice de integração morfológica (ICV) e a quantidade de variação explicada pelo primeiro componente principal. As duas variáveis foram obtidas a partir da matriz de covariância. 108

Figura 4.18- Relação entre o índice de restrição evolutiva e a quantidade de variação explicada pelo primeiro componente principal. As duas variáveis foram obtidas a partir da matriz de covariância. O hábito alimentar das espécies está apresentado no gráfico 110

Figura 4.19- Relação entre o índice de flexibilidade evolutiva e a quantidade de variação explicada pelo primeiro componente principal. As duas variáveis foram obtidas a partir da matriz de covariância.

Figura 4.20- Relação entre o índice de flexibilidade evolutiva e a quantidade de variação explicada pelo primeiro componente principal. As duas variáveis foram obtidas a partir da matriz de covariância. O hábito alimentar das espécies está apresentado no gráfico.

Figura 4.21- Relação entre o índice de flexibilidade evolutiva e a quantidade de variação explicada pelo primeiro componente principal. As duas variáveis foram obtidas a partir da matriz de covariância. O tamanho alométrico é apresentado no gráfico, sendo que espécies representadas por um X mostram variação de tamanho no primeiro CP; nas representadas por + o tamanho de expressa no segundo CP; e o circulo fechado indica que tamanho não é capturado nem pelo primeiro nem pelo segundo CP (diluído)..... 112

Figura 4.22 - Correlação entre os índices de magnitude geral de integração: $r^{2}$ (obtido a partir da matriz de correlação) e ICV (obtido a partir da matriz de covariância). Círculos fechados 
representam os morcegos filostomídeos investigados no presente trabalho e o X representa os demais mamíferos avaliados por Marroig et al., (2009).

Figura 4.23 - Correlação entre os índices de restrição e flexibilidade evolutivas considerando somente os morcegos da Família Phyllostomidae

Figura 4.24- Correlação entre os índices de restrição e flexibilidade evolutivas considerando somente os mamíferos estudados por Marroig et al., (2009).

Figura 4.25- Correlação entre os índices de restrição e flexibilidade evolutivas considerando os morcegos filostomídeos (círculo fechado) e o grupo dos demais mamíferos (x) investigados por Marroig et al., (2009).

Figura 4.26- Correlação entre o índice de integração geral ICV (obtido a partir das matrizes de covariância) e o índice de flexibilidade evolutiva considerando os morcegos filostomídeos (círculos fechados) e o grupo dos demais mamíferos (x) investigados por Marroig et al., (2009).

Figura 4.27- Correlação entre o índice de integração geral ICV (obtido a partir das matrizes de covariância) e o índice de restrição evolutiva considerando os morcegos filostomídeos (círculos fechados) e o grupo dos demais mamíferos (x) investigados por Marroig et al., (2009)..... 122

Figura 4.28- Correlação entre o índice de integração geral ICV e a quantidade de variação explicada pelo primeiro componente principal; ambos obtidos a partir das matrizes de covariância. No gráfico estão representados os morcegos filostomídeos (círculos fechados) e o grupo dos demais mamíferos (x) investigados por Marroig et al., (2009) 123

Figura 4.29- Correlação entre o índice de modularidade (avg+/avg-) da neuroface e o índice de flexibilidade evolutiva para morcegos da Família Phyllostomidae. 
Figura 4.30- Correlação entre o índice de modularidade (avg+/avg-) da neuroface e o índice de flexibilidade evolutiva para o grupo de mamíferos estudados por Marroig et al., (2009). 124

Figura 4.31 - Correlação entre o índice de modularidade (avg+/avg-) para a hipótese de integração total e o índice de restrição evolutiva para morcegos da Família Phyllostomidae. .....125

Figura 4.32- Correlação entre o índice de modularidade (avg+/avg-) para a hipótese de integração total e o índice de restrição evolutiva para o grupo de mamíferos estudados por Marroig et al., (2009). 


\section{RESUMO}

No presente trabalho utilizo as abordagens de genética quantitativa e integração morfológica para compreender a evolução do crânio em morcegos da Família Phyllostomidae. Esses morcegos exibem uma diversidade de especializações alimentares que não encontra precedentes dentre os demais mamíferos, havendo atualmente formas envolvidas na insetivoria, hematofagia, nectarivoria, carnivoria, omnivoria e frugivoria. Neste trabalho comparo as matrizes de correlação e covariância fenotípicas que quantificam a associação entre caracteres que descrevem o crânio entre espécies de filostomídeos, com o objetivo de investigar se há similaridade estrutural entre elas. Além disso, exploro possíveis fatores que podem afetar a sua estabilidade, como a história evolutiva (filogenia), dieta e as associações funcionais e de desenvolvimento entre os caracteres cranianos. Por fim, investigo a presença de módulos nos crânios dos filostomídeos e avalio as consequências evolutivas dos padrões e das magnitudes de integração na evolução desse grupo. A base de dados compreende 35 medidas cranianas de 2665 indivíduos, abrangendo todas a subfamílias, e representando ao todo 48 espécies e 45 gêneros. Os resultados indicam que após um período de diversificação evolutiva de aproximadamente 33.9 milhões de anos, a estrutura fenótipica de variância/covariância se manteve até certo ponto similar entre as espécies de morcegos filostomídeos. Enquanto os padrões estruturais das matrizes de correlação e covariação permaneceram relativamente similares, a magnitude geral de integração se mostrou evolutivamente mais plástica entre as espécies. Os caracteres cranianos que mais divergiram entre as matrizes estão relacionados às regiões do crânio que expressam grande variação morfológica qualitativa e estão diretamente relacionadas aos hábitos alimentares das espécies. A independência entre a distância filogenética e a similaridade estrutural das matrizes de variância/covariância indica que as mudanças e as manutenções dos padrões de covariância são, até certo ponto, dissociados da história evolutiva do grupo. Por outro lado, mudanças nas estruturas de correlação e covariância fenotípicas estão associadas à dieta do grupo. Embora dieta 
e filogenia estejam relacionadas, estes fatores diferem quanto a sua associação (e potencial causalidade) com a evolução tanto do fenótipo médio quanto da estrutura de correlação entre os caracteres do crânio. A dieta mostrou um ajuste melhor do que a filogenia para as matrizes de correlação, e para as matrizes de distância morfológica. Além disso, os resultados demonstram que os filostomídeos compartilham padrão de modularidade craniana relacionado à função e desenvolvimento, e os resultados corroboram a organização modular encontrada em outras linhagens de mamíferos. Em geral, as subregiões oral, nasal e a abóbada craniana aparecem como módulos dominantes nos crânios destes morcegos, e um olhar para aspectos funcionais e de história evolutiva ajudam a compreender os padrões de integração morfológica desse grupo tão diverso e intrigante. Nem todas as espécies de filostomídeos estudadas aqui apresentaram variação associada ao tamanho no primeiro componente principal da matriz de covariância. Mesmo não sendo tamanho, esse componente ainda assim age como uma restrição à evolução. Esse resultado é evidente nos valores de correlação altos e significativos entre os índices de magnitude geral de integração e o primeiro componente principal, e das correlações entre o primeiro CP e os índices de flexibilidade e restrição. Espécies que apresentaram alta magnitude geral de integração entre os caracteres do crânio possuem menor capacidade de evoluir na direção da seleção, sendo portanto mais restritas evolutivamente. Espécies de filostomídeos que apresentam asssociações mais baixas nos caracteres cranianos apresentam maior flexibilidade evolutiva, ou seja, maior capacidade em responder na direção em que a seleção está atuando. 


\section{ABSTRACT}

Here I use a quantitative genetics and morphological integration approaches to understand the evolution of bat skulls of the Phyllostomidae family. These bats display an unprecedented diversity in terms of dietary specialization that is unique in mammals, with insectivorous, hematophagous, nectarivorous, carnivorous, omnivorous and frugivorous species. In this thesis, I compare the covariance and correlation phenotypic matrices, which are a quantification of the relationship among skull traits, in order to investigate whether there is structural similarity between them. Furthermore, I explore possible factors that may affect its stability, such as evolutionary history (phylogeny), dietary habits and functional and developmental associations between cranial traits. Finally, I investigate the presence of modules in the skulls of phyllostomids and assess the evolutionary consequences of the patterns and magnitudes of morphological integration in the evolution of this group. The database comprises 35 cranial measurements of 2665 specimens, including all the subfamilies, representing 45 genera and 48 species. The results indicate that after an approximately 33.9 million years period of evolutionary diversification, the phenotypic variance/covariance structure remained, to some extent, similar among species of phyllostomid bats. While the patterns of covariance and correlation matrices remained relatively similar, the overall magnitude of integration presented considerable variation between species. The cranial traits that diverged the most between the matrices are related to the regions of the skull that display great qualitative morphological variation and are directly related to the dietary habits of the species. The independence between the phylogenetic distance and the structural similarity of variance/covariance matrices indicates that changes and stasis in covariance patterns are, to some extent, decoupled from the evolutionary history of the group. On the other hand, changes in the phenotypic correlation and covariance structure are associated with the dietary habits of the group. While diet and phylogeny are related, these factors differ regarding their association (and potential causality) with evolution, 
both concerning the average phenotype divergence, as well as the correlation structure between cranial traits. The diet showed a better adjustment than the phylogeny for correlation matrices, as well as for the morphological distance matrices. Furthermore, the results demonstrate that the phyllostomids share the same patterns of cranial modularity for functional and developmental hypothesis, and confirm the modular structure found in other lineages of mammals. Generally speaking, the oral, nasal and cranial vault subregions appear as dominant modules in the skulls of these bats, and focusing on functional and evolutionary history aspects help to better understand the patterns of morphological integration of this group that is so diverse and intriguing. Not all species of bats that were included in this study showed size variation in the first principal component of the covariance matrix. Even if this first principal component is not size related, this component still acts as an evolutionary constrain. This result is evident in the high and significant correlation values between the overall integration indexes and the first principal component, and regarding the correlation between the first PC and the flexibility and constraint indexes. Species with high overall magnitude of integration between the skull traits have less ability to evolve in the direction of the selection and, therefore, are more evolutionary constrained. Species of bats that exhibit lower associations of cranial traits show greater evolutionary flexibility, i.e., greater capacity to respond in the direction in which selection is acting. 


\section{INTRODUÇÃO}

Os organismos representam um arranjo complexo de estruturas anatômicas e partes individualizadas que mantêm associações funcionais ao longo do desenvolvimento (Hallgrímsson et al., 2009). A idéia de que as partes dos organismos são coordenadas para formar um todo funcional remonta ao início do século XIX, quando o anatomista francês Georges Cuvier enfatizou o "princípio da correlação das partes" (e.g., Mayr, 1982, p.460).

Na década de 50, o maior interesse e compreensão da integração ao nível específico e populacional pode ser atribuído a cinco ilustres pesquisadores. Everett Olson \& Robert Miller, (1951, 1958) apresentaram métodos quantitativos baseados em correlação, para identificar empiricamente grupos de caracteres fenotípicos que são mais fortemente integrados, com base em fatores compartilhados de desenvolvimento e função. Os botânicos Jean Clausen \& William Hiesey, (1960) exploraram a arquitetura das correlações de caracateres complexos em híbridos intraespecíficos de raças ecológicas em um longo progarama de pesquisa. A pesquisadora botânica Raisa Berg (1960) foi uma das primeiras a formular hipóteses para investigar quais circunstâncias ecológicas deveriam favorecer um maior ou menor grau de integração entre conjuntos específicos de caracteres, hipóteses que são usadas ainda hoje para orientar a pesquisa empírica (Armbruster et al., 1999) na detecção de plêiades (módulos) de corelação (Berg, 1960).

Baseada na obra de Olson \& Miller (1958) integração morfológica refere-se às relações e conexões entre elementos morfológicos. Empiricamente, integração morfológica é reconhecida pela detecção de grupos discretos de caracteres altamente correlacionados, denominados de módulos (Porto et al., 2009). Quando um organismo exibe uma organização modular, espera-se um padrão de correlações altas entre caracteres dentro dos módulos e correlações relativamente mais baixas entre os módulos (Cheverud, 1982, 1984; Olson \& Miller, 1958). Olson \& Miller (1958) já estavam cientes da importância da integração como uma propriedade de variação das 
populações, no sentido dos caracteres evoluirem independentemente uns dos outros (Rolian \& Willmore, 2009). A organização modular observada em uma variedade de organismos têm sido interpretada como o resultado de funções e desenvolvimento compartilhados entre os caracteres (Berg, 1960; Olson \& Miller, 1958). Desenvolvimento e/ou função comuns acarretariam em integração morfológica no fenótipo e, portanto, estariam refletidas em altas correlações entre caracteres (Cheverud, 1982).

Tendo contextualizado teoricamente o fenômeno de integração morfológica, surge um questionamento oportuno: Como poderíamos conduzir estudos de modularidade considerando morfologias complexas como os crânios de mamíferos por exemplo? O crânio é uma estrutura formada por processos de desenvolvimento intrincados, decorrentes da interação entre vários genes e tecidos (Cheverud, 1996). É portanto, um modelo particularmente útil para se conduzir estudos de integração morfológica, devido à complexidade do crescimento dos ossos e tecidos e das diversas funções dispensadas como olfato, visão, respiração, mastigação e deglutição.

Para compreendermos a evolução de caracteres complexos, como crânios de mamíferos, é primordial termos em mente que evolução é na verdade dependente de variação. De acordo com Leigh Van Valen, (1974) a variação fenotípica configura a matéria bruta para a seleção natural, e em sua ausência alguns mecanismos básicos de mudança evolutiva não podem operar. As morfologias complexas podem ser descritas por um conjunto de caracteres contínuos mensuráveis, o que permite que mudanças evolutivas sejam quantificadas. Além da variação presente nos caracteres morfológicos, devemos considerar que os mesmos covariam, ou seja, eles apresentam uma correlação entre si e variam conjuntamente até certo ponto. Padrões de covariação são importantes dentro de um contexto evolutivo porque podem fornecer idéias sobre os processos que controlaram a evolução passada dos caracteres, bem como podem nos dar indícios sobre as trajetórias futuras de evolução (Lande \& Arnold, 1983). O estudo de covariação entre caracteres tem recebido atenção crescente e desempenha um papel crítico na biologia evolutiva, com implicações na reconstrução de gradientes de seleção, mapeamento das relações 
genótipo-fenótipo, restrições, evolvabilidade, modularidade e integração morfológica (Agrawal \& Stinchcombe, 2009; Cheverud \& Marroig, 2007; Cheverud, 1982, 1984; Draghi \& Wagner, 2008, 2009; Hallgrímsson et al., 2009; Hansen \& Houle, 2008; Hansen, 2003; Lande \& Arnold, 1983; Magwene, 2001; Marroig \& Cheverud, 2005; Marroig et al., 2011; Marroig \& Cheverud, 2010; Marroig et al., 2012; Marroig et al., 2009; Porto et al., 2013; Porto et al., 2009; Schlosser \& Wagner, 2004; Schluter, 1996; Shirai \& Marroig, 2010; Steppan et al., 2002; Wagner \& Altenberg, 1996; Wagner, 1984, 1988; Webster \& Zelditch, 2009; Young \& Hallgrímsson, 2005; Zelditch \& Wood, 2008; Zelditch, 1988).

No campo da genética quantitativa, as matrizes de correlação e covariância são particularmente úteis para descrever caracteres complexos e quantificar mudanças evolutivas. A resposta evolutiva de um conjunto de caracteres quantitativos sob seleção direcional é descrita pela equação multivariada de resposta à seleção proposta por Lande, (1979):

\section{$\Delta \mathrm{z}=\mathrm{G} \beta$}

Nesta equação, o $\Delta \mathbf{z}$ é o vetor de diferenças nas médias entre as gerações, e representa portanto, a direção e a magnitude da resposta evolutiva. O padrão de correlação entre os caracteres é representado pela matriz de covariância genética aditiva (matriz $\mathbf{G}$ ). G é um parâmetro fundamental na teoria evolutiva, pois resume a proporção da variância e da covariância que é efetivamente herdada, e além disso tem um importante papel na ligação entre micro e macroevolução (Steppan et al., 2002). E por fim, o $\beta$ é o vetor que representa o gradiente de seleção (ou a força de seleção) operando sobre cada caráter individualmente. Olhando mais uma vez para a equação podemos concluir que a matriz de covariância genética $(\mathbf{G})$ interage com o vetor de seleção $(\boldsymbol{\beta})$ para nos fornecer a direção da resposta evolutiva $(\boldsymbol{\Delta} \mathbf{z})$.

Do ponto de vista evolutivo, variância e covariância são parâmetros genéticos que governam a evolução morfológica por seleção natural. Para compreendermos de fato a relevância das associações entre os caracteres no estudo evolutivo, vamos analisar o exemplo apresentado 
na Figura 1.1. Consideremos, por exemplo, dois caracteres quantitativos positivamente correlacionados, como comprimento e largura de determinado osso: caso haja seleção atuando na direção de aumentar a média de apenas um desses caracteres, é fácil perceber que a média do outro também aumentará (Figura 1.1). A influência de $G$ na evolução é a extensão desse raciocínio para o espaço multivariado; assim, a resposta de um caráter pode, por exemplo acontecer em direções diferentes da que a seleção natural está agindo, simplesmente por causa da sua associação com outros caracteres (Oliveira, 2009). O raciocínio da associação entre os caractres estará diretamente embutido nos conceitos que apresento a seguir.
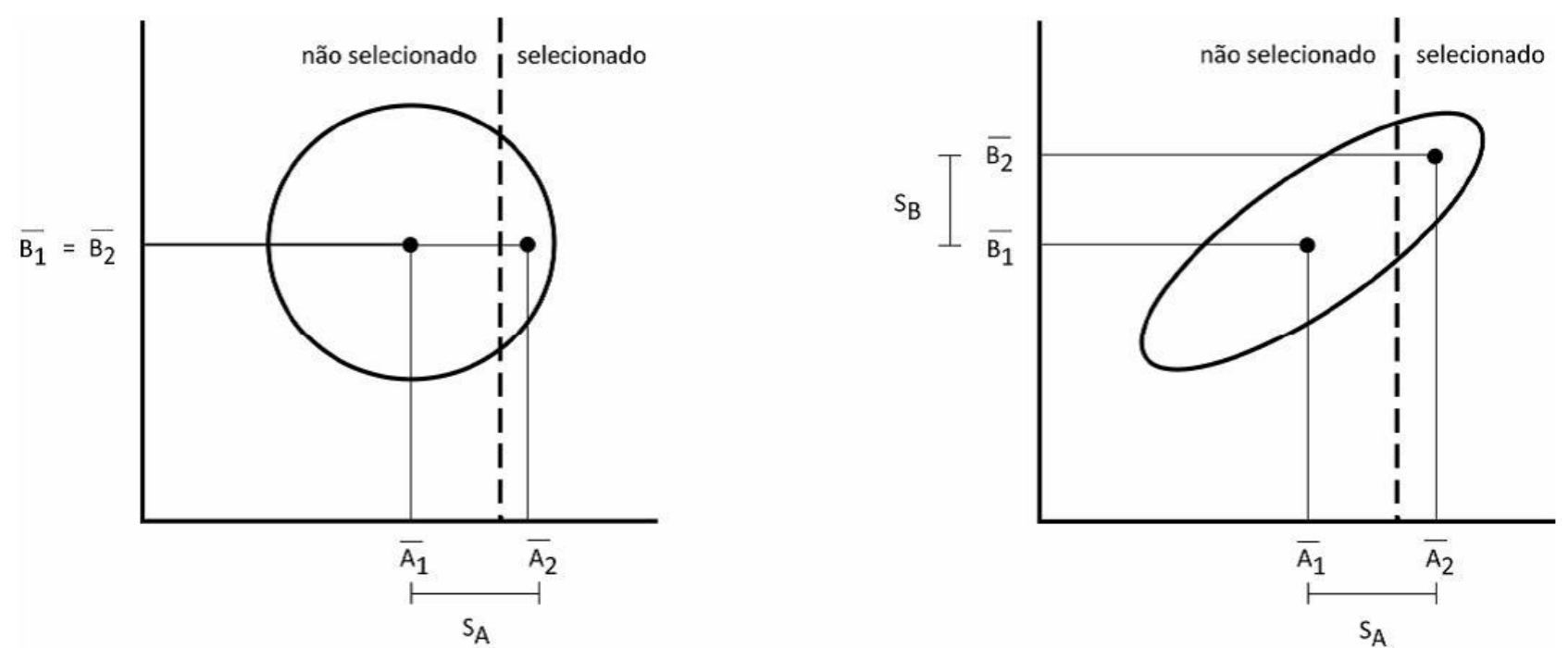

Figura 1.1 Representação da ação de seleção natural sobre dois caracteres, A e B. Os círculos pretos representam as médias das populações antes e depois da seleção, enquanto que a elipse em torno da média representa a dispersão dos dois caracteres na população. $\mathrm{Na}$ situação à esquerda, os dois caracteres não estão correlacionados; nessa situação, a seleção sobre A (SA) leva a média da população de A1 para A2, sem modificar a média de B (a média do caráter B se mantém constante antes e depois da ação da seleção, ou seja, B1=B2). Na situação à direita, os dois caracteres estão correlacionados e, quando a seleção atua em A exatamente da mesma maneira, observa-se evolução também na média de B

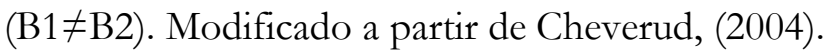


Quando estamos interessados em quantificar e comparar a modularidade entre grupos, dois aspectos complementares da integração morfológica devem ser analisados conjuntamente: os padrões e as magnitudes de integração (Marroig \& Cheverud, 2001). O padrão de integração se refere às relações entre os elementos morfológicos e pode ser avaliado por meio da análise de correlação ou covariância entre os caracteres. Já a magnitude de integração se refere ao nível ou à intensidade das associações entre os caracteres (Porto et al., 2009). Para compreendermos melhor esses dois aspectos da integração morfológica proponho à apreciação da Figura 1.2. Essa figura apresenta a tabela de correlações entre quatro medidas cranianas em duas espécies hipotéticas, A e $\mathrm{B}$, e seus respectivos gráficos. Note que dois caracteres pertencem à face (F1 e F2) e dois pertencem ao neurocrânio (N1 e N2). É possível observar que enquanto os padrões de associação entre os caractres é o mesmo, a magnitude geral de integração difere entre as duas espécies. Isto fica evidente não apenas pelo exame dos gráficos mas pela própria comparação dos componentes principais de cada matriz que apresentam exatamente a mesma orientação, alterando apenas a magnitude da variação associada (autovalores). $\mathrm{Na}$ espécie $\mathrm{A}$, as correlações são maiores, refletindo portanto maior magnitude geral de integração entre os caracteres. Em B, a magnitude geral de integração é baixa, ou seja, a média de todas as correlações é pequena e podemos observar que os caracteres estão mais fracamente associados, particularmente entre as regiões neural e facial. 
Espécie A

\begin{tabular}{cccccc}
\hline CP/Caracteres & F1 & F2 & N1 & N2 & Autovalores \\
\cline { 1 - 5 } CP1 & 0.57 & 0.57 & 0.42 & 0.42 & 2.17 \\
CP2 & -0.42 & -0.42 & 0.57 & 0.57 & 1.13 \\
CP3 & 0.00 & 0.00 & -0.71 & 0.71 & 0.50 \\
CP4 & 0.71 & -0.71 & 0.00 & 0.00 & 0.20 \\
\hline Caracteres & F1 & F2 & N1 & N2 & \\
\cline { 1 - 3 } F1 & 1.00 & & & & \\
F2 & 0.80 & 1.00 & & & \\
N1 & 0.20 & 0.20 & 1.00 & & \\
N2 & 0.20 & 0.20 & 0.50 & 1.00 &
\end{tabular}

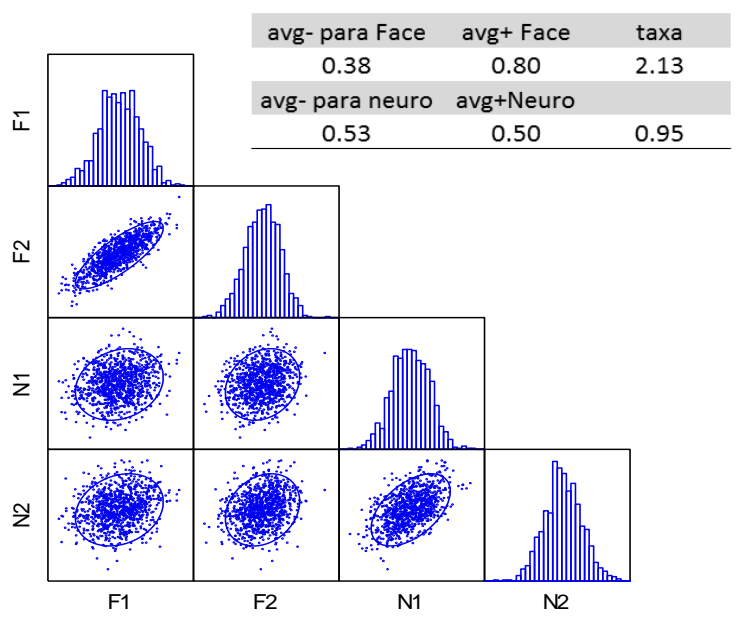

Espécie B

\begin{tabular}{cccccc}
\hline CP/Caracteres & F1 & F2 & N1 & N2 & Autovalores \\
\cline { 1 - 5 } CP1 & 0.57 & 0.57 & 0.42 & 0.42 & 1.59 \\
CP2 & -0.42 & -0.42 & 0.57 & 0.57 & 1.06 \\
CP3 & 0.00 & 0.00 & -0.71 & 0.71 & 0.75 \\
CP4 & 0.71 & -0.71 & 0.00 & 0.00 & 0.60 \\
\hline \hline Caracteres & F1 & F2 & N1 & N2 & \\
\cline { 1 - 3 } F1 & 1.00 & & & & \\
F2 & 0.40 & 1.00 & & & \\
N1 & 0.13 & 0.13 & 1.00 & & \\
N2 & 0.13 & 0.13 & 0.25 & 1.00 & \\
\cline { 1 - 3 }
\end{tabular}

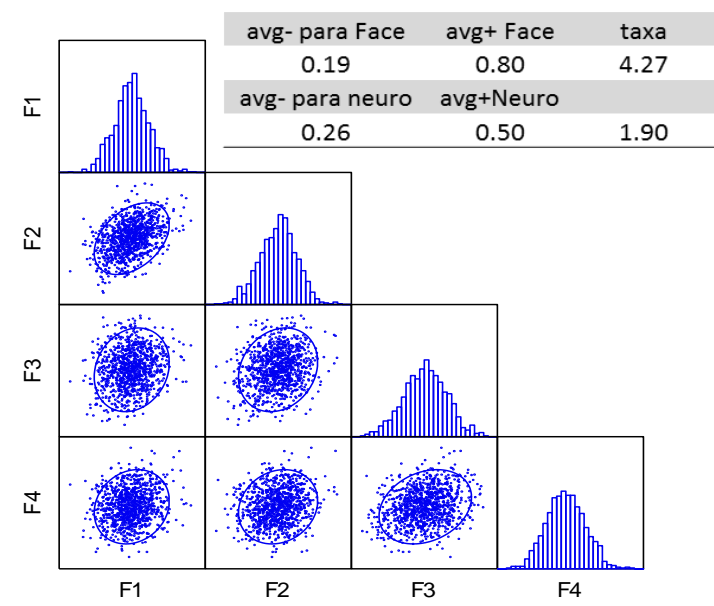

Figura 1.2 -Tabela de correlações entre quatro medidas cranianas de duas espécies hipotéticas, A e $\mathrm{B}$, e suas respectivas representações gráficas. Também são apresentados os quatro primeiros componentes principais e os autovalores para cada espécie, bem como o índice (taxa) de modularidade que mede o grau de distinção dos módulos. Este índice examina se a média das correlações entre os caracteres integrados (avg+), é maior que a média dos caracteres não integrados (avg-). Neste caso, as espécies têm exatamente o mesmo padrão de relação entre os caracteres, porém diferem na magnitude de suas correlações. A espécie A apresenta magnitude de integração maior do que a espécie B. Note que os caracteres estão mais fortemente associados em A do que em B.

Nos exemplos acima vimos que a maneira como os caracteres estão interconectados pode ter implicações importantes para a evolução. Poderíamos pensar por exemplo que, dependendo de suas covariâncias genéticas, populações de uma mesma espécie e geograficamente próximas poderiam responder de formas completamente diferentes à seleção. Dentro desse contexto, uma abordagem paupável, utilizando o arcabouço teórico da genética quantitativa para entender a evolução dos caracteres complexos seria: investigar se o padrão e a magnitude das associações é semelhante ou não entre linhagens, e avaliar as consequências evolutivas destas 
associações entre os caracteres. Se dois grupos (como aqueles expressos na Figura 1.2) apresentam exatamente a mesma relação entre os caracteres, mas diferem significativamente na intensidade como os caracteres estão conectados (magnitude de integração), suas respostas às forças evolutivas, como seleção natural poderão ser notóriamente diferentes (Hansen \& Houle, 2008; Marroig et al., 2009). Com base na teoria de genética quantitativa Hansen \& Houle, (2008) desenvolveram ferramentas analíticas para avaliar o potencial evolutivo de uma população utilizando a matriz de covariância. Dois conceitos serão abordados aqui: flexibilidade e restrições evolutivas (Hansen \& Houle, 2008; Marroig et al., 2009). A flexibilidade evolutiva é uma medida do quanto uma população é capaz de responder na direção em que a seleção está atuando (Marroig et al., 2009). Por sua vez, a restrição evolutiva é definida como quaisquer limitações no curso ou no resultado da evolução (Arnold, 1992), e indica o quão restrita uma matriz está em responder na direção em que a seleção atua (Marroig et al., 2009). Aplicando esses conceitos à Figura 1.2 temos que: enquanto as duas populações têm o mesmo padrão de correlação, a espécie B com baixa magnitude geral de integração irá responder mais facilmente às direções do morfoespaço porque seus caracteres não estão fortemente associados. Dessa forma, podemos dizer que a espécie B é mais flexível evolutivamente que a espécie A. Por outro lado, grupos com altas magnitudes de integração (espécie A) apresentam uma menor capacidade em responder na direção da seleção, sendo portanto mais restritos evolutivamente. Note que nós podemos usar a equação multivariada de resposta à seleção porposta por Lande, (1979) para simular o comportamento evolutivo de diferentes espécies em termos de suas flexibilidades e restrições evolutivas.

Com base nos estudos realizados com mamíferos, alguns padrões gerais podem ser observados das comparações da modularidade e intregração morfológica, e suas potenciais consequências evolutivas (Cheverud, 1996; Marroig \& Cheverud, 2001; Marroig et al., 2009; Oliveira et al., 2009; Porto et al., 2009; Shirai \& Marroig, 2010): (1) os padrões de correlação são muito conservados na maioria dos táxons; (2) a magnitude de integração não é conservada e 
mostrou-se bastante plástica, mesmo em grupos próximos (ver Oliveira et al., 2009; Porto et al., 2009; Shirai \& Marroig, 2010); (3) o principal fator afetando a evolução da magnitude de integração é a porcentagem de variação associada ao primeiro componente principal; (4) quanto maior a porcentagem de variação associada a tamanho, maiores as correlações e menos evidentes os módulos (Porto et al., 2009; Porto et al., 2013; Shirai \& Marroig, 2010); (5) espécies que apresentam alta magnitude geral de integração entre os caracteres do crânio possuem menor capacidade de evoluir na direção da seleção, sendo portanto mais restritas evolutivamente; enquanto espécies com asssociações mais baixas entre os caracteres cranianos apresentam maior flexibilidade evolutiva (Marroig et al., 2009).

Note que estes padrões gerais citados acima foram descritos de forma comparativa em matrizes fenotípicas, e uma questão que surge naturalmente se refere à obtenção da matriz $G$ e a relação desta com as matrizes fenotípicas (P). A estimativa das correlações genéticas entre caracteres morfológicos requerem tamanhos amostrais grandes de indivíduos relacionados em uma genealogia conhecida (Cheverud, 1996), uma tarefa logisticamente difícil para a maioria dos organismos. Entretanto, matrizes de covariância fenotípicas (matrizes P) são mais fáceis de serem obtidas e podem ser utilizadas como substitutas da matriz $\mathrm{G}$, se P for similar ou proporcional à sua contraparte genética (Cheverud, 1996; Marroig \& Cheverud, 2001; Prôa et al., 2012), o que ocorre especialmente nos casos de alta herdabilidade de caracteres morfológicos (Ackermann \& Cheverud, 2004; Cheverud, 1988; Game \& Caley, 2006; Kolbe et al., 2011). Investigações dedicadas à avaliação da constância ou proporcionalidade entre matrizes de correlação genéticas (G) e fenotípicas (P) para caracteres morfológicos entre populações ou taxa sugerem que os padrões fenotípicos são geralmente uma boa estimativa das suas contrapartes genéticas (Arnold \& Phillips, 1999; Arnold, 1981; Atchley et al., 1981; Cheverud \& Routman, 1995; Cheverud, 1988, 1996; Kohn \& Atchley, 1988; Marroig \& Cheverud, 2001; Roff, 1995, 1996; Venable \& Burquez, 1990; Waitt \& Levin, 1998). Dessa forma, matrizes P podem ser obtidas diretamente de 
populações de espécies depositadas em coleções científicas como é o caso do presente estudo, e serem utilizadas na equação proposta por Lande, (1979) em substituição à matriz G.

Mas, na orientação dos nossos estudos, como poderíamos de fato estar seguros de que a matriz fenotípica é uma boa substituta da matriz genética? A resposta à esta questão pode ser obtida a partir da comparação de matrizes. A comparação dos padrões estruturais de covariação fenotípica entre populações e espécies é uma etapa imprescindível na análise evolutiva de caracteres quantitativos. A consistência da estrutura de covariância genética pode ser inferida por meio da comparação dos padrões de variação fenotípicas em populações relacionadas (Lande, 1979). Se a estrutura de covariação fenotípica for similar entre populações, espécies ou taxa comparados, estudos comparativos de genética quantitativa podem ser conduzidos com confiança (Marroig \& Cheverud, 2001; Marroig et al., 2009). Mais ainda, estas matrizes P estimadas podem ser comparadas com algumas poucas matrizes $G$ que estejam disponíveis, para mediar as comparações em larga escala das matrizes fenotípicas (no caso dos mamíferos, há matrizes G para uma população de primatas do gênero Saguinus e duas de roedores Akodon e Calomys, com o mesmo sistema de medidas utilizado nesta tese). Comparações prévias dos padrões em mamíferos demonstraram correspondência entre os padrões de covariância expressos por G e por P (Marroig \& Cheverud, 2001; Oliveira, 2009).

Finalmente, para compreendermos se uma estrutura de covariância fenotípica ou genética é similar ou dissimilar nós precisamos não só documentar empiricamente os seus padrões como também explorar possíveis fatores que possam afetar a sua estabilidade. Nesse sentido é importante investigar a influência da história evolutiva do grupo (filogenia) e fatores ecológicos como a dieta, nas estruturas de correlação e covariância fenotípicas. Outra possível fonte de variação estrutural das matrizes de correlação e covariância são as associações funcionais e de desenvolvimento entre os caracteres cranianos. Um resultado comum de estudos prévios indicou que a integração morfológica do crânio está relacionada em parte à processos funcionais e de desenvolvimento (Ackermann \& Cheverud, 2000; Cheverud \& Routman, 1995; Cheverud, 
1982, 1989, 1996; Marroig \& Cheverud, 2001; Zelditch \& Carmichael, 1989), como postulado por Olson \& Miller (1958) e Berg (1960).

No presente trabalho eu utilizo as abordagens de genética quantitativa e integração morfológica para compreender a evolução dos caracteres cranianos em morcegos pertencentes à Família Phyllostomidae. Nos próximos parágrafos eu me dedico à apresentar esse fascinante grupo de estudo e por fim apresento as questões específicas que conduzem esta investigação.

Dentro da Ordem Chiroptera, a Família Phyllostomidae apresenta o maior número de gêneros (56), e compreende a terceira maior família de morcegos em número de espécies (mais de 160) (Simmons, 2005). Trata-se de um clado endêmico do Novo Mundo, encontrado em regiões tropicais e subtropicais, com registros que se estendem do sudoeste do Arizona e Ilhas do Caribe ao norte da Argentina (Simmons, 2005). Representantes dessa família originaram-se há aproximadamente 33.9 milhões de anos atrás entre o Oligoceno e o Eoceno (Baker et al., 2012). As relações evolutivas dos filostomídeos têm sido extensivamente abordadas na literatura (Baker \& Honeycutt, 1989; Baker et al., 2012; Baker, 2003; Bininda-Emonds \& Cardillo, 2007; Bussche \& Baker, 1993; Bussche, 1992; Datzmann et al., 2010; Honeycutt \& Sarich, 1987; Bininda-Emonds \& Gittleman, 2005; Rojas et al., 2011; Wetterer et al., 2000), e os resultados indicam que as subfamílias tradicionalmente reconhecidas são monofiléticas e que a maioria dos taxa que compartilham especializações alimentares formam clados distintos. No presente trabalho, sigo a classificação proposta por Baker et al., $(2003,2012)$ para a família Phyllostomidae, na qual são reconhecidas 11 subfamílias, 12 tribos e 56 gêneros (Figura 1.3).

Morcegos da Família Phyllostomidae exibem uma diversidade de especializações alimentares que não encontra precedentes dentre os demais mamíferos (Findley, 1993; Freeman, 2000; Gardner, 1977; Giannini \& Kalko, 2004; Gimenez et al., 1996; Wetterer et al., 2000), havendo atualmente formas envolvidas na insetivoria, hematofagia, nectarivoria, carnivoria, omnivoria e frugivoria (Baker et al., 2012). A diversidade de hábitats, hábitos de vida e história natural são refletidas em suas distintas morfologias, com mudanças no tamanho do corpo e em 
particular no crânio. Membros dessa família abrangem tamanhos que vão do menor macho frugívoro, Ametrida centurio, com antebraço na média de $26 \mathrm{~mm}$ e peso de aproximadamente sete gramas, ao maior morcego das Américas, o carnívoro V ampyrum spectrum com antebraço na média de $106 \mathrm{~mm}$, podendo pesar 200 gramas. Além das adaptações morfológicas, a diversificação ecológica do grupo é acompanhada por mudanças comportamentais e fisiológicas (Baker \& Bass, 1979; Dumont, 1999; Eguiarte \& Búrquez, 1987; Freeman, 2000; Gribel \& Hay, 1993; Helversen \& Winter, 2003; Kelm \& Helversen, 2007; Phillips, 1971; Voigt \& Speakman, 2007; Winter \& Helversen, 2003).

A extraordinária diversidade craniana, a história natural e o longo tempo de evolução fazem desse grupo um bom modelo para se investigar a evolução de morfologias complexas. Nesse sentido, os morcegos filostomídeos têm sido objeto de estudos ecomorfológicos e funcionais associados à dieta (Aguirre \& Herrel, 2003; Dumont et al., 2003; Dumont \& Nicolay, 2006; Dumont et al., 2012; Dumont, 2004; Findley, 1993; Freeman, 1984, 1995, 1988, 1992, 2000; Freeman \& Stockwell, 2003; Freeman \& Lemen, 2010; Goudy-Trainor \& Freeman, 2002; Herrel \& Smet, 2008; Nogueira \& Monteiro, 2005; Nogueira et al., 2009; Santana et al., 2010; Santana et al., 2011; Santana et al., 2012; Swartz et al., 2003). Na última década, a investigação da força de mordida, associada à análise de elementos finitos, tem sido incorporada em alguns estudos, permitindo uma análise mais refinada da ligação entre forma do crânio e estratégias de alimentação (Dumont et al., 2009; Dumont et al., 2003; Dumont, 2005; Grosse \& Dumont, 2007). A combinação de técnicas de morfometria geométrica e métodos comparativos também têm sido usada para avaliar os processos evolutivos que estiveram por trás da diversificação do fenótipo (tamanho e forma da mandíbula) e dieta nos filostomídeos (Monteiro \& Nogueira, 2011). Os mesmos autores investigaram a integração morfológica em crânios e mandíbulas de morcegos filostomídeos, contrastando hipóteses ecológicas e fatores de desenvolvimento (Nogueira et al., 2009). Considerando outros grupos de morcegos, em publicação recente, Santana \& Lofgren, 
(2013) usaram filogenia, morfometria geométrica e análises comparativas para investigar modularidade no crânio de morcegos do Velho Mundo, pertencentes à Família Rhinolophidae.

O presente trabalho conta com uma base de dados bastante representativa da diversidade de morcegos da Família Phyllostomidae: são 35 medidas cranianas de 2665 indivíduos, abrangendo todas a subfamílias, e representando ao todo 48 espécies e 45 gêneros. Nesta tese, utilizando o arcabouço teórico da genética quantitativa e da integração morfológica, eu comparo as matrizes de correlação e covariância fenotípicas entre 48 espécies de morcegos filostomídeos com o objetivo de investigar se há similaridade estrutural entre elas. Utilizando os dados sobre a história evolutiva (filogenia) e sobre os hábitos alimentares das espécies, avalio se esses fatores afetam os padrões estruturais das matrizes de correlação e covariância fenotípicas. Além disso investigo se as relações de desenvolvimento e função entre os caracteres mantiveram a covariância estrutural relativamente estável durante a diversificação evolutiva desse grupo. Seguindo a proposta metodológica de Cheverud (1995), investigo a presença de módulos nos crânios dos filostomídeos, e por fim, estudo as consequências evolutivas dos padrões e das magnitudes de integração na evolução desse grupo.

Este trabalho é um passo incial para a compreensão da diversificação craniana dos morcegos da Família Phyllostomidae. A extensa base de dados que coletei será utilizada ao longo dos próximos anos para investigar outras questões concernentes à evolução desse grupo. Algumas dessas idéias estão relacionadas: (1) ao papel relativo da seleção natural e deriva genética na geração de diversidade do grupo; (2) à detecção de irradiação adaptativa usando os critérios propostos por Schluter, (2000); (3) às linhas de menor resistência evolutiva (Schluter, 1996), avaliando suas associações com o ritmo da mudança evolutiva e a magnitude de integração entre os caracteres; (4) às taxas de diversificação e expansão de nichos alimentares em morcegos filostomídeos. 


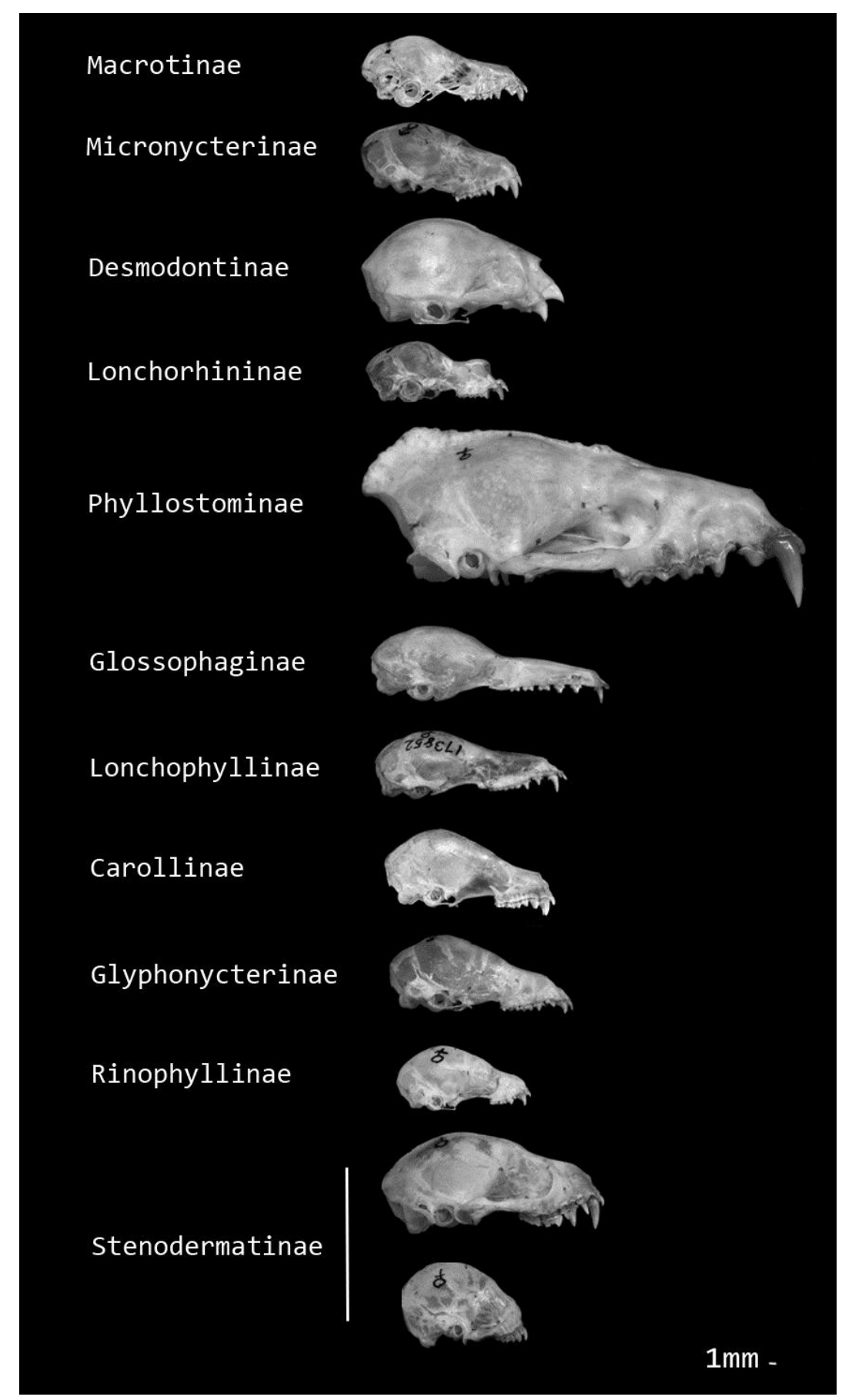

Figura 1.3- Crânios de 12 gêneros representando as 11 subfamílias de Phyllostomidae (sensu Baker et al., 2003; Baker et al., 2012). A imagem ilustra as diversas morfologias cranianas presentes na família. A figura foi adaptada de Baker et al., 2012. Os crânios de cima para baixo representam: Macrotus waterhousii, Lampronycteris brachyotis, Diaemus youngi, Lonchorbina orinocensis, Vampyrum spectrum, Choeronycteris mexicana, Lonchophylla robusta, Carollia brevicauda, Trinycteris nicefori, Rhinophylla pumilio, Vampyrodes major e Centurio senex. Imagens dos crânios: Dani Rossoni, com exceção de M. waterhousii e C. brevicauda que foram extraídos do Animal Diversity Web. 


\section{HIPÓTESES}

\section{Hipótese 1}

Os padrões estruturais e as magnitudes de integração expressos nas matrizes de correlação e covariância fenotípicas são até certo ponto similares entre as espécies de morcegos da Família Phyllostomidae.

\section{Hipótese 2}

Os padrões de similaridade das matrizes de correlação e covariância foram influenciados pela história evolutiva dos morcegos filostomídeos.

\section{Hipótese 3}

Mudanças na estrutura de correlação e covariância fenotípicas estão associadas a fatores ecológicos, como a dieta do grupo.

\section{Hipótese 4}

As relações funcionais e de desenvolvimento entre os caracteres cranianos em filostomídeos influenciam os padrões de variação das matrizes fenotípicas. 


\section{Hipótese 5}

Caracteres que mais divergiram estão relacionados às regiões do crânio que expressam grande variação morfológica qualitativa devido aos hábitos alimentares das espécies.

\section{Hipótese 6}

Os morcegos filostomídeos compartilham uma padrão de integração morfológica concernente à função e desenvolvimento.

\section{Hipótese 7}

A quantidade de variação associada ao tamanho atua como uma força de restição no potencial de mudança evolutiva nos morcegos da Família Phyllostomidae.

\section{Hipótese 8}

Espécies que apresentam alta magnitude geral de integração entre os caracteres do crânio possuem menor capacidade de evoluir na direção da seleção, sendo mais restritas evolutivamente. Por outro lado, espécies com asssociações mais baixas nos caracteres cranianos apresentam maior flexibilidade evolutiva, ou seja, maior habilidade em responder na direção em que a seleção está atuando. 


\section{MATERIAL E MÉTODOS}

\subsection{Amostras}

Medi ao todo 3277 espécimes de morcegos pertencentes à Família Phyllostomidae, depositados nas seguintes coleções brasileiras e norte americanas: Museu de Zoologia da Universidade de São Paulo (MZUSP, São Paulo, SP), Coleção de Chiroptera de São José do Rio Preto (DZSJRP, São José do Rio Preto, SP), Museu Nacional (MN, Rio de Janeiro, RJ), Museu Paraense Emílio Goeldi (MPEG, Belém, PA), Field Museum of Natural History (FMNH, Chicago, IL), National Museum of Natural History (NMNH, Washington DC), American Museum of Natural History (AMNH, Nova Iorque, NY), Museum of Texas Tech University (TTU, Lubbock, TX) e Museum of Vertebrate Zoology (MVZ, Berkeley, CA). Considerando a amostra total, utilizei somente espécies com número de indivíduos acima de 34 (valor mínimo considerado neste estudo para estimar as matrizes de covariância com confiança). As espécies excluídas das análises, serão utilizadas em trabalhos futuros sobre evolução da média dos caracteres, pois estas análises não envolvem a estimativa de matrizes de covariância e portanto, não necessitam de tamanho amostral elevado.

Utilizei no presente trabalho 2665 indivíduos, representantes de 48 espécies de morcegos filostomídeos. Apresento na Tabela 3.1 o número de indivíduos medidos para cada espécie, seguindo a classificação taxonômica de subfamília proposta por Baker, (2003) e Baker et al., (2012). Nas coleções brasileiras que visitei, alguns gêneros e espécies de Phyllostomidae estão bem representados por localidade, mas em comparação com as coleções norte americanas, os exemplares daqui encontram-se em sua maioria preservados em via-úmida. Como são realizadas medidas morfométricas cranianas no meu trabalho, foco diretamente em animais com crânio extraído e limpo. Durante as coletas de dados no Brasil, medi ao todo 581 indivíduos contrastando com 2696 digitalizados nas coleções norte americanas. 
Tabela 3.1- Lista de espécies de morcegos da Família Phyllostomidae utilizadas no presente estudo. O número de indivíduos por espécies está destacado entre parênteses. Ao todo são 2665 indivíduos distribuídos em 48 espécies, representando 11 subfamílias. Utilizei a classificação taxonômica de subfamília proposta por Baker, (2003) e Baker et al., (2012).

\begin{tabular}{|c|c|c|}
\hline Subfamília Macrotinae & Subfamília Glossophaginae & Subfamília Stenodermatinae \\
\hline Macrotus californicus (59); M. waterhousii (60) & Monophyllus redmani (58) & Chiroderma villosum (60) \\
\hline Subfamília Micronycterinae & Glossophaga soricina (35) & Vampyriscus bidens (48) \\
\hline Micronycteris microtis (60) & Leptonycteris curasoae (61) & Uroderma magirostrum (60) \\
\hline Subfamília Desmodontinae & Brachyphylla cavernarum (52) & Vampyressa thyone (62) \\
\hline Diphylla ecaudata (56) & Erophylla sezekorni (60) & Mesophylla macconnelli (60) \\
\hline Desmodus rotundus (86) & Phyllonycteris poeyi (60) & Vampyrodes major (62) \\
\hline Diaemus youngi (59) & Anoura geoffroyi (39) & Platyrrbinus vittatus (59) \\
\hline Subfamília Lonchorhininae & Choeronycteris mexicana (51) & Enchisthenes hartii (62) \\
\hline Lonchorbina aurita (39); L. orinocensis (40) & Subfamília Lonchophyllinae & Artibeus fimbriatus (51); A. lituratus (40) \\
\hline Subfamília Phyllostominae & Lionycteris spurrelli (60) & Dermaura phaeotis (45) \\
\hline Macrophyllum macropbyllum (51) & Lonchophylla robusta (68) & Ariteus flavescens (59) \\
\hline Trachops cirrbosus (60) & Subfamília Carollinae & Stenoderma rufum darioi (60) \\
\hline Lophostoma silviculum (70) & Carollia brevicauda (69) & Centurio senex (66) \\
\hline Tonatia saurophila (50) & Subfamília Glyphonycterinae & Pygoderma bilabiatum (57) \\
\hline Mimon crenulatum (39) & Trinycteris nicefori (61) & Sphaeronycteris toxophyllum (64) \\
\hline Phylloderma stenops (34) & Subfamília Rhinophyllinae & Ametrida centurio (48) \\
\hline Phyllostomus hastatus (64) & Rbinophylla pumilio (52) & Phyllops falcatus haitiensis (50) \\
\hline \multicolumn{3}{|l|}{ Chrotopterus auritus (58) } \\
\hline Vampyrum spectrum (41) & & \\
\hline
\end{tabular}




\subsection{Taxonomia}

No presente trabalho, sigo a classificação de subfamília proposta por Baker et al., (2003, 2012) na qual são reconhecidas 11 subfamílias e 12 tribos para a família Phyllostomidae (Figura 3.1). Esse autor reconhece e 56 gêneros. É importante ressaltar que dois gêneros reconhecidos atualmente, Dryadonycteris e Xeronycteris, não foram inclusos nos estudos citados acima, o que aumentaria para 57 o número de gêneros descritos. Xeronycetris é um gênero monotípico, pertencente à subfamília Glossophaginae, descrito por Gregorin \& Ditchfield (2005), conhecido somente por quatro espécimes coletados em três localidades no nordeste do Brasil. Driadonycteris (Dryadonycteris capixaba) foi descrito recentemente por Nogueira et al., (2012), e pertence à subfamília Glossophaginae. Utilizei revisões atualizadas de gêneros e espécies de filostomídeos disponíveis na literatura (Baker \& Bass, 1979; Gray et al., 2001; Mancina, 2010; Peters et al., 2006; Van Den Bussche et al., 2003; Ditchfield, \& Santos, 2008; Tavares \& Velazco, 2010; Tavares, 2008; Velazco \& Cadenillas, 2011; Velazco \& Patterson, 2008; Velazco \& Solari, 2003; Velazco et al., 2010; Velazco \& Simmons, 2011; Velazco, 2005). Além disso contei com o auxílio do pesquisador Dr. Paul Velazco nas decisões taxonômicas tomadas durante a seleção das espécies (e espéciemes) medidos neste trabalho. 


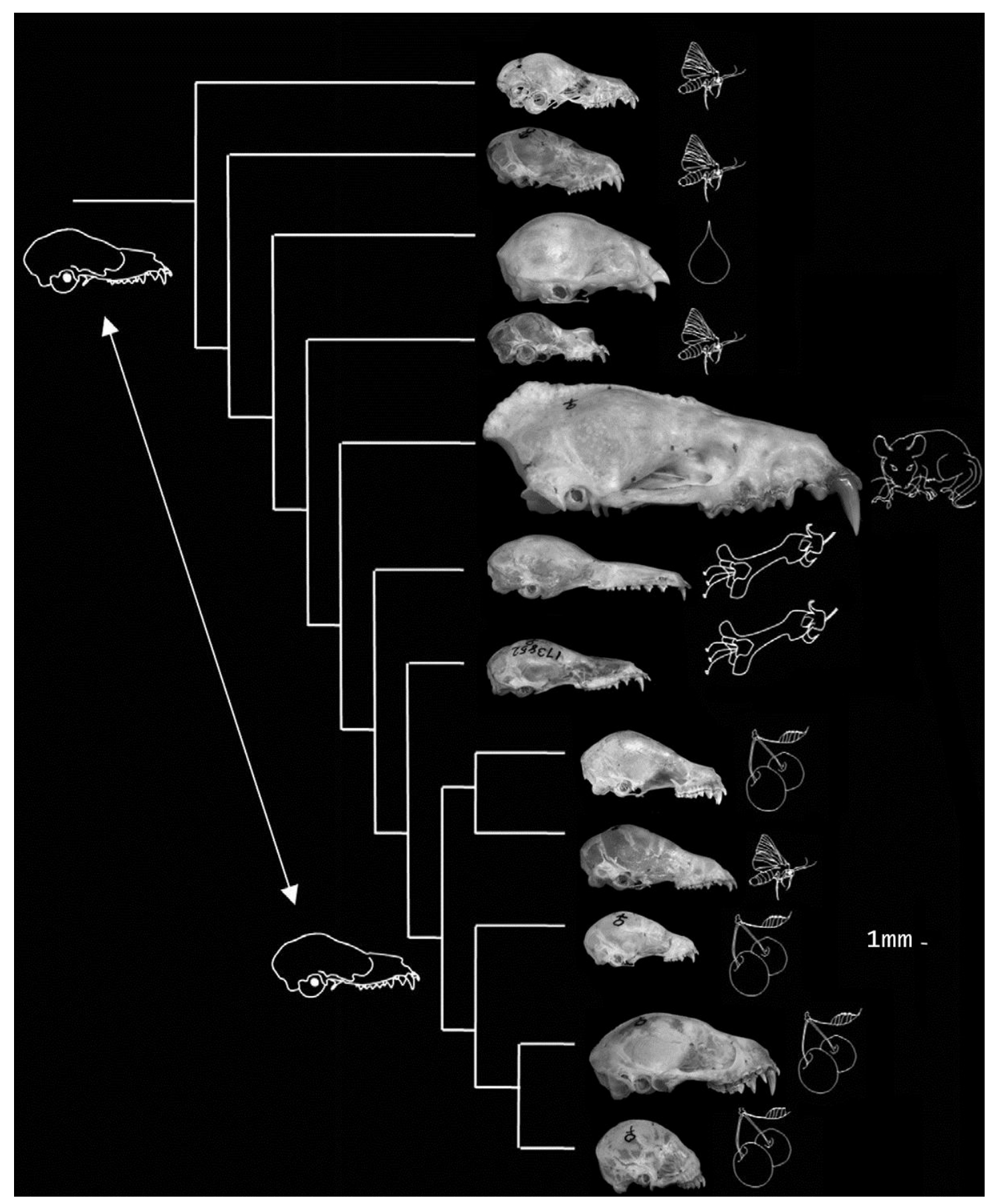

Figura 3.1- Perspectiva filogenética da variação craniana em espécies atuais (ramos terminais) a partir de um ancestral semelhante à Macrotus-Micronycteris-Glyphonycteris (crânio desenhado). A figura foi adaptada de Baker et al., 2012. Desenhos ao lado dos crânios representam a dieta principal de cada espécie (insetivoria, hematofagia, carnivoria, nectarivoria e frugivoria). Os crânios de cima para baixo representam: Macrotus waterbousii, Lampronycteris brachyotis, Diaemus youngi, Lonchorbina orinocensis, Vampyrum spectrum, Choeronycteris mexicana, Lonchophylla robusta, Carollia brevicauda, Trinycteris nicefori, Rhinophylla pumilio, Vampyrodes major e Centurio senex. 


\subsection{Marcadores anatômicos}

Em cada indivíduo, registrei 21 pontos de referência anatômicos com um digitalizador Microscibe MX (Microscribe, Chicago, IL). Com base nesses pontos, calculei um conjunto de 35 distâncias lineares que descrevem a morfologia craniana, calculando a média para as que estão presentes nos dois lados do crânio. Estes marcadores e respectivas distâncias foram inicialmente estabelecidos por Cheverud, (1982), e utilizados em macacos do Novo (Marroig \& Cheverud, 2001) e Velho Mundo (Oliveira et al., 2009) bem como em diversas ordens de mamíferos (Porto et al., 2009; Marroig et al., 2009; Porto et al., 2013), e representam as regiões do crânio que compartilham um histórico de desenvolvimento e função, e ao mesmo tempo, a estrutura craniana como um todo.

Os marcadores são posicionados no encontro de suturas e outras estruturas cranianas discretas, e são homólogos entre as diversas ordens de mamíferos estudadas no Laboratório de Evolução de Mamíferos (LEM), o que permite comparar os resultados obtidos no presente trabalho com àqueles citados acima. Os 21 marcadores e as 35 distâncias euclidianas agrupadas em cinco unidades funcionais e de desenvolvimento (sensu Cheverud, 1995) encontram-se respectivamente na Tabela 3.2 e na Tabela 3.3. Na Figura 3.2 apresento os marcadores posicionados no crânio de indivíduos da espécie Chrotopterus auritus e Phyllostomus hastatus.

Medi cada ponto no crânio duas vezes a fim de estimar as repetibilidades para os caracteres. Após os cálculos de repetibilidade das medidas, a média das duas réplicas foi calculada e usada como a melhor estimativa do valor de cada caráter em cada exemplar. Se um espécime estivesse danificado em alguma região que contivesse pontos de referência laterais, utilizava a medida do lado intacto como a média; espécimes com pontos de referência na linha mediana danificados não foram digitalizados. Restringi a amostragem a indivíduos adultos com base na ossificação da região basiesfenóide e basioccipital. Na Figura 3.3 apresento o crânio de um indivíduo jovem, em que é possível observar a sincondrose do esfeno-occipital exposta. 
Tabela 3.2- Descrição dos marcadores anatômicos mensurados com auxílio do digitalizador Microscribe MX. Apresento também os ossos e as suturas cranianas envolvidas para cada marcador em morcegos da família Phyllostomidae. A descrição dos ossos e das suturas cranianas são baseadas na literatura de Evans \& Evans, (1993) e Giannini et al., (2006).

\begin{tabular}{|c|c|c|c|}
\hline Marcador & Descrição & Ossos envolvidos & Suturas envolvidas \\
\hline IS & intradental superior & premaxila & sutura interincisiva \\
\hline $\mathbf{P M}$ & sutura premaxilar-maxilar no alvéolo & premaxila; maxila & sutura maxilloincisiva \\
\hline NSL & Nasale & nasal & sutura internasalis \\
\hline NA & Nasion & nasal; frontal & sutura frontonasalis \\
\hline $\mathbf{B R}$ & Bregma & frontal; parietal & sutura sagittalis; sutura coronalis \\
\hline PT & Pterion & frontal; parietal; orbitoesfenoidal & sutura sphenofrontalis; sutura sphenoparietalis \\
\hline ZS & zygomaxilar superior & maxila; jugal & sutura zygomaticomaxillaris \\
\hline $\mathbf{Z I}$ & zygomaxilar inferior & maxila; jugal & sutura zygomaticomaxillaris \\
\hline MT & tuberosidade maxilar & palatino; maxila & sutura palatomaxillaris \\
\hline PNS & espinha posterior nasal & palatino & sutura interpalatina \\
\hline APET & petreo temporal anterior & basisfenóide; basioccipital & spheno-occipital synchondrosis \\
\hline $\mathbf{B A}$ & Basion & basioccipital & - \\
\hline OPI & Opisthion & supraoccipital & - \\
\hline EAM & meato auditivo anterior externo & Maleus & - \\
\hline PEAM & meato auditivo posterior externo & Maleus & - \\
\hline ZYGO & sutura zigo-temporal inferior & jugal; esquamosal & sutura temporozygomatica \\
\hline TSP & junção temporo-esfeno-parietal & parietal; alisfenoide; esquamosal & sutura squamosa; sutura sphenoparietalis \\
\hline TS & junção temporo-esfenoidal no petreo & esquamosal; alisfenoide & sutura sphenosquamosa \\
\hline JP & jugular process & basioccipital; exoccipital & posterior basicochlear comissure \\
\hline LD & Lambda & interparietal; supraoccipital & sutura occipitointerparietalis (lambdoidea) \\
\hline AS & Asterion & parietal; supraoccipital & sutura occipitoparietalis \\
\hline
\end{tabular}


Tabela 3.3- 35 medidas cranianas lineares (distâncias entre os marcadores) e a classificação dos caracteres nos seis grupos funcionais/de desenvolvimento e nas duas regiões do crânio.

\begin{tabular}{|c|c|c|}
\hline Distâncias & Grupo Funcional/Desenvolvimento & Região \\
\hline IS-PM & Oral & Face \\
\hline IS-NSL & Nasal & Face \\
\hline IS-PNS & Oral, Nasal & Face \\
\hline PM-ZS & Oral & Face \\
\hline PMZI & Oral & Face \\
\hline PM-MT & Oral & Face \\
\hline NSL-NA & Nasal & Face \\
\hline NSL-ZS & Nasal & Face \\
\hline NSL-ZI & Oral, Nasal & Face \\
\hline NA-BR & Abóbada craniana & Neurocrânio \\
\hline NA-PNS & Nasal & Face \\
\hline BR-PT & Abóbada craniana & Neurocrânio \\
\hline BR-APET & Abóbada craniana & Neurocrânio \\
\hline PT-APET & Abóbada craniana & Neurocrânio \\
\hline PT-BA & Abóbada craniana & Neurocrânio \\
\hline PT-EAM & Abóbada craniana & Neurocrânio \\
\hline PT-ZYGO & Zigomático & Face \\
\hline PT-TSP & Abóbada craniana, zigomático & Neurocrânio, Face \\
\hline ZS-ZI & Oral & Face \\
\hline ZI-MT & Oral & Face \\
\hline ZI-ZYGO & Zigomático & Face \\
\hline ZI-TSP & Zigomático & Face \\
\hline MT-PNS & Oral & Face \\
\hline PNS-APET & Base do crânio & Neurocrânio \\
\hline APET-BA & Base do crânio & Neurocrânio \\
\hline APET-TS & Base do crânio & Neurocrânio \\
\hline BA-EAM & Base do crânio & Neurocrânio \\
\hline EAM-ZYGO & Zigomático & Face \\
\hline ZYGO-TSP & Zigomático & Face \\
\hline LD-AS & Abóbada craniana & Neurocrânio \\
\hline BR-LD & Abóbada craniana & Neurocrânio \\
\hline OPI-LD & Abóbada craniana & Neurocrânio \\
\hline PT-AS & Abóbada craniana & Neurocrânio \\
\hline JP-AS & Base do crânio & Neurocrânio \\
\hline BA-OPI & Base do crânio & Neurocrânio \\
\hline
\end{tabular}



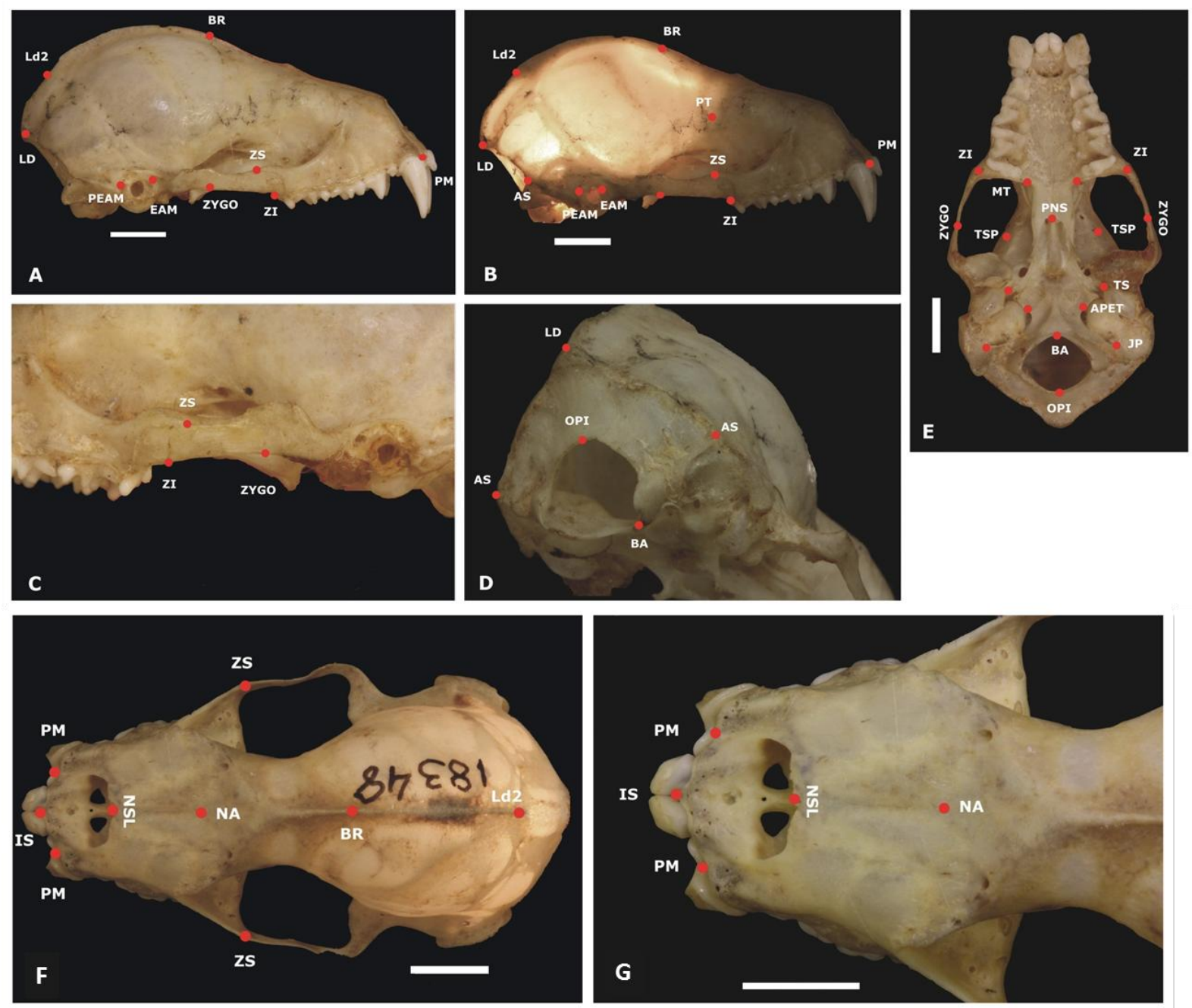

Figura 3.2- Marcadores cranianos em Chrotopterus auritus (A-E; MZUSP 3077) e Phyllostomus hastatus (F-G; MZUSP 18348). A e B - vista lateral. C - vista oblíqua dorsolateral com detalhe do osso jugal. D - vista oblíqua do occipital. E - vista ventral. F - vista dorsal. G - vista dorsal com detalhe dos ossos nasais e frontais. Escala $=5 \mathrm{~mm}$. 


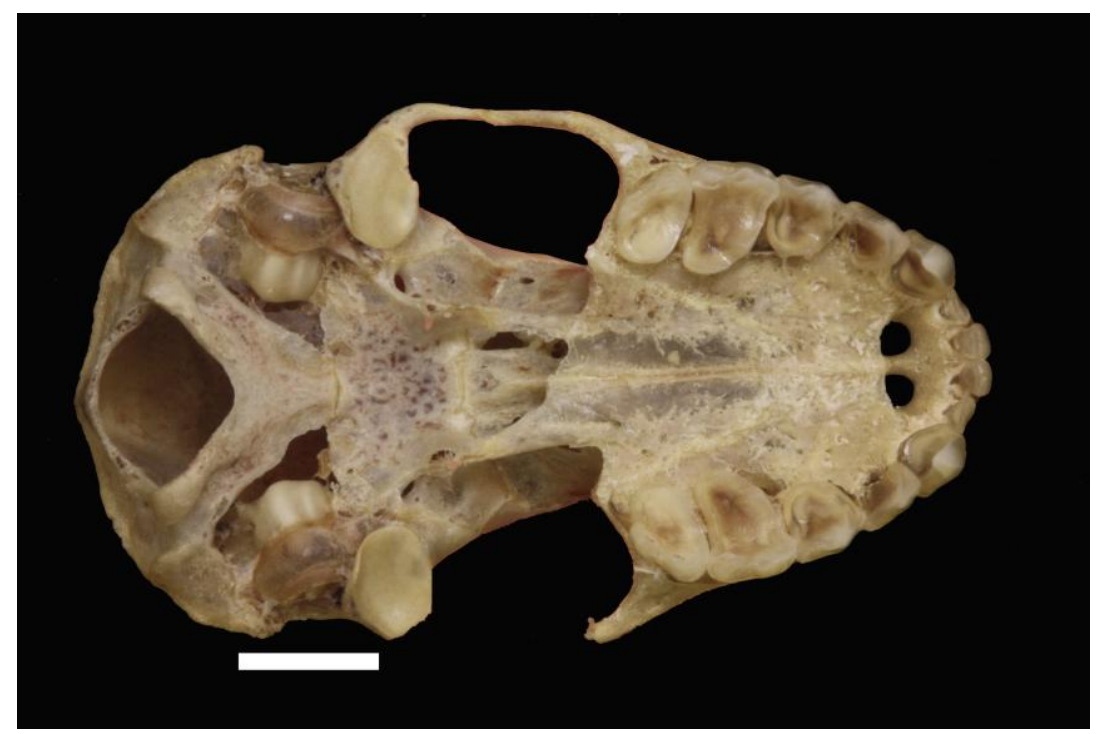

Figura 3.3- Vista ventral do crânio de um indivíduo jovem de Artibeus lituratus (MZUSP 27794). Nesta imagem é possível observar a sincondrose esfeno-occipital (synchondrosis sphenoccipitalis), que delimita os ossos basiesfenóide e basioccipital. Escala: $5 \mathrm{~mm}$. Foto: Dani Rossoni.

\subsection{Padronização dos marcadores anatômicos em Phyllostomidae}

Aqui eu dedico alguns parágrafos às dificuldades e progressos alcançados na padronização dos marcadores anatômicos nos crânios de morcegos filostomídeos. Esse processo foi decisivo para que o trabalho pudesse se concretizar.

Os marcadores anatômicos são dados ricos em informações quando utilizamos métodos morfométricos. Eles formam um sistema de representação do crânio e possibilitam a comparação de seus diferentes aspectos como, por exemplo, função, tamanho e forma. Dentro desse sistema de representação, a topologia e a conectividade dos seus elementos, exibidas pelas posições relativas dos ossos e suturas, fornecem explicações sobre os processos biológicos, como por exemplo, desenvolvimento e função. 
Embora tenham sido realizados divresos estudos sobre anatomia craniana funcional em filostomídeos (Freeman, 1984, 1988, 1992; Freeman \& Weins, 1997), esse grupo ou mais especificamente, a subordem Microchiroptera permanece essencialmente inexplorada do ponto de vista de uma descrição detalhada sobre osteologia craniana. Giannini et al., (2006) provêem uma descrição detalhada do crânio de Pteropus, um gênero pertencente à subordem Megachiroptera, família Pteropodidae. Embora as características morfológicas sejam extremamente variáveis entre as duas subordens, eu utilizei este estudo como base auxiliar na compreensão da nomenclatura dos ossos dos crânios e das suturas em morcegos. É o único estudo puramente descritivo do ponto de vista anatômico e segue o Comitê Internacional de Nomenlatura Anatômica (I.C.V.G.A.N, 2012).

Considerando estruturas tão pequenas e delicadas como o crânio dos filostomídeos, adotei alguns padrões que me auxiliaram nas marcações dos pontos como utilização constante de lupa no reconhecimento dos marcadores, e a inserção de uma lâmpada de $5 \mathrm{~mm}$ aproximadamente no interior do foramen magnum dos espécimes, o que me auxiliou na visualização das suturas. Também utilizei crânios de indivíduos jovens como modelo, pois as suturas e ossos não estão completamente fusionados, sendo mais evidentes nesses indivíduos. Vale lembrar que indivíduos jovens não entraram na minha amostragem, e foram apenas utilizados de base para a compreensão dos ossos nos crânios de espécimes adultos. Fotografei todos os crânios jovens com suturas bem definidas que encontrei durante às visitas às coleções científicas brasileiras e norte americanas.

Vale por fim ressaltar que as decisões tomadas com relação ao estabelecimento da homologia e padronização dos marcadores foram acompanhadas pelo Dr. Norberto Giannini, o qual prontamente me auxiliou em colaboração com o estudo. Apresento em anexo (anexo A1) os 21 marcadores anatômicos cranianos utilizados em meu trabalho, descrevendo detalhadamente os ossos e as suturas que envolvem esses marcadores em morcegos filostomídeos. Apresento 
também em anexo (anexo A2) crânios de alguns indivíduos jovens, em vista dorsal, ventral e lateral ilustrando os marcadores e as suturas aparentes.

\subsection{Repetibilidade das medidas}

Inicialmente utilizei Steam and Leaf como ferramenta de análise de dados exploratória (Tukey, 1977), com o propósito de obter uma visão geral da distribuição das medidas para cada distância e identificar possíveis valores discrepantes na amostra (outliers). Além disso, investiguei cada variável em relação a desvios de normalidade.

Como cada espécime foi digitalizado duas vezes, pude verificar o erro associado à mensuração através do cálculo de repetibilidade (Lessells \& Boag, 1987) utilizando rotinas desenvolvidas no ambiente de programação R ( $\mathrm{R}$ Development Core Team, 2010). A repetibilidade pode ser definida como a porcentagem da variação total das medidas que deve ser atribuída às diferenças entre espécimens e não está associada ao erro de observação intraindividual (diferença entre a primeira e segunda medição). O cálculo é realizado atráves de uma ANOVA simples sendo o indivíduo o fator independente, ou seja, cada indivíduo tem duas medidas (as réplicas) para cada variável (as distâncias). A repetibilidade foi calculada a partir da fórmula de Lessells \& Boag, (1987), que definiram que:

$$
r=s_{A}^{2} /\left(s^{2}+s_{A}^{2}\right)
$$

No qual $\mathrm{r}$ é a repetibilidade, o $\mathrm{s}_{\mathrm{A}}^{2}$ é o componente da variância entre os grupos e $\mathrm{s}^{2}$ é o componente da variância dentro dos grupos. Estes componentes são calculados a partir dos quadrados médios da ANOVA, sendo que o componente $s^{2}$ é simplesmente o quadrado médio dentro dos grupos $\left(\mathrm{MS}_{\mathrm{w}}\right)$ e $\mathrm{S}_{\mathrm{A}}^{2}$ é:

$$
\mathrm{S}_{\mathrm{A}}^{2}=\left(\mathrm{MS}_{\mathrm{w}}-\mathrm{MS}_{\mathrm{B}}\right) / \mathrm{n}_{0}
$$


Sendo $\mathrm{MS}_{\mathrm{B}}$ o quadrado médio entre os grupos e $\mathrm{n}_{0}$ é igual o tamanho do grupo, que neste caso é dois, uma vez que o grupo é formado por duas réplicas. Todas as análises subsequentes foram realizadas utilizando-se a média das medidas repetidas para cada exemplar.

\subsection{Estimativas das matrizes de correlação e de covariância}

\subsubsection{Controle para variação geográfica e dimorfismo sexual}

Os efeitos relacionados a dimorfismo sexual, variação geográfica das espécies e suas possíveis interações não estão nos ojetivos deste trabalho. O que se busca aqui é uma representação quantitativa dos padrões e magnitudes de integração representativas de uma espécie, e não das diferenças na média entre os sexos ou populações. Dessa forma, fontes de variação que não se relacionam diretamente ao mapa genotípico-fenotípico (G. Wagner \& Altenberg, 1996) foram controladas durante o processo de estimativa das matrizes de correlação e de covariância. Este é um procedimento de correção primordial porque as estimativas de correlação entre as variáveis podem ser infladas pelas diferenças nas médias dos caracteres entre os grupos.

Um exemplo preciso de um fator que influencia na morfologia, são as diferenças entre sexos em espécies que apresentam dimorfismo sexual. Nesses casos, apesar de existirem diferenças significativas entre machos e fêmeas nas médias, e apesar dessas diferenças serem importantes fontes de variação intra-específica, espera-se que ambos os sexos compartilhem a mesma arquitetura genética (uma expectativa que pode, é claro, ser testada empiricamente). Neste caso, se estimarmos uma matriz fenotípica sem levar em conta as diferenças médias entre os sexos, o padrão de variação fenotípico determinado pela arquitetura genética poderá ser obscurecido pela variação morfológica entre os sexos. 
Dessa forma variações geográficas, dimorfismo sexual e a possível interação entre estas variáveis foram avaliadas por meio de testes de análise multivariada baseado na estatística lambda de Wilk's (MANOVA). Em todos os casos que as fontes de variação influenciassem significativamente os dados $(\mathrm{p}<0.05)$, as matrizes de covariância foram estimadas usando a matriz residual de um modelo geral linear com as 35 medidas cranianas como variáveis dependentes e as fontes significativas de variação como variáveis independentes. Nestes casos, a partir do resíduo do modelo, obtive a estimativa das matrizes de covariância e de correlação fenotípicas. Nos casos em que não detectei efeito das fontes de variação estimei as matrizes sem o uso dos resíduos. $\mathrm{Na}$ Tabela 3.4 apresento o modelo utilizados no controle das fontes de variação, durante as estimativas das matrizes fenotípicas de correlação e covariância para cada espécie. Este cálculos e os subsequêntes foram realizados através de rotinas desenvolvidas no ambiente de programação estatítica R (R Development Core Team, 2010). As funções utilizadas podem ser obtidas no endereço eletrônico: Github.com/lem-usp/Morphometrics. 
Tabela 3.4- Fontes de variação controladas durante a estimativa das matrizes de correlação e covariância fenotípicas para cada uma das 48 espécies de morcegos da Família Phyllostomidae contempladas neste estudo. É possível observar também o tamanho amostral e o número de indivíduos para fêmeas e machos.

\begin{tabular}{|c|c|c|c|c|c|c|c|c|c|}
\hline Espécies & Modelo & $\mathbf{F}$ & $\mathbf{M}$ & Total & Espécies & Modelo & $\mathbf{F}$ & $\mathbf{M}$ & Total \\
\hline Macrotus californicus & Sexo & 34 & 25 & 59 & Choeronycteris mexicana & - & 29 & 20 & 49 \\
\hline Macrotus waterhousii & Sexo & 33 & 27 & 60 & Lionycteris spurrelli & - & 34 & 26 & 60 \\
\hline Micronycteris microtis & - & 24 & 36 & 60 & Lonchophylla robusta & Sexo & 33 & 35 & 68 \\
\hline Diphylla ecaudata & Sexo + Localidade & 30 & 26 & 56 & Carollia brevicauda & Sexo & 40 & 29 & 69 \\
\hline Desmodus rotundus & Sexo & 43 & 43 & 86 & Trinycteris nicefori & - & 34 & 27 & 61 \\
\hline Diaemus youngi & Sexo + Localidade & 32 & 27 & 59 & Rhinophylla pumilio & Sexo + Localidade & 31 & 21 & 52 \\
\hline Lonchorhina aurita & - & 15 & 24 & 39 & Chiroderma villosum & Sexo & 35 & 25 & 60 \\
\hline Lonchorhina orinocensis & Sexo & 13 & 27 & 40 & Vampyriscus bidens & - & 23 & 25 & 48 \\
\hline Macrophyllum macrophyllum & Sexo + Localidade & 28 & 23 & 51 & Uroderma magnirostrum & - & 42 & 18 & 60 \\
\hline Trachops cirrhosus & - & 30 & 30 & 60 & Vampyressa thyone & Sexo + Localidade & 36 & 26 & 62 \\
\hline Lophostoma silviculum & Sexo + Localidade & 41 & 29 & 70 & Mesophylla macconnelli & Sexo + Localidade & 32 & 28 & 60 \\
\hline Tonatia saurophila & Sexo + Localidade & 28 & 22 & 50 & Vampyrodes major & - & 33 & 29 & 62 \\
\hline Mimon crenulatum & - & 16 & 23 & 39 & Platyrrhinus vittatus & - & 35 & 24 & 59 \\
\hline Phylloderma stenops & Sexo + Localidade & 17 & 17 & 34 & Enchisthenes hartii & Sexo + Localidade & 39 & 23 & 62 \\
\hline Phyllostomus hastatus & Sexo + Localidade & 35 & 29 & 64 & Artibeus fimbriatus & - & 26 & 25 & 51 \\
\hline Chrotopterus auritus & Sexo + Localidade & 19 & 39 & 58 & Artibeus lituratus & Sexo & 20 & 20 & 40 \\
\hline Vampyrum spectrum & Sexo + Localidade & 24 & 17 & 41 & Dermanura phaeotis & - & 18 & 27 & 45 \\
\hline Monophyllus redmani & Sexo & 28 & 30 & 58 & Ariteus flavescens & Sexo & 40 & 19 & 59 \\
\hline Glossophaga soricina & - & 23 & 12 & 35 & Stenoderma rufum & Sexo & 34 & 26 & 60 \\
\hline Leptonycteris curasoae & Sexo & 27 & 34 & 61 & Centurio senex & Sexo + Localidade & 48 & 18 & 66 \\
\hline Brachyphylla cavernarum & Sexo + Localidade & 30 & 22 & 52 & Pygoderma bilabiatum & Sexo & 29 & 28 & 57 \\
\hline Erophylla sezekorni bambifrons & Sexo & 30 & 30 & 60 & Sphaeronycteris toxophyllum & Sexo & 42 & 22 & 64 \\
\hline Phyllonycteris poeyi & Sexo & 25 & 20 & 45 & Ametrida centurio & Sexo + Localidade & 32 & 16 & 48 \\
\hline Anoura geoffroyi & - & 10 & 29 & 39 & Phyllops falcatus & Sexo + Localidade & 28 & 22 & 50 \\
\hline
\end{tabular}




\subsection{Comparação de padrões entre as matrizes fenotípicas}

\subsubsection{Matrizes de correlação: Krzanowski (KRZ)}

A estrutura das matrizes de correlação fenotípicas foram comparadas por meio do método da projeção de Krzanowski (Blows et al., 2004; Krzanowski, 1979; Marroig \& Cheverud, 2010; Marroig et al., 2011). Esse método permite a comparação de duas matrizes calculando os ângulos entre os pares de eixos ortogonais correspondentes (componentes principais). A equação abaixo é utilizada para encontrar a projeção da matriz, S, baseada no subespaço dos primeiros 16 componentes principais, considerando um espaço dimensional total de 35 componentes:

$$
\mathbf{S}=\mathbf{A}^{\mathrm{T}} \mathbf{B} \mathbf{B}^{\mathrm{T}} \mathbf{A},
$$

onde $\mathbf{A}$ corresponde aos 16 primeiros componentes principais dispostos em coluna (norma $=1$ ), referentes à primeira matriz sendo comparada; B refere-se aos 16 primeiros componentes principais da segunda matriz $\mathrm{e}^{\mathrm{T}}$ representa a matriz de autovetores transposta. A matriz $\mathbf{S}$ representa os cossenos dos ângulos mínimos entre um conjunto de vetores arbitrários ortogonais no subespaço da matriz A, que mais se aproximam da direção de outro grupo de vetores ortogonais no subespaço da matriz B. Sendo assim, a matriz $\mathbf{S}$ é uma matriz de correlação na qual conhecemos a priori o traço que é igual ao níumero de dimensões ou o posto da matriz. Dessa forma, a soma dos autovalores de $\mathbf{S}$ pode ser usada para determinar o índice de similaridade entre os dois subespaços representados pelas duas matrizes (Blows et al., 2004).

O somatório dos autovalores de $\mathbf{S}$ é igual à soma dos quadrados dos cosenos dos ângulos entre os dois conjuntos dos eixos ortogonais (Blows et al., 2004), e encontram-se na faixa de 0 a 16 (no caso deste exemplo), bem como todos os autovalores de $\mathbf{S}$ apresentarão valores entre 0 e 1 . Portanto, a soma dos autovalores de $\mathbf{S}$ representam uma medida conveniente de similaridade dos dois subespaços porque está delimitada dentro de um intervalo de valores que tem uma interpretação direta (Blows et al., 2004; Krzanowski, 1979). A interpretação dos 
resultados segue a seguinte lógica: se o somatório for próximo de zero, os dois subespaços serão dissimilares, e estarão se aproximando da ortogonalidade, enquanto um somatório de $\mathrm{k}=16$ indicará que duas matrizes originais compartilham a mesma orientação (Blows et al., 2004). Para exemplificar, descrevi a soma dos autovalores dividido pelo valor máximo possível, que corresponde ao número de dimensões sendo utilizadas para representar ambos os subespaços (k = 16), lembrando que este índice poderá variar potencialmente de zero (não há semelhança estrutural) a um (similaridade estrutural completa no subespaço dos 16 componentes principais).

\subsubsection{Matrizes de covariância: Random Skewers (RS) e Krzanowski (KRZ)}

Os padrões expressos pelas matrizes de covariância fenotípicas foram comparados através do método de Adagas Aleatórias (Random Skewvers ou RS; Cheverud, 1996; Cheverud \& Marroig, 2007; Marroig \& Cheverud, 2001). Em linhas gerais, esse método consiste em simular a ação de seleção natural sobre um par de matrizes e comparar suas respostas. Caso as respostas sejam suficientemente semelhantes, considera-se as matrizes também como semelhantes.

Para simular a seleção, gerei 10.000 vetores aleatórios, cada um com o mesmo número de elementos das matrizes (ou seja, 35), extraídos de uma distribuição normal e normalizados para possuir comprimento total de valor 1; em outras palavras, cada um desses vetores é uma coluna com 35 números aleatoriamente gerados, sendo que a soma dos quadrados desses números é igual a 1. Multipliquei cada um dos 10.000 vetores por cada matriz e, como cada vetor aplicado sobre as matrizes é igual, eventuais diferenças nos vetores-resposta resultantes serão devidas às diferenças nas matrizes. A média da correlação de vetores entre os vetores-resposta de cada matriz é, dessa forma, uma medida do grau de similaridade das matrizes.

Essa técnica de comparação de matrizes é diretamente derivada da teoria de genética quantitativa, baseada na equação de resposta multivariada à seleção (Lande, 1979): 


\section{$\Delta \mathrm{z}=\mathrm{G} \beta$}

Em que $\beta$ representa o vetor de seleção, $\mathbf{G}$ representa as relações entre os caracteres e $\Delta \mathbf{z}$ representa a mudança (ou resposta) evolutiva nos caracteres em questão (J. Cheverud \& Marroig, 2007).

Explicitamente, neste procedimento de RS, eu testo a hipótese nula de ausência de estrutura compartilhada entre as matrizes de covariação fenotípicas dos filostomídeos (ou seja, H0: as matrizes não são similares, H1: os padrões expressos pelas matrizes comparadas são similares). Na interpretação dos resultados, se a correlação média do vetor observado exceder em $95 \%$ as correlações entre os vetores aleatórios, se deduz que há uma similaridade estrutural significativa entre as matrizes de covariância. E nesse caso rejeita-se a hipótese nula. Também comparei as matrizes de covariância utilizando o método da projeção de Krzanowski (Krzanowski, 1979; Marroig \& Cheverud, 2010), explicado detalhadamente na seção de comparação de matrizes de correlação. Os resultados das projeções de RS e KRZ são facilmente interpretáveis, e fornecem um índice de similaridade global (correlação), que corresponde à uma medida total de similaridade entre duas matrizes (Marroig \& Cheverud, 2010; Marroig et al., 2011).

\subsection{Detectando caracteres similares e dissimilares entre as matrizes}

No meu teste eu espero corroborar a hipótese de existência de similaridade estrutural entre as matrizes. Mas também presumo encontrar diferentes graus de associação tanto no padrão quanto na magnitude de integração entre os 35 caracteres que compõem as matrizes das espécies de filostomídeos. Esta verificação desperta outros questionamentos, como por exemplo: quais os caracteres mensurados que mais divergiram entre os filostomídeos? E, quais os 
caracteres cranianos que permaneceram mais similares entre as diferentes morfologias apresentadas por estes morcegos?

Vimos que os métodos de Krzanowski e Random Skewwers descritos acima nos dão uma resposta sobre se as matrizes de correlação e covariação são ou não globalmente similares, porém eles não são capazes de destacar onde as diferenças e similaridades se concentram. O método de decomposição de resposta à seleção (SRD; Marroig et al., 2011) é uma extensão da abordagem de RS, e foi desenvolvido como uma ferramenta exploratória para detectar similaridades e diferenças dos caracteres entre as matrizes. O SRD identifica em quais caracteres duas matrizes diferem mais, bem como em quais caracteres elas permanecem particularmente semelhantes.

No SRD os vetores respostas $(\boldsymbol{\Delta} \mathbf{z})$ obtidos, são decompostos em seus subcomponentes de resposta direta (aqueles devido à seleção direta em um caráter) e indireta à seleção (devidos à seleção atuando sobre os outros caracteres e a covariância destes com o caráter em questão). Para cada caráter haverá um vetor caráter-específico resultante de cada vetor resposta $(\boldsymbol{\Delta} \mathbf{z})$, ou seja, um total de 10.000 vetores caráter-específico por caráter. A correlação média entre esses vetores de resposta caráter-específicos é obtida repetindo-se o processo para cada um dos 10.000 vetores de seleção aleatórios, e a partir daí teremos os valores de SRD. Cada caráter é comparado entre as duas matrizes, investigando-se a distribuição das correlações dos vetores resposta. Caracteres semelhantes entre duas matrizes nas suas respostas à seleção direta e correlacionada irão apresentar valores médios de SRD altos (próximos à média global do valor do SRD), e variância pequena. De forma contrária, caracteres dissimilares em suas respostas à seleção irão apresentar valores médios baixos e variância altas (Marroig et al., 2011).

A partir dos resultados do SRD, determinei uma razão para cada espécie e caráter, com a finalidade de demonstrar de forma sucinta quais os caracteres que mais divergiram por espécie e quais os caracteres que divergiram mais de forma global (incluindo-se todas as espécies). Nessa razão, dada uma distância (ou caráter) específica, o numerador será o número de vezes que uma 
determinada espécie diferiu significativamente em relação às outras, e o denominador o número total de comparações de cada espécie em relação às demais.

Indo um pouco mais além, também podemos fazer uso do SRD como uma ferramenta para explorar as relações dos caracteres cranianos com o hábito alimentar dos morcegos da Família Phyllostomidae. Sabemos que a diversidade de hábitos alimentares desses morcegos são refletidas em suas distintas morfologias, em particular no crânio. Nesta linha de raciocínio, será que os caracteres que mais divergiram estão relacionados às regiões do crânio que morfologicamente expressam maior diversidade aos nossos olhos? Essa diversidade qualitativa à que me refiro pode ser observada na Figura 3.1.

Para investigar esta questão, gerei 35 matrizes (uma para cada distância) utilizando os valores médios do SRD, e comparei cada uma das 35 matrizes com a matriz de dieta, através do teste de Mantel considerando correlações significativas $(p<0.05)$. Espero encontrar um correlação significativa para os caracteres que se encontram em regiões do crânio que expressam grande variação morfológica devido aos hábitos alimentares das espécies, como por exemplo caracteres relacionados à região da face.

\subsection{Repetibilidade e ajuste das matrizes}

É preciso estar ciente de que padrões de variação e covariação genética e fenotípicos comparados entre os taxa são apenas estimativas baseadas em uma amostra, e dessa forma, não expressam valores populacionais reais (Cheverud, 1996b). Levando-se isso em consideração, compreendemos que as matrizes não são conhecidas, mas sim estimadas com algum grau de erro (Cheverud, 1988). O erro decorrente da imperfeição na estimativa dos elementos individuais das matrizes limitam a correlação máxima possível entre elas. Desta forma é preciso avaliar a repetibilidade das matrizes, a fim de verificar o nível de similaridade observada (Cheverud, 
1996b). Este valor reflete a representatividade da amostra em relação à população real e, portanto, está associado ao tamanho $n$ amostral. Depois de ter a repetibilidade calculada, pode-se, então, estabelecer limites máximos para a similaridade esperada entre duas matrizes dado o erro observado nas suas estimativas (Marroig \& Cheverud, 2001).

Ao compararmos duas matrizes a máxima correlação entre elas não é 1 como seria esperado, mas sim um valor inferior a isso. Isso acontece simplesmente por efeito de amostragem. Desta forma, a técnica de ajustar as matrizes de acordo com suas repetibilidades, nada mais é do que remover este viés da amostragem no cálculo das correlações entre matrizes. Em outras palavras, a repetibilidade é uma medida de confiança nas estimativas das matrizes com aquele tamanho amostral (Cheverud, 1995; Cheverud, 1996). Para se obter a correlação ajustada $\left(\mathrm{r}_{\text {adi }}\right)$ a partir do valor da correlação observada $\left(\mathrm{r}_{\mathrm{obs}}\right)$ entre duas matrizes utilizei a fórmula proposta por Cheverud (1996),

$$
r_{a d j}=\frac{r_{o b s}}{\left(t_{1} t_{2}\right)^{1 / 2}}
$$

Onde t1 e t2 são as repetibilidades das duas matrizes envolvidas na comparação. Estas repetibilidades foram calculadas utilizando-se um método de reamostragem com reposição dos resíduos do GLM de cada população (Marroig \& Cheverud, 2001). Foram feitas 1000 reamostragens destes resíduos (para cada população) e a cada reamostragem uma nova matriz de covariância e correlação foram calculadas. Posteriormente, a similaridade destas matrizes foram determinadas através do método de RS e KRZ e a média entre as comparações das matrizes foi usado como valor de repetibilidade (t).

Ao compararmos duas matrizes a máxima correlação entre elas não é 1 como seria esperado, mas sim um valor inferior a isso. Isso acontece simplesmente por efeito de amostragem. Desta forma, a técnica de ajustar as matrizes de acordo com suas repetibilidades, nada mais é do que remover este viés da amostragem no cálculo das correlações entre matrizes. 
Em outras palavras, a repetibilidade é uma medida de confiança nas estimativas das matrizes com aquele tamanho amostral (Cheverud, 1995; Cheverud, 1996). Para se obter a correlação ajustada $\left(\mathrm{r}_{\text {adj }}\right)$ a partir do valor da correlação observada $\left(\mathrm{r}_{\mathrm{obs}}\right)$ entre duas matrizes utilizei a fórmula proposta por Cheverud (1996),

$$
r_{a d j}=\frac{r_{o b s}}{\left(t_{1} t_{2}\right)^{1 / 2}}
$$

Onde t1 e t2 são as repetibilidades das duas matrizes envolvidas na comparação. Estas repetibilidades foram calculadas utilizando-se um método de reamostragem com reposição dos resíduos do GLM de cada população (Marroig \& Cheverud, 2001). Foram feitas 1000 reamostragens destes resíduos (para cada população) e a cada reamostragem uma nova matriz de covariância e correlação foram calculadas. Posteriormente, a similaridade destas matrizes foram determinadas através do método de RS e KRZ e a média entre as comparações das matrizes foi usado como valor de repetibilidade (t).

\subsection{Magnitudes de integração}

Calculei dois índices de magnitude de integração entre os caracteres: (1) o coeficiente de determinação médio $\left(\mathrm{r}^{2}\right)$, calculado através da matriz de correlação; (2) o coeficiente de variação dos autovalores (ICV), calculado utilizando-se a matriz de covariância. O coeficiente de determinação médio $\left(\mathrm{r}^{2}\right)$ é um índice que representa a magnitude geral de integração entre os caracteres e tem sido utilizado extensivamente em estudos de integração morfológica (Chernoff \& Magwene, 1999; Cheverud et al., 1989; Oliveira et al., 2009; Porto et al., 2009; Porto et al., 2013; Sokal \& Rohlf, 1995). Seu cálculo corresponde à média dos coeficientes de correlação elevados ao quadrado, e mostra o quão associados, no geral, estão os caracteres na matriz. Por ser obtido 
através das matrizes de correlação, este é um índice que independe da escala dos organismos. O coeficiente de variação dos autovalores (ICV; Porto et al., 2013; Shirai \& Marroig, 2010) é obtido dividindo-se os desvios padrões dos autovalores $\left(\sigma_{(\lambda)}\right)$ pela média dos autovalores $(\lambda)$. Este índice é apropriado para comparações que envolvem organismos com grandes diferenças no valor absoluto do tamanho corporal e para matrizes de covariância. Animais de maior porte apresentam médias, variâncias e covariâncias maiores, e consequentemente, autovalores maiores. Desta forma, o efeito de escala pode ser controlado através do uso do ICV.

\subsection{Fator ecológico: Dieta}

Elaborei uma matriz ecológica baseada na proporção de ítems alimentares compartilhados entre as diferentes espécies de filostomídeos, a fim de investigar se a dieta influencia a estrutura das matrizes de correlação e covariação fenotípicas. Usei a matriz de dados de dieta dos morcegos filostomídeos proposta por Rojas et al., (2011) a qual inclui insetivoria, carnivoria, hematofagia, nectarivoria e frugivoria como categorias alimentares. Estes autores realizaram uma pesquisa cuidadosa e extensa para construir a matriz de hábitos alimentares de filostomídeos, e agruparam as cinco dietas como: (0) ausente, (1) complementar, (2) predominante e (3) estrita. $\mathrm{Na}$ tabela $\mathrm{A} 3 \mathrm{em}$ anexo, apresento a matriz de hábitos alimentares proposta por Rojas et al., (2011), considerando as 48 espécies que compõem o presente estudo.

A partir dessa tabela original de Rojas et al., (2011), construí uma matriz de dieta de 35 por 35 elementos. Para cada espécie de morcego, atribuí valores contínuos correspondentes à porcentagem de contribuição de cada ítem na sua dieta total. Por exemplo, Lonchorbina aurita é uma espécie essencialmente caçadora de insetos mas também complementa a sua dieta com frutas. Nesse caso, o valor de 0.666 foi inserido na casela insetivoria e o valor de 0.333 na casela de frugivoria. A quantidade de dieta compartilhada entre cada par de espécies foi calculada como 
sendo o somatório das cinco categorias, onde cada categoria tem um valor que corresponde à raiz quadrada dos produtos dos valores de ambas espécies na mesma categoria alimentar. Desta forma, os valores na matriz de dieta variaram entre zero e um.

A matriz de dieta foi correlacionada com os resultados de similaridade das matrizes de correlação (KRZ) e covariância (RS e KRZ), bem como com a matriz de distâncias filogenéticas, usando a correlação de matrizes seguida do teste de Mantel. Espero encontrar uma correlação positiva e significativa entre dieta e as matrizes de similaridade fenotípicas, caso os padrões de similaridade das matrizes tenham sido influenciados ao longo da evolução do grupo, devido às adaptações a dietas diferentes. No meu teste de hipóteses considerei correlações significativas $(\mathrm{p}<0.05)$.

\subsection{Fator histórico: Distâncias Filogenéticas}

Utilizei uma matriz de distâncias filogenéticas para investigar se os padrões de similaridade das matrizes de correlação e covariância foram influenciados pela história evolutiva dos morcegos filostomídeos. Estas distâncias foram obtidas de uma filogenia proposta recentemente por Dávalos e colaboradores (Systematic Biology, In review). Optei pela utilização dessa hipótese filogenética por ser a mais atual e completa, com maior número de espécies e genes analisados conjuntamente, incluindo também espécies fósseis. Nessa filogenia estão representadas 36 espécies de filostomídeos que compõem o presente estudo.

Converti a árvore em matriz de distâncias filogenéticas usando a função cophenetic.phylo (pacote "ape") do R (versão 3.0.1), seguindo o método proposto por de Vienne et al., (2011). As distâncias filogenéticas são os próprios comprimentos dos ramos da árvore, calculados com base em dados moleculares. A matriz de distâncias filogenéticas foi correlacionada com os resultados de similaridade das matrizes de correlação (KRZ) e covariância (RS e KRZ), usando a correlação 
de matrizes seguida do teste de Mantel. Isso indicará se, e o quanto, os padrões de correlação e covariação estão estruturados filogeneticamente. Dessa forma, se os padrões de similaridade foram influenciados pela história evolutiva dos morcegos filostomídeos, espero encontrar uma correlação negativa e significativa entre as distâncias filogenéticas e as matrizes de similaridade fenotípicas. A correlação será negativa porque a filogenia é representada por uma matriz de dissimilaridade e as estruturas de correlação e covariação por matrizes de similaridade. No meu teste de hipóteses considerei correlações significativas $(\mathrm{p}<0.05)$. Dado que espécies filogeneticamente próximas podem apresentar dietas mais similares, removi a correlação entre a matriz de dieta e de filogenia, através de regressão linear, obtendo dessa maneira uma matriz de dieta residual (que corresponde à parte de variação em dieta que é independente da filogenia) e uma matriz de filogenia residual (que corresponde à parte de variação em filogenia que independe da dieta). Correlacionei essas matrizes residuais com as matrizes de similaridade e com a matriz de distãncias morfológicas.

\subsection{Outros fatores: Distâncias morfológicas}

Elaborei um matriz de distâncias morfológicas para investigar se variações na estrutura de correlação e covariância entre as espécies de filostomídeos condizem às distâncias entre suas médias. Estimei as distâncias de Mahalanobis $\left(\boldsymbol{D}^{2}\right)$ entre as espécies, seguindo a fórmula:

$$
D^{2} i j=(\mu i-\mu j) W^{-1}(\mu i-\mu j)
$$

onde $\mu \mathbf{i}$ e $\mu \mathbf{j}$ são os vetores de médias de cada caráter do primeiro e do segundo táxon, respectivamente (Rebecca Rogers Ackermann, 2002).

A distância de Mahalanobis é uma métrica que mede a diferença multivariada entre duas populações baseada em informações de variação e covariação e, portanto, pode ser utilizada para calcular a distância morfológica entre dois grupos (i e j). Comparei a matriz de distâncias 
morfológicas com as matrizes de filogenia e dieta, usando a correlação de matrizes seguida do teste de Mantel, considerando correlações significativas $(\mathrm{p}<0.05)$.

\subsection{Hipóteses de modularidade}

A motivação deste tópico é compreender se os morcegos filostomídeos compartilham um padrão de integração morfológica relacionado à função e desenvolvimento. Para investigar a integração morfológica craniana em morcegos filostomídeos, utilizei matrizes teóricas baseadas em função e desenvolvimento compartilhados entre os caracteres, seguindo a abordagem de Cheverud, (1995, 1996). A idéia se baseia em comparar as correlações efetivamente observadas nos caracteres fenotípicos cranianos dos morcegos filostomídeos ao padrão esperado segundo um conjunto teórico. Construí as matrizes teóricas da seguinte maneira: quando dois caracteres pertenciam ao conjunto functional e de desenvolvimento sendo testado (isto é, aos módulos hipotéticos), o valor 1 era colocado na matriz teórica; se não pertencia, o valor 0 era adicionado.

No total, utilizei nove hipóteses de modularidade em diferentes níveis hierárquicos. Cinco delas testam para a existência de subregiões funcionais no crânio: oral, nasal, zigomática, abóbada e base cranianas. As outras duas matrizes teóricas exploram a presença de regiões de desenvolvimento: face e neurocrânio (Moore, 1981). Outra matriz teórica, denominada integração neuro-somática, associa todos os caracteres dentro do neurocrânio e da face, e explora as relações de padrões de crescimento entre caracteres que se desenvolvem mais cedo (neurais) e os tardios (faciais). Por fim, associei as cinco subregiões do crânio em uma única matriz de integração total.

As matrizes teóricas foram correlacionadas às matrizes de correlação observadas para cada espécie, e o teste de Mantel foi usado para verificar a probabilidade referente à cada comparação. Baseada nas hipóteses de integração, utilizei um índice de modularidade que mede o quanto um determinado módulo se destaca em comparação a todas as demais correlações em 
uma matriz. Mais precisamente, esse índice examina se a média das correlações entre os caracteres supostamente integrados, segundo uma certa hipótese teórica (avg+), é maior que a média dos caracteres supostamente não-integrados (avg-). Se essa hipótese em questão estiver relacionada com o fenótipo de um dado grupo, espera-se que avg+ seja maior que avg-. De fato, a razão entre as duas médias (avg+/avg-), segundo uma dada hipótese, traz informações sobre a magnitude de integração entre os caracteres do módulo hipotetizado em relação a todos os outros caracteres. A razão avg+/avg-, portanto, mede o grau de distinção dos módulos: se as correlações dentro de um módulo forem maiores que em outros módulos ou entre módulos, essa razão será maior que 1; caso contrário, será menor ou igual a 1.

Por fim, correlacionei os índice de integração morfológica entre os caracteres ( $\mathrm{r}^{2}$ e ICV) com os índices de modularidade (avg+/avg-) correspondentes às nove hipóteses de integração morfológica, utilizando Systat 11 (SSPS, Inc. 2004, Chicago, IL). Estes resultados serão apresentados graficamente, com os respectivos valores dos coeficientes de correlação e as probabilidades de associação.

\subsection{Flexibilidade evolutiva e Restrição}

Qualquer matriz que quantifica modularidade e integração em caracteres complexos tem uma estrutura que impõe uma restrição à mudança evolutiva (Arnold et al., 2001). Dizer que uma matriz apresenta uma determinada estrutura, significa que há correlações não nulas entre os caracteres que a compõem.

Tendo como base teórica o trabalho de Marroig et al., (2009), realizei simulações das respostas evolutivas à seleção nas matrizes de covariância, com o propósito de investigar as restrições na capaciadade dos crânios de filostomídeos em responder na direção da seleção. Esta abordagem é baseada na equação multivariada de resposta à seleção proposta por (Lande, 1979), 
onde: $\boldsymbol{\Delta} \mathbf{z}=\mathbf{G} \boldsymbol{\beta}$. Nesse caso, uso a matriz fenotípica $\mathbf{P}$ como substituta da matriz genética $\mathbf{G}$, assumindo que a similariadade da estrutura é mantida em relação à sua contraparte fenotípica (J. Cheverud, 1988). São criados 10.000 vetores de seleção a partir de números aleatórios com distribuição normal. Esses vetores de seleção são normalizados para apresentarem todos comprimentos iguais a um. A matriz fenotípica referente a cada espécie é submetida a esta série de vetores aleatórios de seleção $(\beta)$ e o que obtemos dessa combinação são os vetores de resposta à seleção $(\boldsymbol{\Delta} \mathbf{z})$.

Dois índices são calculados baseados nos vetores de resposta à seleção: a flexibilidade evolutiva e o índice de restrição (Marroig et al., 2009). Esses índices são então comparados entre as matrizes e espécies. Flexibilidade corresponde ao coseno do ângulo (isto é, a correlação) entre o vetor do gradiente de seleção $(\boldsymbol{\beta})$ e o vetor de resposta evolutiva ( $\boldsymbol{\Delta} \mathbf{z}$; Marroig et al., 2009). Ou ainda, de acordo com Hansen \& Houle, (2008), flexibilidade refere-se à razão entre evolvabilidade e respondabilidade.

Biologicamente falando, a flexibilidade captura a capacidade de uma população em responder na direção em que a seleção está agindo, independente da magnitude da resposta evolutiva (Marroig et al., 2009). Quanto menor a correlação entre o vetor resposta em relação ao vetor de seleção, menor a capacidade de determinada população evoluir na direção da seleção (Porto et al., 2013). Em meu estudo, dizer que uma espécie é mais flexível em comparação à outra, significa dizer que seu aparato craniano possui uma maior habilidade em responder na direção em que a seleção está atuando.

Por outro lado, restrições evolutivas podem ser definidas como quaisquer limitações ou viés no curso da evolução (Arnold, 1992; Marroig et al., 2009). A restrição evolutiva é calculada como sendo a relação entre os vetores respostas e o primeiro componente principal de cada matriz de covariância. Correlacionei cada um dos 10.000 vetores respostas com o primeiro componente principal de cada matriz, e calculei a correlação média entre eles. O primeiro componente principal das matrizes de covariância, é aquele que, dentre todos os componentes, 
carrega a maior parte da variação presente na matriz, definindo o que Schluter, (1996) chamou de "linha de menor resistência evolutiva". Essa linha pode ser entendida como a direção em que a evolução é mais fácil de acontecer, mesmo que a seleção não atue exatamente nessa direção. Assim, a média das correlações entre as respostas derivadas de vetores aleatórios e o primeiro componente principal é uma medida do quanto as restrições, embutidas no padrão e na magnitude das relações entre caracteres, podem enviesar a evolução craniana.

Por fim, correlacionei os índices de integração morfológica entre os caracteres ( $\mathrm{r}^{2}$ e ICV) com os índices de flexibilidade e restrição evolutivas, utilizando Systat 11 (SSPS, Inc. 2004, Chicago, IL). Estes resultados serão apresentados graficamente, com os respectivos valores dos coeficientes de correlação e as probabilidades de associação.

\subsection{Variação devida ao tamanho}

No estudo de caracteres quantitativos a variação devida ao tamanho é um fator importante que deve ser levado em consideração. De acordo com Porto et al., (2013), a variação de tamanho se refere à variação do comprimento de um caráter, que está conectada com a variação em todos os outros caracteres, no sentido de que elas aumentam ou diminuem em conjunto, obtendo-se a variação partilhada por todos os traços (covariação isométrica ou alométrica). Dessa forma, a alometria, termo criado por Huxley \& Teissier, (1936), designa as alterações das dimensões relativas das partes do corpo que estão correlacionadas com as transformações das dimensões globais (Gayon, 2000).

Obtive a porcentagem de variação explicada pelo primeiro componente principal (CP1) das matrizes de covariância de todas as espécies que compõem o meu estudo. Esta métrica indica a quantidade de variação presente em uma dada matriz que está associada ao tamanho. Meu intuito nesta questão é investigar se a variação atribuída ao tamanho influencia a evolução 
fenotípica nos morcegos filostomídeos. Dessa forma, para cada espécie, correlacionei a porcentagem de variação no $\mathrm{CP} 1$ aos índices de integração morfológica $\mathrm{r}^{2}$ e ICV e também às métricas de flexibilidade e restrição evolutivas.

Um outo ponto importante nesta etapa é avaliar nos filostomídeos em quais dos componentes principais o tamanho se expressa. Em estudos realizados com diferentes grupos de mamíferos foi detectado que a porcentagem de variação relacionada ao tamanho se encontra no primeiro CP (Marroig \& Cheverud, 2005; Oliveira et al., 2009; Porto et al., 2009, 2013), e este componente atua como uma força de restrição no potencial de mudança evolutiva (ver Marroig et al., 2009). Para examinar esta questão, selecionei os doze primeiros componentes principais de cada matriz de covariância. Criei um vetor normalizado de comprimento 35 (correspondente ao número de distâncias que tenho). Os valores desse vetor normalizado são iguais a 0.169 (obtido por: $1 / \sqrt{ } 35$ ), e o somatório desse vetor igual a 1 . Correlacionei cada um dos doze componentes principais com o vetor normalizado, e considerei valores de correlação maiores e/ou iguais a 0.7 como sendo tamanho.

Nesta investigação espero encontrar um dos três resultados apresentados abaixo:

(1) CP1 é tamanho;

(2) tamanho se encontra em outro CP que não o primeiro;

(3) tamanho está disperso ao longo dos componentes principais, de forma que não é capturado por nenhum deles.

Caso o tamanho não seja detectado no primeiro $\mathrm{CP}$, será necessário avaliar então o quanto de variação relativa está relacionada com tamanho. Para isso, multipliquei os resíduos de cada variável pelo vetror isométrico e fiz o somatório visando obter a projeção de cada indivíduo neste vetor (denominei essa métrica de variação relativa associada ao tamanho). Quando a variância associada a este vetor hipotético de tamanho isométrico é dividida pela variância total (soma dos autovalores), obtemos a variação relativa de cada indivíduo ao longo da direção de 
tamanho. Por fim, correlacionei a variação relativa associada ao tamanho aos índices de integração morfológica $\mathrm{r}^{2}$ e ICV e também às métricas de flexibilidade e restrição evolutivas.

\subsection{Morcegos filostomídeos no contexto dos demais mamíferos}

Como dito anteriormente, a homologia dos marcadores anatômicos cranianos entre as diversas ordens de mamíferos estudadas no Laboratório de Evolução de Mamíferos (LEM) permite a comparação dos resultados dessa extensa base de dados. A minha meta neste ponto é situar os morcegos filostomídeos no contexto de alguns grupos de mamíferos estudados no LEM, considerando dois aspectos relevantes: (1) as magnitudes de integração, e (2) suas consequências evolutivas.

Para isso, utilizei o conjunto de dados apresentado no manuscrito de Marroig et al., (2009), que inclui 15 ordens de mamíferos (ver tabela A4 nos anexos). Considerando então os morcegos filostomídeos e os demais mamíferos, correlacionei os índices de integração morfológica entre os caracteres ( $\mathrm{r}^{2}$ e ICV) com os índices de modularidade (avg+/avg-) correspondentes às hipóteses de integração, bem como com os índices de flexibilidade e restrição evolutivas. Para os demais mamíferos (não filostomídeos) extraí o ICV de Porto et al., (2013) e as demais variáveis de Marroig et al., (2009). Utilizei Systat 11 (SSPS, Inc. 2004, Chicago, IL) para estas análises. Estes resultados serão apresentados graficamente, com os respectivos valores dos coeficientes de correlação e as probabilidades de associação. 


\section{RESULTADOS}

\subsection{Repetibilidade das medidas}

As repetibilidades calculadas com base nas repetições para cada um dos 35 caracteres cranianos é apresentada na Tabela 4.1. Nessa tabela, encontram-se os valores de repetibilidade das distâncias para cada espécie, bem como as médias e desvios padrões associados. Os valores das médias das repetibilidades, mínimos e máximos, variaram respectivamente de 0.77 a 0.96 , e os desvios padrões de 0.02 a 0.09 . Os caracteres apresentaram distribuição normal nas análises univariadas dentro das espécies. Nas tabelas A5 e A6 em anexo, apresento respectivamente as médias e os desvios padrões das réplicas dos dados (primeira e segunda medida por caráter craniano).

A maioria dos valores de repetibilidade esteve acima de 0.9. Os menores valores de repetibilidade estiveram associados às distâncias IS-PM, ZS-ZI, ZI-MT, IS-NSL e BA-OPI (valores mínimos em torno de 0.6). Esses valores baixos podem ser atribuídos ao tamanho diminuto dos crânios e à pequena distância apresentada entre os marcadores IS (intradental superior) e o PM (junção da pré-maxila-maxila no alvéolo); ZS (zigomaxilar superior) e o ZI (zigomaxilar inferior); ZI e o MT (tuberosidade do maxilar) e IS (intradental superior) e o NSL (nasal). Nesse caso, o erro, mesmo quando pequeno em escala absoluta, representa uma parte considerável da variação total. Por sua vez, os marcadores anatômicos BA (basion) e OPI (opisthion), são categorizados como marcadores anatômicos do tipo II (O’Higgins, 2000). O fato de não serem delimitados por suturas pode ter dificultado a tomada de dados justificando o menor valor de repetibilidade obtido. Ainda assim, vale ressaltar que as repetibilidades mais baixas estiveram associadas a desvios padrões pequenos, e as réplicas na aquisição dos dados mantiveram-se dentro do limite aceitável de erro de mensuração de $0.4 \mathrm{~mm}$. Desta forma, o impacto do erro de mensuração deve ser pequeno na interpretação dos resultados que obtive. 
Tabela 4.1- Repetibilidade das 35 medidas cranianas em morcegos da Família Phyllostomidae. Médias e desvios padrões estão na parte inferior da tabela.

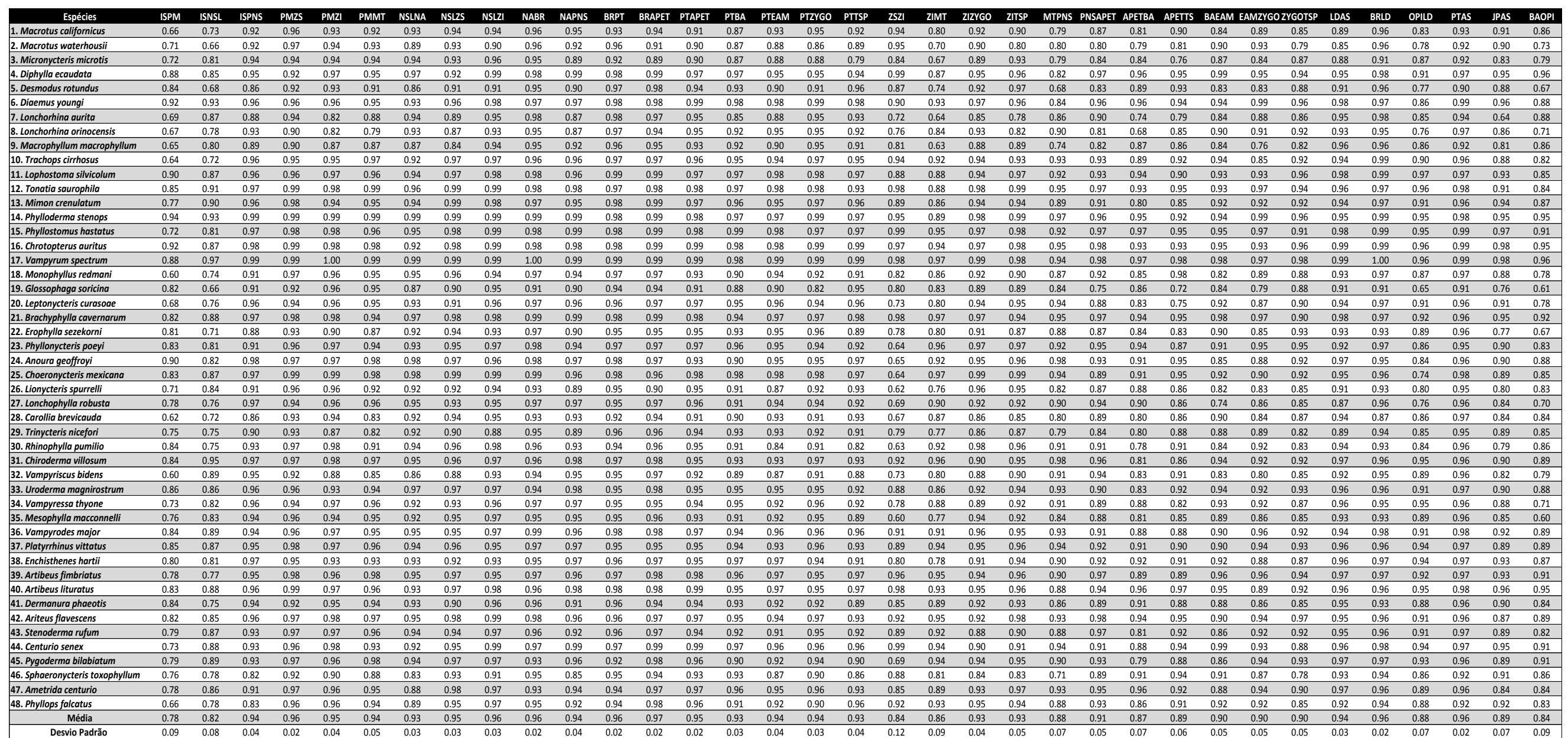




\subsection{Similaridade estrutural das matrizes fenotípicas}

$\mathrm{Na}$ Tabela 4.2 apresento os resultados de similaridade entre as matrizes de correlação obtidos pelo método da projeção de Kræanowski (Krzanowski, 1979). Nas Tabelas 4.3 e 4.4 respectivamente, apresento a similaridade entre as matrizes de covariância, obtida a partir do método da projeção de Kræanowski e também por meio do método de Adagas Aleatórias (Random Skewvers ou RS; Cheverud, 1996b; Marroig \& Cheverud, 2001; Cheverud \& Marroig, 2007). As correlações observadas estão acima da diagonal e as correlações ajustadas estão abaixo da diagonal. As repetibilidades estão destacadas em negrito na diagonal da matriz. Todas as comparações entre as matrizes de correlação e covariação entre as espécies de filostomídeos foram significativas $(\mathrm{p}<0.001)$. Os resultados apresentados neste tópico corroboram a hipótese de que os padrões estruturais expressos nas matrizes de correlação e covariância fenotípicas são até certo ponto similares entre as espécies de morcegos da Família Phyllostomidae.

Apresento a similaridade média para os valores observados e ajustados entre as espécies de morcegos filostomídeos baseada em comparações de matrizes de correlação (figura 4.1). $\mathrm{Na}$ Figura 4.2 apresento a similaridade média dos valores observados e ajustados baseada em comparações de matrizes de covariância determinada por Krz̧anowski; e na Figura 4.3 apresento a similaridade média dos valores observados e ajustados baseada em comparações de matrizes de covariância determinada por Random Skewwers. Na Tabela 4.5 observam-se os valores mínimo, máximo, a média e o desvio padrão da similaridade média das matrizes de correlação e covariância, calculados a partir dos valores observados. Na Tabela 4.6 apresento as mesmas estatísticas básicas descritas acima, porém calculadas a partir dos valores ajustados. A análise das médias dos valores de similaridade observados e ajustados entre as matrizes de correlação e de covariância indicam alta semelhança entre as espécies. Nos resultados gráficos (Figuras 4.1, 4.2 e 
4.3), é possível notar que os valores de similaridade média para cada espécie mostraram-se muito semelhantes quando calculados por meio das matrizes de correlação ou de covariância.

Vampyressa thyone mostrou os maiores valores de similaridade média ajustados e observados na comparação das matrizes de correlação, enquanto Centurio senex apresentou o menor valor observado e Phylloderma stenops o menor valor ajustado (Figura 4.1). Na comparação das matrizes de covariância pelo método de Krzanowski, Vampyressa thyone também apresentou os maiores valores de similaridade média observados e ajustados, e Centurio senex os menores (Figura 4.2). Na comparação das matrizes de covariância pelo método de $R S$, Choeronycteris mexicana apresentou os menores valores de similaridade média observados e ajustados e Trinycteris necefori os maiores (Figura 4.3). Detectei relação significativa entre o número de indivíduos e a similaridade média dos valores observados e ajustados, tanto para matrizes de correlação estimadas por Krzanowski, quanto para as matrizes de covariância estimadas por Krzanowski e RS (Figura 4.5, Figura 4.4, Figura 4.6).

As repetibilidades das matrizes de correlção e de covariância foram altas indicando confiabilidade em suas estimativas. Os valores de repetibilidade das matrizes de covariância foram maiores que os obtidos para matrizes de correlação (Tabela 4.7). O menor valor de repetibilidade da matriz de correlação foi encontrado em Phyllops falcatus (0.84) e o maior valor em Choeronycteris mexicana (0.90). Nas matrizes de similaridade estimadas por krz o valor mais baixo de repetibilidade foi registrado em Phyllops falcatus (0.84) e o mais alto em Lionycteris spurrelli (0.90). Nas matrizes de similaridade estimadas por $R S$ o valor mais baixo de repetibilidade foi registrado em Glossophaga soricina (0.89) e o mais alto em Choeronycteris mexicana (0.96). Observei associação significativa entre o número de indivíduos e os valores de repetibilidade da matriz de covariância estimada por RS (Figura 4.7). Não houve relação significativa entre o número amostral e os valores de repetibilidade das matrizes de correlação $(r=0.03, p=0.79)$ e de covariância $(r=0.15$, $\mathrm{p}=0.32)$ estimadas por Krzanowski. 
$\mathrm{Na}$ matriz de correlação, os menores valores de similaridade observada (isto é, não ajustadas para a repetibilidade das matrizes) foram obtidos da comparação entre Phylloderma stenops e Centurio senex (0.571), Glossophaga soricina e Centurio senex (0.574), Lophostoma silviculum e Centurio senex (0.578) e Lonchophylla robusta e Centurio senex (0.579). O maior valor de similaridade ajustada foi obtido da comparação entre Choeronycetris mexicana e Leptonycteris curasoae (0.901) (Tabela 4.2).

Nas matrizes de covariância, comparadas por meio de Kržanowski, os menores valores de similaridade observadas foram obtidos das seguintes comparações entre espécies: Anoura geoffroyi e Centurio senex (0.564), Phylloderma stenops e Centurio senex (0.584), Lionycteris spurrelli e Centurio senex (0.594) e Lonchophylla robusta e Centurio senex (0.599). Os maiores valores de similaridade ajustada para esta matriz foram obtidos das comparações entre Vampyriscus bidens e Trinycteris nicefori (0.889), Lonchophylla robusta e Lionycteris spurrelli (0.902) e Vampyressa bidens e Chiroderma villosum (0.910) (Tabela 4.3).

Nas matrizes de covariância, comparadas por meio de $R S$, encontrei quinze valores de similaridade observada entre o 0.43 e 0.50 , sendo o menor obtido da comparação entre Choeronyctreis mexicana e Centurio senex. Quando os valores foram ajustados na matriz, apenas cinco das quinze correlações ainda permaneceram com valores baixos entre 0.45 e 0.50 . Estas comparações envolvem os seguintes pares de espécies: Centurio senex e Choeronyctreis mexicana (0.45), Ariteus flavescens e Choeronycteris mexicana (0.46), Centurio senex e Anoura geoffroyi (0.47), Choeronycteris mexicana e Lonchorbina aurita (0.48) e Sphaeronycteris toxophyllum e Choeronycteris mexicana (0.5). Os maiores valores de similaridade ajustada na matriz de covariância comparada por $R S$, foram obtidos das comparações entre Trachops cirrhosus e Macrotus californicus (0.903) e Uroderma magnirostrum e Chiroderma villosum (0.911) (Tabela 4.4). 
Tabela 4.2- Similaridade entre as matrizes de correlação determinada por Krzanowski. A diagonal, em negrito, contém a repetibilidade das matrizes. Comparações observadas estão na metade superior e as ajustadas na metade inferior.

Espécies Macrotus californicus 2. Macrotus waterhousi 3. Micronycteris microtis 4. Diphylla ecaudata 5. Desmodus rotundus 6. Diaemus youngi 7. Lonchorhina aurita 8. Lonchorhina orinocensis 9. Macrophyllum macrophyllum 10. Trachops cirrhosus 11. Lophostoma silvicolum 11. Lophostoma silvicolu 12. Tonatia saurophila 13. Mimon crenulatum 14. Phylloderma stenops 15. Phyllostomus hastatus 16. Chrotopterus auritus 17. Vampyrum spectrum 18. Monophyllus redman 19. Glossophaga soricina 20. Leptonycteris curasoae 21. Brachyphylla cavernarum 22. Erophylla sezekorni 23. Phyllonycteris poey 24. Anoura geoffroyi 25. Choeronycteris mexi 26. Lionycteris spurrelli 27. Lonchophylla robusta 28. Carollia brevicauda 28. Carollia brevicauda 29. Trinycteris nicefori 30. Rhinophylla pumilio 31. Chiroderma villosum 32. Vampyriscus bidens
33. Uroderma magnirostrum 33. Uroderma magnirost
34. Vampyressa thyone 35. Mesophylla macconne 36. Vampyrodes major 37. Platyrrhinus vittatus 38. Enchisthenes hartii 39. Artibeus fimbriatus 40. Artibeus lituratus 41. Dermanura phaeotis 42. Ariteus flavescens 43. Stenoderma rufum 44. Centurio senex 45. Pygoderma bilabiatum 46. Sphaeronycteris toxophyllum 47. Ametrida centurio 48. Phyllops falcatus $\begin{array}{lllllllllllllllllllllllllllllllllllllllllllllllll}1 & 2 & 3 & 4 & 5 & 6 & 7 & 8 & 9 & 10 & 11 & 12 & 13 & 14 & 15 & 16 & 17 & 18 & 19 & 20 & 21 & 22 & 23 & 24 & 25 & 26 & 27 & 28 & 29 & 30 & 31 & 32 & 33 & 34 & 35 & 36 & 37 & 38 & 39 & 40 & 41 & 42 & 43 & 44 & 45 & 46 & 47 & 48\end{array}$

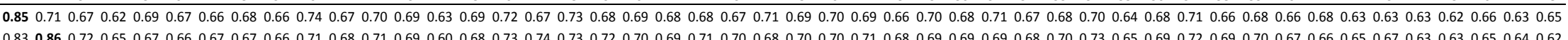

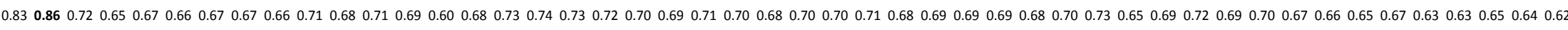

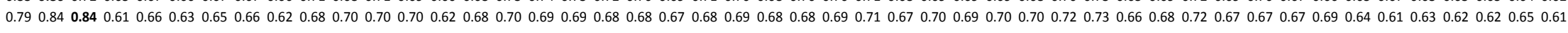

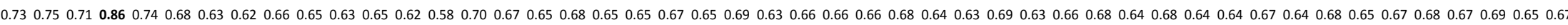

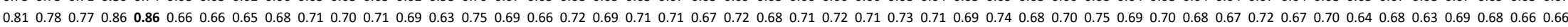

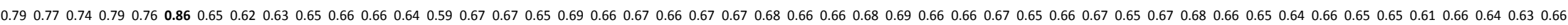

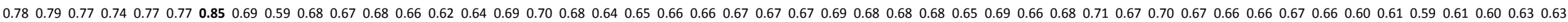

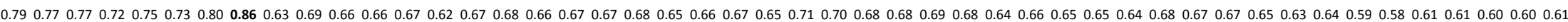

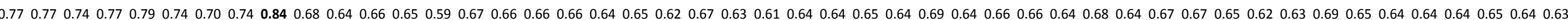

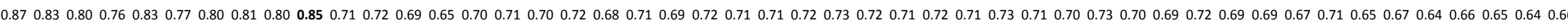

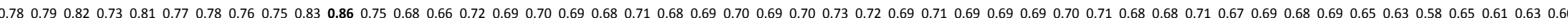

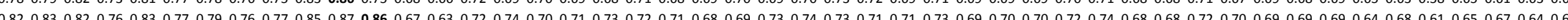

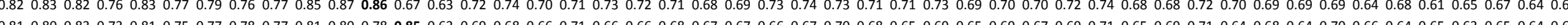

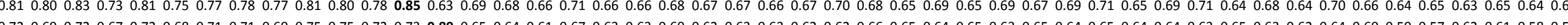
(1)

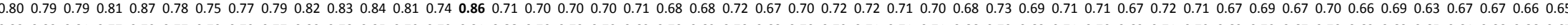

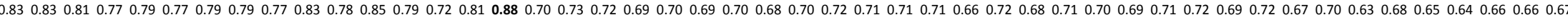

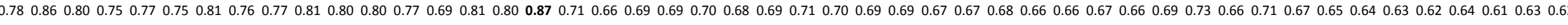

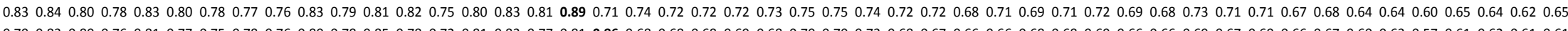

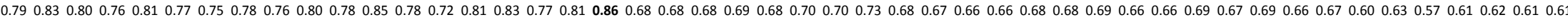

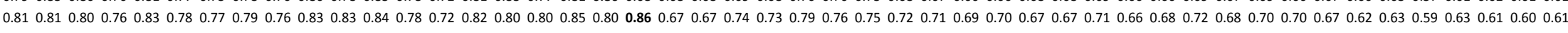

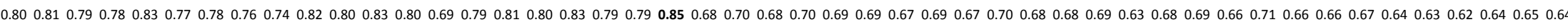

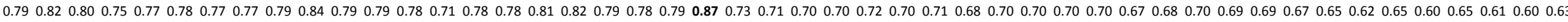

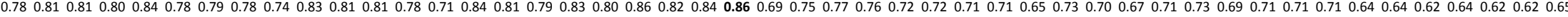

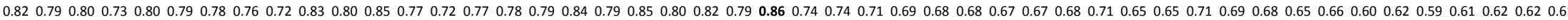

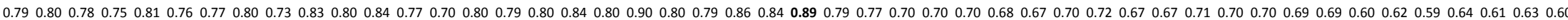

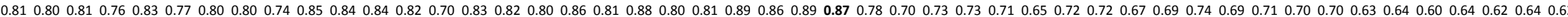

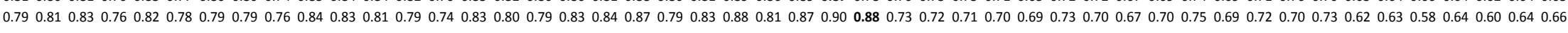

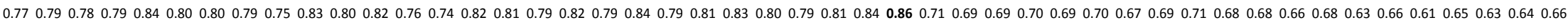

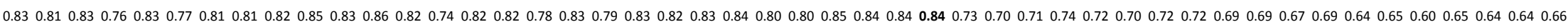

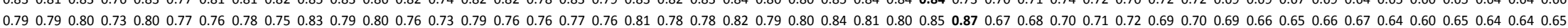

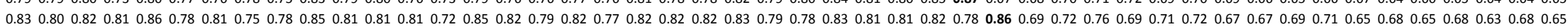

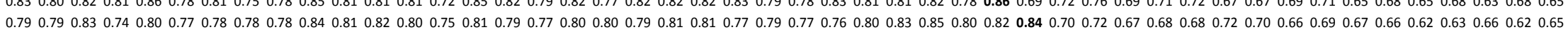

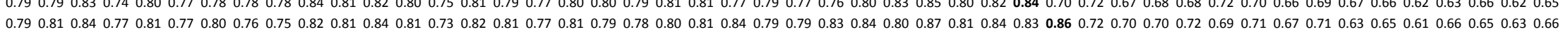

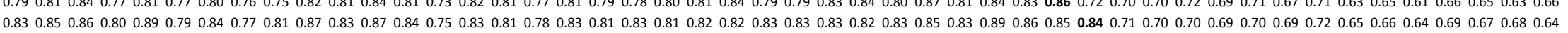

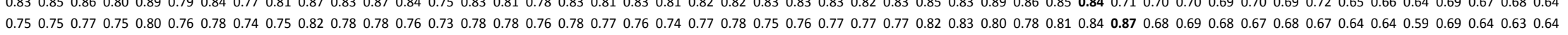

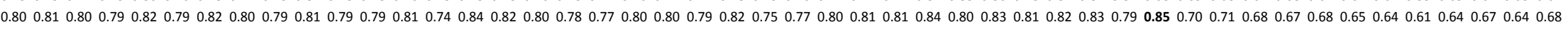

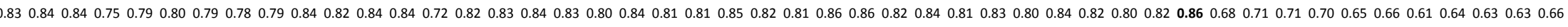

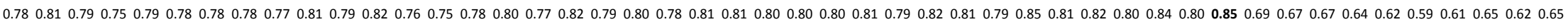

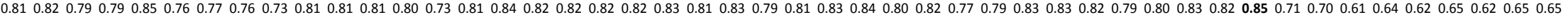

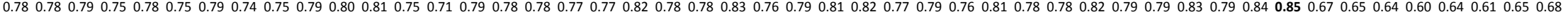

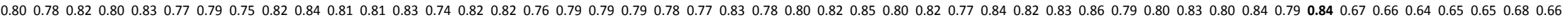

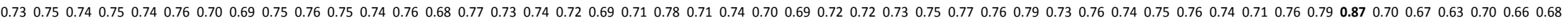

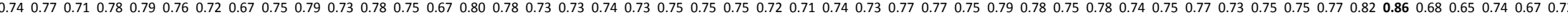

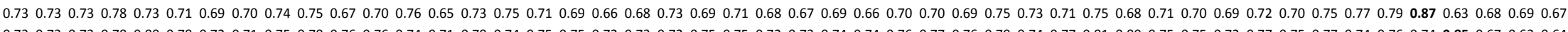

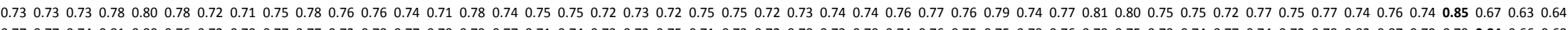

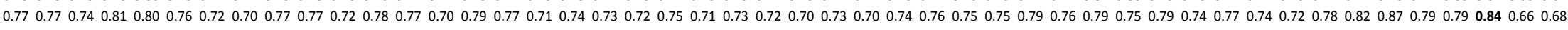

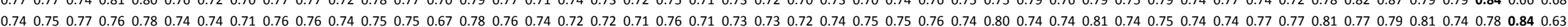

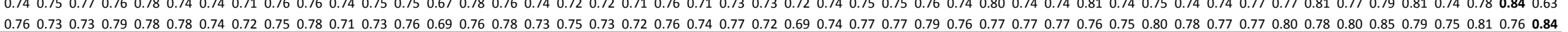


Tabela 4.3- Similaridade entre as matrizes de covariância, determinada por Kræanowski. A diagonal, em negrito, contém a repetibilidade das matrizes. Comparações observadas estão na metade superior e as ajustadas na metade inferior.

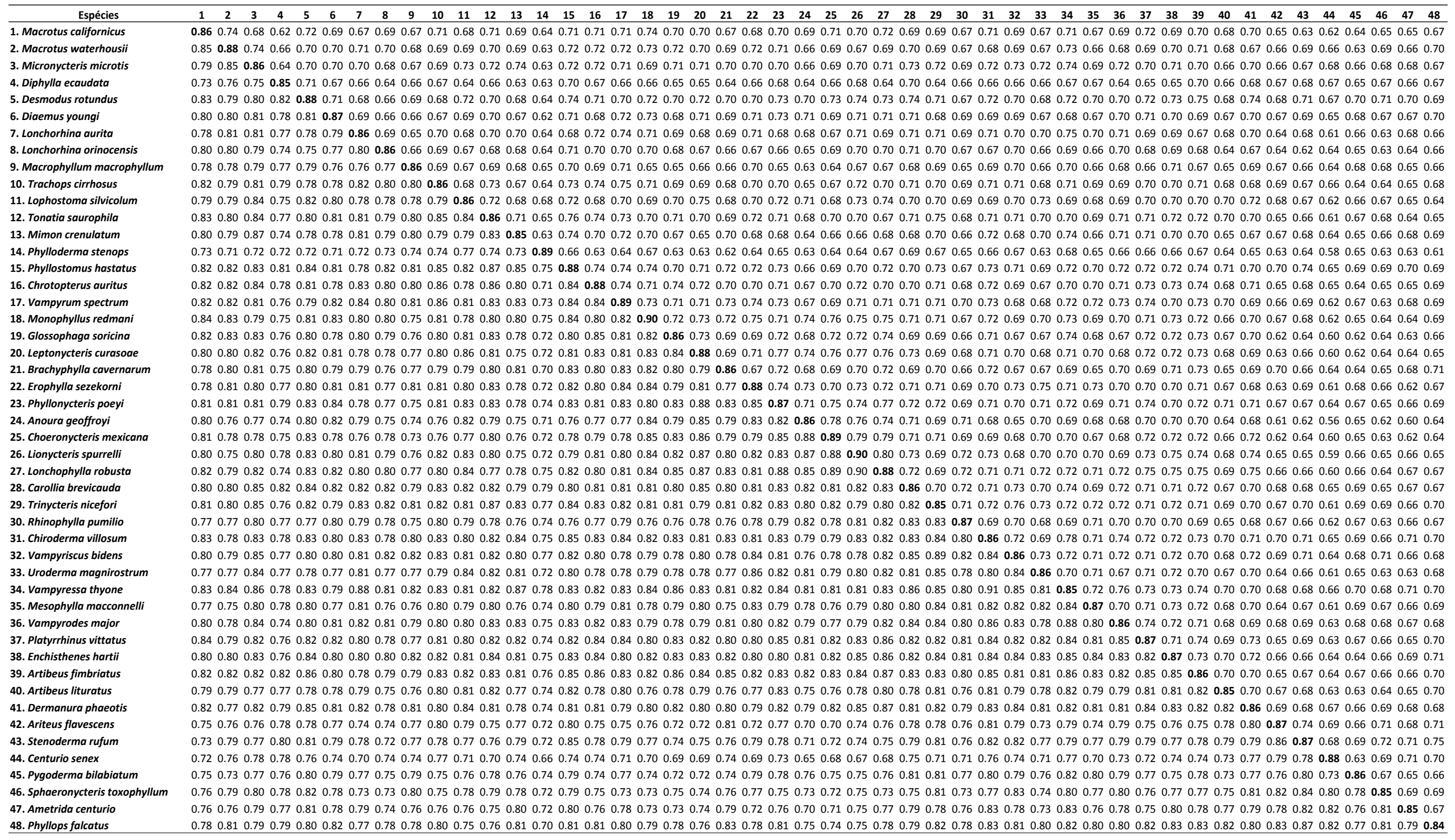


Tabela 4.4- Similaridade entre as matrizes de covariância, determinada por Random Skewvers. A diagonal, em negrito, contém a repetibilidade das matrizes.

Comparações observadas estão na metade superior e as ajustadas na metade inferior.

\begin{tabular}{|c|c|c|c|c|c|c|c|c|c|c|c|c|c|c|c|c|c|c|c|c|c|c|c|c|c|c|c|c|c|c|c|c|c|c|c|c|c|c|c|c|c|c|c|c|c|}
\hline Espécies & 1 & 2 & 3 & 4 & 5 & 6 & 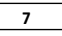 & 0 & 3 & 10 & 11 & 12 & $13 \quad 14$ & $14 \quad 15$ & $15 \quad 16$ & $16 \quad 17$ & 18 & 19 & 202 & 21 & $22 \quad 23$ & 24 & 20 & 26 & 27 & 29 & 30 & 政 & 32 & 33 & 34 & 30 & 200 & ז & 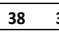 & 然 & 40 & 41 & 42 & 43 & 44 & 45 & 40 & $4 r$ & 40 \\
\hline 1. Macrotus californicuu & 0.93 & 0.73 & 0.720 & 0.710 & 0.74 & 0.71 & 0.63 & 0.73 & 0.77 & 0.840 & $0.74 \quad 0$. & 0.740 .7 & $\begin{array}{ll}.76 & 0.6\end{array}$ & $\begin{array}{lll}1.69 & 0.7\end{array}$ & $\begin{array}{ll}.77 & 0.7\end{array}$ & $\begin{array}{l}0.72 \\
0.73\end{array}$ & 730.68 & $\begin{array}{ll}8 & 0.67\end{array}$ & $0.79 \quad 0$. & $\begin{array}{ll}0.76 & 0.7\end{array}$ & $0.79 \quad 0.75$ & $\begin{array}{ll}5 & 0.71\end{array}$ & $0.65 \quad 0$ & 0.730. & 0.810 .7 & $\begin{array}{lll}.76 & 0.82\end{array}$ & $\begin{array}{ll}.82 & 0.66\end{array}$ & 0.74 & 0.73 & 0.720 & 0.750. & 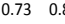 & 0.810. & 0.800. & 0.79 & 0.770 & 0.77 & 0.750 & $0.66 \mathrm{O}$ & 0.73 & 0.65 & & & & 0.73 \\
\hline & & & & & 1.660 & 0.59 & 0.63 & 0.6 & 0.66 & 0.730 & 0. & & 65 & 1.54 & & & $\begin{array}{ll}75 & 0.59\end{array}$ & $\begin{array}{ll}9 & 0.65\end{array}$ & 0.7 & & & & 0.500 & 65 & & & & & & & & & & & & & & & & & & 0.57 & & & 0.61 \\
\hline licronycteris $n$ & $r^{\prime}$ & 0.76 & .95 & & 0.64 & 0.58 & 0.52 & 0.58 & 0.66 & 0.74 & 0.760. & 0.82 & .81 & 1.64 & . 72 & 56 & 560.54 & 0.64 & $0.69 \quad 0$. & $0.610 .7-70$ & 0.71 & $\begin{array}{ll}9 & 0.70\end{array}$ & .53 & .71 0. & 0.76 & 78 & 0. & 0. & 0.68 & 0.840 & $0.81 \quad 0$. & 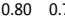 & 0. & $0.78 \quad 0$. & 0. & 0 & 0 & & & 0.71 & & 0.6 & 0 & & \\
\hline biphylla ecaudd & 77 & 0.67 & 540 & 93 & 0.71 & $0.68 \mathrm{c}$ & 0.65 & 0.67 & 0.71 & 0.720 & 0.640. & 0.590 .6 & $\begin{array}{ll}.61 & 0.6\end{array}$ & $\begin{array}{ll}1.60 & 0.7\end{array}$ & $\begin{array}{ll}.71 & 0.6\end{array}$ & $0.66 \quad 0.66$ & 560.61 & 10.60 & $0.67 \quad 0$. & $0.660 .6>35$ & $0.64 \quad 0.69$ & $\begin{array}{l}90.52 \\
0\end{array}$ & $0.50 \quad 0$ & 0.610. & $0.670 .6 \mathrm{C} \quad \mathrm{c}$ & $\begin{array}{lll}.69 & 0.79\end{array}$ & $\begin{array}{ll}75 & 0.57\end{array}$ & 0.66 & $0.67 \mathrm{C}$ & $0.64 \quad 0$ & $0.67 \quad 0$. & $0.680 .7>3$. & $\begin{array}{ll}0.76 & 0 .\end{array}$ & 0.650. & 0.6 & & & & .05 & & & & & & \\
\hline Desmodus rot & & 0.70 & $\begin{array}{lll}58 & 0\end{array}$ & 0.750 & 0.950 & 0.73 & 0.70 & 0.68 & 0.74 & 0.750 & $0.76 \quad 0$. & 0.69 & 69 & 164 & 1.76 & $\begin{array}{l}0.66 \\
0.65\end{array}$ & $\begin{array}{ll}65 & 0.66\end{array}$ & $\begin{array}{ll}6 & 0.69\end{array}$ & 0.750. & $\begin{array}{ll}0.65 & 0.7\end{array}$ & $0.70 \quad 0.78$ & $\begin{array}{ll}8 & 0.56\end{array}$ & 0.560 & $0.68 \quad 0$. & $\begin{array}{ll}0.68 & 0.7\end{array}$ & $\begin{array}{ll}1.72 & 0.7\end{array}$ & $\begin{array}{ll}.77 & 0.61\end{array}$ & 0.71 & 0.70 & 0.660 & $0.70 \quad 0$. & $\begin{array}{ll}0.72 & 0.7\end{array}$ & $0.78 \quad 0$. & $0.70 \quad 0$. & $0.74 \quad 0$ & 0.660 & 0.690 & 0.720 & 0.610 & 0.760 & 0.62 & 0.71 & 0.8 & $0.6-6>3$ & 0.78 \\
\hline Diaemus youn & & 0.63 & & 730 & 0.780 & 0.93 & 0.62 & 0.73 & 0.71 & 0.710 & 0.680. & 0.61 & 62 & 1.58 & 772 & $\begin{array}{ll}57 & 0.61\end{array}$ & $61 \quad 0.60$ & 0.62 & $0.69 \quad 0$. & $\begin{array}{ll}0.65 & 0.7\end{array}$ & $0.72 \quad 0.68$ & $\begin{array}{ll}8 & 0.56\end{array}$ & 0.540 & $0.63 \quad 0$. & $\begin{array}{ll}0.64 & 0.7\end{array}$ & 71 & $\begin{array}{ll}.71 & 0.55\end{array}$ & 0.61 & 0.67 & 0.580 & $\begin{array}{ll}0.68 & 0 .\end{array}$ & $\begin{array}{ll}0.70 & 0.7\end{array}$ & & & & & & & & & & & & & 0.72 \\
\hline Ehorhina au & & & 50 & 70 & 740 & 0.67 & 0.93 & 0.68 & 0.63 & 0.630 & $0.64 \quad 0$. & .53 & 56 & $\begin{array}{ll}.51 & 0.5\end{array}$ & ..58 & 30.72 & 720.65 & 0.61 & $0.69 \quad 0$. & $0.57 \quad 0.6(4)-30$ & $0.62 \quad 0.67$ & $\begin{array}{ll}70.53 \\
\end{array}$ & $0.45 \quad 0$ & $0.53 \quad 0$. & $0.66 \quad 0.5$ & $\begin{array}{ll}.58 & 0.65 \\
\end{array}$ & 0.48 & $0.58 \mathrm{c}$ & $0.60 \mathrm{C}$ & 0.54 & $0.60 \quad 0$. & 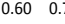 & $\begin{array}{ll}0.76 & 0 .\end{array}$ & 0 & 0 & 0 & & 50 & 20 & $0.61 \mathrm{c}$ & 30 & 0. & 0.69 & & .66 \\
\hline ontm & & 0 & & & 73 & 0.79 & 0.74 & 0.91 & 69 & $0.74 \mathrm{O}$ & 0.65 & 57 & 62 & 157 & & 59 & 590.60 & 0.66 & $c$ & $0.7-2-3$ & $0.73 \quad 0.68$ & $\begin{array}{ll}80.58 \\
\end{array}$ & 0.62 & 0.62 & 0.72 & 0.68 & 0.5 & $0.6-6>>3$ & & & $0.63 \quad 0$. & 0. & 0. & 0. & & & & & & & & & & & .67 \\
\hline & & 0.71 & & 780 & 0.79 & 0.77 & 0.68 & 0.75 & 0.91 & 0.770 & $\begin{array}{cc}0.76 & 0 .\end{array}$ & 0.65 & 69 & .62 & 8 & $\begin{array}{ll}9 & 0.67\end{array}$ & $57 \quad 0.61$ & 10.62 & 0.71 & $\begin{array}{ll}0.63 & 0.7\end{array}$ & 0.710 .71 & $\begin{array}{ll}1 & 0.55\end{array}$ & 0.520 & 0.640. & $\begin{array}{ll}0.67 & 0.7\end{array}$ & $\begin{array}{ll}1.72 & 0.73\end{array}$ & $\begin{array}{ll}.75 & 0.59\end{array}$ & 0.70 & 0.75 & 0.660 & 0.720. & $0.75 \quad 0.7$ & $\begin{array}{ll}0.79 & 0 .\end{array}$ & $\begin{array}{ll}0.70 & 0\end{array}$ & $0.77 \quad 0$ & 0.640 & 0.690 & $0.68 \quad 0$ & 0.640 & $0.76 \mathrm{~d}$ & $.65 \mathrm{c}$ & $0.72 \mathrm{G}$ & 0.78 & & 0.71 \\
\hline$T r a g$ & & 0.78 & & & 0.79 & 0.77 & 0.68 & 0.80 & 0.84 & 0.930 & $0.80 \quad 0$. & 76 & .76 & 170 & & $\begin{array}{ll}0 & 0.73\end{array}$ & $\begin{array}{ll}73 & 0.66\end{array}$ & $\begin{array}{ll}6 & 0.69\end{array}$ & $0.79 \quad 0$. & $\begin{array}{lll}0.71 & 0.7\end{array}$ & $0.76 \quad 0.76$ & $\begin{array}{ll}6 & 0.67\end{array}$ & 0.620 & $\begin{array}{ll}0.76 & 0 .\end{array}$ & $\begin{array}{ll}0.81 & 0.7\end{array}$ & $17908 \quad-8$ & $.82 \quad 0.66$ & 0.81 & 0.77 & 0.780 & $0.82 \quad 0$. & $\begin{array}{ll}0.80 & 0.8\end{array}$ & & & $0.83 \quad 0$ & $0.75 \quad 0$ & & & & & 0.64 & & & & 0.69 \\
\hline Lophostoma sil & 0.79 & 33 & & ig & 800 & $0.72 \mathrm{c}$ & 0.68 & 0.69 & 0.82 & 0.850 & 0.95 & 79 & .79 & 1.68 & 9.81 & 50.68 & $\begin{array}{ll}58 & 0.59\end{array}$ & 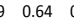 & $0.73 \quad 0$. & $\begin{array}{ll}0.61 & 0.7\end{array}$ & $\begin{array}{lll}0.72 & 0.73\end{array}$ & $\begin{array}{ll}3 & 0.61\end{array}$ & 0.530 & $\begin{array}{ll}0.69 & 0 .\end{array}$ & $\begin{array}{ll}0.72 & 0.7\end{array}$ & $\begin{array}{ll}.73 & 0.79\end{array}$ & $\begin{array}{ll}9 & 0.58\end{array}$ & 0.79 & 0.71 & 0.770 & $\begin{array}{cc}0.76 & 0 .\end{array}$ & $\begin{array}{lll}0.76 & 0.7\end{array}$ & $0.78 \quad 0$. & $\begin{array}{ll}0.77 \quad 0 .\end{array}$ & 0 & $0.70 \quad 0$ & 0.770 & 0.740 & 0.600 & 0.780 & 0.60 & 0.72 & 0.710 & 0. & 0.69 \\
\hline & & & & & & & & & & & 34 & 3 & & & & & 0 & & & & & 3 & & &.$/ 3$ & & & & & & & & & & & & & & & & & & & & \\
\hline & & & & & 740 & 0.67 & & & & 0.820 & $\begin{array}{ll}0.84 & 0 .\end{array}$ & 0.88 & & & & & $61 \quad 0.63$ & & $0.69 \quad 0$. & $\begin{array}{ll}0.62 & 0.7\end{array}$ & $0.72 \quad 0.69$ & $9 \quad 0.66$ & 0.540 & $\begin{array}{ll}0.71 & 0 .\end{array}$ & 0.73 & .73 & $\begin{array}{ll}79 & 0.59\end{array}$ & 0.76 & 1 & & $\begin{array}{cc}0.76 & 0 .\end{array}$ & $\begin{array}{lll}0.77 & 0.7\end{array}$ & 0.750. & $0.79 \quad 0$. & $0.76 \quad 0$ & & & & & & & & & & 69 \\
\hline Phyl & & 0.58 & 100 & 650 & 0.690 & 0.63 & 0.56 & 0.62 & 0.68 & 0.760 & $\begin{array}{ll}0.73 & 0 .\end{array}$ & 0.71 & .76 & 191 & & $\begin{array}{ll}66 & 0.55\end{array}$ & $\begin{array}{ll}55 & 0.58\end{array}$ & 0.55 & $0.68 \quad 0$. & $0.58 \quad 0.6$ & $0.62 \quad 0.60$ & $\begin{array}{ll}0 & 0.60\end{array}$ & 0.490 & 0.610. & $\begin{array}{ll}0.69 & 0.6\end{array}$ & $\begin{array}{ll}1.65 & 0.6\end{array}$ & $\begin{array}{ll}.67 & 0.53\end{array}$ & 0.69 & 0.66 & 0.700 & $0.74 \quad 0$. & $\begin{array}{ll}0.66 & 0.6\end{array}$ & $0.65 \quad 0$. & $\begin{array}{ll}0.69 & 0 .\end{array}$ & $0.73 \quad 0$ & $0.63 \quad 0$ & 0.650 & 0.640 & 0.510 & 0.610 & 0.55 & 0.61 & 0.61 & 0.62 & .62 \\
\hline+2 & & & & & 810 & $0.77 \mathrm{c}$ & 0.62 & 0.75 & 0.84 & $0.84 \mathrm{O}$ & 0.86 & 82 & 82 & .74 & .94 & 0.65 & 0.61 & 0.66 & $0.71 \quad 0$. & $\begin{array}{llll}0.68 & 0.7 & \end{array}$ & $\begin{array}{ll}0.75 & 0.73\end{array}$ & $\begin{array}{lll}3 & 0.61\end{array}$ & $0.60 \quad 0$ & $\begin{array}{llll}0.69 & 0 . & & \end{array}$ & 0.710 .7 & $0.7 \%$ & 0.64 & 0.77 & $0.73 \mathrm{C}$ & 0.780 & $0.73 \quad 0$. & $\begin{array}{llll}0.75 & 0.8 & \end{array}$ & $\begin{array}{llll}0.80 & 0 . & \end{array}$ & 0. & 0 & 0 & 0 & & & 0. & & .72 & .73 & & .74 \\
\hline & & & & & & & & & & & 0 & & & & & & & & & & & & & & & & & & & & & & & & & & & & & & & & & & \\
\hline & & & & & & 0.66 & & & & 0.780 & $\begin{array}{ll}0.72 & 0 .\end{array}$ & 0.68 & .66 & 59 & & & $\begin{array}{ll}34 & 0.59\end{array}$ & & $\begin{array}{ll}0.75 & 0 .\end{array}$ & $\begin{array}{lll}64 & 0.6\end{array}$ & 0.65 & & & $\begin{array}{ll}0.63 & 0 .\end{array}$ & 750.6 & $.650 .14<>$ & $\begin{array}{lll}70 & 0.60\end{array}$ & & & & & $\begin{array}{lll}66 & 0.8\end{array}$ & $80 \quad 0$. & $0.70 \quad 0$. & $0.66 \quad 0$ & $0.68 \quad 0$ & 0.660 & & & 0.640 & & & & & 政 \\
\hline$m i$ & 3 & 0.62 & 80 & 660 & 0.690 & 0.64 & 0.69 & 0.64 & 0.66 & 0.710 & $\begin{array}{ll}0.63 & 0 .\end{array}$ & 0.62 & 68 & .63 & .65 & $0.59 \quad 0.63$ & $63 \quad 0.94$ & 0.61 & $0.70 \quad 0$. & $0.56 \quad 0.6$ & $0.62 \quad 0.64$ & $4 \quad 0.59$ & 0.560 & $0.63 \quad 0$. & $\begin{array}{ll}0.70 & 0.6\end{array}$ & $\begin{array}{ll}0.64 & 0.65\end{array}$ & $\begin{array}{ll}.65 & 0.57\end{array}$ & 0.56 & 0.59 & 0.580 & 0.590. & $\begin{array}{lll}0.62 & 0.6\end{array}$ & 0.660. & $\begin{array}{ll}0.67 & 0 .\end{array}$ & $0.64 \quad 0$ & 0.590 & 0.610 & 0.570 & 0.490 & 0.60 & $48 \mathrm{c}$ & 0.61 & 0.64 & 0.49 & 0.61 \\
\hline hacosoricint & & & & 660 & 1.750 & $0.68 \mathrm{c}$ & 0.67 & 0.73 & 0.68 & 0.760 & 0.700. & 0.74 & .70 & 161 & .72 & $0.71 \quad 0.71$ & 710.66 & 0.89 & $0.71 \quad 0$. & $0.650 .7 \quad 5 \quad 3$ & $0.72 \quad 0.78 \quad$ & $\begin{array}{ll}80.69 \\
\end{array}$ & $0.73 \quad 0$ & 0.790. & $0.73 \quad 0.6$ & $\begin{array}{llll}.69 & 0.7 & \end{array}$ & $\begin{array}{lll}.70 & 0.75 & \end{array}$ & 0.69 & $0.63 \mathrm{c}$ & $0.63 \quad 0$ & $0.68 \quad 0$. & $\begin{array}{llll}0.68 & 0.7\end{array}$ & $\begin{array}{llll}0.71 & 0 . & & \end{array}$ & $\begin{array}{lll}0.71 & 0 .\end{array}$ & 0.680 & 0.660 & 0.700 & 0.650 & 0.570 & 0.67 & 0.52 & .61 & 0.64 & 0.63 & 68 \\
\hline & & & & & & & & & & & & & & & & & & & & & & & & & & & & & & & & & & & & & & & & & & & & & \\
\hline & & & & & 9 & $0 \mathrm{c}$ & & 0.74 & 0.69 & $0.77 \quad 0$ & $\begin{array}{llll}0.65 & 0 . & \end{array}$ & 0.64 & $.6 /$ & 1.64 & & & 61 & & 0.78 & $92 \quad 0.7 \quad 3$ & $\begin{array}{l}0.73 \quad 0.68 \\
\end{array}$ & & 0.610 & 0.590. & 0.71 & 0.7 & 63 & 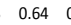 & & & $0.64 \quad 0$. & $\begin{array}{lll}0 & 0.1\end{array}$ & $\begin{array}{lll}0.70 & 0 . & \end{array}$ & 0.7 & & & & & & & & & & & \\
\hline Erophylla sezekorni & 0.86 & 0.71 & 60 & 690 & 740 & 0.78 & 0.67 & 0.80 & 0.77 & 0.820 & 0.76 & 79 & 1.78 & 168 & .81 & $\begin{array}{ll}0.74 & 0.70\end{array}$ & $\begin{array}{ll}70 & 0.66\end{array}$ & 0.79 & 0.800 & $0.79 \quad 0.5$ & $0.93 \quad 0.75$ & $\begin{array}{ll}5 & 0.73\end{array}$ & 0.650 & 0.710. & $\begin{array}{ll}0.78 & 0.7\end{array}$ & $1.77 \quad 0.8$ & $\begin{array}{ll}81 & 0.65\end{array}$ & 0.73 & 0.73 & 0.710 & $0.74 \quad 0$. & $\begin{array}{lll}0.75 & 0.7\end{array}$ & 0.760. & $0.76 \quad 0$. & $0.76 \quad 0$ & $0.73 \quad 0$ & 0.760 & 0.720 & 0.620 & 0.730 & 610 & 0.67 & 0.68 & 0.68 & 0.73 \\
\hline$P h y$ & & & $\begin{array}{ll}30 \\
0\end{array}$ & 4 & $82 \quad 0 \quad-2>$ & $0.73 \mathrm{c}$ & 0.72 & 0.74 & 0.77 & $0.82 \quad 0$ & 0.77 & 79 & 4 & 1.65 & .78 & 3 & $75 \quad 0.69$ & 0.86 & $0.86 \quad 0$. & 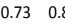 & $0.80 \quad 0.93$ & $\begin{array}{ll}3 & 0.67\end{array}$ & $0.72 \quad 0$ & $0.83 \quad 0$. & $0.780 .7 \mathrm{r} \quad \mathrm{l}$ & $\begin{array}{llll}.77 & 0.88 & \end{array}$ & $\begin{array}{ll}.80 & 0.79\end{array}$ & 0.73 & $0.68 \mathrm{c}$ & & & 0.8 & $\begin{array}{lll}0.81 & 0 . & \\
\end{array}$ & $\begin{array}{llll}0.76 & 0 . & \end{array}$ & 0.740 & 0.740 & 0.740 & 0.690 & 0.590 & 0.730 & & & & & .73 \\
\hline & & & & & & & & & & & & & & & & & & & & & & & & & & & 0. & & & & & & & & & & & & & & & & & & \\
\hline & & & & & & & & & & & & & & & & & & & & & & & & & & & & & & & & & & & & & & & & & & & & & \\
\hline Lionycteris spurre & & 0.69 & 6 & 66 & 720 & 0.680 & 0.570 & 0.67 & $0.70 \mathrm{c}$ & 0.820 & 73 & 79 & .77 & 167 & .74 & $\begin{array}{ll}5 & 0.67 \\
5\end{array}$ & $\begin{array}{ll}57 & 0.67\end{array}$ & 5 & 0.80 & .64 & $\begin{array}{lll}0.76 & 0.89\end{array}$ & $9 \quad 0.79$ & 0.800 & $0.93 \quad 0$. & $\begin{array}{ll}0.79 & 0.7\end{array}$ & $\begin{array}{l}0.76 \quad 0.78 \\
\end{array}$ & $\begin{array}{ll}78 & 0.79\end{array}$ & 0.72 & 0.66 & 0.72 & $0.70 \quad 0$. & $0.74 \quad 0.7$ & $0.73 \quad 0$. & 0.760. & $0.73 \quad 0$ & 0.690 & 0.730 & 0.700 & 0.560 & 0.710 & 0.52 & 0.69 & 0.62 & & .67 \\
\hline & & & & & 720 & 0.690 & 0.710 & 0.77 & 0.72 & 0.860 & .76 & 8 & 8 & 4 & 76 & 7 & $\begin{array}{ll}30 & 0.74\end{array}$ & 0.79 & 0.89 & .760 & 0.83 & $\begin{array}{ll}3 & 0.85\end{array}$ & 0.710 & 0.840. & $0.95 \quad 0.7$ & .72 & $78 \quad 0.64$ & 0.76 & 0.71 & 0.75 & $0.75 \quad 0$. & $\begin{array}{lll}0.75 & 0.8\end{array}$ & $0.80 \quad 0$. & $0.82 \quad 0$ & $0.79 \quad 0$ & $0.74 \quad 0$ & 0.740 & 0.730 & 0.570 & 0.670 & 0.55 & .64 & .63 & & 64 \\
\hline & & & & & & & & & & & & & & & & & & & & & & & & & & & & & & & & & & & & & & & & & & & & & \\
\hline & & & & & & & & & & & & & & & & & & & & & & & & & & & & & & & & & & & & & & & & & & & & & \\
\hline & & 9 & & 610 & 650 & 0.590 & 0.510 & 0.61 & 0.64 & 0.710 & 0.61 & 67 & 64 & 77 & .68 & 00 & $54 \quad 0.60$ & 2 & $0.72 \quad 0$. & .67 & 0 & $\begin{array}{ll}5 & 0.72\end{array}$ & 0.830 & 0.840. & $\begin{array}{ll}0.68 & 0.7\end{array}$ & $\begin{array}{l}.79 \\
0.74\end{array}$ & $74 \quad 0.94$ & 0.68 & $0.60 \mathrm{C}$ & 0.63 & $\begin{array}{lll}0.65 & 0 .\end{array}$ & $\begin{array}{ll}0.66 & 0.7\end{array}$ & $0.70 \quad 0$. & 0.690. & 0.640 & 0.640 & 0.670 & 0.600 & 0.540 & 0.650 & .48 & $0.62 \mathrm{c}$ & 0.56 & & 0.62 \\
\hline & & & & 10 & 750 & 0.660 & 0.620 & 0.70 & 0.76 & 0.870 & 0.84 & 84 & 2 & 5 & .82 & $\begin{array}{l}0.80 \quad 0.76 \\
\end{array}$ & $\begin{array}{ll}76 & 0.60\end{array}$ & 5 & 0.80 & 69 & 78 & $\begin{array}{ll}8 & 0.77\end{array}$ & 0.610 & $0.77 \quad 0$. & $0.80 \quad 0.8$ & .80 & 2 & 0.94 & 0.77 & 0.86 & $0.84 \quad 0$. & 0. & 0 & 0.8 & 0 & 0.730 & 0. & 0. & 0.640 & 0.74 & 0.60 & 68 & 0.67 & & 0.65 \\
\hline & & & & & 年 & 0 & & & & & 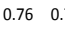 & & & & & & 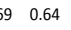 & & & & & & & & & & & & & & & & & & & & & & & & & & & & \\
\hline & & & & & & & & & & & & & & & & & & & & & & & & & & & & & & & & & & & & & & & & & & & & & \\
\hline & & 3 & & 720 & 40 & 0.730 & 0.640 & 0. & 0.78 & 0.880 & 80 & 32 & 81 & 79 & 1.78 & 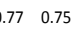 & 0 & 30 & 0 & $0.68 \quad 0.7 \quad 5$ & 9 & $\begin{array}{lll}8 & 0.75\end{array}$ & $0.56 \quad 0$ & $\begin{array}{ll}0.75 & 0 .\end{array}$ & 0.7 & 31 & 9 & 0 & $0.78 \mathrm{G}$ & 0.87 & $\begin{array}{cc}0.94 & 0 .\end{array}$ & 0.7 & $0.78 \quad 0$. & $\begin{array}{ll}0.81 \quad 0\end{array}$ & $0.81 \quad 0$ & $0.74 \quad 0$ & 0.780 & & & 0.72 & & & & & 67 \\
\hline & & & & 40 & 0.770 & 0.750 & 0.64 & 0.72 & 0.81 & 0.86 & 0.80 & 81 & 4 & 12 & 1 & .78 & 0.66 & 0.75 & 0.79 & 65 & 81 & $9 \quad 0.72$ & 0.58 & $\begin{array}{ll}0.80 & 0 .\end{array}$ & $\begin{array}{ll}0.79 & 0.8\end{array}$ & .82 & $\begin{array}{ll}3 & 0.70\end{array}$ & 40 & 0.77 & 0.85 & 0.880. & 0.7 & 0. & $0.78 \quad 0$. & $\begin{array}{lll}0.79 & 0\end{array}$ & 0.7 & 0.7 & & & 0.77 & 58 & 70 & & & 71 \\
\hline & & & & $8200-20$ & 30 & 0 & 0 & $c^{2}$ & 50 & 0.860 & 82 & .76 & 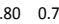 & .71 & 5 & .80 & $35 \quad 0.70$ & 00 & $c^{2}+2$ & 0.75 & 1 & $\begin{array}{ll}6 & 0.70\end{array}$ & 30 & 0 & 0.84 & 0.8 & 0. & 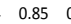 & & & & & 0. & 0 & & 0.730 & 0.760 & & & & & & & & .75 \\
\hline & & & & & & & & & & & & & & & & & & & & & & & & & & & & & & & & & & & & & & & & & & & & & \\
\hline & & & & $\begin{array}{lll}40 & 0\end{array}$ & 0 & & & & & 0 & 2 & 0.80 & 82 & 79 & .84 & 81 & 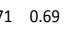 & 0 & 0 & 3 & 2 & 00 & 0.660 & $\begin{array}{cc}0.78 \quad 0 .\end{array}$ & 0.84 & 2 & 8 & 60 & 0.86 & 5 & 0.87 & 0.8 & 0.860. & $0.88 \quad 0$ & $0.93 \quad 0$ & $0.70 \quad 0$ & $0.76 \quad 0$ & & & & & & & & 70 \\
\hline & & & & & & 0.680 & & & 0 & & $\begin{array}{ll}75 & 0 .\end{array}$ & & & & & & & & & & & & & & & 76 & 8 & & & & 0.80 & & & & & $0.92 \quad 0$ & & & & & & & & & \\
\hline & & & & & & 0.710 & & & 0 & & & & & 72 & & & 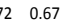 & & & & 1 & 1 & & 0 & 0.8 & & & & & & & & 0. & & & & & & & & & & & & \\
\hline & & & & & & & & & & & & 81 & & 71 & & & & & & & & & & & & & & & & & & & & & & & & & & & & & & & \\
\hline & & & & & 0 & & & & & & & .65 & & .56 & & & & & & & & & & & & & & & & & & & & & & & & & & & & & & & \\
\hline & & & & 0 & & 0.770 & & & & & $83 \quad 0$ & & & & & & 0.64 & & & & & & & & 0.71 & & & & & & & & & & & & & & & 0.92 & & & & & \\
\hline & & & & & & & & & & & & & & & & & t. & & & & & & 0.450 & & & & & & & & & & & $\begin{array}{ll}0.63 & 0 .\end{array}$ & 0. & & & & & & & & & & \\
\hline & & & & & & & & & & & & & & & & & & & & & & & & & & & & & & & & & & & & & & & & & & & & & \\
\hline & & & & & & & & & & & & & & & & & & & & & & & & & & & & & & & & & & & & & & & & & & & & & \\
\hline & & & & & 0.7 & & & & & & & 0.1 & & & & & & & & & & & & 0.7 - & & & & & & & & & & & & & & & & & & & & & \\
\hline 48. Phyllops falcatuu & & & 0.67 & 0.16 & $0.85 \quad 0$ & & & & & & $\begin{array}{llll}0.74 & 0 . & \end{array}$ & $0.70 \quad 0.7$ & $\begin{array}{lll}76 & 0.6\end{array}$ & 1.68 & .81 & 65 & & & 0.74 & $\begin{array}{llll}71 & 0.8 & \end{array}$ & $\begin{array}{l}0.80 \quad 0.80\end{array}$ & & $0.62 \quad 0$ & $\begin{array}{ll}0.73 & 0 .\end{array}$ & $\begin{array}{ll}0.69 & 0.7\end{array}$ & 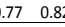 & $\begin{array}{ll}82 & 0.68\end{array}$ & & 0.75 & & 0.730. & $0.77 \quad 0.8$ & & $0.76 \quad 0$. & $0.76 \quad 0$ & & $0.75 \quad 0$ & & & 0.86 & 0.74 & & 0.85 & 0.73 & \\
\hline
\end{tabular}




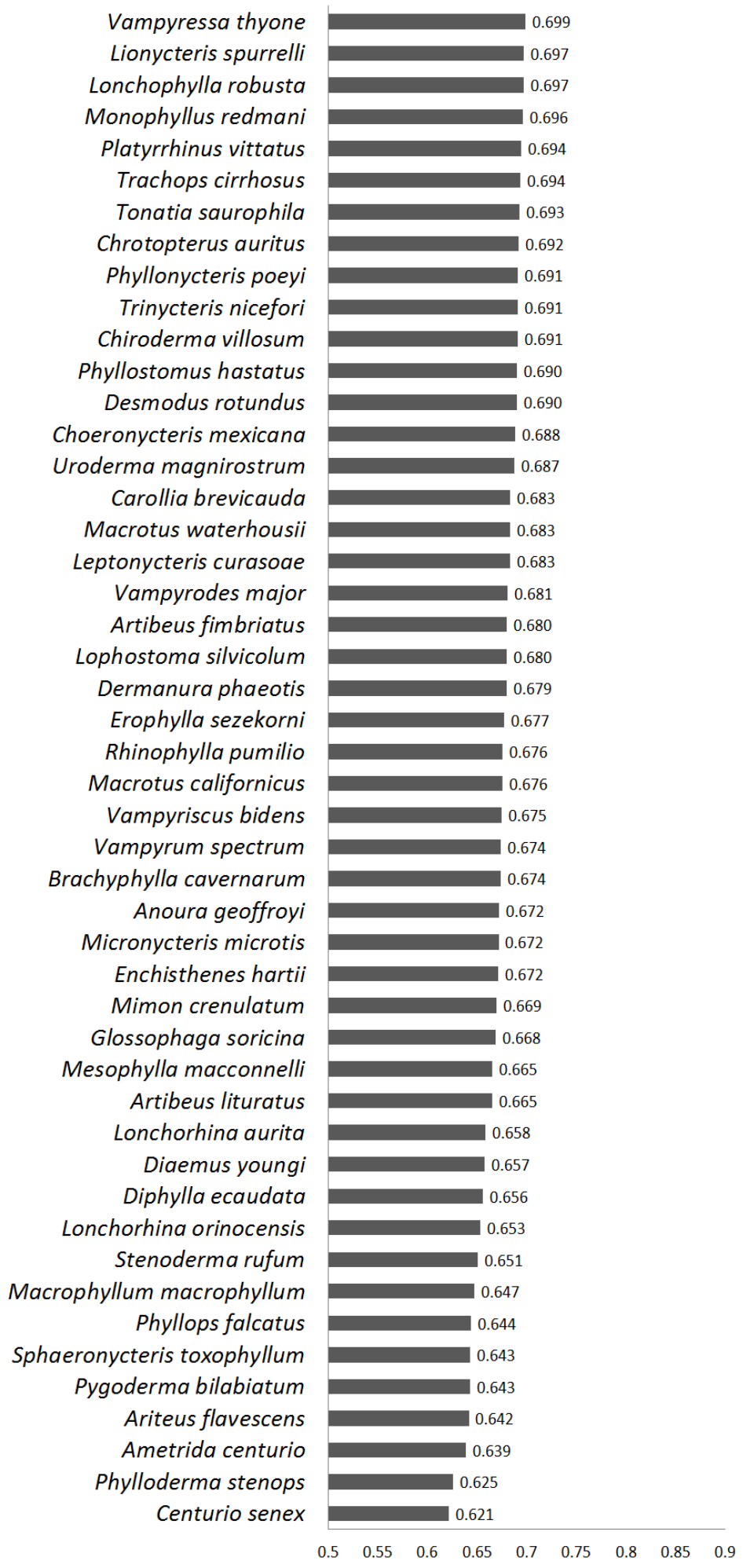

Vampyressa thyone

Lionycteris spurrelli

Lonchophylla robusta

onophyllus redmani

Chrotopterus auritus

Phyllonycteris poeyi

Trinycteris nicefori

Chiroderma villosum

Chllostomus hastatus

Desmodus rotundus

Choeronycteris mexicana

Carollia brevicauda

Macrotus waterhousi

Vurasoce

Vampyrodes major

Aribeus fimbriatus

ophostoma silvicolum

Dermanura phaeotis

Erophylla sezekorni

Rhinophylla pumilio

Macrotus californicus

Vampyriscus bidens

Vampyrum spectrum

Anoura geoffroyi

Micronycteris microtis

Enchisthenes harti

Mimon crenulatum

Glossophaga soricina

Diaemus young

Stenoderma rufum

Stenodermarufum

Phyllops falcatus

cteris toxophyllum

Ariteus flavescens

Ametrida centurio

$\begin{array}{lllllllll}0.5 & 0.55 & 0.6 & 0.65 & 0.7 & 0.75 & 0.8 & 0.85 & 0.9\end{array}$
Vampyressa thyone

Trachops cirrhosus

Trinycteris nicefori

Platyrrhinus vittatus

Chiroderma villosum

Lionycteris spurrelli

Tonatia saurophila

Desmodus rotundus

Phyllonycteris poeyi

Lonchophylla robusta

Phyllostomus hastatus

Dermanura phaeotis

Uroderma magnirostrum

Artibeus fimbriatus

Monophyllus redmani

Leptonycteris curasoae

Vampyrodes major

Chrotopterus auritus

Vampyriscus bidens

Macrotus waterhousii

Carollia brevicauda

Macrotus californicus

Lophostoma silvicolum

Micronycteris microtis

Enchisthenes hartii

Brachyphylla cavernarum

Choeronycteris mexicana

Mimon crenulatum

Erophylla sezekorni

Rhinophylla pumilio

Anoura geoffroyi

Artibeus lituratus

Glossophaga soricina

Vampyrum spectrum

Lonchorhina aurita

Mesophylla macconnelli

Diaemus young

Diphylla ecaudata

Vacrophyllum macrophyllum

Phyllops falcatus

Lonchorhina orinocensis

Stenoderma rufum

Sphaeronycteris toxophyllum

Pygoderma bilabiatum

Ametrida centurio

Ariteus flavescens

Centurio senex

Phylloderma stenops

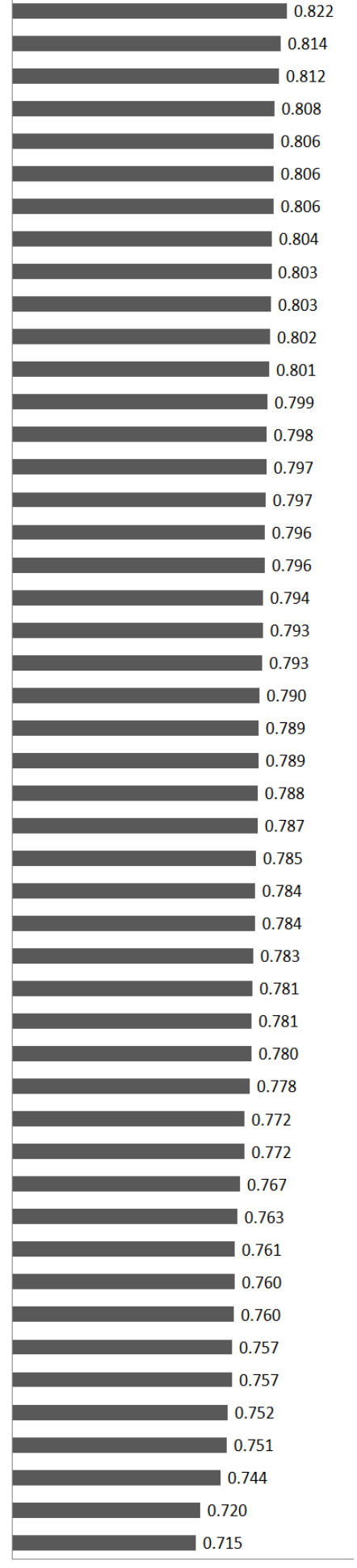

$\begin{array}{lllllllll}0.5 & 0.55 & 0.6 & 0.65 & 0.7 & 0.75 & 0.8 & 0.85 & 0.9\end{array}$

Figura 4.1- Similaridade média dos valores observados (esquerda) e ajustados (direita) entre os morcegos da Família Phyllostomidae, baseada em comparações de matrizes de correlação (método Krz̧anowski). 
Vampyressa thyone Phyllostomus hastatus

Lonchophylla robusta

Chiroderma villosum

Artibeus fimbriatus

Lionycteris spurrelli

Desmodus rotundus

Vampyrum spectrum

Enchisthenes hartii

Phyllonycteris poeyi

Monophyllus redmani

Platyrrhinus vittatus

Carollia brevicauda

Trinycteris nicefori

Chrotopterus auritus

Vampyriscus bidens

Micronycteris microtis

Tonatia saurophila

Erophylla sezekorni

Leptonycteris curasoae

Dermanura phaeotis

Vampyrodes major

Lophostoma silvicolum

Choeronycteris mexicana

Macrotus waterhousii

Trachops cirrhosus

Diaemus youngi

Mesophylla macconnelli

Macrotus californicus

Lonchorhina aurita

Glossophaga soricina

Brachyphylla cavernarum

Uroderma magnirostrum

Mimon crenulatum

Rhinophylla pumilio

Phyllops falcatus

Stenoderma rufum

Anoura geoffroyi

Artibeus lituratus

Lonchorhina orinocensis

Macrophyllum macrophyllum

Ariteus flavescens

Ametrida centurio

Sphaeronycteris toxophyllum

Diphylla ecaudata

Pygoderma bilabiatum

Phylloderma stenops

Centurio senex

$\begin{array}{lllllllll}0.5 & 0.55 & 0.6 & 0.65 & 0.7 & 0.75 & 0.8 & 0.85 & 0.9\end{array}$

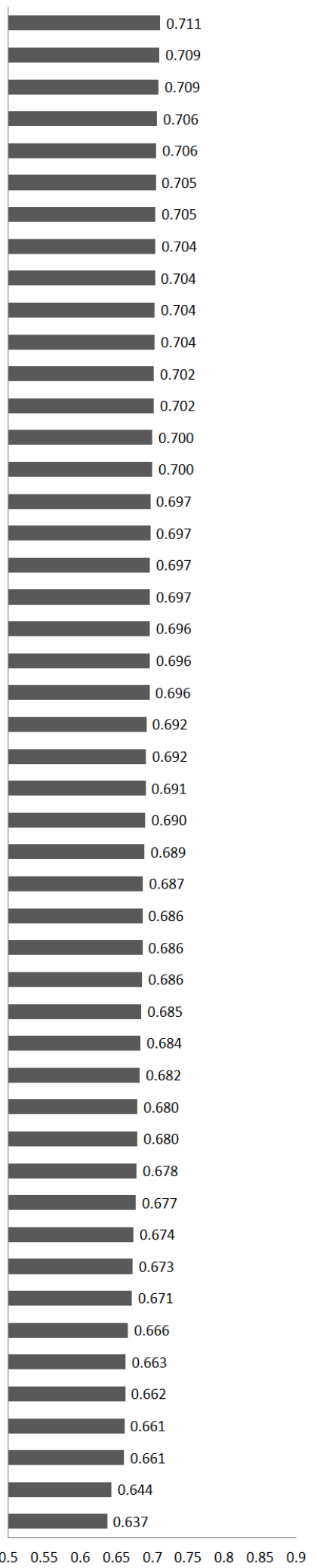

Vampyressa thyone

Chiroderma villosum

Artibeus fimbriatus

Trinycteris nicefori

Phyllostomus hastatus

Enchisthenes hartii

Carollia brevicauda

Lonchophylla robusta

Phyllonycteris poeyi

Vampyriscus bidens

Platyrrhinus vittatus

Micronycteris microtis

Dermanura phaeotis

Tonatia saurophila

Desmodus rotundus

Vampyrodes major

Vampyrum spectrum

Chrotopterus auritus

Trachops cirrhosus

Lionycteris spurrelli

Leptonycteris curasoae

Lophostoma silvicolum

Monophyllus redmani

Erophylla sezekorni

Phyllops falcatus

Glossophaga soricina

Diaemus youngi

Macrotus californicus

Lonchorhina aurita

Mimon crenulatum

Macrotus waterhousii

Brachyphylla cavernarum

Uroderma magnirostrum

Mesophylla macconnelli

Choeronycteris mexicana

Artibeus lituratus

Anoura geoffroyi

Stenoderma rufum

Rhinophylla pumilio

Macrophyllum macrophyllum

Lonchorhina orinocensis

Sphaeronycteris toxophyllum

Ametrida centurio

Diphylla ecaudata

Pygoderma bilabiatum

Ariteus flavescens

Phylloderma stenops

Centurio senex

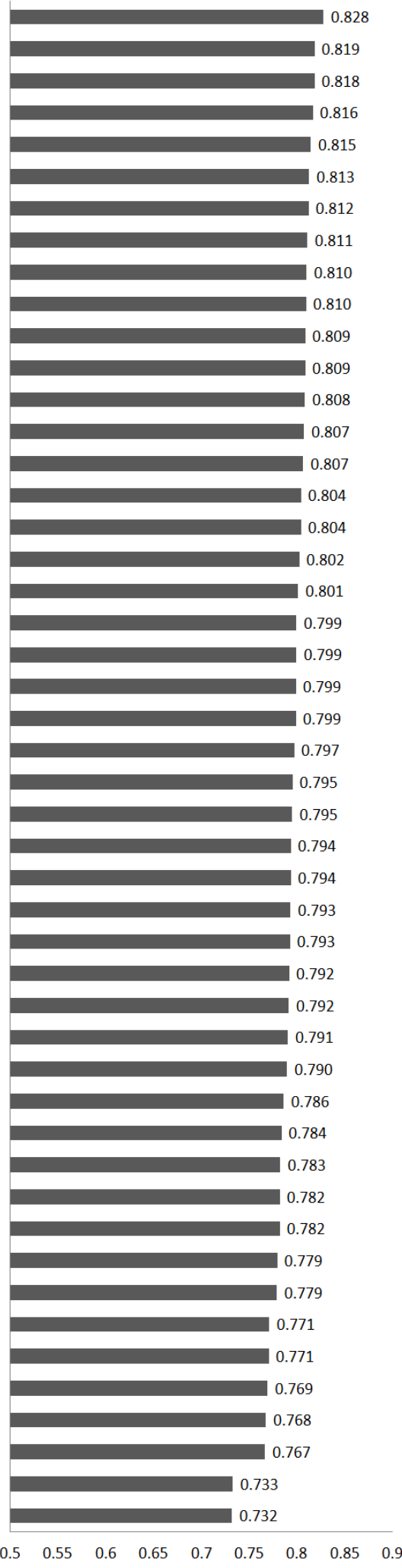

Figura 4.2- Similaridade média dos valores observados (esquerda) e ajustados (direita) entre os morcegos da Família Phyllostomidae, baseada em comparações de matrizes de covariância (método Krz̨anowskì). 
Trinycteris nicefori Vampyrodes major

Trachops cirrhosus

Macrotus californicus

Platyrrhinus vittatus

Enchisthenes hartii

Chiroderma villosum

Vampyressa thyone

Phyllostomus hastatus Mesophylla macconnelli

Lonchophylla robusta

Carollia brevicauda

Leptonycteris curasoae

Phyllonycteris poeyi

Artibeus lituratus

Erophylla sezekorni

Stenoderma rufum

Lophostoma silvicolum

Uroderma magnirostrum

Dermanura phaeotis

Mimon crenulatum

Tonatia saurophila

Desmodus rotundus

Lionycteris spurrelli

Macrophyllum macrophyllum

Micronycteris microtis

Chrotopterus auritus

Vampyriscus bidens

Artibeus fimbriatus

Sphaeronycteris toxophyllum

Phyllops falcatus

Glossophaga soricina

Ametrida centurio

Diphylla ecaudata

Pygoderma bilabiatum

Diaemus youngi

Vampyrum spectrum

Macrotus waterhousii

Lonchorhina orinocensis

Brachyphylla cavernarum

Anoura geoffroyi

Rhinophylla pumilio

Phylloderma stenops

Ariteus flavescens

Monophyllus redmani

Lonchorhina aurita

Centurio senex

Choeronycteris mexicana

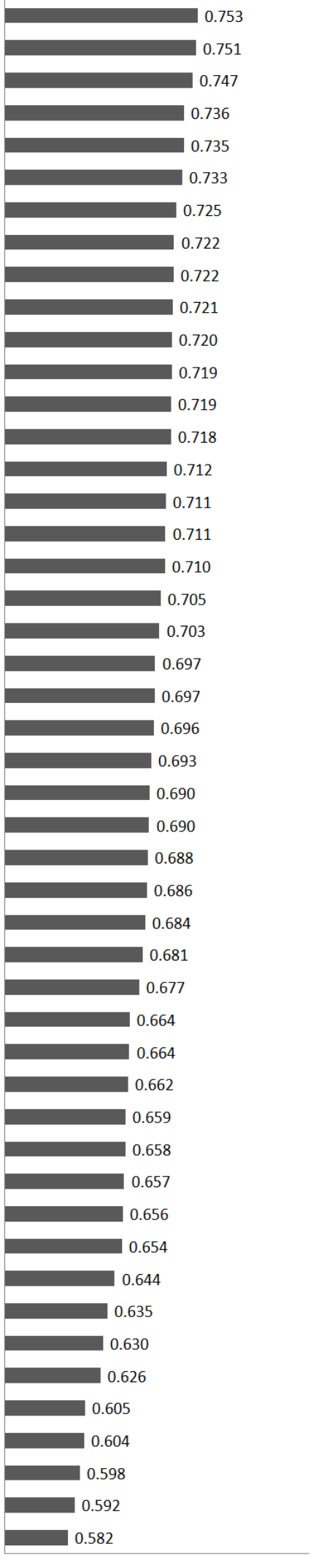

$\begin{array}{lllllllll}0.5 & 0.55 & 0.6 & 0.65 & 0.7 & 0.75 & 0.8 & 0.85 & 0.9\end{array}$

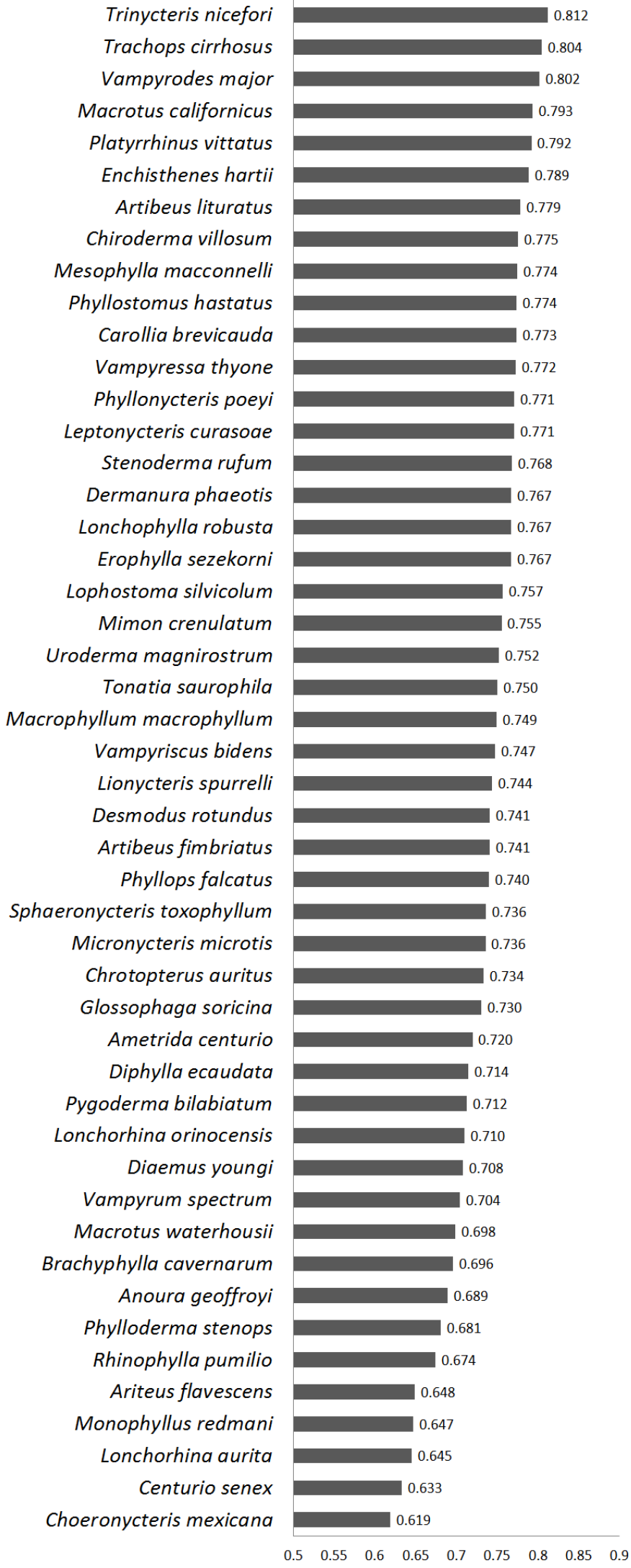

Trinycteris nicefori

Trachops cirrhosus

rnicus

inus vittatus

isthenes hart

Artibeus lituratus

esophylla macconnelli

yllostomus hastatus

Carollia brevicauda

tonycteris curasoae

Stenoderma rufum

Dermanura phaeotis

chophylla robusta

Desmodus rotundus

Artibeus fimbriatus

Phyllops falcatus

Sphaeronycteris toxophyllum

Micronycteris microtis

Chrotopterus auritus

lossophaga soricina

Ametrida centurio

Diphylla ecaudato

Pyoderma bilabiatum

Lonchorhina orinocensis

Diaemus young

Vampyrum spectrum

acrotus waterhousii

ylloderma stenop

inophylla pumilio

Ariteus flavescens

Monophyllus redman

chorhina aurita

Centurio senex

$\begin{array}{lllllllll}0.5 & 0.55 & 0.6 & 0.65 & 0.7 & 0.75 & 0.8 & 0.85 & 0.9\end{array}$

Figura 4.3 - Similaridade media dos valores observados (esquerda) e ajustados (direita) entre os morcegos da Família Phyllostomidae, baseada em comparações de matrizes de covariância (método Random Skewers). 
Tabela 4.5- Estatística básica calculada a partir dos valores de similaridade média observados das matrizes de correlação (Krzanowski; Kry) e covariância (Krzanowski; Krz e Ramdom Skewers; RS).

\begin{tabular}{lccc}
\hline \multicolumn{5}{c}{ Similaridade média das matrizes (valores observados) } \\
\hline \multicolumn{1}{c}{ Estatística básica } & Cor (Krz) & Cov (Krz) & Cov (RS) \\
\hline Mínimo & 0.62 & 0.64 & 0.58 \\
Máximo & 0.70 & 0.71 & 0.75 \\
Média & 0.67 & 0.69 & 0.68 \\
Desvio padrão $(\sigma)$ & 0.02 & 0.02 & 0.04 \\
\hline \hline
\end{tabular}

Tabela 4.6- Estatística básica calculada a partir dos valores de similaridade média ajustados das matrizes de correlação (Krzanowski; Krz) e covariância (Krzanowski; Krž e Ramdom Skewers; RS).

\section{Similaridade média das matrizes (valores ajustados)}

\begin{tabular}{lccc}
\hline \multicolumn{1}{c}{ Estatística básica } & Cor $(\mathrm{Krz})$ & Cov $(\mathrm{Krz})$ & Cov (RS) \\
\hline Mínimo & 0.72 & 0.73 & 0.62 \\
Máximo & 0.82 & 0.83 & 0.81 \\
Média & 0.78 & 0.79 & 0.74 \\
Desvio padrão $(\sigma)$ & 0.02 & 0.02 & 0.05 \\
\hline \hline
\end{tabular}



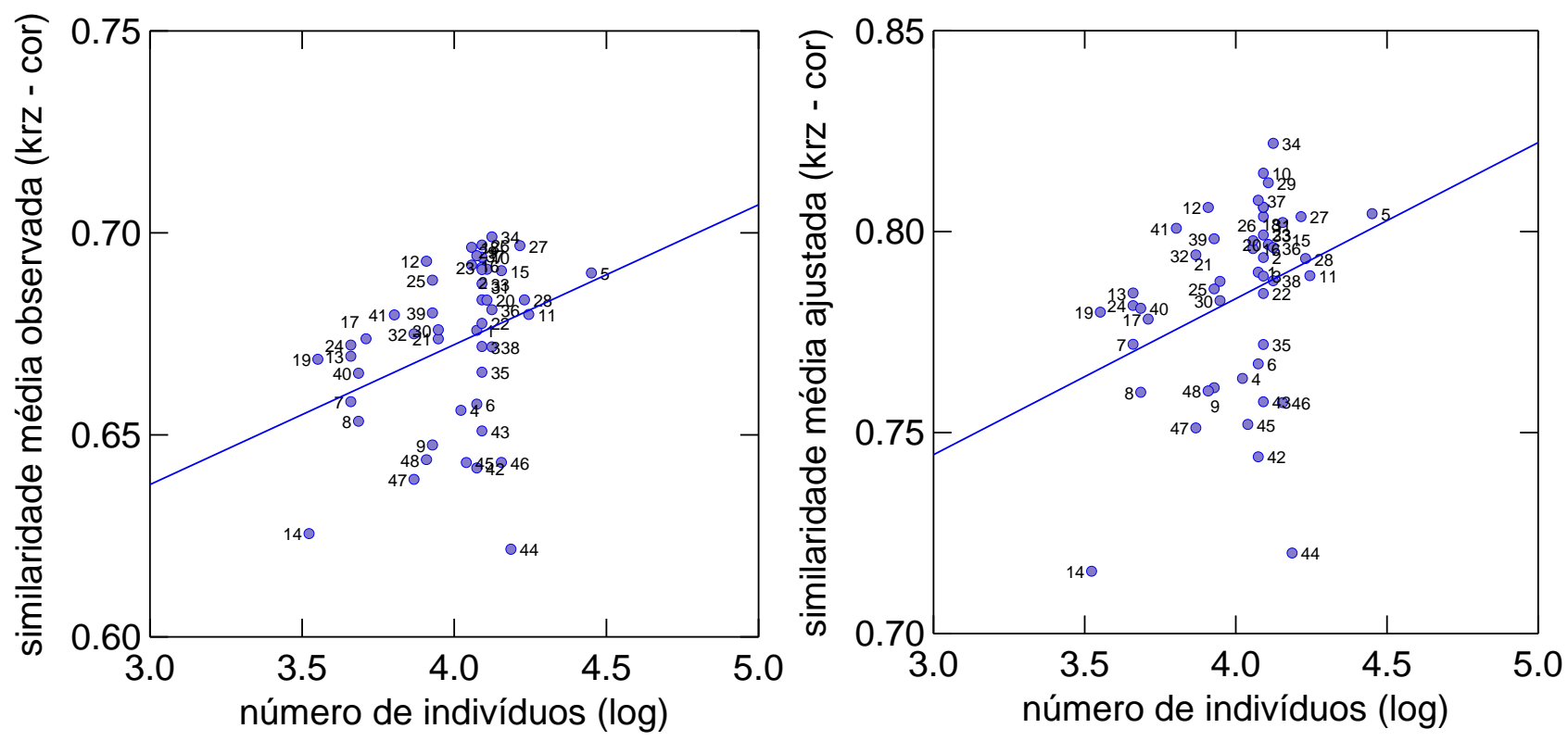

Figura 4.5- Correlação entre o número de indivíduos e a similaridade média observada $(r=0.34, p=0.02)$ e ajustada ( $\mathrm{r}=0.33, \mathrm{p}=0.02$ ) das matrizes de correlação estimadas por Kræanowski. Os números que representam as espécies nos gráficos equivalem àqueles utilizados nas matrizes (tabela 4.2 p.ex.)
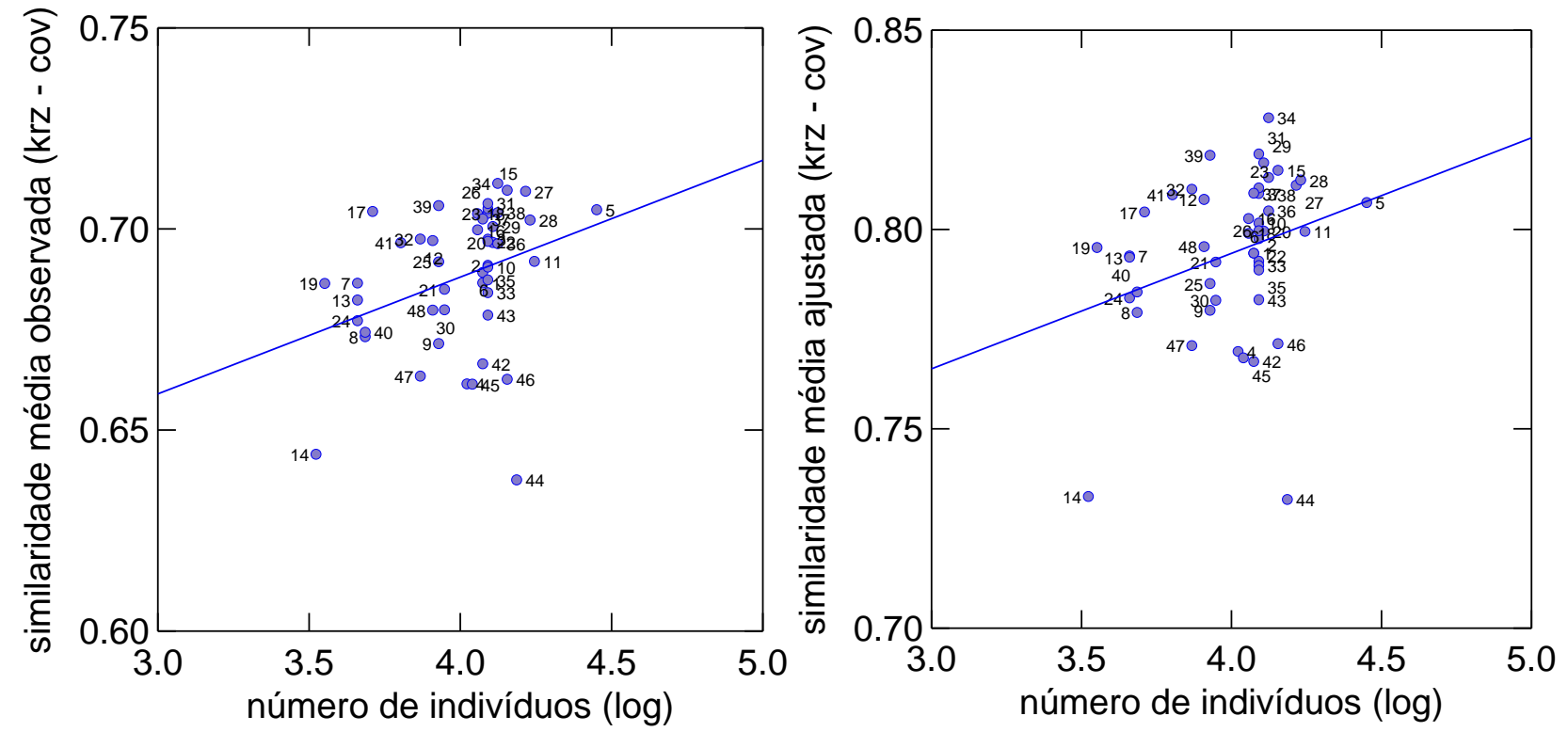

Figura 4.4- Correlação entre o número de indivíduos e a similaridade média observada $(r=0.33, p=0.02)$ e ajustada $(\mathrm{r}=0.29, \mathrm{p}=0.05)$ das matrizes de covariância estimadas por Kræaanowski. Os números que representam as espécies nos gráficos equivalem àqueles utilizados nas matrizes (tabela 4.2 p.ex.). 

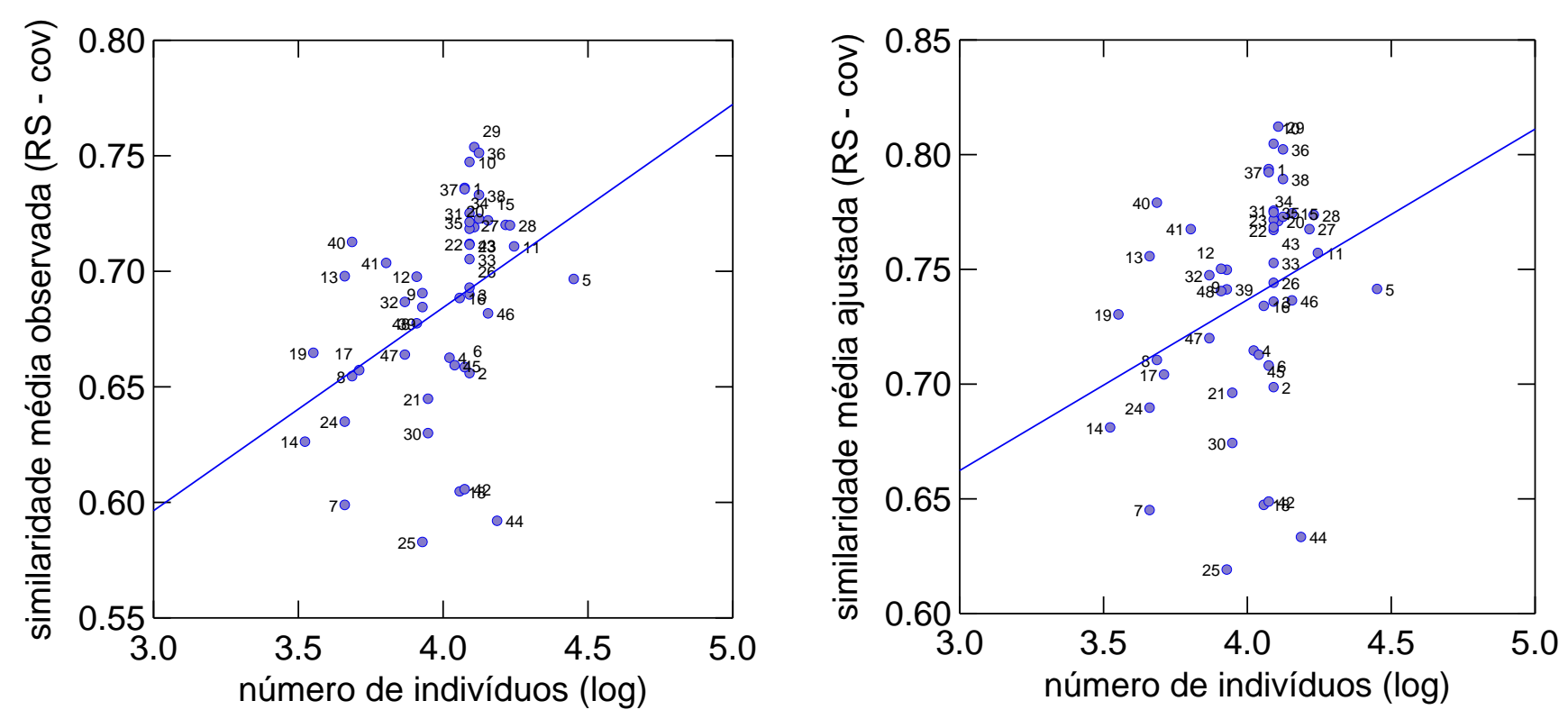

Figura 4.6- Correlação entre o número de indivíduos e a similaridade média observada $(r=0.40, \mathrm{p}<0.01)$ e ajustada $(\mathrm{r}=0.30, \mathrm{p}=0.03)$ das matrizes de covariância estimadas por Random Skewers. Os números que representam as espécies nos gráficos equivalem àqueles utilizados nas matrizes (tabela 4.2 p.ex.).

Tabela 4.7- Estatística básica calculada a partir dos valores de repetibilidade das matrizes de correlação (Krzanowski; Krv) e covariância (Kræanowski ; Kry e Ramdom Skewers; RS).

Repetibilidade das matrizes

\begin{tabular}{lccc}
\hline \multicolumn{1}{c}{ Estatística básica } & Cor $(\mathrm{Krz})$ & Cov $(\mathrm{Krz})$ & Cov (RS) \\
\hline Mínimo & 0.84 & 0.84 & 0.89 \\
Máximo & 0.90 & 0.90 & 0.96 \\
Média & 0.86 & 0.87 & 0.93 \\
Desvio padrão $(\sigma)$ & 0.01 & 0.01 & 0.01 \\
\hline \hline
\end{tabular}




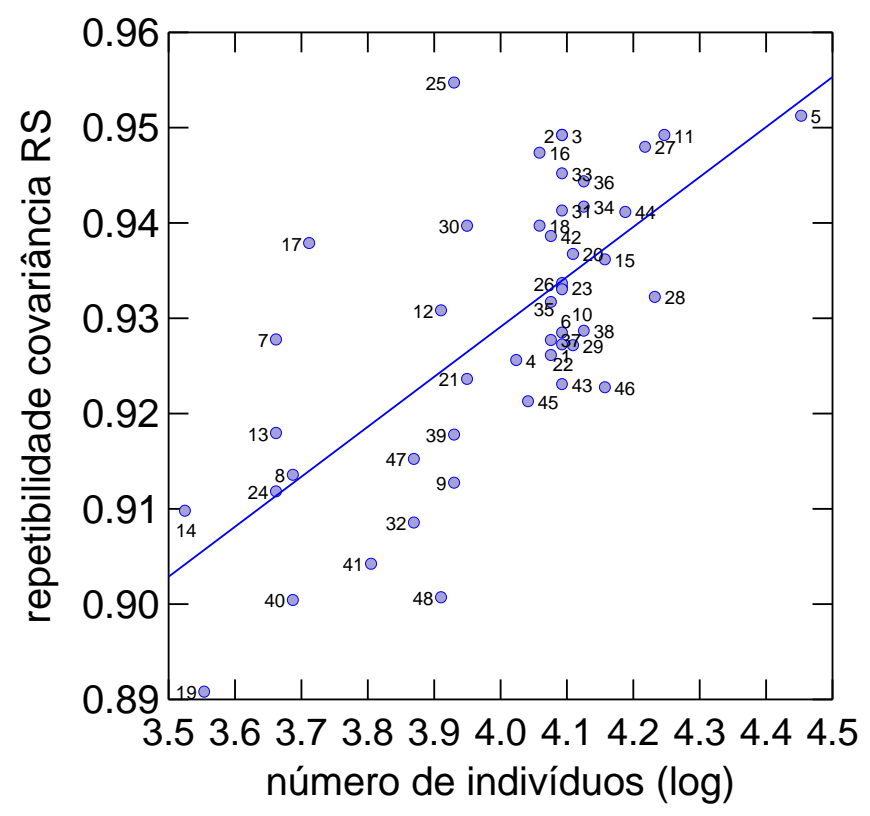

Figura 4.7 Correlação entre o número de indivíduos e os valores de repetibilidade da matriz de correlação $(\mathrm{r}=0.40, \mathrm{p}<0.01)$. Os números que representam as espécies nos gráficos equivalem àqueles utilizados nas matrizes (tabela 4.2 p.ex.).

\subsection{Magnitudes de integração}

A magnitude geral de integração entre os caracteres $\left(r^{2}\right)$, calculada através da matriz de correlação, variou entre os filostomídeos, desde o mínimo de 0.04 (Sphaeronycteris toxophyllum) até o máximo de 0.15 (Micronycteris microtis). Na Figura 4.8 apresento o índice de integração entre os caracteres $\left(\mathrm{r}^{2}\right)$ para cada espécie e os respectivos intervalos de confiançade $95 \%$. Não observei associação significativa entre o índice de magnitude geral de integração $\left(\mathrm{r}^{2}\right)$ e o número de indivíduos que compõem a minha amostra $(\mathrm{r}=0.1, \mathrm{p}=0.48)$. Também não encontrei associação significativa enre a matriz de diferenças na magnitude de integração e as matrizes de similaridade de correlação e covariância (considerando-se tanto valores observados quanto ajustados). 
A magnitude geral entre os caracteres, representado pelo ICV (utilizando-se matriz de covariância) variou desde 1.54 (Sphaeronycteris toxophyllum) a 2.72 (Lonchorbina aurita). Apresento as estatísticas básicas para os dois índices de integração na Tabela 4.8. Correlacionei os dois índices de integração ( $\mathrm{r}^{2}$ e ICV) e obtive um valor igual a 0.76 .

Tabela 4.8- Resultados de estatística básica para os índices de magnitiude geral de integração: $\mathrm{r}^{2}$ (obtido a pertir da matriz de correlação) e ICV (obtido a partir da matriz de covariância).

\begin{tabular}{lcc}
\hline \hline Estatística básica & $\mathbf{r}^{2}$ & ICV \\
\hline Mínimo & 0.046 & 1.545 \\
Máximo & 0.15 & 2.725 \\
Média & 0.082 & 2.013 \\
Desvio padrão $(\sigma)$ & 0.026 & 0.308 \\
Variância & 0.001 & 0.095 \\
\hline \hline
\end{tabular}




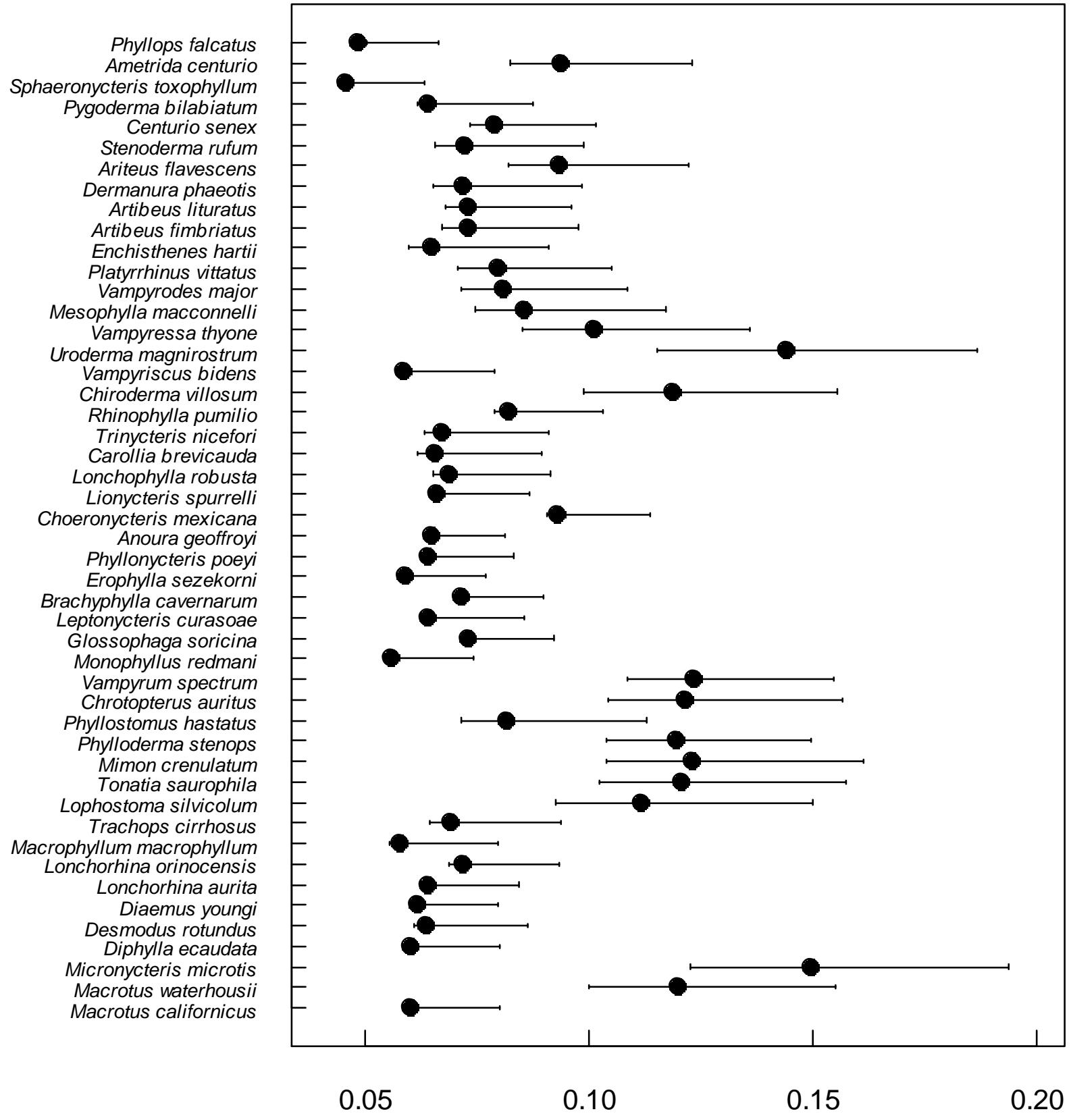

Figura 4.8- Índice de magnitude geral das correlação entre caracteres para cada espécie de morcego filostomídeo, e os respectivos intervalos de confiança de 95\%. 


\subsection{Dieta, Filogenia e Distâncias morfológicas}

Encontrei correlação positiva e significativa entre a similaridade nos padrões de correlação e covariação e a matriz de dieta. Os resultados das correlações foram praticamente os mesmos para valores ajustados e observados (Tabela 4.9). Os resultados corroboram a hipótese de que mudanças na estrutura das matrizes de correlação e covariância fenotípicas em filostomídeos estão associadas à dieta. Constatei correlação negativa e significativa entre a matriz de distâncias filogenéticas e as matrizes de similaridade nos padrões de correlação e covariação comparadas por KrzanowskeiI, considerando os valores observados e ajustados (Tabela 4.9). Considerando essas matrizes, os resultados corroboram a hipótese de que os padrões de correlação e covariação são ao menos parcialmente dependentes da história filogenética do grupo. Por outro lado, não encontrei associação significativa entre a matriz de distâncias filogenéticas e a matriz de covariância comparadas por Random Skemers (considerando valores observados e ajustados) (Tabela 4.9). Também observei correlação negativa e significativa entre a matriz de distâncias morfológicas e as matrizes de similaridade entre as espécies de morcegos filostomídeos, para valores observados e ajustados (Tabela 4.9). 
Tabela 4.9- Resultados das correlações entre a similaridade observada nos padrões de correlação e covariação (observadas à esquerda e ajustadas à direita) e as matrizes de dieta, filogenia e distâncias morfológicas. Valores destacados em negrito, itálico e sublinhado são significativos $(\mathrm{p}<0.05)$.

\begin{tabular}{cccc|ccc}
\hline & \multicolumn{3}{c|}{ Valores observados } & \multicolumn{3}{c}{ Valores ajustados } \\
\hline \hline & $\begin{array}{c}\text { Covariância } \\
\text { (RS) }\end{array}$ & $\begin{array}{c}\text { Covariância } \\
\text { (KRZ) }\end{array}$ & $\begin{array}{c}\text { Correlação } \\
\text { (KRZ) }\end{array}$ & $\begin{array}{c}\text { Covariância } \\
\text { (RS) }\end{array}$ & $\begin{array}{c}\text { Covariância } \\
\text { (KRZ) }\end{array}$ & $\begin{array}{c}\text { Correlação } \\
\text { (KRZ) }\end{array}$ \\
\hline Dieta & $\underline{\mathbf{0 . 2 2}}$ & $\underline{\mathbf{0 . 3}}$ & $\underline{\mathbf{0 . 3 5}}$ & $\underline{\mathbf{0 . 2 2}}$ & $\underline{0.3}$ & $\underline{0.35}$ \\
Filogenia & -0.16 & $\underline{-0.24}$ & $\underline{-0.22}$ & -0.18 & $\underline{-0.26}$ & $\underline{-0.20}$ \\
$\begin{array}{c}\text { Distância } \\
\text { morfológica }\end{array}$ & $\underline{-0.33}$ & $\underline{-0.22}$ & $\underline{-0.30}$ & $\underline{-0.34}$ & $\underline{-0.28}$ & $\underline{-0.36}$ \\
\hline
\end{tabular}

Na Tabela 4.10 apresento os resultados de correlação entre as matrizes de dieta, filogenia, distâncias morfológicas e diferenças na magnitude de integração $\left(\mathrm{r}^{2}\right)$. A matriz de similaridae de dieta mostrou uma correlação negativa e significativa com a matriz de distância filogenética, indicando que espécies relacionadas filogeneticamente apresentam dietas similares. A matriz de dieta também correlacionou-se significativamente com a matriz de distâncias morfológicas. Distâncias morfológicas e filogenéticas apresentaram correlações significativas, indicando que grupos separados por uma pequena distância morfológica são os mais próximos filogeneticamente. Não observei associação significativa entre as diferenças par a par no $r^{2}$ e os demais fatores investigados.

Tabela 4.10 - Correlações par a par entre as matrizes de dieta, filogenia, distâncias morfológicas e diferenças na magnitude de integração $\left(r^{2}\right)$. Valores destacados em negrito, itálico e sublinhado são significativos $(\mathrm{p}<0.05)$.

\begin{tabular}{lcccc}
\hline \hline \multicolumn{1}{c}{ Matrizes } & Dieta & Filogenia & Dist. morfológica & $\mathbf{r}^{2}$ \\
\hline Dieta & 1 & & & \\
Filogenia & $\underline{-0.64}$ & 1 & & \\
Dist. Morfológica & $\underline{-0.47}$ & $\underline{0.25}$ & 1 & 1 \\
$\mathbf{r}^{2}$ & 0.00 & 0.06 & 0.05 & \\
\hline \hline
\end{tabular}


Observei correlação significativa entre a matriz residual de dieta (variação em dieta que é independente da filogenia) e a matriz de correlação estimada por Kzanowski, tanto para valores observados quanto para valores ajustados (Tabela 4.11). Não encontrei correlação significativa entre a matriz residual de deita e as matrizes de covariância estimadas por Kzanowski e RS. Não detectei associação entre a matriz residual de filogenia (variação em filogenia que é independente de dieta) e as matrizes de similaridade (Tabela 4.11).

Tabela 4.11- Resultados da correlação entre a similaridade observada e ajustada nos padrões de correlação e covariação e as matrizes residuais de dieta removendo o efeito da filogenia (dieta filogenia) e da filogenia removendo-se o efeito da dieta (filogenia - dieta). Valores destacados em negrito, itálico e sublinhado são significativos $(\mathrm{p}<0.05)$.

\begin{tabular}{lccc|ccc}
\hline & \multicolumn{3}{c|}{ Valores observados } & \multicolumn{3}{c}{ Valores ajustados } \\
\hline & $\begin{array}{c}\text { Covariância } \\
\text { (RS) }\end{array}$ & $\begin{array}{c}\text { Covariância } \\
\text { (KRZ) }\end{array}$ & $\begin{array}{c}\text { Correlação } \\
\text { (KRZ) }\end{array}$ & $\begin{array}{c}\text { Covariância } \\
\text { (RS) }\end{array}$ & $\begin{array}{c}\text { Covariância } \\
\text { (KRZ) }\end{array}$ & $\begin{array}{c}\text { Correlação } \\
\text { (KRZ) }\end{array}$ \\
\hline Dieta - Filogenia & 0.1 & 0.0 .8 & $\underline{\mathbf{0 . 2 6}}$ & 0.08 & 0.06 & $\underline{\mathbf{0 . 2 4}}$ \\
Filogenia - Dieta & -0.06 & -0.14 & 0.00 & -0.08 & -0.16 & 0.00 \\
\hline
\end{tabular}

Encontrei uma relação significativa entrea matriz residual de dieta e a matriz de distâncias morfológicas $\left(\mathrm{D}^{2}\right)$. Por outro lado, não detectei associação significativa entre filogenia residual e a matriz de distâncias morfológicas. Tanto a matriz de dieta residual quanto a matriz de filogenia residual não estiveram correlacionadas significativamente com as diferenças par a par na magnitude geral de integração (Tabela 4.12). 
Tabela 4.12- Resultados das correlações entre as matrizes de dieta residual (Dieta - Filogenia) e filogenia residual (Filogenia - Dieta) com as matrizes de distâncias morfológicas e de diferenças na magnitude de integração $\left(r^{2}\right)$. Valores destacados em negrito, itálico e sublinhado são significativos $(\mathrm{p}<0.05)$.

\begin{tabular}{ccc}
\hline & \multicolumn{2}{c}{ Matrizes } \\
\hline \hline Matrizes & Distância morfológica $\left(D^{2}\right)$ & Diferença magnitude integração $\left(r^{2}\right)$ \\
\hline Dieta - Filogenia & $\underline{-0.40}$ & 0.08 \\
Filogenia - Dieta & -0.05 & 0.10 \\
\hline
\end{tabular}

\subsection{Detectando caracteres similares e dissimilares entre as matrizes}

Na Tabela 4.13 são apresentadas as porcentagens de divergência total dos caracteres cranianos em filostomídeos. Os resultados estão dispostos em ordem decrescente de porcentagem de divergência observada para cada caráter. Os caracteres ZS-ZI e APET-TS, associados respectivamente à região da face e neurocrânio, foram os que mais divergiram entre as espécies.

Gerei 2256 gráficos, que correspondem às possíveis combinações par a par das 48 matrizes de covariância fenotípicas. Apresento dois exemplos gráficos que sintetizam de forma clara os resultados da comparação entre matrizes de covariância pelo método de SRD. A Figura 4.9, mostra a comparação das matrizes das espécies Trachops cirrhosus e Trinycteris nicefori. À esquerda do gráfico estão as estimativas dos valores médios do SRD para as 35 distâncias com os intervalos de confiança de 95\%. À direita, a relação entre média e desvio padrão centralizados destes escores. Nota-se que os caracteres ZS-ZI, ZI-MT, BR-PT, BA-OPI, JP-AS, IS-PM, NSL-NA, PT-TSP, ZI-TSP, APE-TBA, BA-EAM e LD-AS, são os que contribuem significativamente para a dissimilaridade entre as duas matrizes, pois apresentam valores médios baixos de SRD e valores altos de desvio-padrão. 
A Figura 4.10 nos mostra a comparação entre as matrizes de covariância fenotípicas de Mesophylla macconnelli e Vampyressa thyone. Neste caso, APET-TS, JP-AS, ZS-ZI, BA-OPI, LD-AS, BR-LD, IS-PM apresentam valores médios de SRD baixos, com notável destaque para APET-TS, e variâncias altas, indicando alterações na direção dos vetores de resposta à seleção para esses caracters cranianos entre as duas espécies de morcegos avaliadas.

As tabelas A7 e A8 apresentadas em anexo, trazem informações sobre os caracteres que mais divergiram, e aqueles que permaneceram mais semelhantes entre as espécies. $\mathrm{Na}$ tabela A7 (anexo) estão as distâncias relacionadas à face e subregiões que a compõem. As distâncias relacionadas à região do neurocrânio e suas subregiões são apresentadas na tabela A8 (anexo). Podemos interpretar as informações contidas nessas tabela por meio de dois exemplos antagônicos a seguir. O caráter IS-NSL apresenta o valor 47 em Phyllops falcatus, o que significa dizer que, quando a matriz desta espécie foi comparada com todas as outras matrizes, este caráter específico divergiu em todas as comparações possíveis. Em outro extremo, o caráter PT-BA, relacionado à subregião da abóbada (no neurocrânio) mostra valor zero em V ampyrum spectrum, indicando que esta distância não divergiu dentre todas as comparações. Ainda é possível afirmar que em Vampyrum spectrum, PT-BA foi o caráter que se manteve mais similar se considerarmos a subregião da abóbada craniana. Essa tabela foi pensada como uma forma de sintetizar a extensa gama de resultados que o método de SRD fornece. Ela nos dá uma idéia de quais caracteres relacionados às regiões e subregiões do crânio mais divergiram, e quais se mantiveram mais semelhantes entre as diferentes morfologias estudadas.

Encontrei correlações significativas quando comparei cada uma das 35 matrizes de distâncias (utilizando os valores médios do SRD) com a matriz de dieta. Na Tabela 4.14 apresento todos os resultados obtidos dessa correlação. Na Tabela 4.15 apresento somente os caracteres que apresentaram correlações significativas no teste $(\mathrm{p}<0.05)$. Sete caracteres relacionados à face apresentaram correlação significativa com a matriz de dieta. Esses caracteres estão relacionadas à 
subregião oral (PM-ZI, PM-MT e MT-PNS), nasal (NSL-NA e NA-PNS), e dois deles abarcam as duas subregiões (IS-PNS e NSL-ZI). Um caráter associado ao neurocrânio, localizado subregião da base craniana, correlacionou-se significativamente com a matriz de dieta (PNS-APET). Os resultados encontrados corroboram a hipótese de que caracteres que mais divergiram estão relacionados às regiões do crânio que expressam grande variação morfológica, devido aos hábitos alimentares das espécies. 
Tabela 4.13- Divergência total dos caracteres cranianos em morcegos filostomídeos, obtida a partir do método de SRD.

\begin{tabular}{|c|c|c|c|c|}
\hline Regiões & Subregiões & Caracteres & Divergência total & Divergência total (\%) \\
\hline Face & oral e zigomática & ZSZI & 0.837 & $83.7 \%$ \\
\hline Neurocrânio & base & APETTS & 0.733 & $73.3 \%$ \\
\hline Face & zigomática & EAMZYGO & 0.680 & $68.0 \%$ \\
\hline Face & oral & ISPM & 0.673 & $67.3 \%$ \\
\hline Neurocrânio & base & BAOPI & 0.652 & $65.2 \%$ \\
\hline Neurocrânio & abóbada & OPILD & 0.633 & $63.3 \%$ \\
\hline Neurocrânio & abóbada & LDAS & 0.613 & $61.3 \%$ \\
\hline Neurocrânio & base & APETBA & 0.557 & $55.7 \%$ \\
\hline Neurocrânio & abóbada & JPAS & 0.546 & $54.6 \%$ \\
\hline Face & nasal & NSLNA & 0.536 & $53.6 \%$ \\
\hline Face & zigomática & ZIZYGO & 0.480 & $48.0 \%$ \\
\hline Face & oral & MTPNS & 0.475 & $47.5 \%$ \\
\hline Face & nasal & ISNSL & 0.473 & $47.3 \%$ \\
\hline Face & zigomática & ZITSP & 0.457 & $45.7 \%$ \\
\hline Face & oral & ZIMT & 0.449 & $44.9 \%$ \\
\hline Face & zigomática & ZYGOTSP & 0.412 & $41.2 \%$ \\
\hline Neurocrânio & base & PNSAPET & 0.388 & $38.8 \%$ \\
\hline Neurocrânio & abóbada & BRPT & 0.378 & $37.8 \%$ \\
\hline Face & nasal & NAPNS & 0.301 & $30.1 \%$ \\
\hline Neurocrânio & abóbada & NABR & 0.277 & $27.7 \%$ \\
\hline Neurocrânio & base & BAEAM & 0.205 & $20.5 \%$ \\
\hline Neurocrânio & abóbada & BRAPET & 0.143 & $14.3 \%$ \\
\hline Neurocrânio & abóbada & BRLD & 0.113 & $11.3 \%$ \\
\hline Face & zigomática & PTZYGO & 0.093 & $9.3 \%$ \\
\hline Face/Neurocrânio & zigomática e abóbada & PTTSP & 0.093 & $9.3 \%$ \\
\hline Face & oral e nasal & ISPNS & 0.054 & $5.4 \%$ \\
\hline Face & oral & PMZS & 0.051 & $5.1 \%$ \\
\hline Face & oral & PMZI & 0.049 & $4.9 \%$ \\
\hline Neurocrânio & abóbada & PTAS & 0.046 & $4.6 \%$ \\
\hline Neurocrânio & abóbada & PTEAM & 0.038 & $3.8 \%$ \\
\hline Face & oral e nasal & NSLZI & 0.035 & $3.5 \%$ \\
\hline Face & nasal & NSLZS & 0.027 & $2.7 \%$ \\
\hline Neurocrânio & abóbada & PTAPET & 0.020 & $2.0 \%$ \\
\hline Neurocrânio & abóbada & PTBA & 0.012 & $1.2 \%$ \\
\hline Face & oral & PMMT & 0.003 & $0.3 \%$ \\
\hline
\end{tabular}




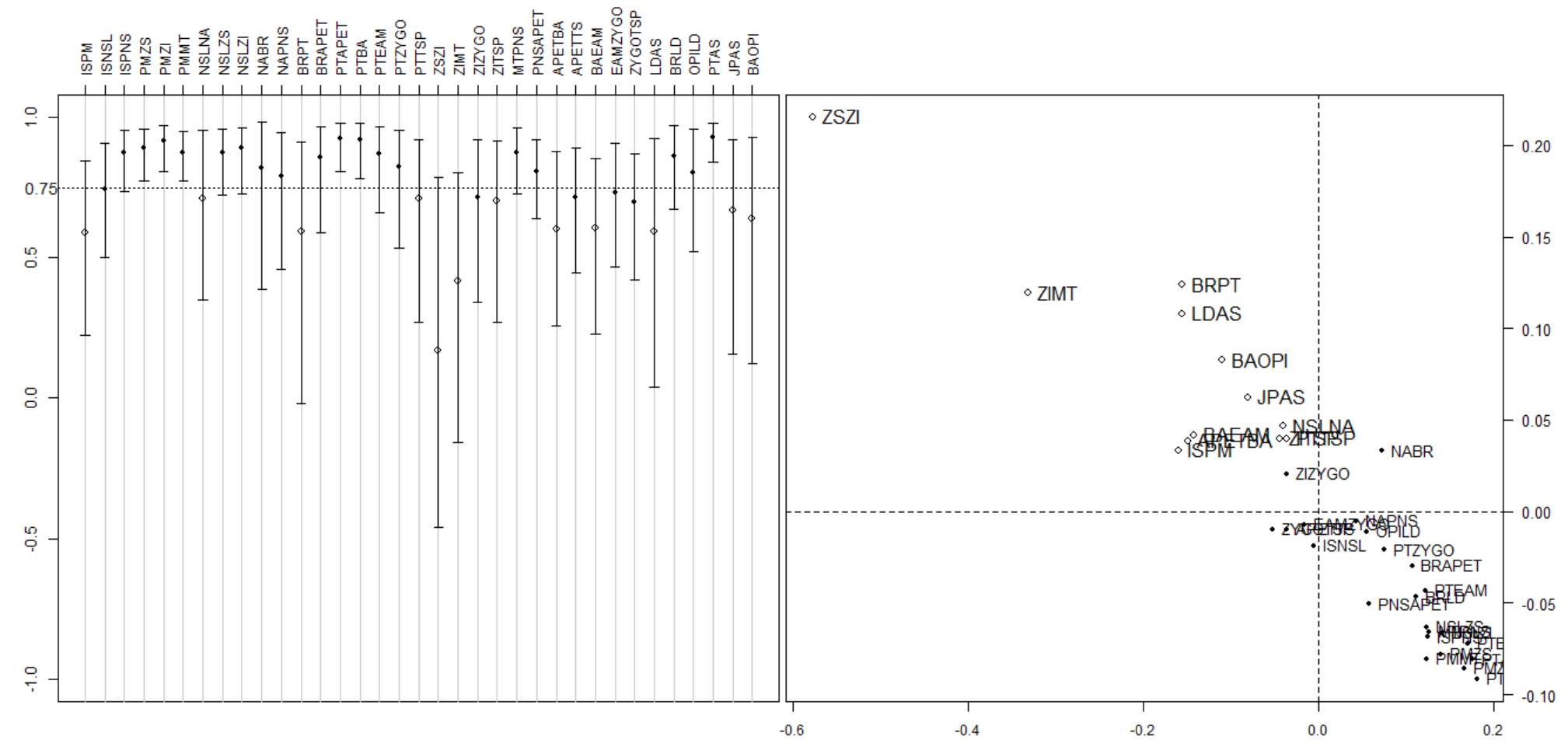

Figura 4.9- Comparação entre as matrizes de covariância fenotípicas de Trachops cirrhosus e Trinycteris nicefori através do método SRD. À esquerda, estimativas de valores médios de SRD para as 35 distâncias euclidianas com seus respectivos intervalos de confiança de $95 \%$. À direita, a relação entre média e desvio padrão centralizados destes escores. Círculos abertos indicam caracteres cujos valores nestes dois parâmetros são significativamente menores que o valor médio para $\mathrm{p}<0.025$. 


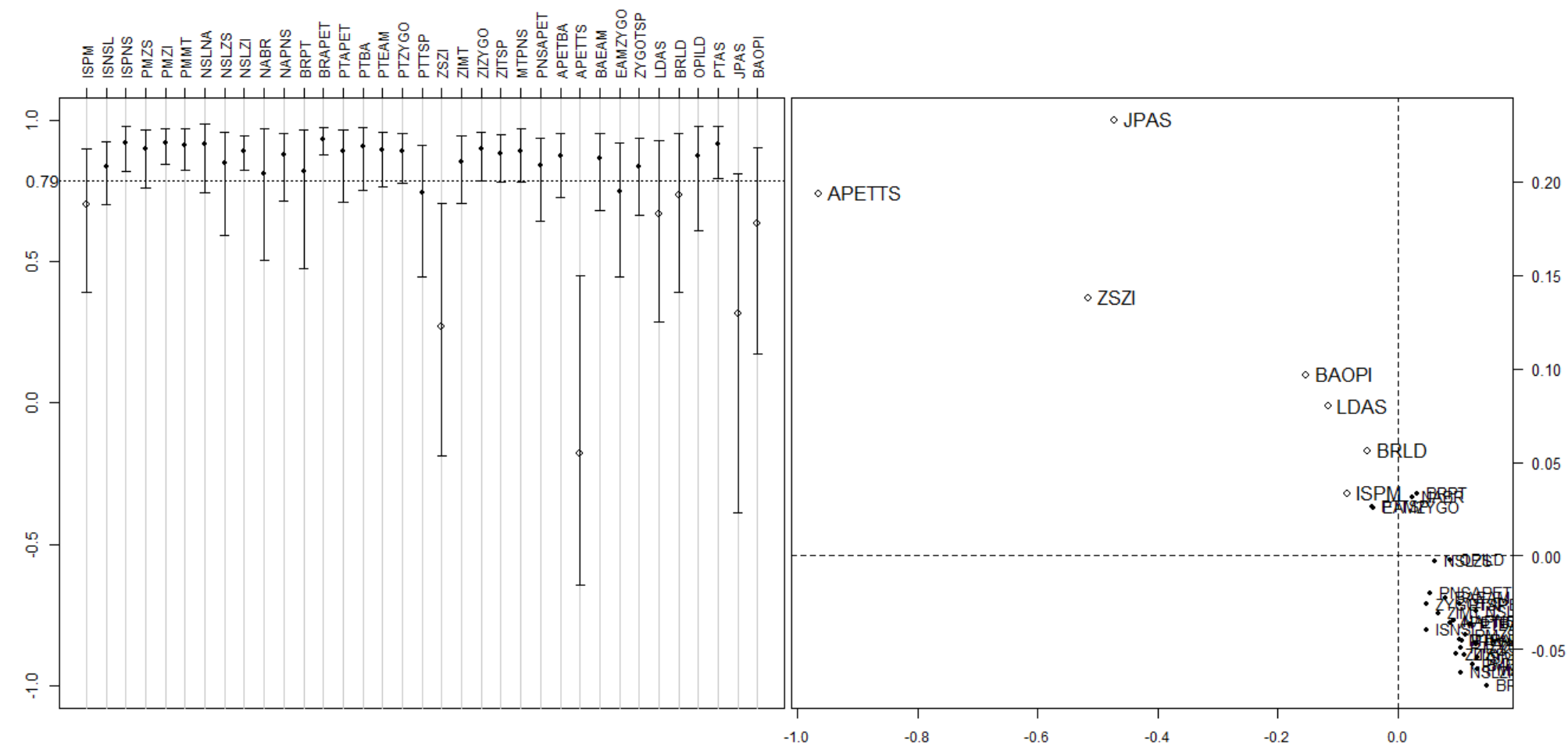

Figura 4.10- Comparação entre as matrizes de covariância fenotípicas de Mesophylla macconnelli e Vampyressa thyone através do método SRD. À esquerda, estimativas de valores médios de SRD para as 35 distâncias euclidianas com seus respectivos intervalos de confiança de $95 \%$. À direita, a relação entre média e desvio padrão centralizados destes escores. Círculos abertos indicam caracteres cujos valores nestes dois parâmetros são significativamente menores que o valor médio para $\mathrm{p}<0.025$. 
Tabela 4.14- Resultados de correlação entre as 35 matrizes de distâncias (utilizando os valores médios do SRD) e a matriz de dieta. Caracteres destacados em negrito, itálico e sublinhado são significativos $(\mathrm{p}<0.05)$.

\begin{tabular}{|c|c|c|c|c|c|c|c|c|c|c|c|c|}
\hline Caracteres & ISPM & ISNSL & ISPNS & PMZS & PMZI & PMMT & NSLNA & NSLZS & NSLZI & NABR & NAPNS & BRPT \\
\hline$r$ & 0.09 & 0.07 & 0.25 & 0.06 & 0.22 & 0.19 & 0.30 & 0.16 & 0.30 & 0.03 & 0.27 & -0.04 \\
\hline$p$ & 0.18 & 0.27 & 0.02 & 0.26 & 0.03 & 0.04 & 0.00 & 0.07 & 0.01 & 0.34 & 0.01 & 0.65 \\
\hline Caracteres & BRAPET & PTAPET & PTBA & PTEAM & PTZYGO & PTTSP & ZSZI & ZIMT & ZIZYGO & ZITSP & MTPNS & PNSAPET \\
\hline$r$ & 0.08 & 0.17 & 0.16 & 0.16 & 0.12 & 0.10 & -0.09 & 0.06 & 0.07 & 0.07 & 0.30 & 0.15 \\
\hline$p$ & 0.17 & 0.07 & 0.08 & 0.09 & 0.13 & 0.13 & 0.86 & 0.23 & 0.19 & 0.23 & 0.01 & 0.05 \\
\hline Caracteres & APETBA & APETTS & BAEAM & EAMZYGO & ZYGOTSP & LDAS & BRLD & OPILD & PTAS & JPAS & BAOPI & \\
\hline$r$ & 0.09 & 0.06 & 0.10 & 0.11 & 0.12 & -0.09 & 0.02 & 0.08 & 0.10 & 0.06 & 0.05 & \\
\hline p & 0.14 & 0.20 & 0.16 & 0.11 & 0.14 & 0.84 & 0.42 & 0.16 & 0.15 & 0.25 & 0.24 & \\
\hline
\end{tabular}

Tabela 4.15- Caracteres significativos da correlação entre 35 matrizes de distâncias (utilizando os valores médios do SRD) e a matriz de dieta.

\begin{tabular}{|c|c|c|c|c|c|c|c|c|}
\hline \multirow{3}{*}{$\begin{array}{c}\text { Regiões } \\
\text { Subregiões } \\
\text { Caracteres }\end{array}$} & \multicolumn{7}{|c|}{ FACE } & \multirow{3}{*}{$\begin{array}{c}\text { NEUROCRÂNIC } \\
\text { BASE } \\
\text { PNSAPET }\end{array}$} \\
\hline & \multicolumn{3}{|c|}{ ORAL } & \multicolumn{2}{|c|}{ NASAL } & \multicolumn{2}{|c|}{ ORAL/NSAL } & \\
\hline & $\underline{P M Z I}$ & $\underline{P M M T}$ & MTPNS & NSLNA & NAPNS & $\underline{\text { ISPNS }}$ & $\underline{N S L Z I}$ & \\
\hline$r$ & 0.22 & 0.19 & 0.30 & 0.30 & 0.27 & 0.25 & 0.30 & 0.15 \\
\hline p & 0.03 & 0.04 & 0.01 & 0.00 & 0.01 & 0.02 & 0.01 & 0.05 \\
\hline
\end{tabular}




\subsection{Modularidade no crânio de morcegos filostomídeos}

Os testes de associação entre as hipóteses teóricas de modularidade e as correlações nas matrizes observadas estão na Tabela 4.16, onde valores destacados em negrito, itálico e sublinhado exibem correlações significativas $(p<0.05)$ e valores em negrito correlações marginalmente significativas $(0.1<\mathrm{p}<0.05)$.

A matriz teórica de integração total, que testa a hipótese de que as cinco sub-regiões cranianas estão integradas, correlacionou-se positiva e significativamente a quase todas as espécies de filostomídeos, com exceção de Macrotus waterbousii (Tabela 4.16). Ainda assim, esta espécie apresentou valor de (avg+/avg-) igual a 1.8, indicando que mesmo não mostrando integração significativa, a média das correlações entre caracteres nessa região foi maior do que a média das demais correlações.

A matriz da neuroface, que explora as relações de padrões de crescimento entre caracteres também apresentou correlações positivas e significativas para 39 espécies de filostomídeos (ver Tabela 4.17 para o número de correlações totais, significativas e marginalmente significativas). Neste módulo, não detectei correlação significativa para nove espécies (Tabela 4.17).

A integração na região da face foi observada em 21 espécies, tendo 12 espécies apresentado correlações significativas e nove marginalmente significativas (Tabela 4.17). A integração no neurocrânio foi detectada como significativa apenas em Desmodus rotundus e Phyllops falcatus e, marginalmente significativa em Pygoderma bilabiatum (Tabela 4.16).

Dentre as cinco sub-regiões cranianas, a oral, nasal e abóbada apresentaram o maior número de correlações positivas significativas (40, 32 e 22 espécies, respectivamente) (tabela 4.17). Encontrei correlações significativas na sub-região zigomática para apenas duas espécies: Vampyrodes major e Phyllops falcatus, ambas pertencentes à Família Stenodermatinae (Tabela 4.16). 
Nenhuma espécie de filostomídeos apresentou correlação significativa na sub-região da base do crânio (Tabela 4.16 e Tabela 4.17). As correlações mais altas foram observadas nas subregiões oral e nasal, com destaque para a subfamília Glossophaginae. Dentro desta subfamília, Anoura geoffroyi foi a espécie que apresentou os maiores valores de correlação nas sub-regiões oral e nasal (3.70 e 4.74, respectivamente) (Tabela 4.16). Nas matrizes de integração total e neurofacial, e na matriz de integração da face Anoura geoffroyi também exibe os maiores valores de correlação encontrados, comparada aos demais filostomídeos. Por fim, Phyllops falcatus e Anoura geoffroyi exibiram os maiores valores de correlação para a subregião da abóbada craniana (2.61 e 2.32, respectivamente) (Tabela 4.16).

A seguir, apresento os resultados gráficos (Figura 4.12, Figura 4.11, Figura 4.13, Figura 4.14 e Figura 4.15) das correlações entre o índice de modularidade (avg+/avg-) e os índices de integração morfológica entre os caracteres $\left(\mathrm{r}^{2}\right)$. As dietas para cada espécie também são expressas nos gráficos. Como as espécies Anoura geoffroyi e Phyllops falcatus, mostraram altos valores de correlação, optei por retirar estas espécies em alguns casos para observar se as mesmas se comportavam como outliers na minha análise. Retirei Anoura geoffroyi dos resultados que geraram os gráficos para as hipóteses oral, nasal e total. Retirei Anoura geoffroyi e Phyllops falcatus dos resultados que geraram os gráficos para as hipóteses abóbada e neuroface. Os resultados para as regiões da face, neurocrânio e zigomático compreendem todas as espécies. Na Tabela 4.18 estão os resultados de correlação incluindo todas as espécies, na ausência de $A$. geoffroyi, e removendo A. geoffroyi e P. falcatus. Os modelos que utilizei para a elaboração dos gráficos estão hachurados e é possível observar que não houveram alterações significativas nos valores de um caso para o outro. A minha escolha então se fundou na melhor visualização gráfica dos resultados. Como nenhuma espécie de filostomídeos apresentou correlação significativa na base do crânio, não apresento resultado de regressão para esta subregião.

Nas figuras 4.18 a 4.22, é possivel notar uma associação negativa entre o índice de modularidade (avg+/avg-) e os valores de $r^{2}$ para cada espécie. Espécies com altos valores de 
(avg+/avg-) tendem a apresentar valores baixos de $\mathrm{r}^{2}$, e vice versa. Observei correlações negativas e significativas para as subregiões oral (Figura 4.11) e abóbada craniana (Figura 4.12), para a região do neurocrânio(Figura 4.13) e considerando integração da neuroface (Figura 4.14) e total (Figura 4.15). A Figura 4.11 mostra a associação entre (avg+/avg-) e os valores de $r^{2}$ para a subregião oral, com as espécies e respectivas dietas. O grupo das espécies nectarívoras nesse gráfico mostra uma evidente modularização da subregião oral, enquanto os insetívoros exibem correlações menores. Por fim, na Figura 4.16 apresento o gráfico resultante da análise discriminante considerando os índices de modularidade (avg+/avg-) para todas as regiões e subregiões cranianas e as respectivas dietas. É possível observar clara separção principalmente considerando espécies nectarívoras e hematófagas. 
Tabela 4.16- Razão entre a magnitude da correlação entre caracteres integrados (avg+) e não integrados (avg-) para cada hipótese teórica de integração (razão avg+/avg-, ou índice de modularidade). Valores em negrito, itálico e sublinhados indicam correlações significativas $(\mathrm{p}<0.05)$, e valores somente em negrito indicam correlações marginalmente significativas $(0.05<\mathrm{p}<0.1)$, para os testes de Mantel de integração morfológica.

\begin{tabular}{|c|c|c|c|c|c|c|c|c|c|c|}
\hline \multirow[b]{2}{*}{ Subfamília } & \multirow[b]{2}{*}{ Espécies/modularidade } & \multirow[b]{2}{*}{ oral } & \multicolumn{4}{|c|}{ SUBREGIÕES } & \multicolumn{4}{|c|}{ REGIÕES } \\
\hline & & & nasal & zigomática & base & abóbada & total & face & neurocrânio & neuroface \\
\hline \multirow{2}{*}{ Macrotinae } & Macrotus californicus & 1.73 & 1.97 & 1.33 & -0.23 & $\underline{2.00}$ & $\underline{1.90}$ & 1.22 & 1.19 & $\underline{1.36}$ \\
\hline & Macrotus waterhousii & 1.49 & 2.12 & 1.14 & 0.11 & 0.92 & 1.18 & 1.48 & 0.76 & 1.18 \\
\hline Micronycterinae & Micronycteris microtis & $\underline{1.65}$ & $\underline{1.70}$ & 1.16 & 0.40 & 0.83 & $\underline{1.16}$ & $\underline{1.70}$ & 0.65 & $\underline{1.23}$ \\
\hline \multirow{3}{*}{ Desmodontinae } & Diphylla ecaudata & 1.43 & $\underline{2.61}$ & 1.19 & -0.28 & 1.30 & $\underline{1.44}$ & 1.35 & 0.98 & $\underline{1.28}$ \\
\hline & Desmodus rotundus & 1.41 & $\underline{1.93}$ & 0.79 & 0.67 & $\underline{1.78}$ & $\underline{1.63}$ & 0.92 & $\underline{1.54}$ & $\underline{1.32}$ \\
\hline & Diaemus youngi & $\underline{2.05}$ & $\underline{2.54}$ & 1.45 & 0.89 & 1.61 & $\underline{2.09}$ & 1.37 & 1.34 & $\underline{1.66}$ \\
\hline \multirow{2}{*}{ Lonchorhininae } & Lonchorhina aurita & 1.71 & 1.45 & 0.62 & -0.37 & $\underline{2.04}$ & $\underline{1.64}$ & 1.12 & 1.49 & $\underline{1.50}$ \\
\hline & Lonchorhina orinocensis & $\underline{2.67}$ & 1.69 & 1.34 & 0.40 & 1.89 & $\underline{2.27}$ & 1.37 & 1.45 & $\underline{1.79}$ \\
\hline \multirow{9}{*}{ Phyllostominae } & $\begin{array}{l}\text { Macrophyllum } \\
\text { macrophyllum }\end{array}$ & $\underline{1.86}$ & $\underline{1.89}$ & 1.13 & 0.33 & 1.18 & $\underline{1.46}$ & 1.26 & 0.87 & 1.11 \\
\hline & Trachops cirrhosus & 1.75 & 1.77 & 0.76 & 0.32 & 1.13 & $\underline{1.28}$ & 1.55 & 0.84 & $\underline{1.31}$ \\
\hline & Lophostoma silvicolum & 1.37 & 1.46 & 0.95 & 0.49 & 1.30 & $\underline{1.28}$ & 1.05 & 1.00 & 1.04 \\
\hline & Tonatia saurophila & 1.30 & $\underline{1.68}$ & 1.03 & 0.47 & 1.13 & $\underline{1.20}$ & 1.15 & 0.89 & 1.04 \\
\hline & Mimon crenulatum & $\underline{1.63}$ & 1.13 & 0.94 & 1.04 & 0.93 & $\underline{1.16}$ & 1.15 & 0.94 & 1.08 \\
\hline & Phylloderma stenops & 1.38 & $\underline{2.04}$ & 1.17 & 0.76 & 1.64 & $\underline{1.64}$ & $\underline{1.60}$ & 0.98 & $\underline{1.52}$ \\
\hline & Phyllostomus hastatus & $\underline{1.56}$ & 1.34 & 1.03 & 0.38 & $\underline{1.50}$ & $\underline{1.45}$ & 1.15 & 1.13 & $\underline{1.23}$ \\
\hline & Chrotopterus auritus & 1.64 & 1.85 & 1.31 & 0.11 & 0.95 & $\underline{1.24}$ & $\underline{1.54}$ & 0.81 & $\underline{1.28}$ \\
\hline & Vampyrum spectrum & $\underline{2.12}$ & $\underline{2.54}$ & 0.90 & -0.16 & 0.96 & $\underline{1.37}$ & 1.65 & 0.64 & 1.19 \\
\hline \multirow{8}{*}{ Glossophaginae } & Monophyllus redmani & $\underline{3.01}$ & 1.59 & 0.64 & 0.47 & 2.11 & $\underline{2.33}$ & 1.02 & 1.37 & 1.30 \\
\hline & Glossophaga soricina & $\underline{2.40}$ & $\underline{3.09}$ & 1.42 & -0.18 & 1.22 & $\underline{1.86}$ & 1.84 & 0.79 & $\underline{1.51}$ \\
\hline & Leptonycteris curasoae & $\underline{3.04}$ & 1.47 & 0.29 & 0.49 & 1.24 & $\underline{1.62}$ & 1.24 & 0.86 & 1.08 \\
\hline & Brachyphylla cavernarum & $\underline{2.56}$ & 1.17 & 1.69 & 0.16 & $\underline{2.25}$ & $\underline{2.45}$ & 1.80 & 0.96 & $\underline{1.69}$ \\
\hline & Erophylla sezekorni & $\underline{2.16}$ & 1.45 & 1.58 & -0.44 & $\underline{1.74}$ & $\underline{1.85}$ & 1.55 & 0.97 & $\underline{1.46}$ \\
\hline & Phyllonycteris poeyi & $\underline{1.95}$ & 2.00 & 0.62 & -0.38 & 1.63 & $\underline{1.57}$ & 0.99 & 1.10 & 1.06 \\
\hline & Anoura geoffroyi & $\underline{3.70}$ & $\underline{4.74}$ & 0.48 & -0.06 & $\underline{2.32}$ & $\underline{3.46}$ & $\underline{2.83}$ & 1.05 & $\underline{3.14}$ \\
\hline & Choeronycteris mexicana & $\underline{2.85}$ & 1.68 & 1.03 & 0.04 & 2.20 & $\underline{2.42}$ & 0.95 & 1.51 & 1.34 \\
\hline \multirow{2}{*}{ Lonchophyllinae } & Lionycteris spurrelli & $\underline{2.67}$ & $\underline{2.37}$ & 0.45 & -0.15 & 1.49 & $\underline{1.77}$ & 1.31 & 1.03 & 1.29 \\
\hline & Lonchophylla robusta & $\underline{2.16}$ & 1.72 & 0.90 & -0.39 & 1.32 & $\underline{1.46}$ & $\underline{1.71}$ & 0.77 & $\underline{1.38}$ \\
\hline Carollinae & Carollia brevicauda & $\underline{2.22}$ & $\underline{2.22}$ & 0.40 & 0.18 & 1.27 & $\underline{1.49}$ & 1.24 & 0.94 & 1.15 \\
\hline Glyphonycterinae & Trinycteris nicefori & 1.52 & 1.70 & 1.27 & 0.00 & 1.48 & $\underline{1.49}$ & 1.47 & 1.08 & $\underline{1.49}$ \\
\hline Rhinophyllinae & Rhinophylla pumilio & $\underline{2.76}$ & 2.05 & 0.85 & 0.47 & $\underline{1.66}$ & $\underline{2.10}$ & 1.15 & 1.32 & $\underline{1.39}$ \\
\hline
\end{tabular}


... Continuação da tabela 4.16

\begin{tabular}{|c|c|c|c|c|c|c|c|c|c|c|}
\hline \multirow[b]{2}{*}{ Subfamília } & \multirow[b]{2}{*}{ Espécies/modularidade } & \multirow[b]{2}{*}{ Oral } & \multirow[b]{2}{*}{ nasal } & \multicolumn{3}{|c|}{ SUBREGIÕES } & \multicolumn{4}{|c|}{ REGIÕES } \\
\hline & & & & zigomática & base & abóbada & total & Face & neurocrânio & neuroface \\
\hline \multirow{18}{*}{ Stenodermatinae } & Chiroderma villosum & 1.40 & $\underline{1.83}$ & 1.06 & 0.37 & 1.30 & $\underline{1.36}$ & 1.28 & 0.94 & $\underline{1.19}$ \\
\hline & Vampyriscus bidens & 1.61 & 1.60 & 1.02 & 0.57 & $\underline{1.65}$ & $\underline{1.63}$ & 1.31 & 1.22 & $\underline{1.47}$ \\
\hline & $\begin{array}{l}\text { Uroderma } \\
\text { magnirostrum }\end{array}$ & $\underline{1.53}$ & $\underline{1.62}$ & 1.12 & 0.62 & 0.88 & $\underline{1.15}$ & $\underline{1.51}$ & 0.77 & $\underline{1.21}$ \\
\hline & Vampyressa thyone & $\underline{1.65}$ & $\underline{2.08}$ & 0.94 & 0.63 & 0.95 & $\underline{1.26}$ & $\underline{1.62}$ & 0.82 & $\underline{1.36}$ \\
\hline & Mesophylla macconnelli & 1.66 & 1.57 & 0.84 & 0.18 & 1.29 & $\underline{1.33}$ & 1.34 & 0.91 & $\underline{1.22}$ \\
\hline & Vampyrodes major & $\underline{1.62}$ & $\underline{1.92}$ & $\underline{1.67}$ & 0.47 & 1.33 & $\underline{1.61}$ & 1.33 & 0.99 & $\underline{1.28}$ \\
\hline & Platyrrhinus vittatus & 1.59 & 1.66 & 0.97 & 0.38 & 1.35 & $\underline{1.39}$ & 1.21 & 1.11 & $\underline{1.27}$ \\
\hline & Enchisthenes hartii & $\underline{2.12}$ & $\underline{1.88}$ & 1.04 & 0.32 & $\underline{1.68}$ & $\underline{1.85}$ & $\underline{1.86}$ & 1.03 & $\underline{1.84}$ \\
\hline & Artibeus fimbriatus & $\underline{1.82}$ & 1.88 & 0.87 & 0.25 & 1.18 & $\underline{1.37}$ & $\underline{1.60}$ & 0.72 & $\underline{1.23}$ \\
\hline & Artibeus lituratus & 1.53 & $\underline{2.06}$ & 0.80 & 0.54 & 1.38 & $\underline{1.43}$ & 1.29 & 0.91 & 1.17 \\
\hline & Dermanura phaeotis & 1.60 & 1.67 & 1.35 & 0.41 & 1.16 & $\underline{1.38}$ & $\underline{1.69}$ & 0.94 & $\underline{1.55}$ \\
\hline & Ariteus flavescens & 1.72 & $\underline{2.31}$ & 1.36 & 0.02 & 1.08 & $\underline{1.41}$ & $\underline{1.97}$ & 0.66 & $\underline{1.45}$ \\
\hline & Stenoderma rufum & $\underline{2.45}$ & 1.36 & 1.09 & 0.09 & 1.36 & $\underline{1.65}$ & 1.37 & 1.01 & $\underline{1.33}$ \\
\hline & Centurio senex & $\underline{2.24}$ & $\underline{3.20}$ & 0.18 & $\begin{array}{c}- \\
0.61\end{array}$ & 1.77 & $\underline{1.79}$ & 1.33 & 1.10 & 1.38 \\
\hline & Pygoderma bilabiatum & $\underline{2.89}$ & 1.76 & 1.00 & 0.35 & $\underline{2.19}$ & $\underline{2.50}$ & 1.22 & 1.58 & $\underline{1.74}$ \\
\hline & $\begin{array}{l}\text { Sphaeronycteris } \\
\text { toxophyllum }\end{array}$ & 1.74 & $\underline{2.61}$ & 0.65 & 0.18 & 1.30 & $\underline{1.48}$ & 1.49 & 1.16 & $\underline{1.61}$ \\
\hline & Ametrida centurio & $\underline{2.40}$ & $\underline{2.01}$ & 1.53 & 0.10 & 0.78 & $\underline{1.45}$ & $\underline{2.36}$ & 0.62 & $\underline{1.69}$ \\
\hline & Phyllops falcatus & 1.77 & 1.62 & 1.88 & $\begin{array}{c}- \\
0.25 \\
\end{array}$ & $\underline{2.61}$ & $\underline{2.45}$ & 1.17 & $\underline{2.08}$ & $\underline{2.21}$ \\
\hline
\end{tabular}


Tabela 4.17- Número de correlações significativas, marginalmente significativas e totais considerando as hipóteses de modularidade cranianas para os morcegos da Família Phyllostomidae.

\begin{tabular}{lcccccccccc}
\hline & \multicolumn{4}{c}{ Sub-regiões } & \multicolumn{4}{c}{ Regiões } \\
\hline \hline correlações & oral & nasal & zigomática & base & abóbada & total & face & neurocrânio & neuroface \\
\hline $\mathbf{0 . 0 5 <}<<0.1$ & 12 & 10 & 1 & 0 & 10 & 0 & 9 & 1 & 5 \\
$\mathbf{p}<\mathbf{0 . 0 5}$ & 28 & 21 & 1 & 0 & 12 & 47 & 12 & 2 & 34 \\
total & 40 & 32 & 2 & 0 & 22 & 47 & 21 & 3 & 39 \\
\hline \hline
\end{tabular}

Tabela 4.18- Resultados de correlação incluindo todas as espécies, retirando $A$. geoffroyi e retirando $A$. geoffroyi e $P$. falcatus. Destacados em cinza estão os modelos selecionados para a elaboração gráfica da associação entre a magnitude de integração geral e o índice de modularidade (avg+/avg-).

\begin{tabular}{lcccccc}
\hline \multicolumn{1}{r}{ Modelos } & \multicolumn{2}{c}{ todas as espécies } & \multicolumn{2}{c}{ sem $\boldsymbol{A}$. geoffroyi } & \multicolumn{2}{c}{ sem A. geoffroyi e $\boldsymbol{P}$. falcatus } \\
\hline \multicolumn{1}{c}{ Hipóteses } & $\mathbf{r}$ & $\mathbf{p}$ & $\mathbf{r}$ & $\mathbf{p}$ & $\mathbf{r}$ & $\mathbf{p}$ \\
\hline Face & 0.10 & 0.483 & 0.20 & 0.181 & 0.18 & 0.200 \\
Neurocrânio & -0.52 & $<0.001$ & -0.52 & $<0.001$ & -0.48 & $<0.001$ \\
Neuroface & -0.36 & 0.012 & -0.43 & 0.003 & -0.36 & 0.014 \\
Oral & -0.33 & 0.021 & -0.33 & 0.025 & -0.35 & 0.021 \\
Nasal & -0.13 & 0.366 & -0.09 & 0.535 & -0.12 & 0.400 \\
Zigomática & 0.09 & 0.539 & 0.07 & 0.632 & 0.17 & 0.240 \\
Abóbada & -0.58 & $<0.001$ & -0.57 & $<0.001$ & -0.54 & $<0.001$ \\
Total & -0.48 & 0.001 & -0.52 & $<0.001$ & -0.48 & $<0.001$ \\
\hline \hline
\end{tabular}



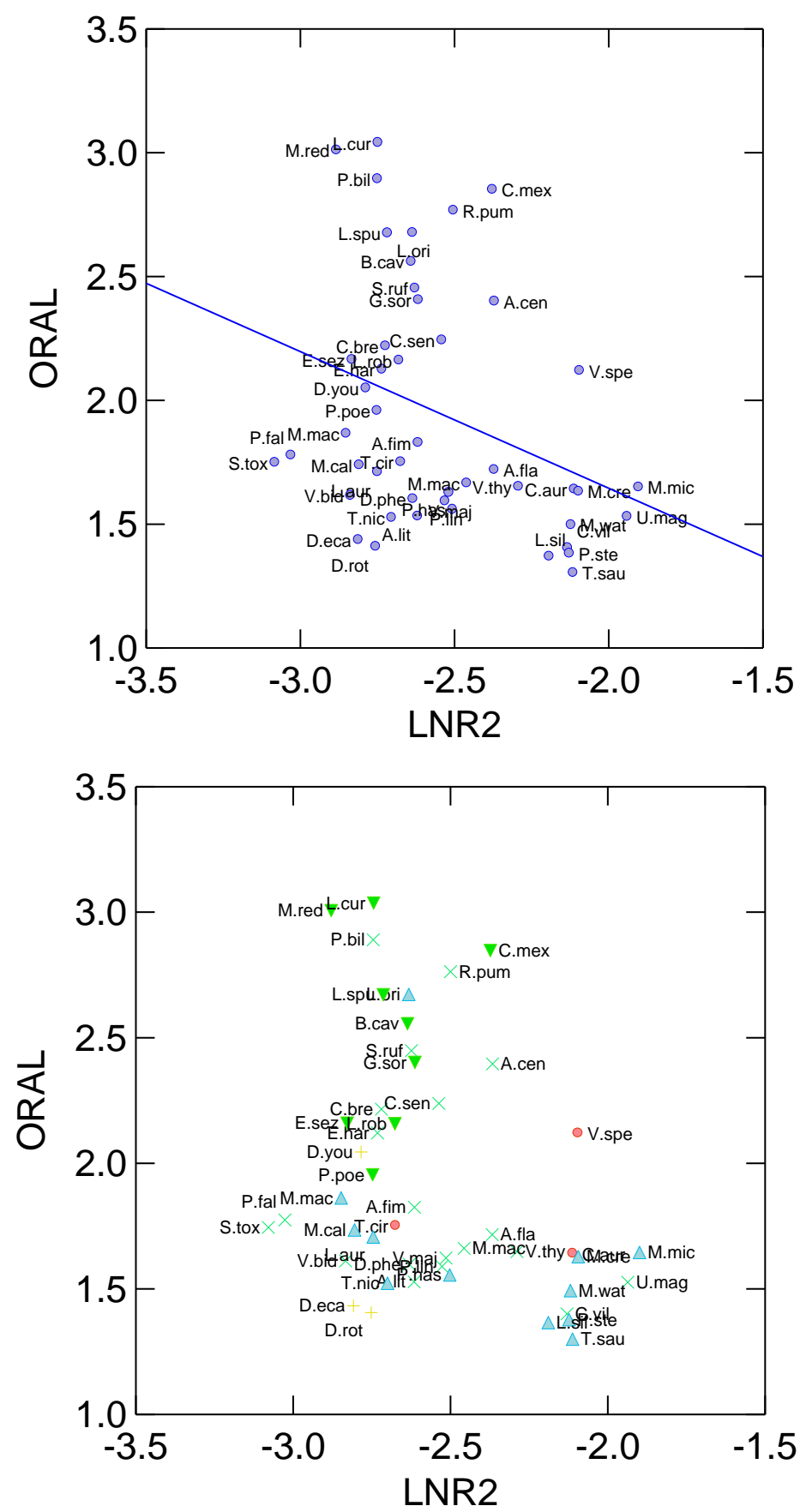

dieta

$\circ \mathrm{C}$

$\times \mathrm{F}$

$+\mathrm{H}$

$\triangle \mathrm{I}$

$\nabla N$

Figura 4.11- Relação do índice de integração morfológica (logarítimo de $\mathrm{r}^{2}$ ) com o índice de modularidade correspondente à hipótese de integração oral. O gráfico na parte superior representa as espécies e o inferior as suas respectivas dietas. 

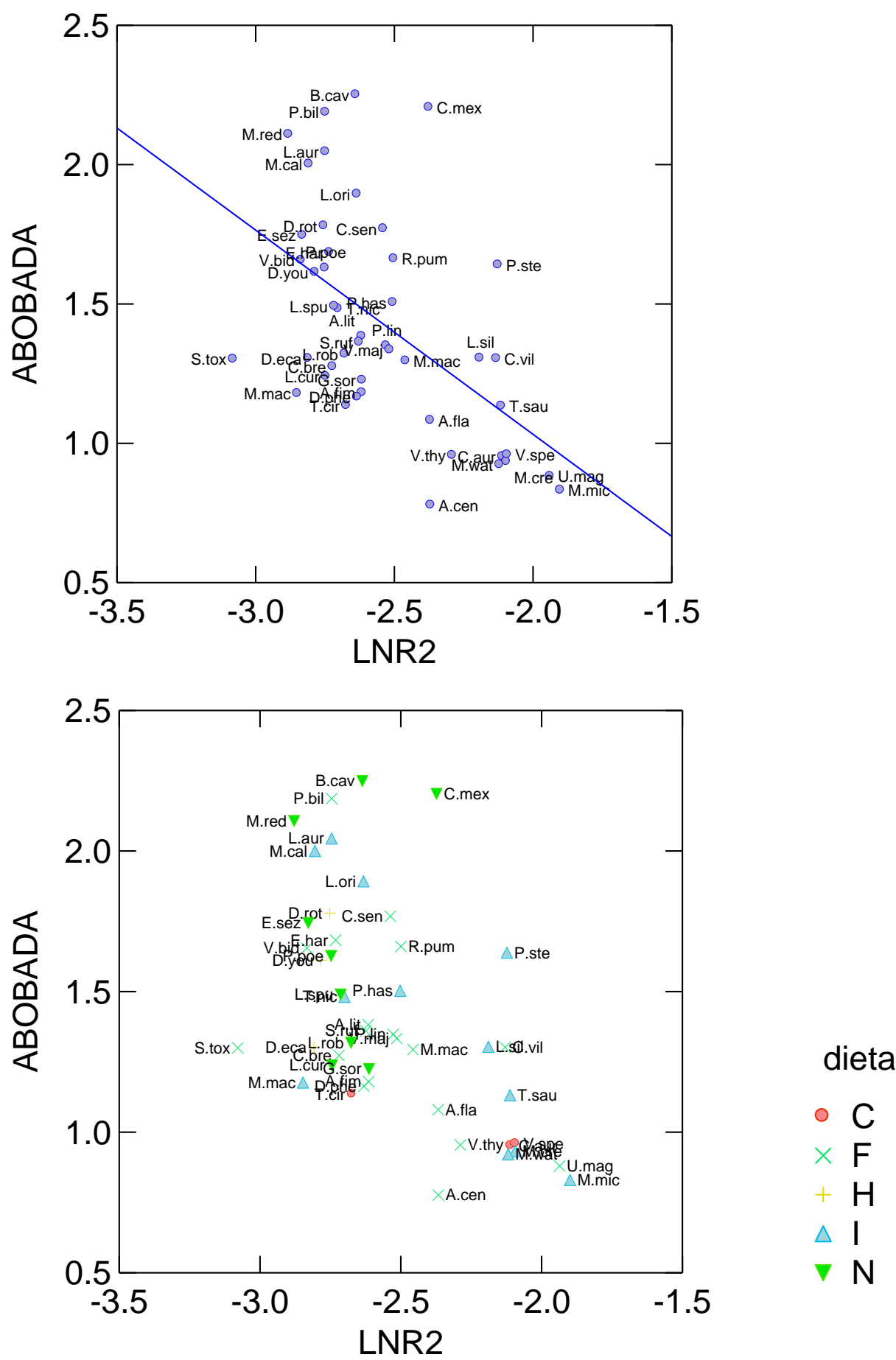

Figura 4.12- Relação do índice de integração morfológica (logarítimo de $\mathrm{r}^{2}$ ) com o índice de modularidade correspondente à hipótese de integração da abóbada craniana. O gráfico na parte superior representa as espécies e o inferior as suas respectivas dietas. 

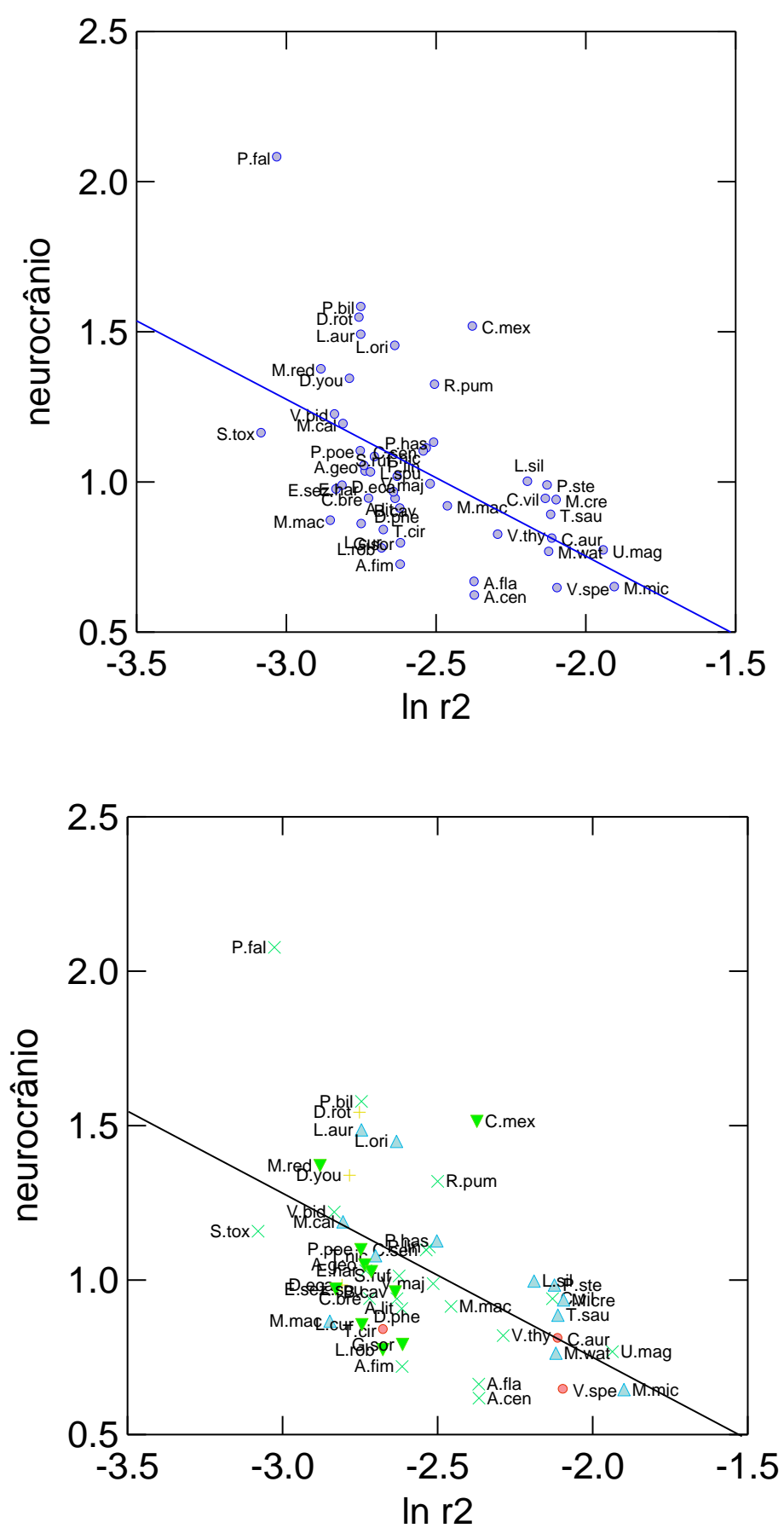

dieta

$\circ \mathrm{C}$

$\times f$

$+\mathrm{h}$

$\Delta \mathrm{i}$

$\nabla \mathrm{n}$

Figura 4.13- Relação do índice de integração morfológica (logarítimo de $\mathrm{r}^{2}$ ) com o índice de modularidade correspondente à hipótese de integração do neurocrânio. O gráfico na parte superior representa as espécies e o inferior as suas respectivas dietas. 

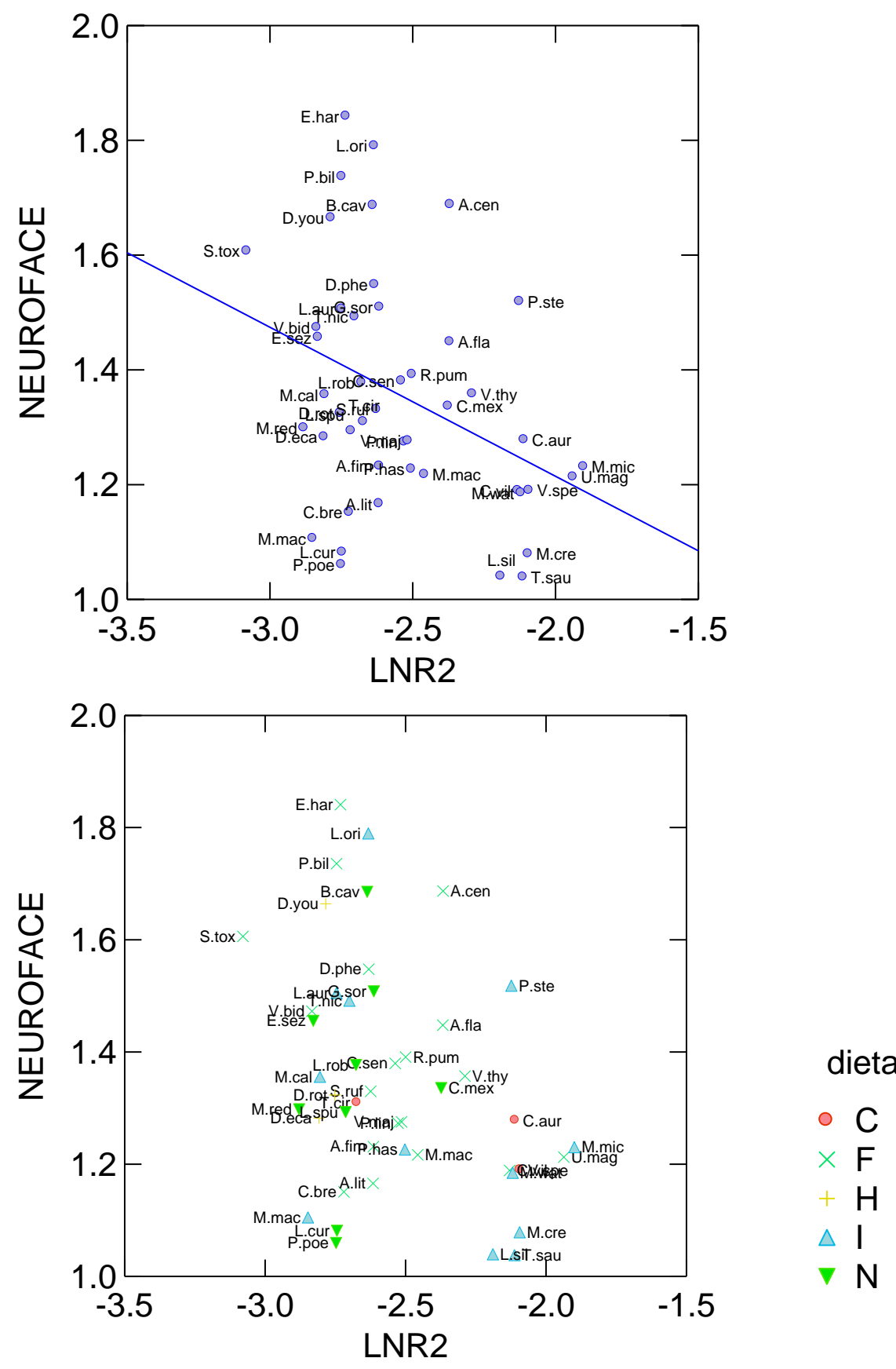

Figura 4.14- Relação do índice de integração morfológica (logarítimo de $\mathrm{r}^{2}$ ) com o índice de modularidade correspondente à hipótese de integração da neuroface. O gráfico na parte superior representa as espécies e o inferior as suas respectivas dietas. 

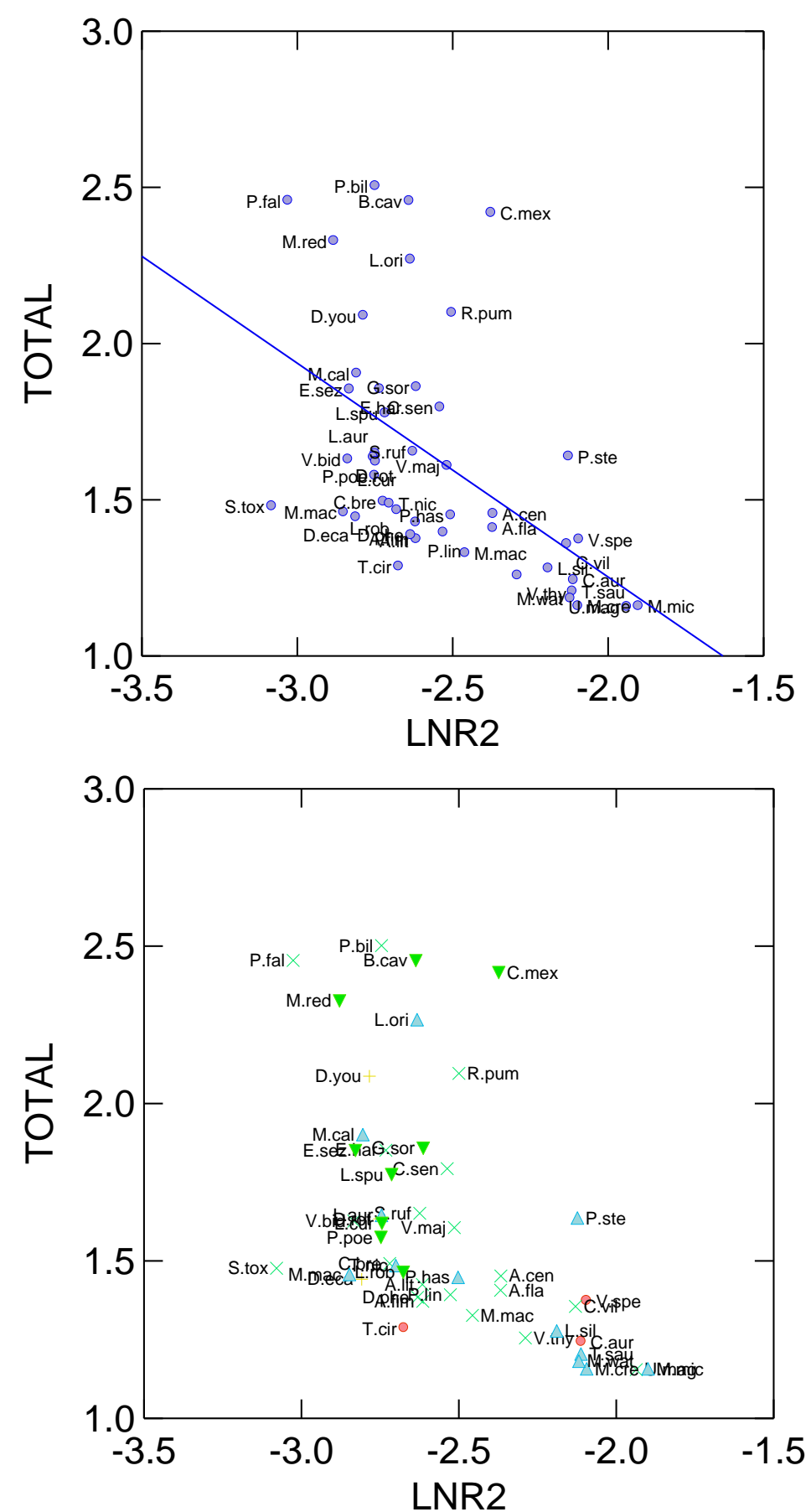

dieta

- C

$\times \mathrm{F}$

$+\mathrm{H}$

$\triangle \mathrm{I}$

$\checkmark N$

Figura 4.15- Relação do índice de integração morfológica (logarítimo de $\mathrm{r}^{2}$ ) com o índice de modularidade correspondente à hipótese de integração total. O gráfico na parte superior representa as espécies e o inferior as suas respectivas dietas. 


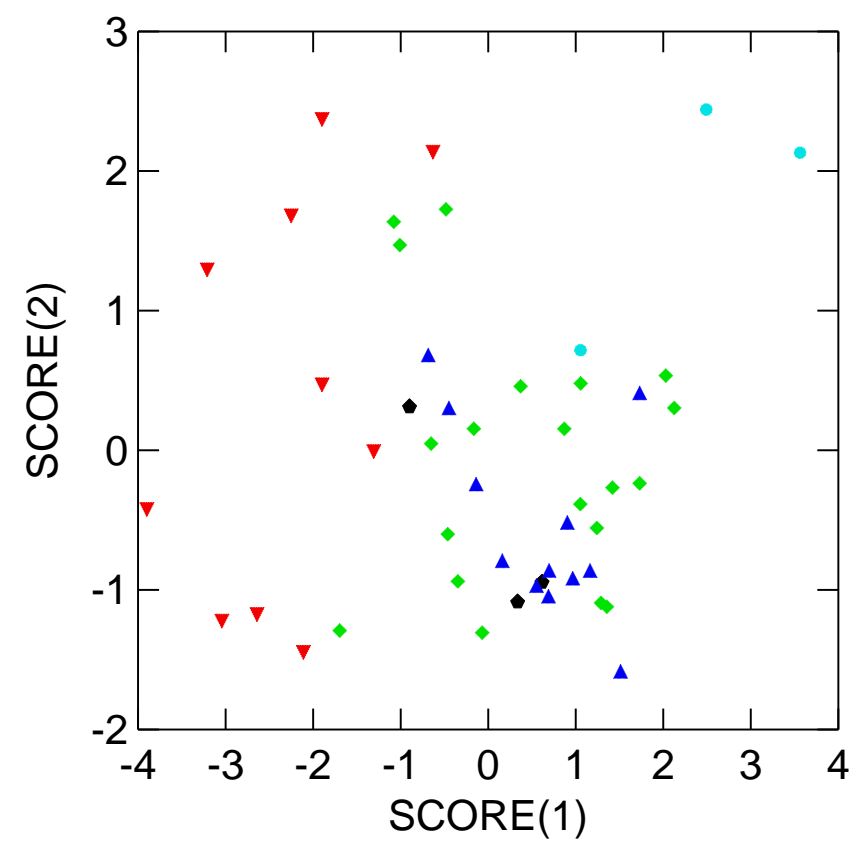

dieta

- C

- $\mathrm{F}$

- $\mathrm{H}$

$\sim \mathrm{I}$

$\checkmark \mathrm{N}$

Figura 4.16- Gráfico resultante da análise discriminante considerando os índices de modularidade (avg+/avg-) para todas as regiões e subregiões cranianas e as respectivas dietas em filostomídeos.

\subsection{Flexibilidade evolutiva e Restrição}

$\mathrm{Na}$ Tabela 4.19, apresento comparativamente os valores do teste de significância para as correlações entre $r^{2}$ e ICV com flexibilidade e restrição. Obtive correlação negativa e significativa entre o índice de integração morfológica $\left(\mathrm{r}^{2}\right)$ e a flexibilidade evolutiva $(\mathrm{r}=-0.7 ; \mathrm{p}<0.001)$. A correlação entre o índice de integração estimado a partir da matriz de covariação (ICV) e a flexibilidade foi ainda maior $(\mathrm{r}=-0.96 ; \mathrm{p}<0.001)$. Estes resultados nos mostram que espécies que apresentam alta magnitude geral de integração entre os caracteres do crânio pussuem em geral menor capacidade de evoluir na direção da seleção. Nesse quesito encontram-se algumas espécies como Choeronycteris mexicana, Vampyrum spectrum e Loncorbina aurita. No outro extremo, destacamse Sphaeronycteris toxophyllum e Phyllops falcatus com asssociações mais baixas nos caracteres 
cranianos e portanto, com maior habilidade em responder na direção em que a seleção está atuando.

Os resultados de correlação entre $r^{2}$ e a restrição evolutiva foram muito semelhantes àqueles entre ICV e restrição $(r=0.81 ; \mathrm{p}<0.001$ e $\mathrm{r}=0.88 ; \mathrm{p}<0.001$, respectivamente). Obtive correlações positivas e significativas entre estas variáveis (Tabela 4.19), em que as espécies Macrotus waterhousii, Micronyctreis microtis e Uroderma magnirostrum figuram crânios mais restritos evolutivamente.

Por meio de análise de variância detectei relação significativa entre dieta (variável categórica) e os índices de integração morfológica $\mathrm{r}^{2}$ e ICV (SS=0.007; df=4; F=3.18; p=0.023 e $\mathrm{SS}=0.822 ; \mathrm{df}=4 ; \mathrm{F}=2.43 ; \mathrm{p}=0.062$, respectivamente). Da mesma manerira encontrei relação significativa entre dieta e flexibilidade $(\mathrm{SS}=0.019 ; \mathrm{df}=4 ; \mathrm{F}=2.82 ; \mathrm{p}=0.036)$ e entre dieta e restrição evolutiva $(\mathrm{SS}=0.050 ; \mathrm{df}=4 ; \mathrm{F}=2.65 ; \mathrm{p}=0.046)$.

Por fim, utilizei os índices de modularidade (avg+/avg-) que apresentaram correlação significativa com o $\mathrm{r}^{2}$ (oral, abóbada, neurocrânio, total e neuroface - ver Tabela 4.18 para detalhes), e os correlacionei aos índices de flexibilidade e restrição. Para essa investigação, e considerando a flexibilidade evolutiva, encontrei relação positiva e significatica apenas para a neuroface $(r=0.3 ; p=0.044)$. O índice de restrição, por sua vez, apresentou correlação negativa e significativa para a subregião oral $(\mathrm{r}=-0.3 ; \mathrm{p}=0.042)$, abóbada craniana $(\mathrm{r}=-0.77 ; \mathrm{p}=0.013)$ e para integração total $(\mathrm{r}=-0.43 ; \mathrm{p}=0.003)$. Ainda considerando o índice de restição evolutiva, existem correlações negativas e marginalmente significativas para a região do neurocrânio $(\mathrm{r}=-0.25$; $\mathrm{p}=0.082)$ e neuroface $(\mathrm{r}=-0.25 ; \mathrm{p}=0.085)$. A representação gráfica desses resultados será apresentada no tópico que insere os filostomídeos aos resultados dos demais mamíferos. 
Tabela 4.19- Resultados da correlação entre os índices de magnitude geral de integração $\left(\mathrm{r}^{2} \mathrm{e}\right.$ ICV) e os índices de flexibilidade e restrição; variação no primeiro componente principal (extraído da matriz de covariância) e a variação relativa relacionada ao tamanho.

\begin{tabular}{lccccc}
\hline \multicolumn{1}{c}{ Índices } & \multicolumn{2}{c}{$\log \mathbf{r}^{2}$} & \multicolumn{3}{c}{ ICV } \\
\hline \multicolumn{1}{c}{ Índices } & $\mathbf{R}$ & $\mathbf{p}$ & $\mathbf{r}$ & $\mathbf{p}$ \\
\hline Flexibilidade & -0.707 & $<0.001$ & -0.967 & $<0.001$ \\
Restrição & 0.814 & $<0.001$ & 0.887 & $<0.001$ \\
Variação no PC1 (cov) & 0.802 & $<0.001$ & 0.961 & $<0.001$ \\
Variação relativa & 0.763 & $<0.001$ & 0.397 & 0.005 \\
\hline \hline
\end{tabular}

\subsection{Variação devida ao tamanho}

$\mathrm{Na}$ Tabela 4.20 apresento a porcentagem de variação explicada pelo primeiro componente principal das matrizes de covariância de todas as espécies que compõem o meu estudo. A porcentagem de variação no primeiro CP variou entre os filostomídeos, desdo o mínimo de 19.6\% (Erophylla sezekorni) até o máximo de 44.8\% (Lonchorbina aurita), apresentando uma média em torno de $29 \%$. Nessa tabela também encontram-se as informações de dieta por espécie, bem como os índices de magnitude geral de integração $\left(\mathrm{r}^{2}\right)$, flexibilidade evolutiva, restrição evolutiva, variação relativa de tamanho (iso relativa) e em qual componente o tamanho foi detectado na matriz de covariância das espécies. Constatei que nem todas as espécies de morcegos filostomídeos apresentaram variação associada ao tamanho no primeiro CP. Das 48 espécies analisadas neste estudo, 23 mostraram variação de tamanho no primeiro CP. Em sete espécies o tamanho se expressa no segundo CP e nas 18 espécies restantes tamanho está disperso entre os componentes, de tal forma que não é capturado por nenhum deles. Quando extraí os componentes principais da matriz de correlação, observei que a maior porcentagem de variação 
associada a tamanho foi capturada no primeiro CP, exceto em sete espécies: Anoura geoffroyi, Ariteus flavescens, Brachyphylla cavernarum, Centurio senex, Choeronycteris mexicana, Diaemus youngi, Lonchorbina orinocensis e Monophyllus redmani.

Encontrei correlação positiva e significativa entre a quantidade de variação no primeiro CP extraído da matriz de covariância e os índices de integração morfológica $r^{2}$ e ICV (Tabela 4.19). Na Figura 4.17, demonstro a associação entre ICV e o primeiro CP obtido a partir da matriz de covariância. Podemos observar que espécies mais integradas morfologicamente (Lonchorbina aurita) apresentam maior variação no primeiro CP, enquanto espécies com valores mais baixos na magnitude geral de correlações entre os caracteres (Sphaeronycteris toxophyllum, por exemplo), demonstram variação menor no primeiro CP.

Apresento na Tabela 4.21 os resultados da correlação entre os índices de restrição e flexibilidade evolutivas com a quantidade de variação no primeiro $\mathrm{CP}$ e a variação relativa relacionada ao tamanho. Observei correlação positiva e significativa entre a quantidade de variação no primeiro CP e o índice de restrição (Tabela 4.21). Na Figura 4.18 é possível observar graficamente a relação entre o índice de restrição e a quantidade de variação no primeiro CP obtido a partir da matriz de covariância. Nota-se que Lonchorbina aurita apresenta a maior quantidade de variação no primeiro CP $(44.7 \%)$ e, dentre todas, representa a espécie mais restrita evolutivamente. $\mathrm{O}$ índice de restrição também apresentou-se correlacionado positiva e significativamente à variação relativa relacionada ao tamanho (Tabela 4.21).

Verifiquei correlação negativa e significativa entre a quantidade de variação no primeiro CP e o índice de flexibilidade evolutiva (Tabela 4.21). Sphaeronycteris toxophyllum e Phyllops falcatus mostraram maiores valores de flexibilidade e baixa quantidade de variação no primeiro CP (Figura 4.19). Quando dieta é plotada no gráfico, notei que com exceção de Choeronycteris mexicana, as demais espécies nectarívoras encontram-se agrupadas na parte inferior direita do gráfico, mostrando valores de flexibilidade relativamente altos e pouca variação explicada pelo primeiro 
CP (Figura 4.20). Na maioria das espécies nectarívoras o tamanho está disperso ao longo dos vários componentes principais (Figura 4.21).

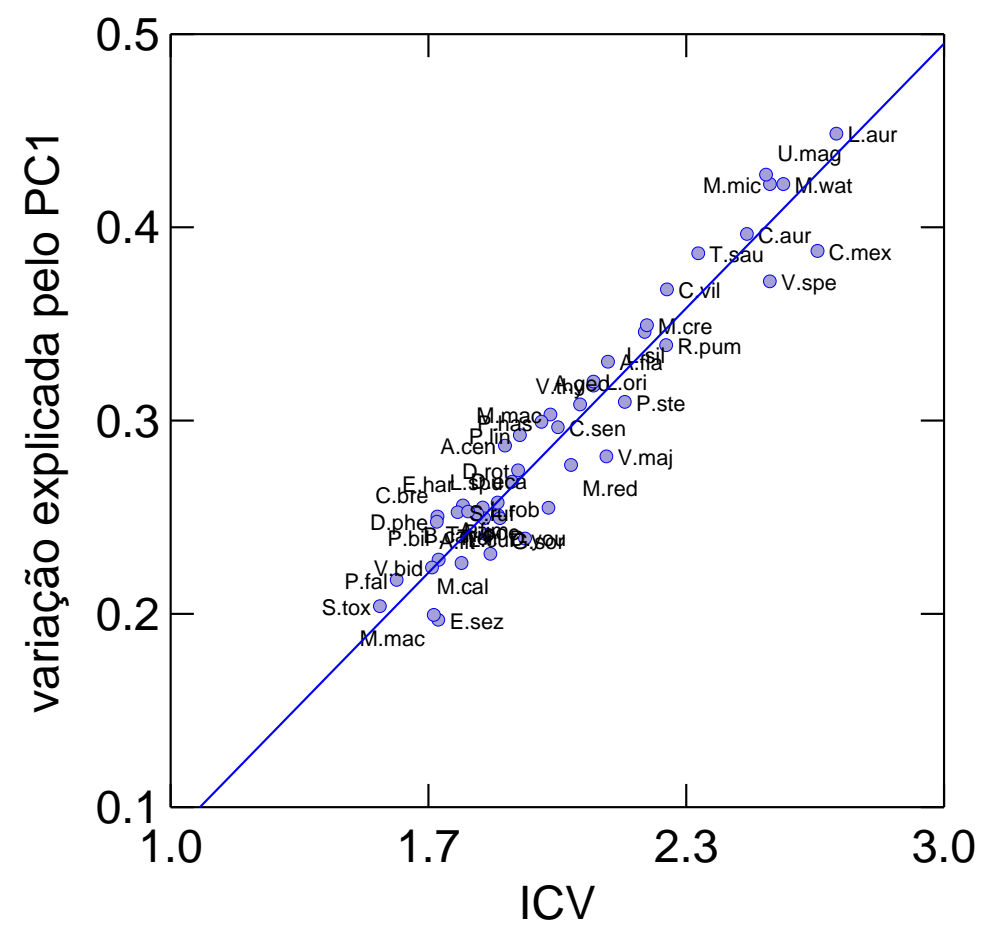

Figura 4.17 - Relação entre o índice de integração morfológica (ICV) e a quantidade de variação explicada pelo primeiro componente principal. As duas variáveis foram obtidas a partir da matriz de covariância. 
Tabela 4.20- Conjunto de dados representando a dieta, o índice de magnitude geral de integração $\left(\mathrm{r}^{2}\right)$, índices de flexibilidade e restrição evolutivas, quantidade de variação no primeiro componente principal (PC1), quantidade relativa de tamanho (iso relativa) e em qual componente tamanho foi detectado(tamanho).

\begin{tabular}{|c|c|c|c|c|c|c|c|}
\hline Espécies & dieta & $r^{2}$ & flexibilidade & restrição & PC1 & iso relativa & tamanho \\
\hline Ametrida centurio & $\mathrm{F}$ & 0.09 & 0.52 & 0.64 & 0.29 & 0.20 & PC1 \\
\hline Artibeus fimbriatus & $\mathrm{F}$ & 0.07 & 0.52 & 0.57 & 0.25 & 0.16 & PC1 \\
\hline Artibeus lituratus & $\mathrm{F}$ & 0.07 & 0.51 & 0.56 & 0.25 & 0.18 & PC1 \\
\hline Carollia brevicauda & $\mathrm{F}$ & 0.07 & 0.55 & 0.59 & 0.25 & 0.16 & PC1 \\
\hline Chiroderma villosum & $\mathrm{F}$ & 0.12 & 0.46 & 0.70 & 0.37 & 0.26 & PC1 \\
\hline Chrotopterus auritus & $\mathrm{C}$ & 0.12 & 0.43 & 0.71 & 0.40 & 0.24 & PC1 \\
\hline Dermanura phaeotis & $\mathrm{F}$ & 0.07 & 0.55 & 0.58 & 0.25 & 0.17 & PC1 \\
\hline Enchisthenes hartii & $\mathrm{F}$ & 0.07 & 0.53 & 0.59 & 0.26 & 0.16 & PC1 \\
\hline Erophylla sezekorni & $\mathrm{N}$ & 0.06 & 0.53 & 0.47 & 0.20 & 0.13 & PC1 \\
\hline Lonchophylla robusta & $\mathrm{N}$ & 0.07 & 0.47 & 0.56 & 0.25 & 0.14 & PC1 \\
\hline Lophostoma silvicolum & I & 0.11 & 0.45 & 0.68 & 0.35 & 0.25 & PC1 \\
\hline Mesophylla macconnelli & $\mathrm{F}$ & 0.09 & 0.50 & 0.63 & 0.30 & 0.16 & PC1 \\
\hline Micronycteris microtis & I & 0.15 & 0.44 & 0.75 & 0.42 & 0.32 & PC1 \\
\hline Mimon crenulatum & I & 0.12 & 0.46 & 0.67 & 0.35 & 0.27 & PC1 \\
\hline Phylloderma stenops & I & 0.12 & 0.45 & 0.60 & 0.31 & 0.14 & PC1 \\
\hline Phyllostomus hastatus & I & 0.08 & 0.50 & 0.62 & 0.30 & 0.21 & PC1 \\
\hline Platyrrhinus vittatus & $\mathrm{F}$ & 0.08 & 0.52 & 0.62 & 0.29 & 0.19 & PC1 \\
\hline Stenoderma rufum & $\mathrm{F}$ & 0.07 & 0.53 & 0.58 & 0.25 & 0.18 & PC1 \\
\hline Tonatia saurophila & I & 0.12 & 0.45 & 0.72 & 0.39 & 0.27 & PC1 \\
\hline Trachops cirrhosus & $\mathrm{C}$ & 0.07 & 0.52 & 0.56 & 0.25 & 0.16 & PC1 \\
\hline Trinycteris nicefori & I & 0.07 & 0.53 & 0.57 & 0.25 & 0.18 & PC1 \\
\hline Uroderma magnirostrum & $\mathrm{F}$ & 0.14 & 0.45 & 0.75 & 0.43 & 0.32 & PC1 \\
\hline Vampyressa thyone & $\mathrm{F}$ & 0.10 & 0.48 & 0.65 & 0.32 & 0.21 & PC1 \\
\hline Ariteus flavescens & $\mathrm{F}$ & 0.09 & 0.48 & 0.65 & 0.33 & 0.13 & PC2 \\
\hline Centurio senex & $\mathrm{F}$ & 0.08 & 0.49 & 0.61 & 0.30 & 0.11 & PC2 \\
\hline Lonchorhina aurita & I & 0.06 & 0.41 & 0.76 & 0.45 & 0.08 & PC2 \\
\hline Lonchorhina orinocensis & I & 0.07 & 0.48 & 0.63 & 0.32 & 0.10 & PC2 \\
\hline Macrophyllum macrophyllum & I & 0.06 & 0.54 & 0.49 & 0.20 & 0.13 & PC2 \\
\hline Sphaeronycteris toxophyllum & $\mathrm{F}$ & 0.05 & 0.57 & 0.51 & 0.20 & 0.10 & PC2 \\
\hline Vampyrodes major & $\mathrm{F}$ & 0.08 & 0.47 & 0.58 & 0.28 & 0.18 & PC2 \\
\hline Anoura geoffroyi & $\mathrm{N}$ & 0.06 & 0.48 & 0.63 & 0.31 & 0.12 & diluído \\
\hline Brachyphylla cavernarum & $\mathrm{N}$ & 0.07 & 0.51 & 0.55 & 0.24 & 0.09 & diluído \\
\hline Choeronycteris mexicana & $\mathrm{N}$ & 0.09 & 0.38 & 0.67 & 0.39 & 0.11 & diluído \\
\hline Desmodus rotundus & $\mathrm{H}$ & 0.06 & 0.51 & 0.59 & 0.27 & 0.15 & diluído \\
\hline Diaemus youngi & $\mathrm{H}$ & 0.06 & 0.51 & 0.55 & 0.25 & 0.10 & diluído \\
\hline Diphylla ecaudata & $\mathrm{H}$ & 0.06 & 0.51 & 0.56 & 0.26 & 0.10 & diluído \\
\hline Glossophaga soricina & $\mathrm{N}$ & 0.07 & 0.50 & 0.55 & 0.25 & 0.11 & diluído \\
\hline Leptonycteris curasoae & $\mathrm{N}$ & 0.06 & 0.49 & 0.52 & 0.24 & 0.12 & diluído \\
\hline Lionycteris spurrelli & $\mathrm{N}$ & 0.07 & 0.51 & 0.60 & 0.27 & 0.15 & diluído \\
\hline Macrotus californicus & I & 0.06 & 0.52 & 0.54 & 0.23 & 0.13 & diluído \\
\hline Macrotus waterhousii & I & 0.12 & 0.42 & 0.76 & 0.42 & 0.18 & diluído \\
\hline Monophyllus redmani & $\mathrm{N}$ & 0.06 & 0.48 & 0.58 & 0.28 & 0.08 & diluído \\
\hline Phyllonycteris poeyi & $\mathrm{N}$ & 0.06 & 0.50 & 0.52 & 0.23 & 0.13 & diluído \\
\hline Phyllops falcatus & $\mathrm{F}$ & 0.05 & 0.56 & 0.52 & 0.22 & 0.11 & diluído \\
\hline Pygoderma bilabiatum & $\mathrm{F}$ & 0.06 & 0.54 & 0.52 & 0.23 & 0.13 & diluído \\
\hline Rhinophylla pumilio & $\mathrm{F}$ & 0.08 & 0.44 & 0.64 & 0.34 & 0.13 & diluído \\
\hline Vampyriscus bidens & $\mathrm{F}$ & 0.06 & 0.54 & 0.52 & 0.22 & 0.13 & diluído \\
\hline Vampyrum spectrum & $\mathrm{C}$ & 0.12 & 0.40 & 0.67 & 0.37 & 0.15 & diluído \\
\hline
\end{tabular}




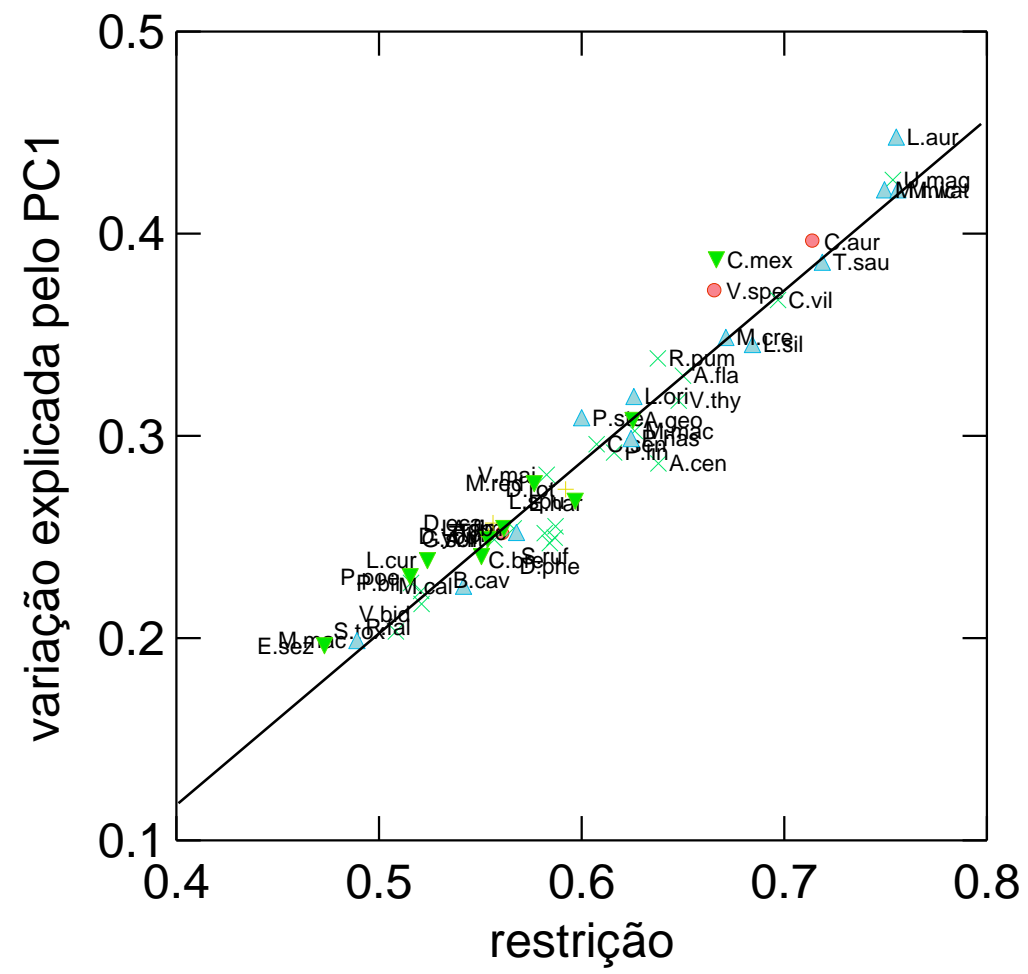

dieta

○ C

$\times \mathrm{F}$

$+\mathrm{H}$

$\triangle 1$

$\nabla N$

Figura 4.18- Relação entre o índice de restrição evolutiva e a quantidade de variação explicada pelo primeiro componente principal. As duas variáveis foram obtidas a partir da matriz de covariância. O hábito alimentar das espécies está apresentado no gráfico.

Tabela 4.21- Resultados da correlação entre os índices de flexibilidade e restrição e a quantidade de variação explicada pelo primeiro componente principal (extraído da matriz de covariância) e a variação relativa relacionada ao tamanho.

\begin{tabular}{cllll}
\hline \hline Índices & \multicolumn{2}{c}{ Flexibilidade } & \multicolumn{3}{c}{ Restrição } \\
\hline Índices & $\mathbf{r}$ & $\mathbf{p}$ & $\mathbf{r}$ & $\mathbf{p}$ \\
\hline Variação no PC1 (cov) & -0.874 & $<0.001$ & 0.975 & $<0.001$ \\
Variação relativa & -0.266 & 0.068 & 0.61 & $<0.001$ \\
\hline \hline
\end{tabular}




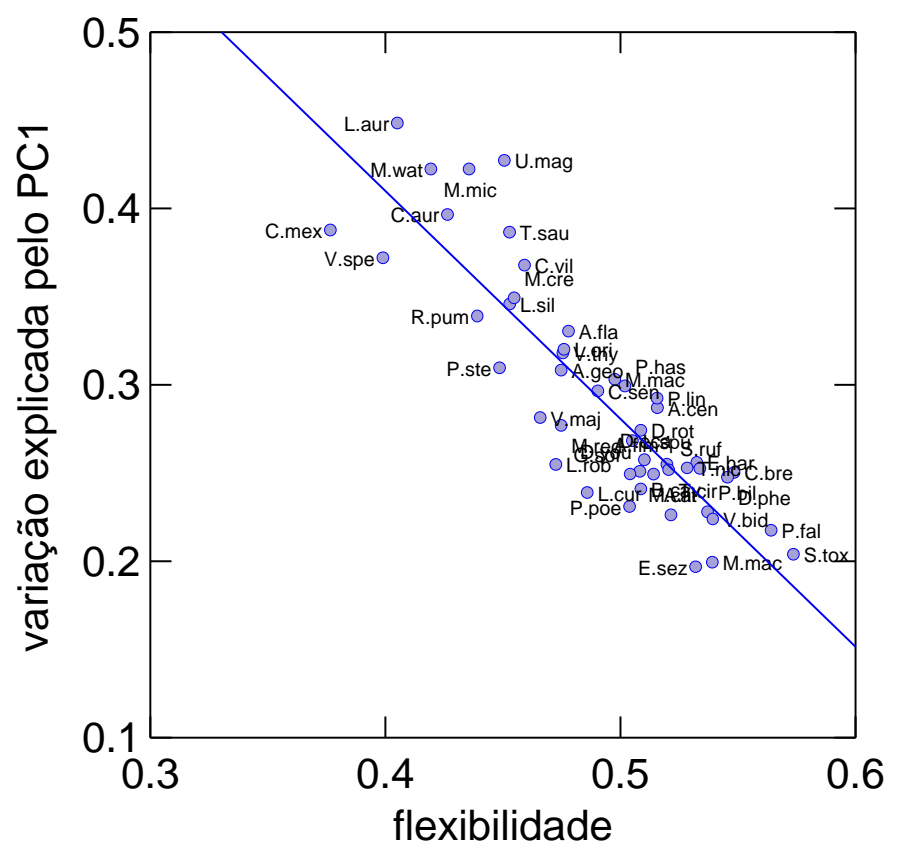

Figura 4.19- Relação entre o índice de flexibilidade evolutiva e a quantidade de variação explicada pelo primeiro componente principal. As duas variáveis foram obtidas a partir da matriz de covariância.

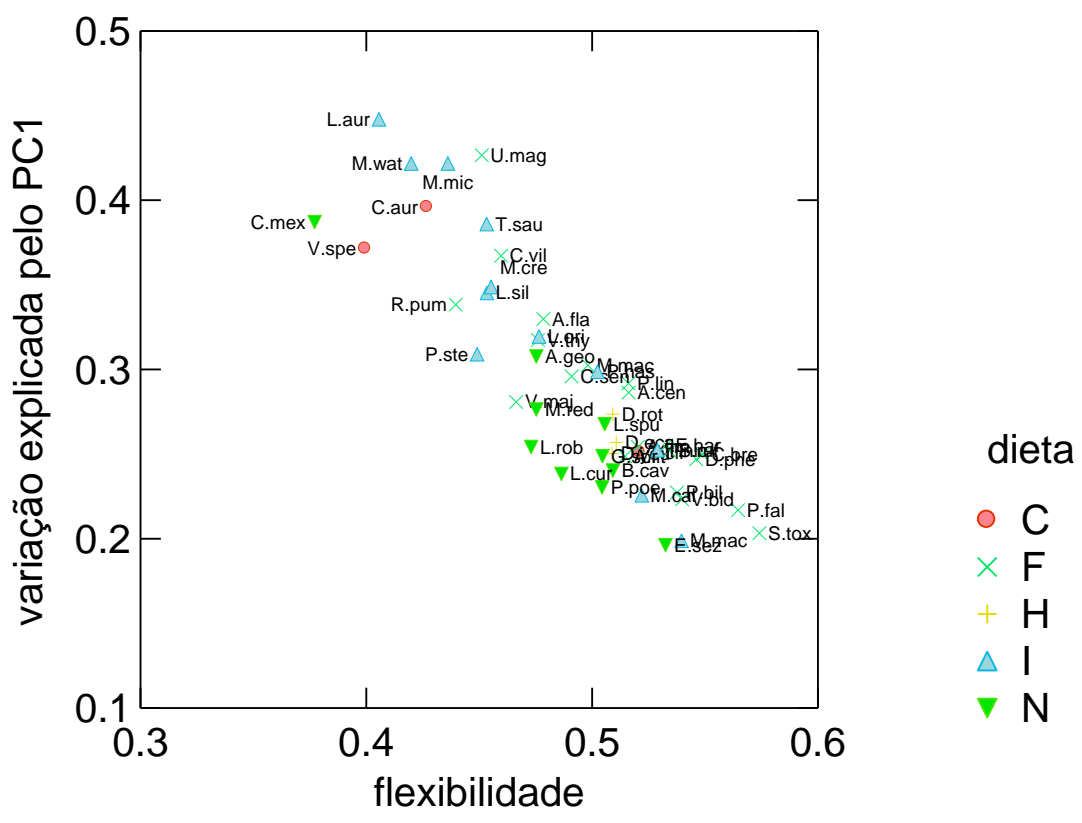

Figura 4.20- Relação entre o índice de flexibilidade evolutiva e a quantidade de variação explicada pelo primeiro componente principal. As duas variáveis foram obtidas a partir da matriz de covariância. O hábito alimentar das espécies está apresentado no gráfico. 


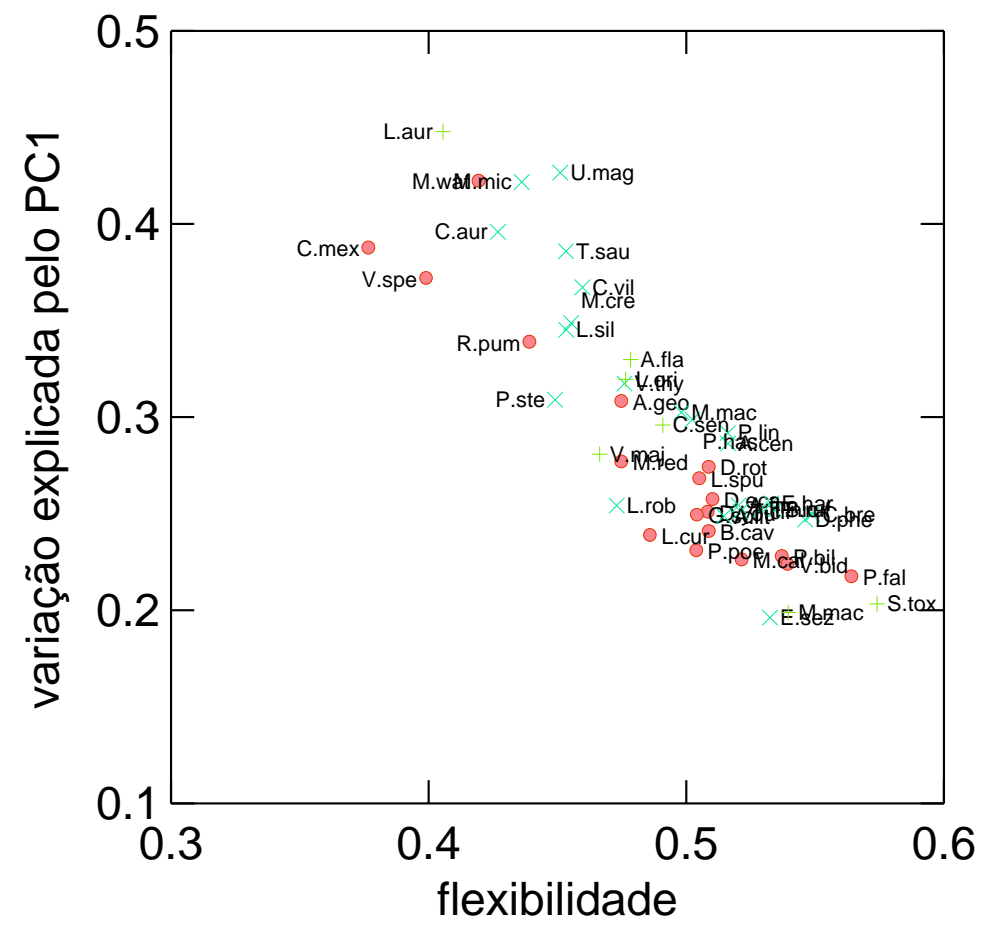

tamanho

- diluído

PC1

PC2

Figura 4.21- Relação entre o índice de flexibilidade evolutiva e a quantidade de variação explicada pelo primeiro componente principal. As duas variáveis foram obtidas a partir da matriz de covariância. O tamanho alométrico é apresentado no gráfico, sendo que espécies representadas por um X mostram variação de tamanho no primeiro CP; nas representadas por + o tamanho de expressa no segundo $\mathrm{CP}$; e o circulo fechado indica que tamanho não é capturado nem pelo primeiro nem pelo segundo CP (diluído).

\subsection{Morcegos filostomídeos no contexto dos demais mamíferos}

Na Tabela 4.22 apresento os resultados das estatísticas básicas calculadas para os índices de magnitude de integração ( $\mathrm{r}^{2}$ e ICV). Os resultados são apresentados comparativamente entre os morcegos filostomídeos que fazem parte deste estudo e os demais grupos de mamíferos examinados por Porto et al., (2009) e Marroig et al., (2009). Da mesma forma, nas Tabela 4.23,Tabela 4.24 e Tabela 4.25 apresento as estatísticas básicas comparativas para flexibilidade, restrição e variação no primeiro CP (obtidas a partir das matrizes de covariância), 
respectivamente. Visando facilitar a escrita ao longo do texto e em exemplos gráficos, refiro-me ao grupo de mamíferos examinados por Marroig et al., (2009) como “demais mamíferos".

Tabela 4.22- Estatísticas básicas calculadas para os índices de magnitude de integração ( $\mathrm{r}^{2} \mathrm{e}$ ICV), apresentadas comparativamente entre os morcegos filostomídeos que fazem parte deste estudo e os demais grupos de mamíferos examinados por Marroig et al., (2009).

\begin{tabular}{|c|c|c|c|c|}
\hline \multirow{2}{*}{$\begin{array}{c}\text { Grupos } \\
\text { Índices de Integração } \\
\end{array}$} & \multicolumn{2}{|c|}{ Phyllostomidae } & \multicolumn{2}{|c|}{ Mamíferos (Marroig et al., 2009) } \\
\hline & $r^{2}$ & ICV & $r^{2}$ & ICV \\
\hline Mínimo & 0.046 & 1.545 & 0.049 & 1.574 \\
\hline Máximo & 0.15 & 2.725 & 0.444 & 4.741 \\
\hline Média & 0.082 & 2.013 & 0.173 & 2.912 \\
\hline Desvio padrão $(\sigma)$ & 0.026 & 0.308 & 0.114 & 1.003 \\
\hline Variância & 0.001 & 0.095 & 0.013 & 1.006 \\
\hline
\end{tabular}

É possível notar que os valores mínimos referentes à magnitude geral de integração entre os caracteres foram bastante similares comparativamente (Tabela 4.22). Sphaeronyctreis toxophyllum, representante da Subfamília Stenodermatinae apresentou o menor valor de $\mathrm{r}^{2}$ para os filostomídeos (0.046), equiparando-se às mais baixas magnitudes de integração já descritas em mamíferos, na qual se destaca o gênero Homo (0.049). Por sua vez, o valor máximo de $\mathrm{r}^{2}$ exibido pelos demais mamíferos superou em três vezes aquele observado em morcegos filostomídeos.

Enquanto a área de distribuição de valores de $\mathrm{r}^{2}$ ocupada pelos filostomídeos é estreita, a faixa de valores de flexibilidade desse grupo se sobrepõe em grande parte àquela ocupada pelos demais mamíferos (Tabela 4.23), principamente no que tange valores mais elevados. O filostomídeos alcançam o valor máximo de flexibilidade evolutiva observado nos demais mamíferos. No que se refere a estes últimos, existem nove ordens e um gênero que apresentam valores de flexibilidade abaixo daqueles apresentados pelos filostomídeos. 
A estatística básica do índice de restrição evolutiva está disposta na Tabela 4.24. Considerando-se os demais mamíferos, o gênero de primatas do novo mundo, Callithrix, apresentou o menor valor de restrição (0.55) enquanto a ordem Peramelimorphia mostrou-se mais restrita evolutivamente (0.93). Dentre os filostomídeos, a espécie nectarívora Erophylla sezekorni, representante da subfamília Glossophaginae apresentou o menor valor de índice e restrição (0.47) e Macrotus watterhousi o maior (0.75).

Por fim, a quantidade de variação máxima explicada pelo primeiro CP nos demais mamíferos (0.80, ordem Peramelimorphia) supera em duas vezes a observada em morcegos filostomídeos (0.44, Lonchorbina aurita) (Tabela 4.25). O gênero Homo e a espécie Erophylla sezekorni, compõem respectivamente os exemplos dos demais mamíferos e filostomídeos que possuem menor quantidade de variação no primeiro CP.

Tabela 4.23 - Estatísticas básicas calculadas para o índices de flexibilidade evolutiva, apresentadas comparativamente entre os morcegos filostomídeos que fazem parte deste estudo e os demais grupos de mamíferos examinados por Marroig et al., (2009).

\begin{tabular}{lc|c}
\hline \hline & Grupos & Mamíferos (Marroig et al., 2009) \\
\hline \multicolumn{1}{c|}{ Índice } & Flexibilidade & Flexibilidade \\
\hline Mínimo & 0.377 & 0.26 \\
Máximo & 0.574 & 0.578 \\
Média & 0.491 & 0.405 \\
Desvio padrão $(\sigma)$ & 0.044 & 0.101 \\
Variância & 0.002 & 0.01 \\
\hline \hline
\end{tabular}


Tabela 4.24- Estatísticas básicas calculadas para o índices de restrição evolutiva, apresentadas comparativamente entre os morcegos filostomídeos que fazem parte deste estudo e os demais grupos de mamíferos examinados por Marroig et al., (2009).

\begin{tabular}{lc|c}
\hline \hline \multicolumn{1}{c|}{ Grupos } & Phyllostomidae & Mamíferos (Marroig et al., 2009) \\
\hline \multicolumn{1}{c}{ Índices } & Restrição & Restrição \\
\hline Mínimo & 0.473 & 0.55 \\
Máximo & 0.756 & 0.93 \\
Média & 0.605 & 0.757 \\
Desvio padrão $(\sigma)$ & 0.073 & 0.13 \\
Variância & 0.005 & 0.017 \\
\hline \hline
\end{tabular}

Tabela 4.25- Estatísticas básicas calculadas para a porcentagem total de variação no primeiro componente principal (obtidas a partir das matrizes de covariância); e apresentadas comparativamente entre os morcegos filostomídeos que fazem parte deste estudo e os demais grupos de mamíferos examinados por Marroig et al., (2009).

\begin{tabular}{lc|c}
\hline \hline \multicolumn{1}{c|}{ Grupos } & Phyllostomidae & Mamíferos (Marroig et al., 2009) \\
\hline \multicolumn{1}{c}{ Índices } & Variação no CP1 & Variação no CP1 \\
\hline Mínimo & 0.196 & 0.23 \\
Máximo & 0.448 & 0.804 \\
Média & 0.292 & 0.477 \\
Desvio padrão $(\sigma)$ & 0.066 & 0.187 \\
Variância & 0.004 & 0.035 \\
\hline \hline
\end{tabular}

Nas Tabelas 4.26, 4.27 e 4.28 apresento também de forma comparativa os resultados de correlação para os índices de flexibilidade, restrição, $\mathrm{r}^{2}$, ICV, quantidade de variação no primeiro CP e avg+/avg- considerando-se integração total e neuroface. Neste contexto, a Tabela 4.26 mostra os resultados para morcegos da Família Phyllostomidae que compõem o presente estudo. A Tabela 4.27 contempla os demais grupos de mamíferos investigados por Marroig et al., (2009) e a Tabela 4.28 mostra os resultados de correlação para filostomídeos e demais mamíferos quando analisados em conjunto. 
Em uma primeira análise das tabelas comparativas é possível observar valores mais baixos de correlação em alguns índices quando comparamos isoladamente filostomídeos aos demais mamíferos. É notória por exemplo, a baixa correlação entre os índices de magnitude geral de integração entre os caracteres do crânio em filostomídeos (0.76), comparado aos demais mamíferos (0.96). Essa correlação aumenta para 0.93 quando analiso todos os grupos conjuntamente (Tabela 4.28). Na Figura 4.22, apresento o gráfico da correlação entre os índices de magnitude de integração considerando os filostomídeos e demais mamíferos.

Tabela 4.26- Correlação entre os índices de flexibilidade, restrição, $\mathrm{r}^{2}, \mathrm{ICV}$, quantidade de variação no primeiro CP e avg+/avg- considerando-se integração total e neuroface. Os resultados são todos significativos $(\mathrm{p}<0.001)$ e apresentados para os morcegos da Família Phyllostomidae que compõem o presente estudo.

Família Phyllostomidae (presente estudo)

\begin{tabular}{lccccc}
\hline & Flexibilidade & Restrição & In r2 & ICV & CP1 \\
\hline Flexibilidade & 1 & & & & \\
Restrição & -0.777 & 1 & & & \\
In r2 & -0.707 & 0.814 & 1 & & \\
ICV & -0.967 & 0.887 & 0.763 & 1 & \\
PC1 & -0.874 & 0.975 & 0.802 & 0.961 & 1 \\
Neuroface & 0.215 & -0.176 & -0.359 & -0.224 & -0.186 \\
Total & 0.1 & -0.43 & -0.481 & -0.193 & -0.265 \\
\hline \hline
\end{tabular}


Tabela 4.27- Correlação entre os índices de flexibilidade, restrição, $\mathrm{r}^{2}$, ICV, quantidade de variação no primeiro CP e avg+/avg- considerando-se integração total e neuroface. Os resultados são todos significativos $(\mathrm{p}<0.001)$ e apresentados para o grupo dos demais mamíferos investigados por Marroig et al., (2009).

Demais mamíferos (Marroig et al., 2009)

\begin{tabular}{lccccc}
\hline & Flexibilidade & Restrição & In r2 & ICV & CP1 \\
\hline Flexibilidade & 1 & & & & \\
Restrição & -0.952 & 1 & & & \\
In r2 & -0.961 & 0.923 & 1 & & \\
ICV & -0.981 & 0.956 & 0.963 & 1 & \\
PC1 & -0.975 & 0.975 & 0.957 & 0.996 & 1 \\
Neuroface & 0.81 & -0.798 & -0.82 & -0.783 & -0.786 \\
Total & 0.907 & -0.872 & -0.88 & -0.862 & -0.861 \\
\hline \hline
\end{tabular}

Tabela 4.28- Correlação entre os índices de flexibilidade, restrição, $r^{2}$, ICV, quantidade de variação no primeiro CP e avg+/avg- considerando-se integração total e neuroface. Os resultados são todos significativos $(\mathrm{p}<0.001)$ e apresentados conjuntamente para os morcegos da Família Phyllostomidae e para o grupo dos demais mamíferos investigados por Marroig et al., (2009).

Filostomídeos e demais mamíferos (Marroig et al., 2009)

\begin{tabular}{lccccc}
\hline & Flexibilidade & Restrição & In r2 & ICV & CP1 \\
\hline Flexibilidade & 1 & & & & \\
Restrição & -0.914 & 1 & & & \\
In r2 & -0.914 & 0.914 & 1 & & \\
ICV & -0.974 & 0.934 & 0.932 & 1 & \\
PC1 & -0.956 & 0.969 & 0.937 & 0.991 & 1 \\
Neuroface & 0.397 & -0.4 & -0.467 & -0.396 & -0.394 \\
Total & 0.441 & -0.551 & -0.598 & -0.48 & -0.511 \\
\hline \hline
\end{tabular}

Padrão semelhante é observado da correlação entre flexibilidade e o índice de restrição evolutiva. Neste caso, os valores de correlação observados são: -0.77 para filostomídeos, -0.91 para os demais mamíferos e - 0.91 em análise conjunta. Nas Figuras 4.23, 4.24, 4.25 apresento os resultados de correlação de forma gráfica, considerando os três casos respectivamente 
(filostomídeos, demais mamíferos e todos juntos). As ordens Peramelimorphia, Diprotodontia, Didelphimorphia, Hyracoidea, Cingulata, Paucituberculata, Lagomorpha e Carnivora, e o gênero Papio (representante dos primatas do velho mundo), encontram-se na faixa dos valores de restrição e flexibilidade não ocupada pelos filostomídeos. Neste espaço, esses mamíferos apresentam os maiores valores de restrição evolutiva, e os menores valores de flexibilidade.

Obtive correlações altamente significativas entre o índice de magnitude geral de integração (ICV) e os índices de flexibilidade e restrição evolutivas (Tabela 4.26, Tabela 4.27, Tabela 4.28). Apresento os gráficos destas correlações nas Figuras 4.26 e 4.27, incluindo os morcegos filostomídeos e demais mamíferos. Quando comparado ao grupo dos demais mamíferos notamos que os morcegos filostomídeos ocupam uma área ampla na escala dos valores de flexibilidade e um espaço estreito no eixo do ICV.

Nos morcegos filostomídeos, detectei correlações mais baixas quando associei flexibilidade e restrição ao índice de magnitude geral de integração obtido através da matriz de correlação $\left(\mathrm{r}^{2}\right)$. Neste caso é possível notar que a correlação entre flexibilidade e o logarítmo de $\mathrm{r}^{2}$ foi igual a -0.70 (Tabela 4.26). Nos demais mamíferos as correlações entre $r^{2}$ e os índices de flexibilidade e restrição permaneceram altas (Tabela 4.27).

Obtive correlações positivas e altamente significativas entre o índice de magnitude geral de integração (ICV) e a quantidade de variação no primeiro CP (Tabela 4.26, 4.27, 4.28). No gráfico (Figura 4.28) é possível observar que aqueles grupos de mamíferos que mostraram os maiores valores de restrição evolutiva, também caracterizam-se por apresentar a maior quantidade de variação no primeiro CP. Nestes grupos, a quantidade de variação no primeiro CP atua como uma força de restrição no potencial de mudança evolutiva. No gráfico é possível observar que os morcegos filostomídeos ocupam uma área estreita na escala dos valores do eixo do ICV.

$\mathrm{Na}$ Figura 4.29, apresento as correlações do índice de modularidade (avg+/ avg-) da neuroface com o índice de flexibilidade para filostomídeos e na Figura 4.30 para os demais 
mamíferos. Os gráficos estão na mesma escala. Como mencionado anteriormente no tópico "Flexibilidade evolutiva e restrição" encontrei correlação positiva e significativa entre flexibilidade e neuroface em morcegos filostomídeos $(\mathrm{r}=0.3 ; \mathrm{p}=0.044)$. Esta correlação é maior (0.81) quando olhamos separadamente para os demais mamíferos (Tabela 4.27), e passa a apresentar o valor de 0.39 quando consideramos os grupos em conjunto (Tabela 4.28).

Da mesma forma, apresento as correlações do índice de modularidade (avg+/ avg-) para a hipótese de integração total com o índice de restrição para filostomídeos (Figura 4.31) e demais mamíferos (Figura 4.32). Nos morcegos filostomídeos o índice de restrição apresentou correlação negativa e significativa com integração total (-0.43). Esta correlação é maior (0.87) quando olhamos para os demais mamíferos (Tabela 4.27), e passa a apresentar o valor de 0.55 quando consider os grupos conjuntamente (Tabela 4.28).

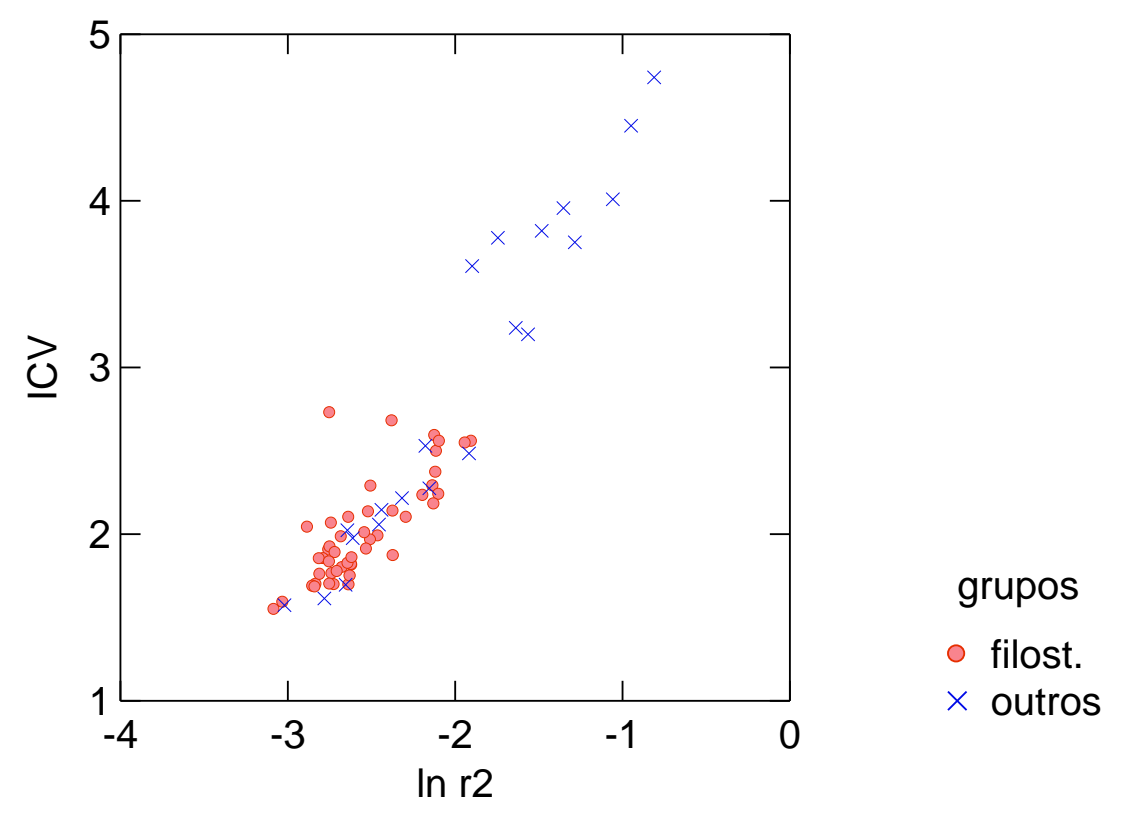

Figura 4.22 - Correlação entre os índices de magnitude geral de integração: $r^{2}$ (obtido a partir da matriz de correlação) e ICV (obtido a partir da matriz de covariância). Círculos fechados representam os morcegos filostomídeos investigados no presente trabalho e o $\mathrm{X}$ representa os demais mamíferos avaliados por Marroig et al., (2009). 


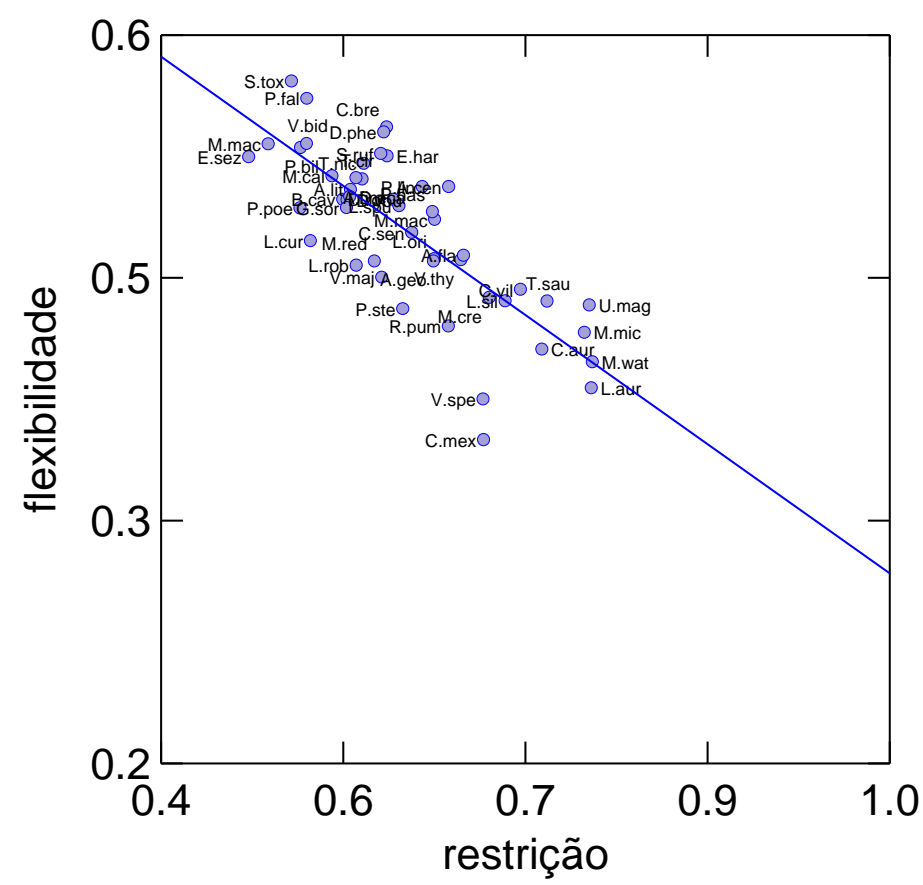

Figura 4.23 - Correlação entre os índices de restrição e flexibilidade evolutivas considerando somente os morcegos da Família Phyllostomidae.

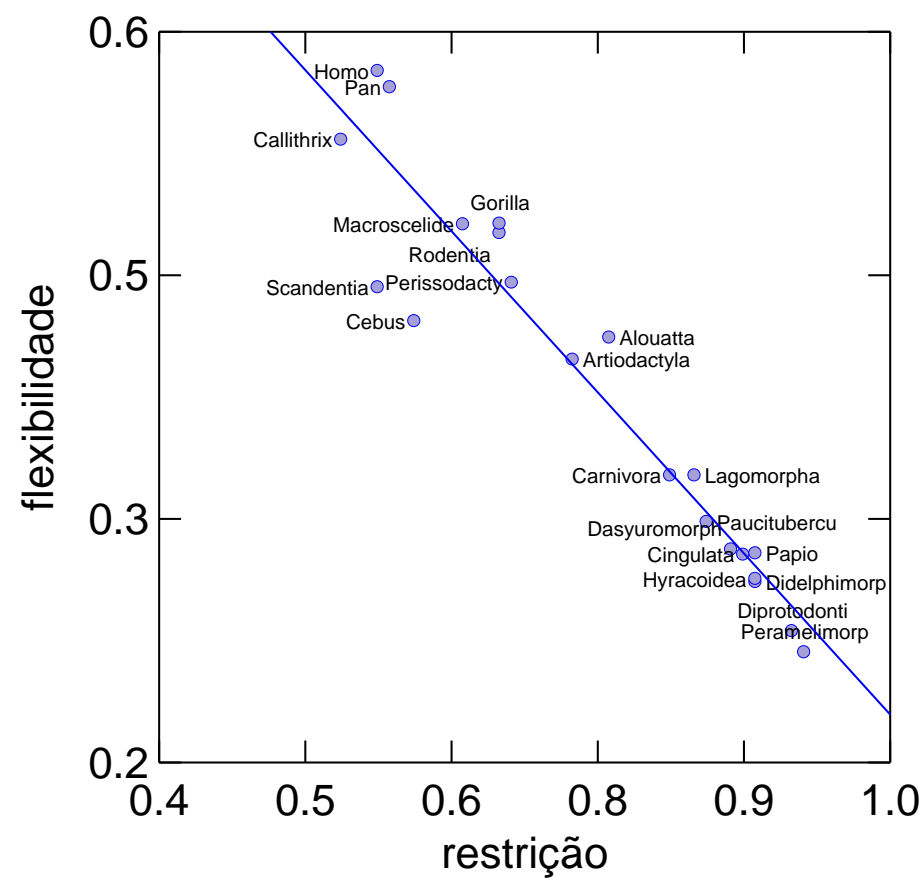

Figura 4.24- Correlação entre os índices de restrição e flexibilidade evolutivas considerando somente os mamíferos estudados por Marroig et al., (2009). 


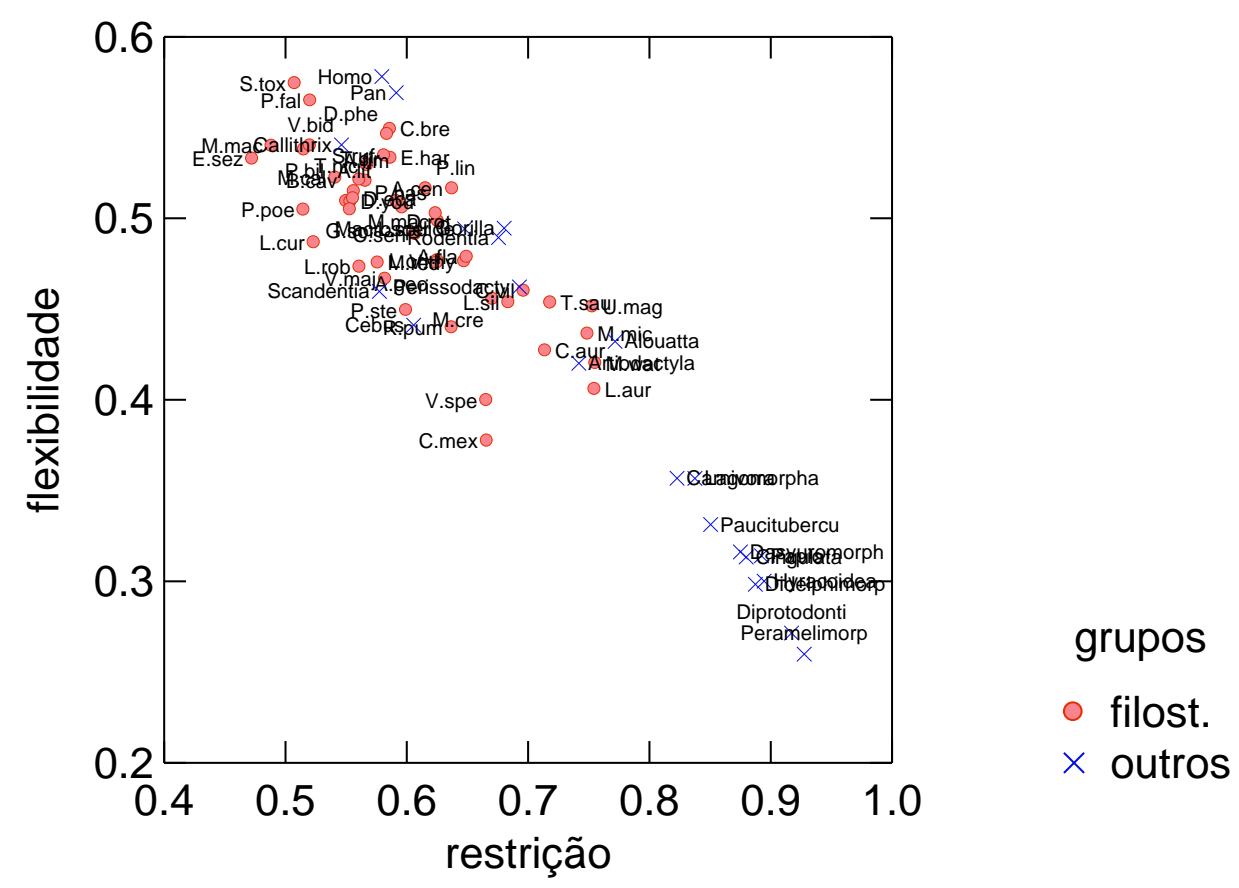

Figura 4.25- Correlação entre os índices de restrição e flexibilidade evolutivas considerando os morcegos filostomídeos (círculo fechado) e o grupo dos demais mamíferos (x) investigados por Marroig et al., (2009).

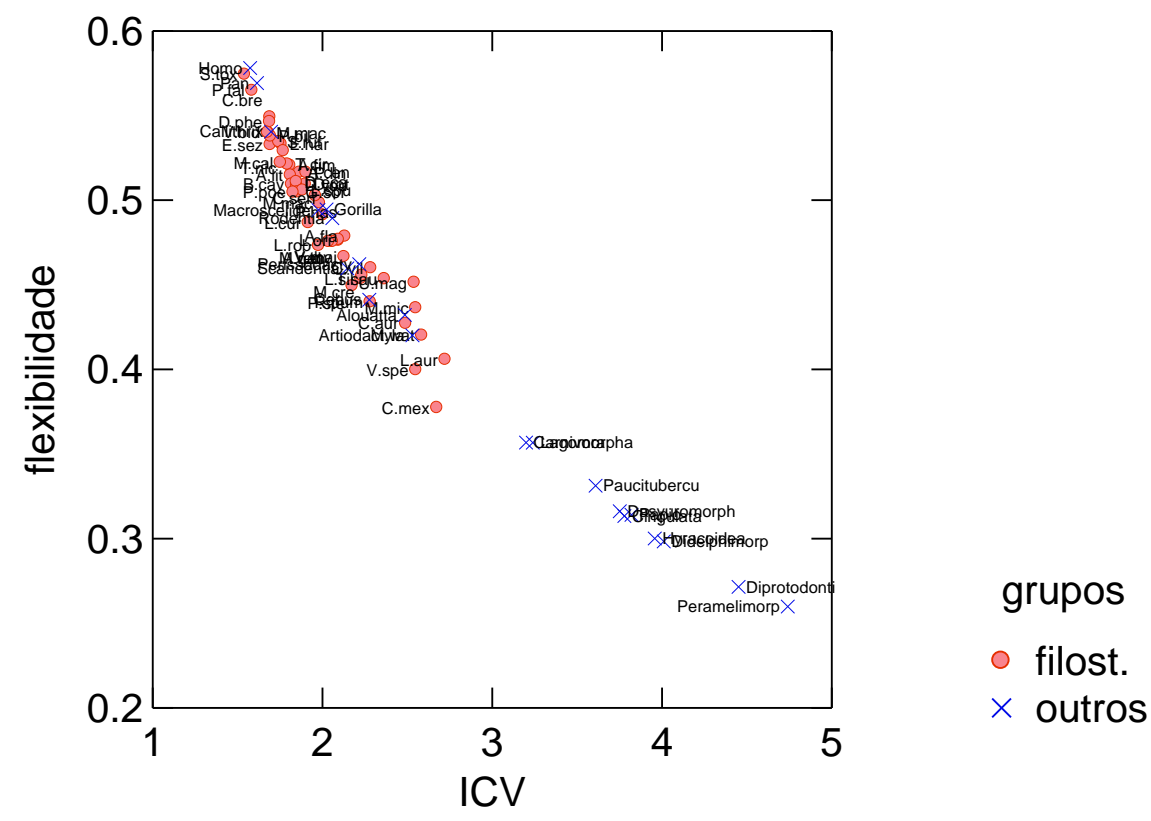

Figura 4.26- Correlação entre o índice de integração geral ICV (obtido a partir das matrizes de covariância) e o índice de flexibilidade evolutiva considerando os morcegos filostomídeos (círculos fechados) e o grupo dos demais mamíferos (x) investigados por Marroig et al., (2009). 


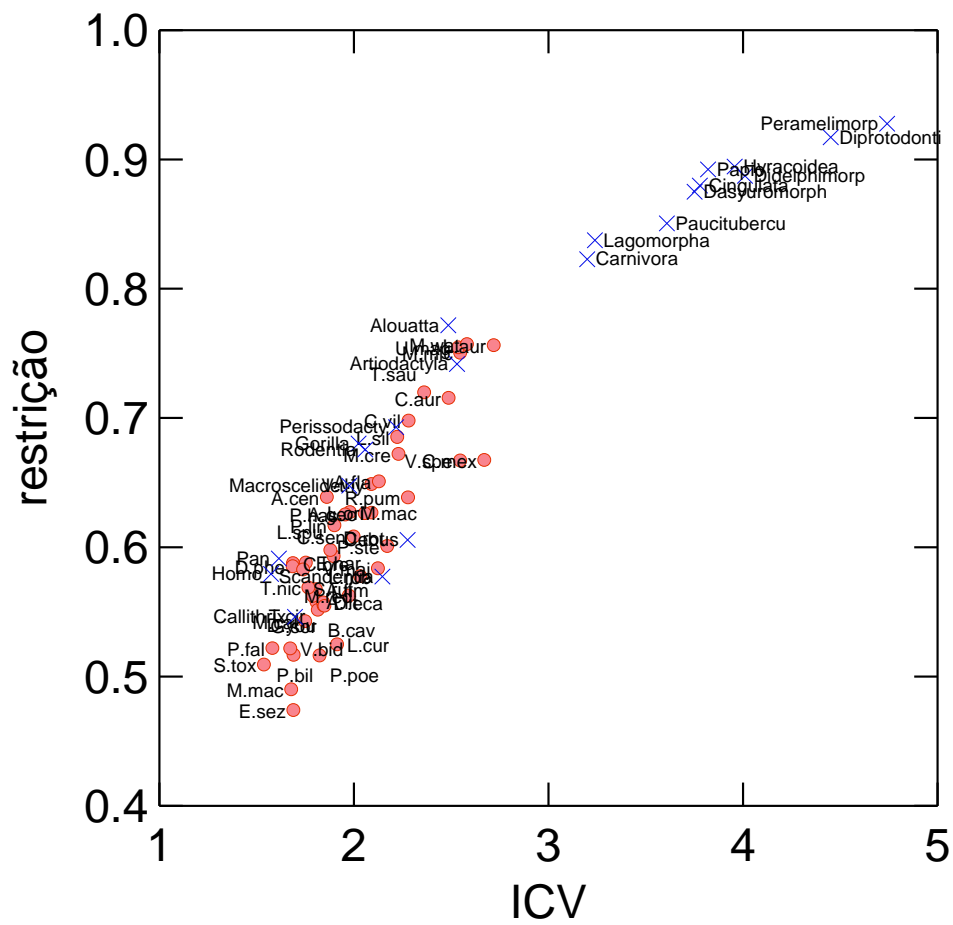

\section{grupos \\ - filost. $\times$ outros}

Figura 4.27- Correlação entre o índice de integração geral ICV (obtido a partir das matrizes de covariância) e o índice de restrição evolutiva considerando os morcegos filostomídeos (círculos fechados) e o grupo dos demais mamíferos (x) investigados por Marroig et al., (2009). 


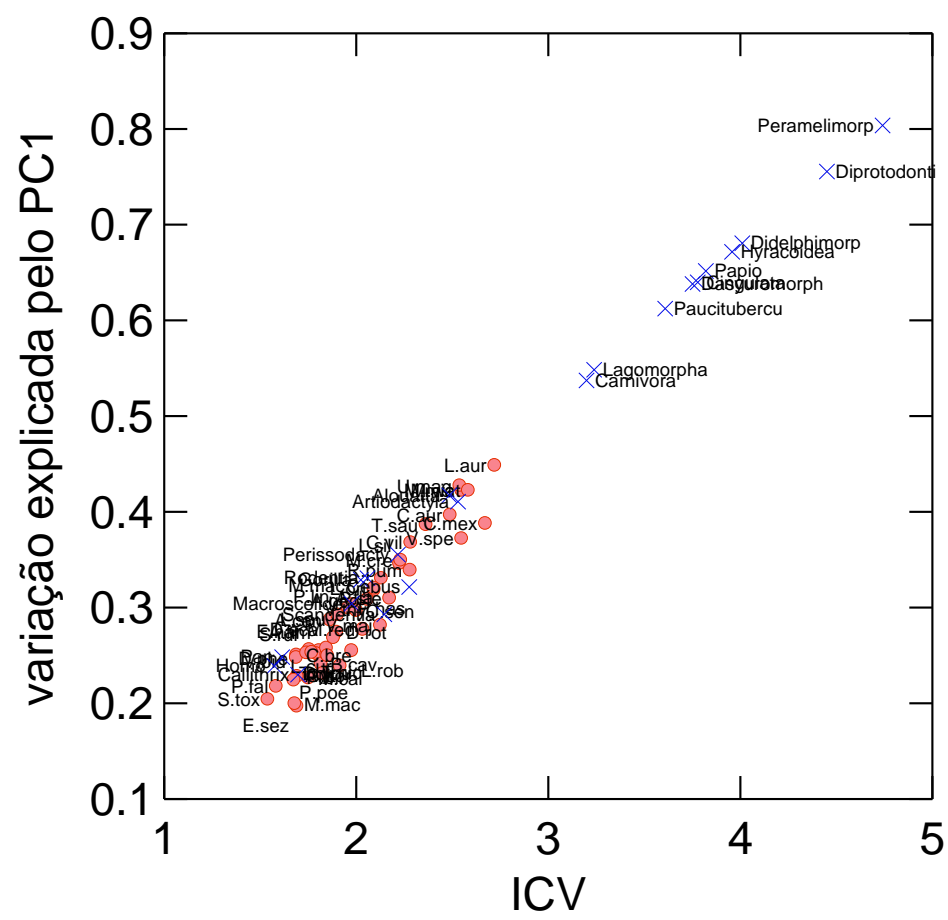

\section{grupos \\ - filost. \\ $\times$ outros}

Figura 4.28- Correlação entre o índice de integração geral ICV e a quantidade de variação explicada pelo primeiro componente principal; ambos obtidos a partir das matrizes de covariância. No gráfico estão representados os morcegos filostomídeos (círculos fechados) e o grupo dos demais mamíferos (x) investigados por Marroig et al., (2009). 


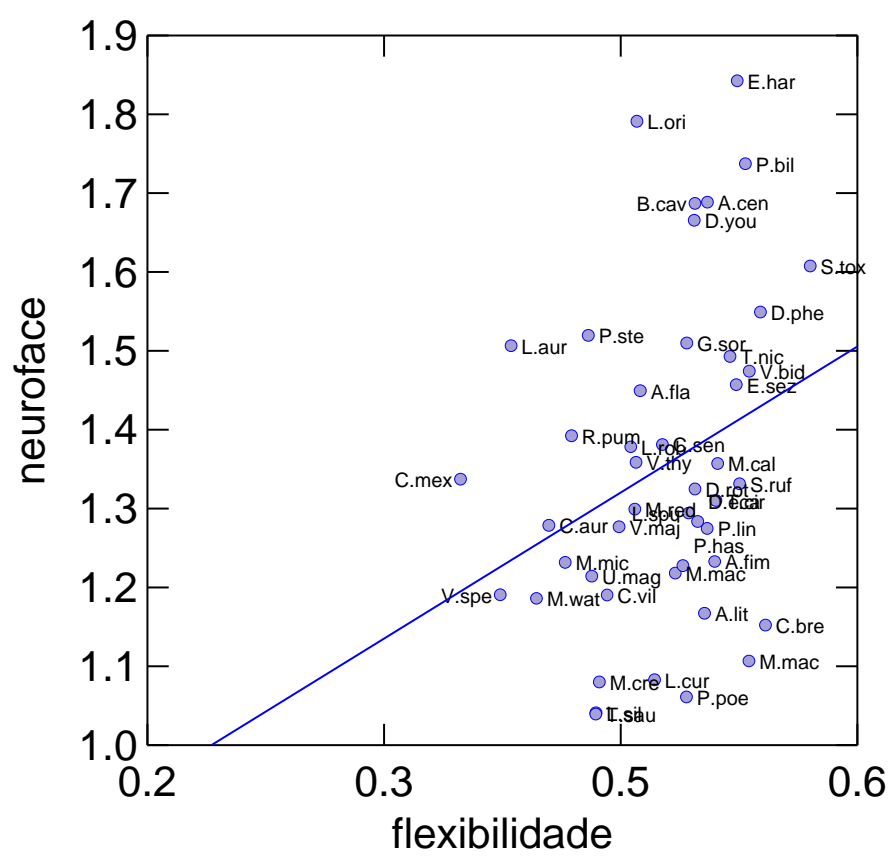

Figura 4.29- Correlação entre o índice de modularidade (avg+/avg-) da neuroface e o índice de flexibilidade evolutiva para morcegos da Família Phyllostomidae.

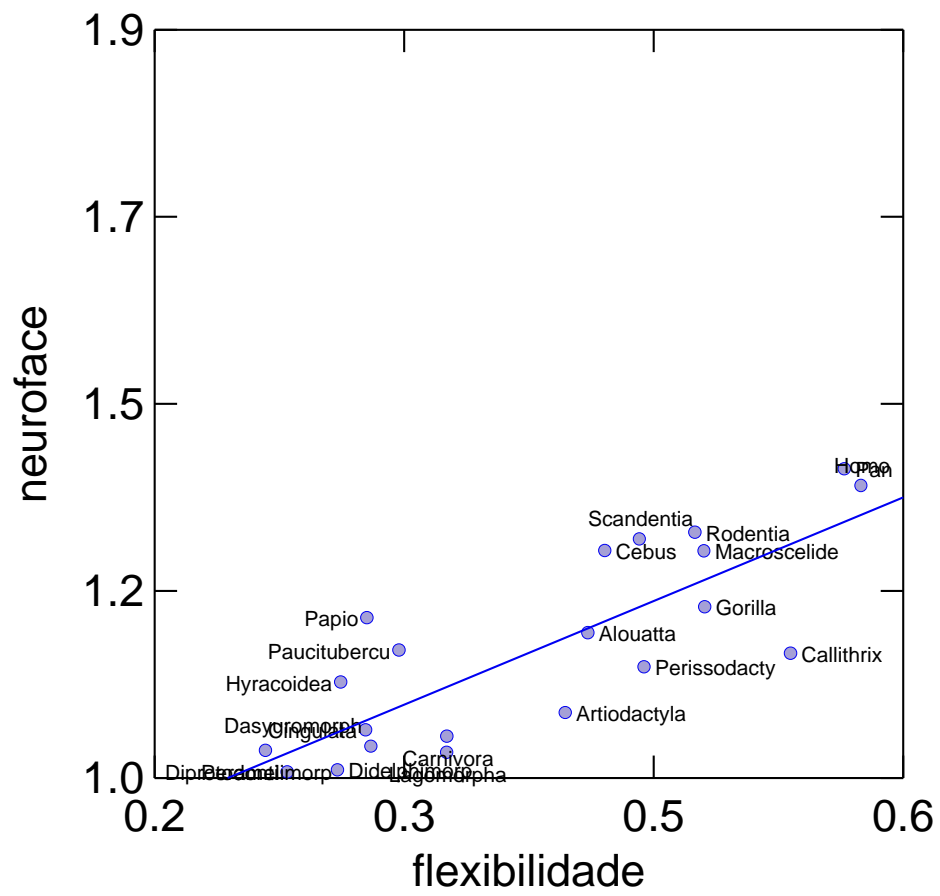

Figura 4.30- Correlação entre o índice de modularidade (avg+/avg-) da neuroface e o índice de flexibilidade evolutiva para o grupo de mamíferos estudados por Marroig et al., (2009). 


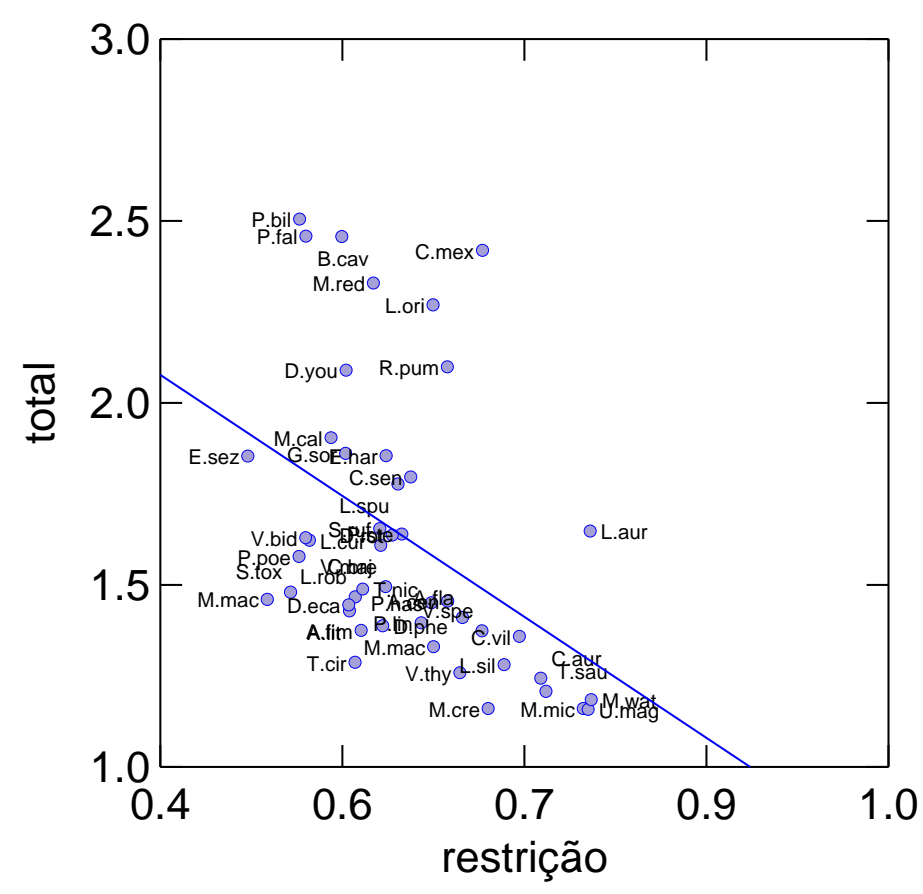

Figura 4.31 - Correlação entre o índice de modularidade (avg+/avg-) para a hipótese de integração total e o índice de restrição evolutiva para morcegos da Família Phyllostomidae.

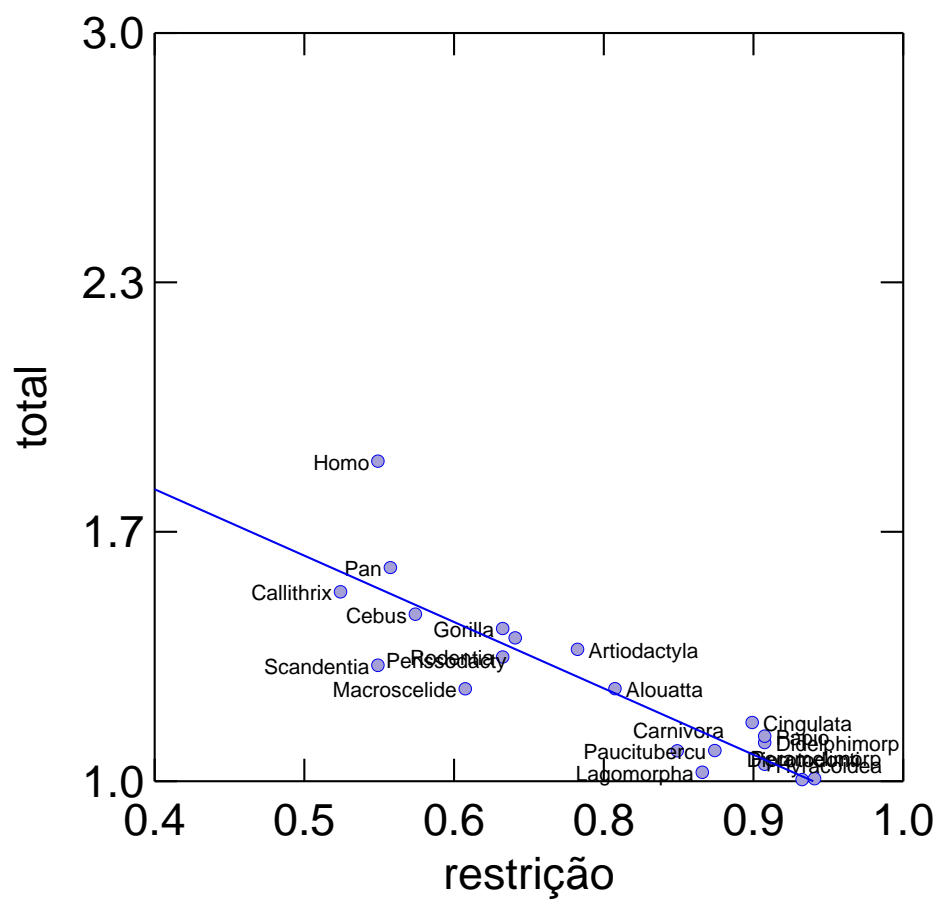

Figura 4.32- Correlação entre o índice de modularidade (avg+/avg-) para a hipótese de integração total e o índice de restrição evolutiva para o grupo de mamíferos estudados por Marroig et al., (2009). 


\section{DISCUSSÃO}

\subsection{Similaridade estrutural das matrizes fenotípicas}

As comparações da estrutura das matrizes fenotípicas, objetivo primordial deste trabalho, revelaram a existência de semelhança significativa nos padrões de correlação e covariação entre as espécies de morcegos da Família Phyllostomidae. Aqui, faço uso de algumas linhas para discutir que a existência de semelhança estrutural alta não é sinônimo de igualdade. Considero este um ponto muito relevante e que exige compreensão. Embora eu tenha observado correlações altas entre as espécies, estas correlações não foram estritamente iguais a um. Uma explicação plausível é a de que uma matriz obtida a partir de uma amostragem populacional, certamente será estimada com algum grau de erro. Esse erro já será suficiente para garantir que as matrizes comparadas não sejam estritamente idênticas ( Cheverud \& Marroig, 2007). Além disso, em populações naturais é improvável que encontremos a mesma estrutura de covariação, já que cada população representa uma entidade única, formada por um número de indivíduos que carregam parte da diversidade genética total das espécies em seus loci (com sua multiplicidade de interações) afetando os fenótipos quantitativos em estudo. Portanto, espera-se a priori que quaisquer populações com reprodução sexuada e recombinação gênica, tenham uma matriz de covariância distinta (Porto et al., 2009).

O meu iteresse se pauta precisamente no quanto de divergência é observada quando as matrizes de correlação e covariância são comparadas. Matrizes estas que refletem a forma, no sentido mais geral da palavra, dos crânios dos morcegos filostomídeos. Desta forma a pergunta é: quão similar é a estrutura de covariação craniana entre os morcegos filostomídeos? Os resultados deste trabalho apontam que elas são suficientemente similares para permitir que estudos que aplicam a genética quantitativa para inferir processos evolutivos sejam realizados utilizando-se 
matrizes fenotípicas com confiança (Marroig \& Cheverud, 2001; Marroig et al., 2009). De fato, quando se considera similaridade e dissimilaridade nos padrões de covariância, algum grau de subjetividade é inevitável, mesmo com rigorosos testes baseados em procedimentos de reamostragem (Marroig \& Cheverud, 2001). Pode-se questionar por exemplo, qual a proporção de divergência na estrutura de covariância seria tolerada para permitir que análises de reconstrução de gradientes de seleção fossem realizadas com confiança? Essa é uma questão que tem sido extensivamente debatida (Arnold \& Phillips, 1999; Cheverud \& Marroig, 2007; Cheverud, 1988; Marroig \& Cheverud, 2001; Shaw et al., 1995; Steppan, 1997; Turelli, 1988), e um longo período de experiência com análises discriminantes levou os pesquisadores à concluir que, desde que a similaridade seja moderada a elevada entre grupos avaliados, o efeito das diferenças nas análises será mínimo (Blackith \& Reyment, 1971; Manly, 1986).

Depois que obtive os resultados de similaridade das matrizes dos morcegos filostomídeos, realizei uma análise de rarefação a fim de avaliar o impacto do erro amostral entre as matrizes. Nessa investigação, selecionei a espécie melhor amostrada em meu trabalho, no caso, representada por 86 indivíduos do morcego hematófago Desmodus rotundus (sendo 43 fêmeas e 43 machos). A análise de rarefação se baseia na correlação de reamostragens aleatórias a partir de uma amostra original (no caso 86 indivíduos), até os menores tamanhos amostrais possíveis. Para cada tamanho amostral são obtidos valores de correlação, o que permite estabelecer uma relação entre essas duas variáveis. No anexo A9 apresento o resultado gráfico considerando todos os tamanhos amostrais possíveis, para matrizes de covariância estimadas pelo método de Random Skewvers e Krzanowski. Considerando uma média geral de aproximadamente 55 indivíduos medidos por espécie, é possível observar que a média dos valores de correlação entre este valor médio é muito similar ao valor de correlação obtido considerando-se 86 indivíduos, tanto entre as comparações realizadas pela projeção de Krzanowski (em torno de 0.85) quanto para Random Skewvers (aproximadamente 0.90). Essa análise foi realizada com o intuito de reforçar ainda mais a 
existência de similaridade estrutural alta entre as matrizes fenotípicas dos morcegos filostomídeos. Para efeito de comparação os valores empíricos médios encontrados aqui foram de 0.75 para RS e 0.80 para Krzanowski o que claramente indica que uma parte substancial da divergência observada na estrutura das matrizes deve ter sido devida ao erro amostral.

Tanto os valores de similaridade média quanto de repetibilidade mostraram-se muito semelhantes quando calculados por meio das matrizes de correlação e de covariância, resultado este que diverge daqueles encontrados por Ackermann, 2002; Cheverud et al., 1989; Marroig \& Cheverud, 2001; Oliveira et al., 2009; Porto et al., 2009. Para estes autores, as comparações das matrizes de covariância resultaram em similaridades e repetibilidades mais altas que aquelas obtidas por meio de comparações das matrizes de correlação. Esta divergência nos resultados pode estar associada aos métodos empregados na comparação das matrizes de correlação. Nos trabalhos citados, as matrizes de correlação foram comparadas por meio de correlação de matrizes elemento por elemento (Cheverud et al., 1989). Esse método equivale a uma correlação linear paramétrica, em que todos os elementos correspondentes em cada matriz (por exemplo, os elementos na coluna 1 e linha 1 das matrizes A e B) são considerados como pontos na análise. No presente estudo, utilizei a projeção de Kræanowski (Krzanowski, 1979) na comparação de matrizes de correlação. Como exposto nos métodos, a análise de Krzanowski considera apenas a metade (menos 1) inicial dos componentes principais totais relativos à matriz em questão. Isso minimiza a influência do erro associado à estimativa das matrizes, uma vez que este geralmente está concentrado nos últimos componentes principais.

No presente estudo, detectei relação significativa entre o número de indivíduos e a similaridade média dos valores observados e ajustados, tanto para matrizes de correlação estimadas por Krzanowski, quanto para as matrizes de covariância estimadas por Krzanowski e RS. A espécie Phylloderma stenops, com o menor número amostral (34) foi a que mais contrbuiu para este resultado. Essa relação entre tamanho amostral e a similaridade média das matrizes já foi 
descrita para outros grupos de mamíferos (Marroig \& Cheverud, 2001, Oliveira et al., 2009, Porto et al., 2009) e é esperada quando olhada sob o prisma da amostragem e número de parâmetros sendo estimados (595 correlações par-a-par).

Os valores de similaridade média e de repetibilidade das matrizes podem ser considerados altos entre os filostomídeos. Os valores médios de repetibilidade das matrizes de correlação estiveram em torno de 0.86 , e valores ainda mais altos foram resgistrados nas matrizes de covariância (valores médios em torno de 0.87 para matrizes de covariância comparadas por Krzanowski, e 0.93 para aquelas comparadas por Random Skewers). Marroig \& Cheverud (2001), encontraram repetibilidades moderadas nas matrizes de correlação em dois gêneros de macacos do novo mundo: Brachyteles (0.43) e Callimico (0.54). Oliveira et al., (2009) também registraram valores abaixo de 0.5 de repetibilidade nas matrizes de correlação em quarto gêneros de macacos do velho mundo (Rhinopithecus, Pygathrix, Simias e Kasi). Estes autores atribuiram esse fato ao tamanho diminuto da amostra representativa destes gêneros.

Entre os morcegos filostomídeos, nenhuma espécie apresentou valores de similaridade média menores que 0.70 para as matrizes de covariância e correlação ajustadas comparadas por Krz. Centurio senex e Phylloderma stenops apresentaram os menores valores de similaridade média considerando as matrizes de covariância e correlação observadas e ajustadas comparadas por Krz. Nas matrizes de covariância comparadas por RS, apenas oito espécies apresentaram valores de similaridade média abaixo de 0.70, sendo Choeronycteris mexicana e Centurio senex responsáveis pelos menores valores (0.62 e 0.63 respectivamente, para valores ajustados). Nas matrizes de covariância comparadas por RS, os menores valores de similaridade observada e ajustada também foram obtidos da comparação entre estas duas espécies. Fato interessante é que neste estudo, Centurio senex e Choeronycteris mexicana representam os maiores extremos de diversidade de forma no que diz respeito à face. Essas espécies distinguem-se respectivamente por um encurtamento e extensão facial notáveis. Freeman (1995) se refere a Centurio senex como "pug-faced" e a 
Choeronycteris mexicana como "long-snouted". Centurio senex é um morcego frugívoro, especializado na ingestão de frutas duras (Dumont et al., 2012; Nogueira et al., 2009; Santana et al., 2010; Santana et al., 2012; Wetterer et al., 2000). O crânio de Centurio é curto e largo, com uma caixa craniana elevada e bastante estreita, praticamente sem rostro e com palato curto e muito largo (Goodwin \& Greenhall, 1961). Por sua vez, Choeronycteris mexicana é nectarívora, possui um rostro alongado, que corresponde a 40 a 50\% do comprimento do crânio (Arroyo-Cabrales et al., 1987), e uma língua longa que se estende a 1/3 do comprimento do corpo. De maneira geral, Centurio senex esteve presente na maioria das comparações que resultaram em valores de similaridade observados e ajustados mais baixos, tanto para matrizes de correlação quanto de covariância (comparadas por $K R Z$ e $R S$ ). Ainda assim, é evidente a similaridade existente nos padrões de correlação e covariação nos caracteres cranianos desse grupo de morcegos tão morfologicamente diverso.

Aqui, um ponto interessante merece reflexão e destaque: Por que observamos tamanha diversidade morfológica craniana (qualitativa), tendo matrizes tão similares? A resposta de tal diversidade observada reside, em parte, no fato das matrizes não serem idênticas. Mais ainda, como as correlações entre os caracteres não são iguais a um, as matrizes têm liberdade evolutiva relativa para mudar. Isto é particularmente verdade nos filostomídeos já que em média as correlações entre os caracteres do crânio variaram entre 0.2 e 0.35 neste grupo. Estes achados corroboram outros estudos em grupos de mamíferos que apresentam variação na morfologia craniana (Ackermann \& Cheverud, 2000; Cheverud, 1996; Marroig \& Cheverud, 2001; Oliveira et al., 2009; Porto et al., 2013; Porto et al., 2009).

Outro ponto relevante é compreendermos como esses padrões são mantidos ao longo da evolução de um grupo. A similaridade nos padrões de covariância descritos aqui está de acordo com observações prévias de padrões comuns de desenvolvimento nos crânios dos mamíferos (Luo, 2011; Moore, 1981; Smith, 1997), e em tetrápodas (Helms et al., 2005; Morriss- 
Kay \& Wilkie, 2005; Noden \& Trainor, 2005; Tapadia et al., 2005). Tal concordância pode ser evidência de que padrões conservados das relações entre os caracteres são mantidos por seleção estabilizadora interna (Cheverud, 1996b; Marroig \& Cheverud, 2001). Este padrão resulta da exigência de coesão estrutural dentro de um organismo, e desta forma o desenvolvimento e a função do crânio são até certo ponto preservadas ao longo da diversificação das linhagens (Porto et al., 2009). Dentro dessa perspectiva, função e desenvolvimento poderiam agir como forças internas responsáveis por manter a estrutura das matrizes. Uma avaliação mais detalhada sobre padrões de integração relacionados às hipóteses de função e desenvolvimento será discutida à frente mas de forma geral a hipótese acima levantada parece ter amplo suporte nos resultados apresentados na seção dessa discussão que aborda "Modularidade no crânio dos morcegos Filostomídeos".

Até o momento analisei o padrão de similaridade estrutural das matrizes fenotípicas em mocegos filostomídeos. É preciso agora incluir a magnitude de integração dos caracteres à esta discussão, pois padrão e magnitude são dois aspectos de um mesmo fenômeno (integração morfológica) e fazem sentido quando interpretados em conjunto.

\subsection{Magnitudes de integração}

A magnitude de integração diz respeito à força da associação entre os caracteres cranianos na matriz. O grau geral de correlação entre as medidas cranianas em filostomídeos variou desde um mínimo de 0.04 (Sphaeronycteris toxophyllum) até um máximo de 0.15 (Micronycteris microtis). Tanto os valores quanto o intervalo de variação observados nos morcegos filostomídeos podem ser considerados baixos em termos absolutos, já que o mínimo e máximo teóricos variam entre zero e um. Trabalhos que investigaram essa métrica em crânios de mamíferos descreveram 
uma amplitude de valores entre 0.04 e 0.55 (Oliveira et al., 2009; Porto et al., 2009). Oliveira (2009) estudou a evolução craniana dos macacos do Velho Mundo (Catarrhini), e encontrou uma variação considerável do $\mathrm{r}^{2}$, desde um mínimo de 0.04 (Homo e Presbytis) até um máximo de 0.28 (Semnopithecus). Dentre os grupos de mamíferos avaliados por (Marroig et al. 2009), os maiores valores de $\mathrm{r}^{2}$ estiveram associados à quatro ordens de Metatheria (Peramelimorphia, Diprotodontia, Didelphimorphia e Dasyuromorphia).

Hubbe (2013) demonstrou precisamente que a métrica de magnitude geral de integração é susceptível à amostras pequenas, podendo apresentar valores maiores em unidades taxonômicas operacionais subamostradas. De acordo com Marroig et al., (2012), matrizes mal estimadas concentram boa parte da variância no primeiro componente principal, simplesmente devido ao erro associado à amostragem. No cálculo da magnitude geral de integração, quanto maior a porcentagem de variância explicada pelo primeiro $\mathrm{CP}$, maior a magnitude geral de integração. Consequentemente, matrizes mal estimadas em decorrência de amostragem pequena apresentarão valores altos de magnitude geral de integração. No presente trabalho as amostras entre as espécies são muito uniformes e, como demonstrado nos resultados, não observei relação significativa entre o número de indivíduos e a magnitude geral de integração.

A abordagem dessa métrica quando feita de forma comparativa entre diferentes grupos de mamíferos, sugere para a Família Phyllostomidae a existência de valores baixos que ocupam uma faixa estreita de dispersão. Porém, olhando o grupo individualmente é possível afirmar que enquanto os padrões estruturais das matrizes de correlação e covariação permaneceram relativamente similares (o coeficiente de variação foi de 11\%), a magnitude geral de integração $\left(\mathrm{r}^{2}\right)$ distinguiu-se mais entre as espécies com um coeficiente de variação de 33 \% (Tabelas 4.5, 4.6 e 4.8). A ausência de associação entre as diferenças par a par no $r^{2}$ entre as espécies e a filogenia, também sugerem que a magnitude das correlações entre os caracteres cranianos é evolutivamente mais plástica que o padrão de associação entre eles. Essa distinção nos valores de $\mathrm{r}^{2}$ entre as 
espécies tem implicações importantes na evolução dos grupos. Duas espécies que apresentam exatamente o mesmo padrão de relação entre os caracteres, mas diferem significativamente na magnitude das correlações poderão apresentar respostas consideravelmente diferentes às forças evolutivas, como seleção natural por exemplo (Hansen \& Houle, 2008; Marroig et al., 2009). Em geral, grupos com baixas magnitudes de integração respondem mais frequentemente na direção dos gradientes de seleção, enquanto altas magnitudes estão associadas a flexibilidades baixas (Hansen \& Houle, 2008; Porto et al., 2009; Marroig et al., 2009). Embora os filostomídeos como grupo possam ser caracterizados como de baixa integração geral comparados aos outos mamíferos claramente existe variação dentro do grupo com algumas espécies chegando a ter em média correlações em torno de 0.39 enquanto outras quase a metade disto $\left(\mathrm{r}^{2} \quad 0.15\right.$ e 0.04 respectivamente).

Os valores baixos de magnitude geral de integração apresentados pelos morcegos filostomídeos e a estreita faixa de dispersão de valores podem ser resultado das estratégias bionômicas do grupo. Analisando dados de crescimento pós-natal, Porto et al., (2013) demonstraram que a magnitude de integração está associada à evolução das estratégias de história de vida em mamíferos. Esses autores observaram que famílias de mamíferos que apresentam menor proporção de investimento energético destinado ao crescimento apresentaram índices de integração morfológica mais baixos. De acordo com Kunz \& Kurta (1987), os morcegos filostomídeos apresentam a maior massa corporal neonatal bem como os maiores antebraços ao nascer. Além disso os filostomídeos são, aparentemente, os mais desenvolvidos de todos os morcegos no nascimento (Kleiman \& Davis, 1979). De acordo com Porto et al (2013), linhagens que destinam um investimento de energia menor no crescimento pós-natal apresentam uma proporção menor de variação total relacionada ao tamanho, e magnitudes de integração baixas (em outras palavras, impacto menor na correlação entre os caracteres devido ao cresimento alométrico). Além disso, essas espécies são mais flexíveis e apresentam menor restrição no seu 
potencial evolutivo de resposta a seleção direcional. Os resultados encontrados por Porto et al (2013) sugerem que diferentes estratégias de crescimento existentes em diferentes espécies tem um impacto fundamental nas suas flexibilidades evolutivas e no potencial de exploração do morfoespaço. Essa é uma abordagem hipotética a fim de compreender as magnitudes de integração mais baixas encontradas em morcegos filostomídeos e serão necessárias investigações mais aprofundadas para avaliar essa hipótese.

\subsection{Associação entre os índices de magnitude geral de integração ( $\mathrm{r}^{2}$ e ICV)}

No presente trabalho, explorei dois índices de magnitude geral de integração dos caracteres: o $\mathrm{r}^{2}$ e o ICV. Como descrito nos métodos, o $\mathrm{r}^{2}$ é obtido a partir da matriz de correlação e o ICV a partir da matriz de covariância. Quando correlacionei esses dois índices, obtive uma valor de 0.76 para os morcegos filostomídeos, o que pode ser considerada uma correlação alta. Porém, observando este resultado comparativamente àquele obtido para as ordens de mamíferos investigadas por Marroig et al., (2009) percebemos uma diferença. A correlação entre o ${ }^{2}$ e o ICV para os demais grupos de mamíferos foi igual a 0.96. Assim surge a questão sobre quais seriam as possíveis causas dessa diferença observada entre as matrizes de correlação e covariância no morcegos filostomídeos, responsável pelo decréscimo da correlação observado entre estes dois índices. Nesse grupo há um efeito de escala nos dados que causa um desacoplamento entre as matrizes de covariância e correlação. Esse fenômeno de escala nos dados pode ser compreendido através de dois cenários possíveis:

1 - No primeiro deles, tanto a média quanto à variância apresentam valores altos. Para facilitar a compreensão podemos pensar nas espécies de morcegos nectarívoras, nas quais há um 
alongamento do rostro. Esse alongamento aumenta a média e a variância dos caracteres envolvidos. Nesse cenário hipotético o fenômeno de escala segue a seguinte lógica: alongameto da região rostral, aumento da média e da variância dos caracteres. Há também domínio destes caracteres nas matrizes de variância/covariância mas este efeito desaparece nas matrizes de correlação

2 - Em um segundo cenário, a média permanence a mesma enquanto a variância aumenta. Uma possível explicação para esse fenômeno seria uma maior plasticidade de desenvolvimento de um caráter craniano. De acordo com Porto (2009) e Marroig (comunicaşão pessoal), a região do ptérion (marcador PT) em crânios de Homo sapiens pode apresentar até quatro padrões diferentes de posicionamento relativo dos ossos frontais, parietais, esfenoidais e temporais. Essa plasticidade no desenvolvimento pode causar um polimorfismo dentro de uma espécie ou mesmo dentro de um único indivíduo (Marroig, comunicação pessoal). No caso dos morcegos, o BR (marcador bregma), posicionado na sutura que delimita o frontal e o parietal, pode ser altamente plástico e específico de cada indivíduo. Nesse caso, a média desse caráter permanence igual enquanto a variância aumenta. Vampyrum spectrum configura um bom exemplo dessa flutuação plástica no marcador BR. Nessa espécie a distânia NA-BR apresenta coeficiente de variação inflado (0.14), e no primeiro componente principal essa distância apresenta a maior contribuição (cerca de $30 \%$ da variação total do CP1), dentre todas as outras distâncias. Em outro extremo a distância BR-LD (note que o marcador BR aparece novamente) apresenta um coeficiente no primeiro componente igual a -0.47 , o que equivale a cerca de $22 \%$ da variação total deste CP. Esses marcadores encontram-se na linha mediana do crânio, e de maneira geral, representam respectivamente o comprimento anterior (nasal e frontal até a linha sagital) e posterior do crânio (linha sagital até o interparietal), sendo o BR (bregma) o marcador que delimita essas distâncias. O deslocamento ou flutuação desse marcador causa esse contraste entre os valores positivo e negativo no CP1 já que 
um BR deslocado frontalmente irá gerar um valor de NA-BR menor e um valor de BR-LD maior e vice-versa para BR deslocado posteriormente.

Esses são possíveis cenários explicativos do efeito da escala dos dados no desacoplamento entre as matrizes de correlação e covariância, e eles poderiam inclusive ocorrer conjuntamente. Vale lembrar que são cenários hipotéticos e mais investigações serão necessárias a fim de compreender os fenômenos observados e determinar de fato os caracteres envolvidos. Essa discussão sobre o efeito de escala nos dados será retomada mais a frente no item que aborda variação de tamanho.

\subsection{Dieta, Filogenia e Distância morfológica}

A inércia filogenética pode ser definida como a proporção de variação fenotípica que está filogeneticamente estruturada (Diniz-Filho, 2000), ou seja, o quanto de variação no fenótipo poderia ser explicada pela filogenia. No presente estudo, um possível indício de inércia filogenética decorreria da seguinte observação: Linhagens filogeneticamente próximas apresentando padrões mais altos de similaridade estrutural das matrizes fenotípicas, quando comparadas a grupos mais distantes filogeneticamente. Encontrei uma relação significativa entre a matriz de distâncias filogenéticas e as matrizes de similaridade nos padrões de correlação e covariação comparadas por Krz̧anowski (considerando os valores observados e ajustados). Por outro lado, não detectei correlação significativa entre a matriz de distâncias filogenéticas e a matriz de covariância comparadas por Random Skewers (para valores observados e ajustados). Considerando o critério de significância, os resultados são parcialmente contraditórios, porém é importante notar aqui que, independente do método de comparação de matrizes, as correlações encontradas são muito baixas (Tabela 4.9), indicando que a estrutura é relativamente 
independente da filogenia. Além disso, é muito importante destacar que o método de Adagas Aleatórias $(R S)$ é uma extensão direta da equação multivariada de resposta à seleção, e portanto, é a partir dele que analisamos se duas matrizes de variância covariância são similares o suficiente para permitir a reconstrução de gradientes de seleção (Cheverud \& Marroig, 2007). Dessa forma, considerando o critério de significância do teste de Mantel para as matrizes de covariância estimadas pelo método de $R S$, bem como as correlações baixas encontradas, a hipótese de que os padrões de similaridade das matrizes de covariância foram influenciados pela história evolutiva dos morcegos filostomídeos é refutada. A independência entre a filogenia e a similaridade estrutural da matriz de covariância indica que as mudanças e as manutenções dos padrões de covariância são, até certo ponto, dissociados da história filogenética dos morcegos filostomídeos. Essa dissociação entre o padrão de similaridade das matrizes e a história filogenética também foi reportada para outros taxa (Bégin \& Roff, 2004; Porto et al., 2009; Revell et al, 2007; Roff \& Mousseau, 2005).

Em contraposição observei que mudanças morfológicas nas médias dos caracteres são ao menos parcialmente dependentes da história evolutiva dos filostomídeos, como indicado pela correlação fraca entre a distância de Mahalanobis $\left(D^{2}\right)$ e a distância filogenética (Tabela 4.10). Estes resultados estão de acordo como o modelo de balanço entre mutação e seleção (Lande, 1980), porque enquanto a média fenotípica foi evoluindo durante a diversificação dos morcegos filostomídeos, a estrutura de covariação (o padrão) permaneceu relativamente estável. Como será visto mais à frente, os resultados de integração morfológica, que revelaram padrões comuns de desenvolvimento nos morcegos filostomídeos também corroboram este modelo. De maneira geral, o balanço entre mutação e seleção proposto por Lande (1980), sugere que o padrão de herança compartilhada entre caracteres irá evoluir para corresponder ao padrão de seleção estabilizadora e ao padrão dos efeitos de mutação (Cheverud, 1996). Aqui dois fatores são muito importantes na determinação do padrão de seleção estabilizadora: as forças internas e externas 
(Marroig \& Cheverud, 2001). A seleção externa é seleção estabilizadora devido à interação do fenótipo com o ambiente externo. Seleção interna por sua vez, também é estabilizadora devido às interações do fenótipo com as características internas do organismo. Por meio dos seus efeitos nos padrões de correlação genética (Cheverud, 1984) a seleção estabilizadora interna irá restringir o padrão de variação disponível à seleção pelo ambiente externo. Nesse caso, somente mutações consistentes ao longo do desenvolvimento serão oferecidas como adapatações potenciais para a seleção externa (Marroig \& Cheverud, 2001). O padrão encontrado nos morcegos filostomídeos é muito similar àquele observado em macacos do Novo mundo (Marroig \& Cheverud, 2001), no qual o padrão de integração relacionado ao desenvolvimento, é um indicativo dos padrões comuns de seleção estabilizadora interna entre eles, produzida por um sistema de desenvolvimento epigenético. Desta forma, padrões de desenvolvimento compartilhados entre os filostomídeos representam a força da seleção estabilizadora interna contabilizando, ao menos em parte, para a manutenção da estrutura de covariância fenotípica relativamente estável durante a diversificação evolutiva na média dos caracteres, como sugerido pela hipótese de balanço entre mutação e seleção (Lande, 1980).

Observei correlação significativa ente distâncias morfológicas $\left(D^{2}\right)$ e as matrizes de similaridade nos padrões de correlação e covariação fenotípicas, indicando que quanto maior a divergência na média dos caracteres, mais diferentes são as matrizes. Os resultados sugerem que a seleção direcional, atuando na diversificação da média dos caracteres, pode ter moldado os padrões de covariação, explicando assim o restante das diferenças entre as matrizes que não pode ser atribuída ao erro de amostragem, discutido acima na seção sobre "Similaridade estrutural da matrizes fenotípicas". Nesse ponto vale reforçar a idéia de que forças internas e externas agindo no padrão de similaridade mantém a estrutura estável mas não imutável, justamente porque temos seleção direcional atuando nas médias dos caracteres. Este é um ponto ainda não testado diretamente nos filostomídeos (seleção direcional sobre as médias durante a diversificação) mas é 
uma hipótese bastante razoável neste ponto dado nosso conhecimento prévio do grupo, ou seja, o grau de modificação qualitativa do crânio observada nestes morcegos e sua associação a nichos alimentares. Além disso a hipótese de seleção direcional encontra suporte indireto também nos resultados desta tese já que dieta está correlacionada tanto com a diferencição morfológica média como com as diferenças nas estruturas das matrizes (Tabelas 4.9 e 4.10). De acordo com Marroig \& Cheverud (2001), enquanto a seleção estabilizadora parece manter a estabilidade estrutural das matrizes, atuando por meio de um sistema de desenvolvimento epigenético comum, a seleção direcional pode, direta ou indiretamente mudar a estrutura de covariância (Marroig \& Cheverud, 2001). Mudanças indiretas na estrutura de covariância podem resultar de seleção direcional atuando para diferenciar as médias da população e, de forma conjunta, alterar variâncias e covariâncias. Mudanças diretas por sua vez, poderão resultar da seleção direcional para um novo padrão de integração morfológico funcional e de desenvolvimento, como por exemplo, mudanças associadas aos diferentes tipos de dieta entre os mocegos da Família Phyllostomidae. Seis grupos de dieta podem ser reconhecidos entre os filostomídeos (Baker et al., 2012). A distribuição dessas categorias de dieta (insetivoria, hematofagia, nectarivoria, omnivoria, carnivoria e frugivoria) ao longo da filogenia da Família Phyllostomidae demonstra às suas associações com os clados, resultado este que é também evidente na correlação $(r=-0.64)$ entre dieta e distância filogenética. Esse resultado indica que espécies relacionadas filogeneticamente apresentam dietas similares. Uma visão geral dos clados atuais que compõem a Família Phyllostomidade nos fornecem evidências desta associação entre a filogenia do grupo e os hábitos alimentares. Três linhagens, reconhecidas como subfamílias Macrotinae, Micronycterinae e Lonchorhininae alimentam-se de material vegetal mas são primeiramente insetívoras. A subfamília Desmodontinae compreende espécies hematófagas, e é possível que as espécies dessa linhagem nunca tenham utilizado material vegetal após sua diversificação a partir dos outros filostomídeos (Baker et al., 2012). A subfamília Phyllostominae por sua vez contém espécies omnívoras, insetívoras estritas (Macrphyllum) e outras que são carnívoras (Vampyrum e Trachops). 
As espécies que compõem as subfamílias Glossopahginae e Lonchophyllinae são reconhecidas como nectarívoras (Ferrarezzi \& Gimenez, 1996; Gardner, 1977), e outros dados disponíveis sugerem que provavelmente complementam sua dieta com pólen, frutas e insetos (Baker et al, 2012). Estes clados fizeram a transição para uma dieta composta de material vegetal e diversas espécies que compõem esses grupos apresentam adapatações extremas para obter néctar das flores, como por exemplo Choeronycteris, Musonycteris (Phillips, 1971), Anoura e Lonchophylla ( Griffiths, 1982), Scleronycteris e Platalina. A subfamília Glyphonycterinae compreende os gêneros Glyphonycteris e Trinycteris que se alimenta principalmente de insetos e algum material vegetal. Espécies dentro do gênero Carollia, subfamília Carollinae, especializaram-se em frutas (Gardner, 1977), epecialmente de Piper, mas também se alimentam de insetos quando a disponibilidade de frutas é limitada (Baker et al., 2012). As espécies atuais que compõem a subfamília Stenodermatinae são frugívoras obrigatórias ou apresentam frugivoria como dieta principal.

Encontrei correlação significativa entre a matriz de dieta e a similaridade nos padrões de correlação e covariação para os morcegos filostomídeos, fato este que evidencia que os hábitos alimentares das espécies influenciam os padrões estruturais das matrizes. Esse achado está de acordo com os dados obtidos para macacos do novo mundo (Marroig \& Cheverud, 2001). Considerando os morcegos filostomídeos e os macacos do Novo mundo (Marroig \& Cheverud, 2001), observa-se que enquanto a similaridade da estrutura de covariância se mostrou independente da história filogenética, os padrões de variação e covariação cranianos nesses dois grupos mostraram-se ao menos parcialmente dependentes dos hábitos alimentares das espécies.

Por fim, quando correlacionei a matriz residual de dieta, ou seja, toda aquela parte da variação em dieta que é independente da filogenia, com as matrizes de similaridade, observei resultado significativo somente para a matriz de correlação estimada por Krzanowski (tanto para valores observados quanto ajustados). Ou seja, utilizando a matriz de correlação, que controla para o efeio de escala, a relação se mostrou significativa. Encontrei uma relação significativa entre 
a matriz residual de dieta e a matriz de distâncias morfológicas $\left(D^{2}\right)$, indicando uma associação entre a média dos caracteres e os hábitos alimentares dessas espécies. Não detectei associação entre a filogenia residual (independente da dieta) e as matrizes de similaridade. Também não houve associação entre a média dos caracteres (distância morfológica) e a história evolutiva do grupo (considerando-se a matriz de filogenia residual). Lembre-se que a correlação entre distância morfológica e filogenia foi significativa quando considerei a matriz de filogenia bruta. Esses resultados das matrizes residuais parecem indicar, até certo ponto, que no caso dos morcegos filostomídeos, dieta e filogenia embora estejam relacionadas, diferem quanto à sua associação (e potencial causalidade) com a evolução tanto do fenótipo médio quanto da estrutura de correlação entre os caracteres do crânio. A dieta mostrou um ajuste maior do que a filogenia para as matrizes de correlação, e para as matrizes de distância morfológica. Além disso os resultados reforçam que não há evidência forte de inércia filogenética já que ao remover a variação na filogenia associada a dieta esta última mantém sua associação tanto com as distâncias morfológicas como com a similaridade estrutural das matrizes (correlação) enquanto o contrário não ocorreu, ou seja, a relação da filogenia sem dieta com a evolução das médias e da estrutura das matrizes desaparece. Ao que tudo indica, esse cenário parece sugerir que a oportunidade de nichos vagos pode ter levado à diversificação filogenética das espécies, bem como à diversificação na média dos caracteres e na estrutura de covariação. Todavia considero prudente destacar que nas comparações com filogenia, utilizei um número de espécies menor do que a que compõe a minha amostra total. Ainda assim, 36 espécies (das 48 totais) pode ser considerado um número bastante representativo. No futuro é possível que o acréscimo de mais espécies ou mesmo a utilização de outras filogenias disponíveis alterem esse resultado. Além disso um teste formal de inércia filogenética (ou de sinal filogenético) tanto para a evolução das médias como das matrizes seria outra abordagem complementar interessante. 


\subsection{Estabilidade com divergência? Caracteres similares e dissimilares entre as matrizes.}

Até o momento vimos que tanto os padrões de similaridade estrutural quanto as magnitudes de integração se mantiveram relativamente estáveis durante a evolução dos morcegos filostomídeos. Embora a mgnitude tenha sido mais plástica em termos de mudanças, a amplitude de valores ocupados pelos filostomídeos parece bem estreita. Esta estabilidade relativa é decorrente da seleção estabilizadora (forças internas e externas) atuando no padrão de similaridade das matrizes. Por outro lado, discuti também que essa estutura, embora estável, não é imutável, devido à seleção direcional atuando na média dos caracteres. O padrão de integração craniana dos morcegos filostomídeos evolui e parte dessa mudança parece estar associada à dieta desse grupo tão morfologicamente diverso. Considerando o padrão global de similaridade observado e a possibilidade de mudança, onde se encontram as divergências nas matrizes que representam os crânios dos morcegos filostomídeos?

Os caracteres ZS-ZI (zigomaxilar superior e zigomaxilar inferior) e APET-TS (região anterior petrosal do temporal e junção temporo-esfenoidal), associados respectivamente à região da face e neurocrânio, foram os que mais divergiram entre as espécies de morcegos filostomídeos. Os marcadores ZS e ZI estão relacionados às subregiões oral e zigomática e são posicionados respectivamente na região dorsal e ventral da sutura zigomaticomaxilar, a qual delimita o processo zigomático da maxila e o osso jugal. O caráter APET-TS por sua vez está relacionado à subregião da base craniana. O APET delimita os ossos basiesfenóide e basioccipital e o TS está relacionado à sutura temporo-esfenoidal. ZS-ZI e APET-TS foram os dois primeiros caracteres mais divergentes entre as espécies. Porém, outros caracteres que apresentaram até 54\% de divergência foram detectados para as subregiões zigomática (EAM-ZYGO), oral (IS-PM), base (BA-OPI e APET-BA), abóbada (OPI-LD, LD-AS e JP-AS), e nasal (NSL-NA). Como será visto na 
discussão abaixo e no ítem que aborda modularidade, essas regiões têm grande importância functional e de desenvolvimento para os morcegos filostomídeos, podendo divergir entre as diferentes morfologias e espécies.

Sete caracteres relacionados à face apresentaram correlação significativa com a matriz de dieta nos testes em que a matriz de divergência par a par e de cada caréter no SRD foram comparados à dieta. Esses caracteres estão relacionadas à subregião oral (PM-ZI, PM-MT, MTPNS), nasal (NSL-NA e NA-PNS), e dois deles abarcam as duas subregiões (IS-PNS e NSL-ZI) mas ainda assim são faciais. Apenas um caráter associado ao neurocrânio correlacionou-se significativamente com a matriz de dieta. Este caráter compõe a subregião da base craniana (PNS-APET).

É possível observar que os caracteres que mais divergiram estão relacionados às regiões do crânio que expressam grande variação morfológica qualitativa e estão diretamente relacionadas aos hábitos alimentares das espécies. Em sua maioria, os marcadores envolvidos nesses resultados capturam distâncias relacionadas à alongamento e retração do rostro e do palato, estando associados à pré-maxila, palato e nasal. O marcador APET por sua vez, localiza-se na base do crânio, e é posicionado próximo aos órgãos da audição e do equilíbrio. É um marcador que delimita os ossos basiesfenóide e basioccipital.

Giannini \& Simmons (2007) elaboraram uma revisão notável sobre a pré-maxila em Chiroptera, e descreveram variações morfológicas observadas na família Phyllostomidae. De acordo com esses autores, variações importantes na forma dos crânios em filostomídeos ocorrem em relação ao comprimento e à forma do rostro. A inclinação da pré-maxila é marcante em alguns taxa nectarívoros (tribo Lonchophyllini, por exemplo), com a pré-maxila acompanhando o alongamento geral do rostro visto nesses morcegos (Giannini \& Simmons, 2007). Gregorin \& Ditchfield (2005) relataram um aumento considerável na inclinação da pré-maxila dentro da tribo 
Lonchophyllini, variando de uma condição moderada em Lionycteris a um caso extremo em Xeronycteris.

Em um outro extremo do espectro alimentar, estão os frugívoros especialistas da tribo Stenodermatini, os quais exibem um rostro extremamente curto e um deslocamento da abertura externa do nasal. Centurio, por exemplo, exibe uma pré-maxila ortocliva em relação ao canino superior, enquanto em Ametrida e Sphaeronycteris a pré-maxila é afetada pela retração extrema da abertura externa do nasal e a torção superior do rostro. Surpreendentemente esses processos morfogenéticos opostos (alongamento extremo versus retração do rostro) produzem um efeito similar na orientação da pré-maxila (Giannini \& Simmons, 2007). Em outro grupo com dieta especialista, os morcegos vampiros da subfamília Desmodontinae, a pré-maxila tem uma forma triangular na vista ventral, e incisivos em forma de lâmina, que convergem rostralmente e são utilizados para cortar a pele de aves e mamíferos para a obtenção de sangue. A pré-maxila é elevada em relação à linha alveolar da maxila, separando efetivamente os largos incisivos dos caninos superiores (Giannini \& Simmons, 2007).

Uma das funções anatômicas do palato é dar supote à bateria de dentes e fortalecer o rostro durante a mastigação (Adams \& Pedersen, 2000). O alongamento do rostro e da língua em morcegos nectarívoros, é acompanhado de uma diminuição no tamanho dos dentes. Nesse grupo há um decréscimo da musculatura relacionada à mastigação e o palato é estreito. Já nos morcegos frugívoros os palatos em geral são curtos e largos.

Interações entre o desenvolvimento cerebral e a base craniana influenciam uma ampla gama de mudanças morfogenéticas do terço médio da face ao longo do desenvolvimento em morcegos (Sperry, 1972), e isso também se aplica a outros grupos. Em primatas, por exemplo, o bulbo olfatório e o encéfalo competem com a região orbital por espaço, influenciando dessa maneira a forma, o tamanho, a posição e a orientação do septo interorbital (Adams \& Pedersen, 2000). Uma discussão mais detalhada sobre a importância da região do neurocrânio, em especial à 
abóbada craniana será apresentada no tópico a seguir. Cabe no entanto notar aqui que os resultados do SRD e a associação destes com a dieta primordialmente mostram caracteres da face como sendo os mais divergentes em termos da estrutura das matrizes e relacionados a mudanças na dieta (Tabelas 4.13 e 4.15; Figura 3.1).

\subsection{Modularidade no crânio de morcegos filostomídeos}

A abordagem proposta por (Cheverud, 1995, 1996) para o estudo de modularidade no crânio de mamíferos está alicerçada em aspectos relacionados a desenvolvimento e função (Olson \& Miller, 1958). O crânio em mamíferos possui grande número de regiões anatômicas associadas às diferentes funções. O desenvolvimento de cada região, por sua vez, está ligado à sua função, possibilitando uma avaliação conjunta função-desenvolvimento na investigação da presença de módulos. A integração morfológica se refere à variação coordenada de caracteres, enquanto a modularidade diz respeito à divisão de sistemas de desenvolvimento em componentes parcialmente dissociados, mas que também apresentam integração uns com os outros em diferentes níveis. Tanto a alta conectividade quanto a independência dos módulos acarretam um complexo de interações hierárquicas que podem variar na estrutura considerada. Antes de iniciar a discussão sobre a presença de módulos nos crânios de morcegos filostomídeos, é importante destacar as limitações impostas pelo método empregado. O método utilizado no presente estudo se baseia na construção de hipóteses a priori para a detecção de modularidade e cada uma delas representa em geral apenas uma hierarquia muito simples de um nível, presença ou ausência de correlações entre elementos. Quando consideramos a integração total por exemplo, estamos avaliando a ocorrência conjunta de todos os módulos do crânio. A hipótese de integração neurofacial contempla as regiões da face e do neurocrânio, que por sua vez, abarcam outras subregiões. Na hipótese de integração facial por exemplo, estão contidas as subregiões oral, nasal 
e zigomática; enquanto na hipótese do neurocrânio consideramos envolvidas as subregiões da base e da abóbada craniana. Cada uma das subregiões também consiste em uma hipótese (devem ser classes diferentes de correlação nas matrizes reais mas não o são nas hipotéticas), e esses módulos menores por sua vez são também integrados em hierarquias maiores. Nesse sistema hierárquico de deteção de modularidade, o método é limitado principalmente quando consideramos as hipóteses individuais (somente face, base ou abóboda por exemplo), porque pegamos um pequeno compartimento e testamos contra todos os outros. Embora sejam definidos limites para caracterizar determinado módulo, é importante destacar que nós não estamos considerando aquela delimitação como isolada, nós entendemos que há uma conectividade com os outros setores. Afinal não existem crânios na qual a face está completamente dissociada do neurocrânio. As classes são criadas com a finalidade de testar para evidência de um processo local, exemplo o módulo oral, mas isso não significa que tratamos aquela parte como isolada de todas as outras. A crítica à abordagem empregada aqui consiste justamente no fato de que por ser um método simples ele não captura a hierarquia do sistema. Além disso ele reduz a integração morfológica em uma estrutura complexa como o crânio, a uma matriz de presença ou ausência de correlações (Chernoff \& Magwene, 1999; Cheverud et al., 1985; Cheverud, 1982). Por sua vez, a vantagem é que, embora seja um método grosseiro, ele é capaz de revelar os módulos mais evidentes, de maneira que o achado de uma correlação significativa, ou mesmo marginalmente significativa, deve ser considerado como de potencial importância biológica (Oliveira, 2009). De maneira geral, esse método continua sendo uma ferramenta eficaz na detecção de módulos biologicamente significativos, e deve-se considerar que as hipóteses teóricas estão fortemente ancoradas em literaturas que refletem o estado da arte sobre o desenvolvimento craniano dos mamíferos (Cheverud \& Routman, 1995; Moore, 1981; Porto et al., 2013; Smith, 1996, 1997, 2001). 
A matriz de correlação de todas as espécies de morcegos filostomídeos esteve correlacionada positivamente ao menos à hipótese teórica mais geral de associação entre os caracteres (integração total). Este resultado demonstra que os filostomídeos compartilham um padrão de modularidade craniana relacionado à função e desenvolvimento, e corrobora a organização modular encontrada em outras linhagens de mamíferos (Ackermann \& Cheverud, 2004; Cheverud \& Routman, 1995; Cheverud, 1996; Goswami, 2006; Marroig \& Cheverud, 2001; Oliveira et al., 2009; Porto et al., 2009; Shirai \& Marroig, 2010).

Baseada nas hipóteses de integração utilizadas, evidenciei módulos distintos em relação à integração total, neurofacial, nas regiões da face e nas subregiões oral, nasal e abóbada craniana. A hipótese de integração total, a qual associa as cinco subregiões do crânio esteve correlacionada significativamente à maioria das espécies de filostomídeos, com exceção de Macrotus waterhousii, que apresentou correlação marginalmente significativa.

A hipótese de integração da neuroface, ou neurosomática, que explora as relações de padrões de crescimento entre os caracteres também apresentou correlações significativas para a maioria das espécies, sugerindo um padrão de integração neurofacial compartilhado entre os morcegos filostomídeos. Isso denota a importância das duas regiões, face e neurocrânio, e seus efeitos de crescimento tardios e precoces, respectivamente. Para uma melhor compreensão, vamos explorar as regiões e subregiões cranianas tendo como escopo o desenvolvimento. O crânio de mamíferos apresenta duas regiões principais: a face e o neurocrânio, e ambas possuem padrões distintos de crescimento durante os estágios de vida (Cheverud, 1982). A região da face apresenta as subregiões oral, muscular (zigomática) e nasal; enquanto o neurocrânio é composto pelas subregiões da base, abóboda e órbita. Nos mamíferos eutérios, o neurocrânio origina-se na mesoderme e apresenta um padrão de crescimento essencialmente precoce, completando seu desenvolvimento no início da vida pós-natal (Moore, 1981), ainda que a base possa sofrer influência de alguns fatores de crescimento tardios. Cérebro e olhos, por exemplo, completam 
seu desenvolvimento cedo, antes que o hormônio de crescimento se manifeste. A face, por sua vez, tem origem a partir da crista neural e apresenta um padrão de crescimento predominantemente tardio, sob influência do hormônio de crescimento (Smith, 1996, 1997; Marroig \& Cheverud, 2001; Ackermann \& Cheverud, 2004). Características faciais, especialmente àquelas influenciadas pelo tamanho da musculatura associada e a cavidade oral, continuam a crescer sob à influência desse hormônio. Dessa forma, espécies que apresentam um padrão de integração facial, provavelmente tem uma contribuição mais pronunciada de fatores de crescimento tardios na sua integração geral. Ao todo, 39 das 48 espécies espécies apresentaram correlações significativas para essa hipótese de modularidade que considera as duas regiões, face e neurocrânio, conjuntamente. Por outro lado, quando testadas separadamente, detectei integração da região da face em 21 espécies e na região do neurocrânio em apenas três espécies. Esse contraste de detecção pode ser explicado pelas diferenças nas magnitudes de correlação entre caracteres faciais e neurocranianos nas espécies (ver Figura 1.2 na introdução). Com exceção da hipótese total e neurossomática, todas as outras hipóteses são testadas incluindo outros módulos no grupo de caracteres zero. Por exemplo, quando eu testo para integração na região do neurocrânio, todo o grupo de correlações dentro da face encontra-se no grupo zero, enquanto dentro do neurocrânio é um. Se as correlações entre caracteres faciais são altas em relação às correlações entre os caracteres neurais, a integração facial será aparente mas a neurocraniana não (ver Figura 1.2 na introdução). Nesse caso, a face poderia obsurecer um possível sinal de modularidade no neurocrânio pois aumentaria a média das correlações do grupo zero.

Nos filostomídeos em geral, as subregiões oral e nasal aparecem como módulos dominantes, resultados estes que corroboram outros estudos (Hubbe, 2013; Marroig \& Cheverud, 2001; Oliveira et al., 2009; Porto et al., 2009; Shirai \& Marroig, 2010; Silva, 2010). Fato interessante foi a evidência de modularidade na subregião da abóbada craniana em vinte e duas espécies de filostomídeos. A abóbada craniana foi detectada como modular apenas em Homo e 
Gorilla (Oliveira et al., 2009; Porto et al., 2009), alguns macacos do Novo Mundo (Marroig \& Cheverud, 2001), e mais recentemente no gênero Priodontes da Ordem Xenarthra (Hubbe, 2013). Porto et al., (2009) sugeriram que a integração da abóbada craniana em Homo e Gorilla pode estar associada à proximidade filogenética dos taxa e ao alto desenvolvimento cerebral nessa linhagem de primatas que apresenta neurocrânio maior.

A subregião zigomática revelou-se como um módulo aparente em duas espécies apenas: Vampyrodes major e Phyllops falcatus, ambas frugívoras pertencentes à subfamília Stenodermatinae. O arco zigomático, ou zigoma, é formado pelo processo zigomático da maxila e o osso jugal, o qual se articula caudalmente com o processo zigomático do esquamosal na região do temporal (Giannini et al., 2006). Dois músculos importantes na mastigação estão relacionados ao arco zigomático: o músculo temporal e o masséter. Ambos têm como função principal a elevação e retração da mandíbula. Eu esperava encontrar integração nessa subregião em grande parte das espécies que consomem alimentos mais duros, como frutas e vertebrados por exemplo. Espécies que apresentam esses hábitos alimentares muitas vezes possuem musculatura temporal grande que conferem maior vantagem mecânica, uma tendência que evoluiu em outros mamíferos que consomem alimentos resistentes, como carnívoros e ungulados (Pérez-Barbería \& Gordon, 1999; Santana et al., 2012; Smith \& Savage, 1959). Ao contrário, espécies que consomem néctar e frutas macias possuem músculo temporal relativamente menor, com menor vantagem mecânica (Santana et al., 2010). Uma outra característica diz respeito à largura do zigomático. Enquanto a largura do zigomático pode ser maior que 80 a $98 \%$ do comprimento condilocanino em morcegos frugívoros e insetívoros, ela abrange menos de 30\% em espécies nectarívoras. Arco zigomático estreito significa menos volume para a musculatura da mandíbula e diminuição da força de mordida. Com o alongamento do rostro e da língua em nectarívoros, nota-se uma diminuição conjunta da importância de músculos relacionados ao fechamento da maxila, particularmente o masseter (Freeman, 2000). Uma explicação para o resultado encontrado é que a 
subregião zigomática é menos influenciada pelo tamanho alométrico que as demais subregiões da face (Hubbe, 2013). Embora tamanho alométrico tenha impacto sobre todas as correlações ele não atua de forma uniforme sobre elas (Shirai \& Marroig, 2010). Um exemplo deste efeito pode ser visto na Figura 1.2 da introdução com dois caracteres da face (F1 e F2) e dois do neurocrânio. Em primatas e marsupiais do novo mundo, o módulo zigomático foi detectado após a remoção do efeito do tamanho alométrico sobre as correlações dos caracteres (Shirai \& Marroig, 2010). Outra explicação possível é a limitação do método empregado na detecção dos módulos como já discutido acima.

Nenhuma espécie de filostomídeo apresentou integração na subregião da base craniana. Além disso os valores do índice de distinção modular foram em sua maioria baixos e em algumas espécies negativos. De acordo com Wible \& Davis (2000) pouco se conhece sobre a variação da maioria das características da base do crânio nos diferentes níveis taxonômicos em Chiroptera. A não evidência de módulo na base reforça o padrão descrito para outras ordens de mamíferos (Marroig \& Cheverud, 2001; Oliveira et al., 2009; Porto et al., 2009; Shirai \& Marroig, 2010). Parte de sua origem está relacionada à mesoderme e parte à crista neural, e de acordo com Hallgrímsson \& Lieberman (2007) ela seria uma região de integração entre a face e o neurocrânio. A sobreposição desses folhetos embrionários ao longo do desenvolvimento poderia levar à uma dificuldade de decifrar a estrutura de covariação, sendo esta uma possível explicação para a não detecção da base como um módulo em mamíferos. Hallgrímsson \& Lieberman (2007) destacaram que a estrutura de covariância emerge por meio de variação no processo de desenvolvimento. De acordo com Hallgrímsson et al., (2009) a integração pode ser vista como o somatório dos processos que induzem covariação entre os caracteres ao longo da ontogenia, independentemente da forma que esta adição leva e da natureza dos processos. Esse autor ressaltou a dificuldade de se analisar estruturas de covariação fenotípica em morfologias complexas, pelo fato de que existem muitos processos de desenvolvimento que variam de tal 
forma que podem influenciar a covariação, tanto espacialmente como temporalmente. Estes processos podem agir em momentos diferentes e podem se sobrepor parcialmente no tempo e no espaço. Consequentemente, cada processo gerador de covariância pode ocultar os efeitos de outros na estrutura geral de covariância (Hallgrímsson et al., 2009).

Monteiro \& Nogueira (2010) examinaram padrões de integração de desenvolvimento individual, populacional e entre espécies considerando as mandíbulas de morcegos filostomídeos. Para examinar e comparar os padrões de integração intra e interespecíficos, eles calcularam matrizes de integração entre componentes mandibulares. Os autores avaliaram se os padrões de correlação evolutiva entre os componentes mandibulares em diferentes eixos ecológicos de divergência entre os filostomídeos estão relacionados aos padrões de integração herdados, ou se os componentes foram selecionados conjuntamente, independente dos caminhos de desenvolvimento. Eles observaram que dependendo do contexto ecológico, a evolução correlacionada de diferentes partes da mandíbula podem ou não refletir a hierarquia subjacente de desenvolvimento. Diferentes eixos de divergência ecológica na diversificação dos morcegos filostomídeos apresentaram padrões de integração notavelmente diferentes, embora os padrões de integração dentro das espécies tenham sido similares àqueles esperados pela integração de desenvolvimento (Monteiro \& Nogueira, 2010). De acordo com os autores, os padrões de integração nas mandíbulas de filostomídeos aparecem maleáveis conforme as espécies se adaptam às exigências seletivas específicas do meio, e foram remodeladas durante transições ecomorfológicos relativamente recentes. As ferramentas e métodos utilizadas neste estudo diferem, porém os resultados até certo ponto se complementam no que diz respeito ao padrões de integração intrapopulacional. Monteiro \& Nogueira (2010) notaram que a integração intrapopulacional em linhagens diferentes é similar à integração de desenvolvimento, independente da especialização da dieta, um resultado que está plenamente de acordo com os descritos nesta tese. Uma diferença importante é que no estudo, Monteiro \& Nogueira (2010) 
utilizaram matrizes de correlação que capturam integrações entre os módulos hipotetizados (como região condilar e alveolar) enquanto no presente estudo temos correlções tanto dentro com entre módulos. Assim por exemplo, uma correlação entre o módulo A e B em um conjunto de taxons poderia ser de 0.5 e significativa enquanto em um outro conjunto de táxons esta correlação seria de 0.2 e não significativa. No entanto, a figura 4 (pg. 732) do trabalho de Monteiro \& Nogueira (2010) mostra claramente que os módulos hipotetizados na mandíbula apresentam correlações positivas em todos os grupos de dieta, um resultado que levou os autores a concluirem que os padrões de integração dentro das populações era similar e em grande parte devido ao desenvolvimento compartilhado, conlusões estas que estão plenamente de acordo com as desta tese. Será interessante em um futuro próximo comparar os resultados obtidos por Monteiro \& Nogueira (2010) em relação a integração evolutiva (isto é, mudança correlacionada de caracteres entre as linhagens) na mandíbula com as do crânio. Isto por que a priori a mandíbula deve refletir, dada sua função específica de alimentação, de maneira mais clara associações e mudanças na dieta enquanto o crânio com suas múltiplas funções e ossos componentes pode apresentar padrões mais complexos de associação durante a evolução devida às potenciais influências multiplas e eventualmente conflitantes.

Métodos de morfometria geométrica têm sido amplamente utilizados para responder questões refentes à integração morfológica (Hallgrímsson et al., 2009; Klingenberg, 2003; Monteiro, 2005; Santana \& Lofgren, 2013; Zelditch \& Wood, 2008) e essa ferramenta pode ser bastante útil para responder questionamentos futuros relacionados aos crânios dos morcegos filostomídeos. Dentro dessa abordagem, destaco abaixo uma questão que considero interessante. O método de mensuração utilizado no presente estudo capta as distância lineares entre os marcadores que representam os crânios das diferentes espécies de filostomídeos. O BA-OPI por exemplo, é um caráter que representa comprimento da abertura do foramen magnum. Um questionamento interessante que envolve essa distância é a relação entre o tipo de vôo e a dieta 
em morcegos. O plano do foramen magnum representa o limite entre o occipital e o eixo cervical (Baer \& Nanda, 1976). Esse plano influencia a postura da cabeça e reflete o grau de flexibilidade no eixo crânio-cervical. A manutenção das vias aéreas também influencia à angulação crâniocervical da cabeça, que por sua vez, influencia a posição relativa e a orientação do estiloióide e a musculatura adjacente (Behlfelt, 1990). A orientação do foramen magnum pode estar relacionada ao tipo de vôo e consequentemente às diferentes estratégias de obtenção de alimento em morcegos. O método utilizado no presente trabalho, não captura a orientação ou a inclinação dessa estrutura, ele capta a distância ou o diâmetro do foramen. Nesse sentido, a morfometria geométrica poderia ser uma ferramenta útil na detecção de orientação e inclinação do foramen magnum, auxiliando na investigação dessa estrutura e de sua relação com o tipo de vôo e dieta nos morcegos.

\subsection{Uma abordagem histórica e funcional na compreensão dos módulos}

A partir daqui, o meu objetivo é utilizar aspectos funcionais a fim de compreender a presença de módulos distintos relacionados às subregiões oral e nasal em grande parte das espécies, e a notável detecção modular da abóboda craniana. A similaridade geral nos padrões de integração morfológica craniana na Família Phyllostomidae, pode ser melhor compreendida quando olhamos para a história evolutiva desse grupo tão diverso e intrigante. Esse olhar nos ajuda a entender as mudanças cranianas ocorridas nas diferentes linhagens, relacionadas com a transição para diferentes tipos de dieta a partir de um ancestral insetívoro.

A história começa há aproximadamente 33.9 milhões de anos atrás (Baker et al., 2012; Teeling et al., 2005), em um período em que vertebrados frugívoros aumentavam em número (Fleming, 1991). Freeman, (2000) levantou a suspeita de que o ancestral dos filostomídeos, 
semelhante às formas dos gêneros atuais Micronycteris e Macrotus, era principalmente insetívoro, mas também se alimentava de frutas. Mais recentemente os resultados obtidos por (Baker et al., 2012) corroboram a hipótese de que o sucesso de diversificação dentro dos filostomídeos foi um resultado de mudança de hábitos de insetivoria estrita para a inclusão de material vegetal na dieta. A transição de insetivoria estrita para uma dieta que inclui plantas ocorreu somente duas vezes, uma na Família Phyllostomidae e outra na Família Pteropodidade que compreende os mocegos do Velho Mundo. É importante ter em mente que a mudança de uma dieta rica em insetos para outra dieta qualquer exige não somente a disponibilidade de uma série de fatores ecológicos, como também requer variabilidade genética ancestral que favoreça a seleção direcional de caracteres apropriados.

Segundo Baker et al., (2012), a linhagem que deu origem aos morcegos hematófagos divergiu à aproximadamente 31 milhões de anos atrás. Uma dieta obrigatória em sangue evoluiu apenas uma vez em tetrápodes. Os gêneros Diaemus e Diphylla se especializaram na obtenção de sangue de aves, enquanto o vampiro comum, Desmodus rotundus, alimenta-se principalmente de sangue de mamíferos. Baker et al., (2012) hipotetizaram um ancestral comum dos morcegos hematófagos e forneceram um possível cenário de mudança de hábito alimentar para esse grupo tão fascinante. Os autores sugerem que um ancestral comum semelhante à Micronycteris, e um espaçamento temporal de aproximadamente quatro milhões de anos, formaram a combinação necessária para o sucesso de uma dieta hematófaga, que envolve a evolução de anticoagulantes, mudanças na dentição, alterações antômicas para deslocar-se no solo até a presa, adaptação sensorial na busca de sangue, entre outras.

Considerando-se uma amostra de 48 espécies de filostomídeos, Desmodus rotundos foi uma espécie dentre três que apresentou integração no neurocrânio. Diaemus youngi e Desmodus rotundus também exibiram integração na subregião da abóbada craniana. Parte da explicação para a detecção de módulo no neurocrânio advêm da relação alométrica, no que diz respeito ao 
aumento e à diminuição da região da face. O raciocínio se baseia na compreensão de quão variáveis são os caracteres da face em filostomídeos. Essa relação se dá da seguinte maneira: quanto maior a variação relativa existente entre os caracteres da face, mais evidentes os módulos nessa região. A integração neural aparece em espécies que apresentam menor quantidade de variação relativa na face. Se a influência do crescimento alométrico na face for menor, as correlações nos caracteres da face também serão menores e integração neural aparece. Um outro aspecto que considero muito interessante é que no grupo dos morcegos hematófagos o órgão vomeronasal, também conhecido como órgão de Jacobson é muito desenvolvido (Reep \& Bhatnagar, 2000a). Esse é um órgão olfatorial, que auxilia na detecção de feromônio emitido pelas presas e se desenvolve a partir do epitélio nasal, na borda anterior da placa neural. Nesse grupo de morcegos a região nasal foi detectada como um módulo distinto em todas as espécies, apresentando correlações altas e significativas. De acordo com Baket et al., (2012) os morcegos hematófagos são candidatos à linhagem de mamíferos que foi submetida a maior magnitude da seleção direcional por um período de tempo restrito (quatro milhões de anos), resultando em extrema modificação morfológica, fisiológica, comportamental, e tantas outras características únicas requeridas para se ter uma dieta rica em sangue. Entretanto é preciso ponderar esta colocação de Baker et al., (2012) porque, mesmo considerando os carateres complexos voltados para uma dieta hematófaga, é pouco provável que a seleção direcional tenha sido tão intensa durante um período de tempo tão longo. Esse raciocínio vai em direção oposta à teoria de integração morfológica que prediz que caracteres integrados evoluem em conjunto e rapidamente.

A transição para uma dieta carnívora (ingestão de vertebrados), ocorreu independentemente em morcegos ao menos seis vezes e a linhagem que deu origem aos morcegos carnívoros da família Phyllostomidae divergiu à aproximadamente 20.75 milhões de anos atrás (Baker et al., 2012). A adaptação mais óbvia à carnivoria pode ser vista nos dentes 
(Freeman, 2000). Os crânios por sua vez são alongados, apresentam grande volume cerebral e canal auricular bem desenvolvido (Freeman, 1984). Esta mudança na dieta proporcionou um aumento de massa corporal, e das espécies atuais, Vampyrum se sobressai como a maior das Américas, atingindo aproximadamente 190 gramas, o que corresponde a 20 vezes da massa corpórea de Micronycteris/Macrotus, e alguns podem exceder um metro de envergadura. De acordo com Freeman (2000), Vampyrum escapou de um morfoespaço insetívoro por meio de um mecanismo evolutivo comum: "tornando-se" grande. De maneira geral, a ecolocação auxilia esses morcegos na navegação durante o vôo e na localização da presa. Morcegos carnívoros, como Trachops e Vampyrum exibem o mais desenvolvido aparato visual e olfativo (Reep \& Bhatnagar, 2000).

De acordo com Baker et al., (2012), os morcegos nectarívoros divergiram dos outros filostomídeos à aproximadamente 21.5 milhões de anos atrás. Debates extensos questionam quantas vezes nectarívoros evoluíram dentro da Família Phyllostomidae (Baker \& Bass, (1979); Baker \& Haiduk, 1982; Baker, 1967; Bussche et al., (1998); Griffiths, (1982); Griffiths, (1983); Haiduk \& Baker, 1982, 1984; Smith \& Hood, 1984; Warner, 1983; Carstens et al., 2002; Datzmann et al., 2010; Wetterer et al., 2000).

Grande parte da diversificação nos nectarívoros ocorreu com o alongamento e encurtamento do rostro, a redução do tamanho dos dentes e a evolução de uma língua especializada em obter néctar das corolas das flores (Freeman, 1995; Freeman, 1998; Freeman 2000; Hill \& Smith, 1984). O pólen é considerado a maior fonte de proteína para nectarívoros estritos e pode ser obtido durante a aquisição de néctar e também de forma independente. A língua tem papel fundamental nesse tipo de dieta e é modificada para se projetar além da margem anterior da maxila por meio dos músculos que controlam sua extensão e retração. Ela tem seu peso e atividade controlados pela mandíbula. Os dentes menores são provavelmente resultado de uma língua maior (Freeman, 1995). A perda ou diminuição de dentes é evidenciada em outros 
grupos de mamíferos mirmecófagos que apresentam rostro e língua alongados, como tamanduás, tatus, aardvarks, pangolins e equidnas. De acordo com Smith \& Redford, (1990) há muitas características convergentes entre morcegos nectarívoros e mamíferos mirmecófagos. O alongamento facial nos morcegos nectarívoros se dá provavelmente em resposta à seleção de uma língua maior associada à músculos de protrusão e retração. A mudança no comprimento rostral também é um fenômeno evolutivo recorrente em mamíferos. Sob influência de seleção natural, ocorreram mudanças no comprimento do rostro entre famílias de carnívoros, fato este que se correlaciona com uma dieta mais generalista em Canidae e mais especializada em Felidae (Freeman, 2000).

Todas as espécies de morcegos nectarívoras investigadas no presente trabalho apesentaram a região oral como um módulo evidente, exibindo taxas de modularidade elevadas. A subfamília Glossophaginae também apresentou correlações na subregião da abóbada craniana. De acordo com Reep \& Bhatnagar, (2000b), o desenvolvimento cerebral em morcegos nectarívoros como Choeronycteris, Leptonycteris, Anoura e Glossophaga é o maior entre a ordem Chiroptera, e o autor associa este fato à alta especialidade do grupo em pairar durante a alimentação. Considerando os morcegos necatrívoros é interessante destacar mais uma vez a relação alométrica entre a quantidade de variação relativa na face e a detecção de modularidade no neurocrânio. Choeronycteris mexicana é uma espécie nectarívora, e neste estudo apresenta o rostro mais alongado dentre todas as espécies. Na matriz de covariância para essa espécie, a porcentagem de variação relacionada a tamanho se encontra dispersa entre os componentes principais, de forma que não é capturado por nenhum deles. Na matriz de correlação tamanho encontra-se no segundo componente principal. Observei que o valor de correlação correspondente à taxa de modularidade na região do neurocrânio para essa espécies foi alta (1.5), embora não tenha sido considerada significativa nos testes de modularidade. Mesmo tendo uma face bastante prolongada, o coeficiente de variação na face em Choeronycteris mexicana é mais baixo, 
ou seja, essa espécie não apresenta tanta variação nos caracteres faciais, e dessa forma as correlações no neurocrânio são mais pronunciadas.

Como já destacado, a subregião da abóbada craniana apresentou um número considerável de correlações positivas e significativas entre as espécies de filostomídeos. A detecção de modularidade na abóbada craniana é bastante interessante quando comparada aos resultados obtidos em outros estudos com mamíferos (Marroig et al., 2001; Oliveira et al., 2009; Porto et al., 2009), e principalmente quando compreendemos a importância dessa subregião no sucesso evolutivo dos morcegos filostomídeos. Ao longo da ontogenia, a mudança no tamanho, forma e orientação de cada elemento ósseo reflete a dinâmica combinada entre a taxa de resposta em que cada tecido ósseo responde por uma maior mineralização e/ou remodelagem de superfícies de ossos existentes, e a expansão volumétrica de espaços capsulares, como o nasal ou o cérebro (Pedersen, 2000).

Enquanto a forma e a orientação de cada elemento é fortemente influenciada pelo volume interno, a ossificação subsequente de cada elemento independe do crescimento capsular. Esta independência permite uma remodelagem epigenética de vários elementos cranianos para acompanhar a variação de desenvolvimento nos tecidos moles internos (Ross \& Henneberg, 1995). Grande avanço sobre o que sabemos sobre a relação entre crescimento ósseo e forma do espaço interno advêm de estudos de patologia craniana (Pedersen \& Anton, 1998 apud Pedersen, 2000). Esses exemplos extremos enfatizam a plasticidade epigenética dos ossos e sua habilidade em acomodar distorções anatômicas, ou mesmo alterações que acompanham uma inovação morfológica (Pedersen, 2000).

Ao responder à uma pressão de crescimento geral, o desenvolvimento dos ossos devem acomodar também mudanças mecânicas, relacionadas ao ambiente, como por exemplo, a transição de um dieta para outra como vimos em filostomídeos, que envolve uma combinação de força, musculatura e desenvolvimento ósseo. Exemplo dessas interações diretas entre força 
muscular, e desenvolvimento ósseo são encontradas por toda a abóbada craniana (Pedersen, 2000). Hoyte, (1997) sugeriu que os músculos mastigatórios influenciam a forma da abóbada craniana, e por consequência a forma e a disposição do cérebro.

Claramente, o desenvolvimento do cérebro tem também um impacto profundo no desenvolvimento e na evolução craniofacial em vertebrados (Pedersen, 2000). E o volume do cérebro tem um papel muito importante na evolução craniofacial dos morcegos (Pedersen, 1993). O tamanho relativo do cérebro em morcegos adultos está associado com à ocupação de um nicho aéreo específico (Eisenberg \& Wilson, 1978; Jolicoeur \& Pirlot, 1984). Insetívoros aéreos e caçadores associados à folhagem são encontrados em ambientes abertos ou ao longo dos limites da floresta e possuem cérebros relativamente pequenos (Pedersen, 1993). Eisenberg \& Wilson (1978) sugeriram que o menor tamanho relativo cerebral apresentado por insetívoros aéreos pode ter evoluído em resposta às pressões seletivas para reduzir o peso e facilitar o vôo, ou porque a ecolocação não requer grande volume neocortical.

Frugívoros e carnívoros por sua vez possuem cérebros maiores e forrageiam em hábitats mais complexos e densos (Eisenberg \& Wilson, 1978; Jolicoeur et al., 1984). Baron et al (1996) encontrou correlação significativa entre tamanho relativo grande do cérebro e estratégia alimentar, e discutiu seus resultados com base na intensificação da memória espacial.

O estudo da modularidade avançou muito ao longo dos últimos dez anos em termos da qualidade e da quantidade de dados disponíveis. Há ampla concordância de que a modularidade é um fenômeno real e biologicamente significativo (Wagner et al., 2007), e que envolve questões sobre a estrutura e a organização dos processos que moldam os caracteres fenotípicos (EspinosaSoto \& Wagner, 2010). O desenvolvimento se dá através de uma seqüência de expressões gênicas que desempenham um papel importante na determinação de características fenotípicas. Considerando que as correlações fenotípicas e genéticas podem ser pensadas como consequência de pleiotropia (Marroig \& Cheverud, 2001) uma possível explicação para essa tendência evolutiva 
é a seleção direcional atuando sobre os efeitos pleiotrópicos que determinam módulos fenotípicos (Cheverud et al., 2004; Pavlicev \& Kenney-Hunt, 2008; Wagner et al., 2007). Alguns modelos simples de genética de populações mostram que uma situação em que os efeitos de um gene sobre outros são modificados diferencialmente por outros loci poderiam produzir maior ou menor modularidade (Wagner et al., 2007; Pavlicev \& Kenney-Hunt, 2008).

\subsection{Variação devida ao tamanho e a sua relação com os demais índices}

O tamanho, ou a alometria (Huxley \& Teissier, 1936), pode ser considerada como uma propriedade emergente do processo de crescimento que inclui a integração de diferentes módulos em uma estrutura funcional simples e coerente, como por exemplo o crânio de mamíferos. De acordo com Porto et al., (2013), grande parte da magnitude global de integração entre os elementos morfológicos pode ser atribuída à variação de tamanho.

Em estudos realizados com diferentes grupos de mamíferos foi detectado que a porcentagem de variação relacionada ao tamanho se encontra no primeiro CP (Marroig et al., 2001; Porto etl al., 2009; Oliveira et al., 2009; Porto et al., 2013). Neste caso, os autores encontraram no primeiro CP correlações altas e positivas com a maior parte das variáveis observadas. Os mesmos autores observaram que, de maneira geral, quanto mais variação estiver concentrada no primeiro $\mathrm{CP}$, mais intensas serão as correlações entre os caracteres, maior será a magnitude geral de integração e menos distintos serão os módulos. Este ponto pode facilmente vizualizado na Figura 4.28. Os marsupiais, com suas altas magnitudes de integração, são bons exemplos sobre como o tamanho pode obscurecer a detecção de módulos (Silva, 2010). Quando a variação de tamanho foi removida nesse grupo, os padrões de modularidade tornaram-se mais 
evidentes e os módulos que não podiam ser observados, passaram a ser consistentemente detectados (Porto et al., 2013).

A relação entre magnitude geral de integração e a distinção de módulos foi claramente corroborada nos morcegos filostomídeos. Observei associação negativa significativa entre o ${ }^{2}$ em vários dos índices de modularidade (avg+/avg-), indicando que quanto maior a magnitude geral de integração, menos evidentes serão os módulos. De forma oposta, um crânio que revela módulos mais distintos apresentará magnitudes de integração mais baixas.

Fato interessante no presente estudo foi a constatação de que nem todas as espécies de filostomídeos que compuseram a minha amostra apresentaram variação associada ao tamanho no primeiro componente principal da matriz de covariância. Das 48 espécies analisadas, 23 mostraram variação de tamanho no primeiro CP. Em sete espécies o tamanho se expressa no segundo CP e em 18 espécies tamanho está disperso entre os componentes, de tal forma que não é capturado por nenhum deles. Por outro lado, quando extraí os componentes principais da matriz de correlação, observei que a maior porcentagem de variação associada a tamanho foi capturada no primeiro CP, exceto em sete espécies: Anoura geoffroyi, Ariteus flavescens, Brachyphylla cavernarum, Centurio senex, Choeronycteris mexicana, Diaemus youngi, Lonchorbina orinocensis e Monophyllus redmani.

Para compreendermos este fenômeno, vamos retomar à discussão sobre o efeito de escala nos dados. Na matriz de covariância, os caracteres mais variáveis são os mais dominantes, e dessa forma o primeiro CP deixa de ser tamanho. Usando a matriz de correlação, que é independente de escala, o efeito da variância desaparece e o tamanho é capturado no primeiro CP. Resumidamente, o efeito da variância em alguns caracteres atua mascarando o efeito do tamanho. Controlando para o efeito de escala na matriz de correlação, o tamanho volta a dominar o primeiro CP. Isso reforça a importância e a aplicabilidade das matrizes de correlação e de covariância em estudos de evolução. Quando se trata da investigação de processos evolutivos 
por exemplo, a escala é um fator que deve ser levado em conta, e neste caso o uso da matriz de covariância é mais apropriado. Matrizes de correlação por sua vez independem de escala, e sua função pode ser direcionada para investigações à cerca da integração morfológica dos organismos.

Ainda assim, encontrei correlação positiva e significativa entre a quantidade de variação no primeiro CP e os índices de integração morfológica $\mathrm{r}^{2}(0.80)$ e ICV (0.96). Espécies mais integradas morfologicamente (Lonchorbina aurita) apresentam maior variação no primeiro CP, enquanto espécies com valores mais baixos na magnitude geral de correlações entre os caracteres (Sphaeronycteris toxophyllum, por exemplo), têm variação menor no primeiro CP. Uma explicação plausível para o valor mais baixo de correlação obtido para o $r^{2}$ em comparação ao ICV, vem do fato de que o $\mathrm{r}^{2}$ é calculado a partir da matriz de correlação e a variação do primeiro CP foi extraída a partir da matriz de covariância.

Outro ponto importante é que a variação associada ao tamanho não somente obscurece a detecção de módulos como também atua como uma força de restrição no potencial de mudança evolutiva (ver Marroig et al., 2009). Os índices de flexibilidade e restrição evolutivas serão discutidos com maior particularidade no próximo tópico, porém também os associo aqui no que diz respeito às suas relações com variação de tamanho. Quanto maior a influência relativa de variação de tamanho, mais restritas as respostas possíveis à seleção natural (Porto et al., 2013). Essa tendência também foi verficada nos morcegos filostomídeos com uma correlação positiva e significativa entre a quantidade de variação no primeiro $\mathrm{CP}$ e o índice de restrição. Em Lonchorbina aurita, a quantidade de variação no primeiro CP atua como uma força de restrição no potencial de mudança evolutiva dessa espécie. De forma contrária Sphaeronycteris toxophyllum e Phyllops falcatus mostraram maiores valores de flexibilidade evolutiva e baixa quantidade de variação no primeiro CP. Com a exceção de Choeronycteris mexicana, as demais espécies nectarívoras apresentaram valores de flexibilidade relativamente altos e pouca variação explicada 
pelo primeiro CP. Na maioria das espécies nectarívoras o tamanho está disperso ao longo dos componentes principais.

Nesse ponto algumas considerações relacionadas a tamanho são importantes e interessantes. Os padrões de variação genética e de desenvolvimento podem restringir ou facilitar a evolução de complexos morfológicos e coordenar a direção e o ritmo da mudança evolutiva (Marroig et al., 2005). Enquanto restrições podem ser percebidas como um obstáculo à evolução em algumas direções, elas tambem podem ser consideradas como facilitadoras do processo adaptativo ao longo do que Schluter (1996) denominou de "linhas de menor resistência evolutiva". Segundo Schluter (1996), como os processos evolutivos atuam sobre a variação que existe nas populações, sua ação ocorre mais facilmente nos eixos em que há mais variação. Dessa forma a evolução ocorreria ao longo das linhas de menor resistência evolutiva, e seria portanto, facilitada nesse eixo. Nos mamíferos, essa linha de menor resistência evolutiva é na maioria das vezes representada pela variação de tamanho (Marroig et al., 2005; Marroig et al., 2009; Porto et al., 2009,). Vimos que em uma quantidade considerável de espécies de filostomídeos a linha de menor resistência evolutiva não é tamanho (nem todos os primeiro componentes principais são tamanho). Fato interessante é que mesmo não sendo tamanho, esse componete ainda age como uma restrição à evolução. Esse resultado é evidente nos valores de correlação altos e significativos entre os índices de magnitude geral de integração e o primeiro componente principal, e das correlações entre o primeiro CP e os índices de flexibilidade e restrição.

\subsection{Flexibilidade evolutiva e Restrição}

Mudanças nos padrões e nas magnitudes de integração podem influenciar a capacidade das espécies em responder à seleção (Marroig et al., 2009). Consequentemene, modularidade tem 
sido com frequência associada ao conceito de evolvabilidade (Hansen, 2003; Hansen \& Houle, 2008; Marroig et al., 2009). A flexibilidade evolutiva mede o quanto uma população ou espécie é capaz de responder na direção da seleção em termos de alinhamento da resposta com a seleção, enquanto o índice de restrição informa a influência relativa da primeiro componente principal sobre a direção das respostas evolutivas, sendo este o eixo que carrega a maior parte da variação presente na matriz de covariância (primeiro CP), definido por Schluter (1996) como "linha de menor resistência evolutiva".

Vale destacar que de maneira geral e comparando com os demais grupos de mamíferos, os morcegos filostomídeos apresentam crânios muito flexíveis, capazes de responder na direção em que a seleção está atuando. Ainda assim é importante considerar que o crânio, mesmo flexível, ainda é uma estrutura integrada e impõe algum grau de restrição evolutiva. Isso fica mais evidente se pensarmos na flexibilidade como um índice que representa valores de correlação. Lembre-se que a flexibilidade representa a correlação entre o vetor do gradiente de seleção $(\boldsymbol{\beta})$ e o vetor de resposta evolutiva ( $\boldsymbol{\Delta} \mathbf{z}$; Marroig et al., 2009). O maior e menor valor de flexibilidade estiveram em torno de 0.57 e 0.38 , respectivamente. Estes valores mostram o quanto as respostas evolutivas são em média defletidas de sua trajetória ótima dada a integração existente no crânio. Embora no geral os filostomídeos sejam caracterizados como um grupo "flexível" em comparação a diversos outros mamíferos (Marroig et al., 2009) é importante notar que esta flexibilidade é bastante limitada, de forma que usalmente, a resposta evolutiva microevolutiva não teria um alinhamento muito forte com a seleção direcional operando. Outra forma de visualziar isto é o fato de que por serem integrados e apresentarem uma parcela substancial da variação concentrada no primeiro CP, sendo ele tamanho ou não, esta linha de menor resistência irá atuar como uma força de restrição evolutiva.

Obtive correlação negativa e significativa entre o índice de integração morfológica (r2) e a flexibilidade evolutiva $(\mathrm{r}=-0.7 ; \mathrm{p}<0.001)$. Essa relação foi ainda maior quando utilizei o 
índice de integração estimado a partir da matriz de covariação (ICV) (r=-0.96; p<0.001), isso porque o índice de flexibilidade também é estimado a partir das matrizes de covariância. Estes resultados mostram que espécies que apresentam alta magnitude geral de integração entre os caracteres do crânio possuem menor capacidade de evoluir na direção da seleção, ou em outras palavras, apresentam mais respostas alinhadas ao eixo de maior variação. Nesse quesito encontram-se algumas espécies como Choeronycteris mexicana, Vampyrum spectrum e Loncorbina aurita.

No outro extremo, destacam-se Sphaeronycteris toxophyllum e Phyllops falcatus com asssociações mais baixas nos caracteres cranianos e portanto, com maior habilidade em responder na direção em que a seleção está atuando. Detectei correlações positivas e significativas entre o índice de restrição evolutiva e os índices de magnitude geral de integração, em que as espécies Macrotus waterhousii, Micronyctreis microtis e Uroderma magnirostrum figuram crânios mais restritos evolutivamente.

Encontrei correlação positiva e significativa entre flexibilidade e a hipótese de integração da neuroface $(r=0.3 ; p=0.044)$. Essa correlação é maior $(r=0.81 ; p<0.001)$ quando olhamos separadamente para os demais mamíferos (Marroig et al., 2009). O mesmo ocorre com a correlação entre o índice de modularidade de integração total com o índice de restrição. Nos morcegos filostomídeos a correlação foi de $\mathrm{r}=-0.43$; $\mathrm{p}=0.003$ e nos demais mamíferos de $\mathrm{r}=0.87$; $\mathrm{p}<0.001$. Esses valores de correlação mais baixos nos filostomídeos é produto do desacoplamento entre as matizes de covariância e correlação observada nesse grupo. Neste caso os índices de modularidade (avg+/avg-) são obtidos a partir das matrizes de correlação enquanto os índices de flexibilidade e restrição são obtidos com base nas matrizes de covariância. Este desacoplamento é resultado de um fenômeno de escala como discutido acima.

Dentro de um contexto comparativo, enquanto a área de distribuição de valores de $\mathrm{r}^{2}$ ocupada pelos filostomídeos é estreita, a faixa de valores de flexibilidade desse grupo se sobrepõe em grande parte àquela ocupada pelos demais mamíferos estudados por Marroig et al., (2009). De 
maneira geral os valores de flexibilidade evolutiva foram altos entre os Eutheria e baixos entre a maioria dos Metatheria. As ordens Peramelimorphia, Diprotodontia, Didelphimorphia, Hyracoidea, Cingulata, Paucituberculata, Lagomorpha e Carnivora, e o gênero Papio (representante dos primatas do velho mundo), encontram-se na faixa dos valores de restrição e flexibilidade não ocupada pelos filostomídeos. Neste espaço, esses mamíferos apresentam os maiores valores de restrição evolutiva, e os menores valores de flexibilidade.

Inserindo os morcegos filostomídeos no contexto dos demais mamíferos parece que a evolução da integração morfológica seguiu uma tendência geral na qual o padrão de modularidade foi mantido similar por seleção estabilizadora, a magnitude geral de integração diminuiu e a distinção dos módulos aumentou. Os crânios de espécies que apresentam magnitude de integração mais baixas são menos restritos evolutivamente, e capazes de responder mais prontamente às pressões de seleção. Este parece ser o contexto no qual se enquandra a maioria das espécies de morcegos da família Phyllostomidae.

As consequências evolutivas dos padrões e das magnitudes de integracao morfológica estimulam questionamentos sobre a evolução dos grupos. A discussão que segue têm apenas o intuito de levantar alguns questionamentos biológicos e motivar investigações futuras. Os pontos que abordo abaixo não compuseram os objetivos da tese, mas como este exercício de escrita nos dá de certa forma a liberdade de uma discussão mais extensa, aproveito para colocar no papel algumas inspirações que advém dos resultados obtidos.

Poderíamos questionar por exemplo, o por quê Sphaeronycteris toxophyllum e Phyllops falcatus apresentaram asssociações mais baixas nos caracteres cranianos e portanto, maior flexibilidade evolutiva. Estas duas espécies (respresentantes da subfamília Stenodermatinae), pertencem a uma tribo que se especializou na dieta de frutas duras, e se diversificou mais recentemente entre os morcegos filostomídeos. Eisenberg \& Wilson (1978) sugeriram que um tamanho relativo grande do cérebro está associado à morcegos em que os recursos alimentares 
estão distribuídos em porções isoladas no espaço, e muitas vezes imprevisíveis no que diz respeito à sua distribuição temporal. Os stenodermatineos apresentam o maior tamanho total cerebral de qualquer subfamília dentro da Família Phyllostomidae (Baron et al, 1996c). Eles foram caracterizados por (Bonaccorso, 1979) como frugívoros de dossel pelo fato de se alimentarem de frutas que crescem nas árvores, e epífitas no nível superior da copa das florestas. De acordo com esse autor, isso requer uma exploração intensiva e uma memória espacial bem desenvolvida. Dumont et al., (2012) corroboraram a hipótese de que mudanças na morfologia do crânio permitiu a expansão de nichos alimentares em Stenodermatinae. Essas evidências encorajam investigações futuras sobre se a taxa de diversificação das espécies de filostomídeos, e a expansão de nichos alimentares está relacionada à uma maior ou menor flexibilidade evolutiva.

Uma outra questão que pode ser levantada é, como espécies diferentes de um mesmo gênero, como Macrotus californicus e Macrotus waterhoussi poderiam divergir tanto com relação às magnitudes de integração, flexibilidade e restrição. M. californicus e $M$. waterhousi apresentaram algumas diferenças interessantes: na primeira foi detectado o módulo na subregião da abóbada craniana (com alta correlação), enquanto em M.waterhousii esse módulo não se mostrou significativo. A magnitude de integração em M. californicus foi duas vezes menor do que a observada em $M$. waterhousii. Além disso $M$. californicus apresentou uma maior flexibilidade evolutiva e menor restrição em comparação com $M$. waterhousii, o que indica que a estrutura craniana da primeira espécie possui uma maior capacidade em responder na direção da seleção.

Sabe-se que o tamanho amostral é uma variável que pode influenciar esses índices, mas nesse caso essa relação pode ser descartada já que as duas espécies possuem número amostral idêntico (cada uma com 60 indivíduos). A fim de entender essas diferenças poderíamos por exemplo abordar algumas particularidades relacionadas à biologia e história de vida das espécies. Estudos comportamentais realizados por Bell \& Fenton, (1986) demonstraram que M. californicus, uma espécie que habita áreas desérticas e utiliza a visão para localizar suas presas, 
possui uma acuidade visual superior a outros morcegos insetívoros, e muito equivalentes às espécies frugívoras e nectarívoras que apresentam aparato visual desenvolvido. Os autores compararam M. californicus a outras duas espécies de morcegos, Antrozous pallidus, um caçador de deserto que localiza a presa pelo som que ela produz e Eptesicus fuscus, uma forrageadora aérea que utiliza a ecolocação para encontrar a presa, e constataram que os olhos de $M$. californicus são mais direcionados anteriormente e tem duas vezes a sobreposição binocular das outras espécies examinadas. Tal acurácia visual poderia explicar uma maior flexibilidade evolutiva comparada com $M$ waterhousii. Vale ressaltar que os fatores descritos acima servem como hipóteses na tentativa de compreender os padrões aqui observados e motivar investigações futuras. Delineamentos experimentais rigorosos deverão ser traçados a fim de testar hipóteses sobre padões particulares e o modo de vida de cada grupo e entre populações diferentes.

Existem alguns questionamentos mais gerais e paupáveis que pretendo investigar ao longo dos próximos anos, utilizando a base de dados que coletei para a Família Phyllostomidae. Uma questão em potencial é investigar o papel relativo da seleção natural e da deriva genética na diversificação craniana desse grupo. Esses resultados servirão de base para testar efetivamente a ocorrência ou não de irradiação adaptativa nos morcegos filostomídeos, seguindo os critérios propostos por Schluter, (2000). Pretendo também utilizar os morcegos da Família Phyllostomidae como modelo para testar idéias relacionadas às linhas de menor resistência evolutiva propostas por Schluter, (1996), avaliando sua associação com a magnitude (intensidade da associação entre os traços) e o ritmo da mudança evolutiva. Tenho interesse também em investigar se a linha de menor resistência evolutiva afetou a taxa de diversificação e especiação desse grupo. Como mencionado nos métodos desta tese, fotografei crânios de indivíduos jovens para a grande maioria das espécies amostradas. A minha meta é trabalhar nessa base de dados de imagens a fim de gerar informações anatômicas e osteológicas cranianas referentes aos morcegos filostomídeos. Além dos morcegos filostomídeos, coletei dados de outras famílias ou subordens de morcegos, 
priorizando a ocorrência de grandes séries que se apresentavam em boas condições (crânios limpos e preservados) e de mesma localidade. No FMNH por exemplo, me deparei com amostras significativas de Madagascar e da Tanzânia (coletas de mesma série temporal e localidade), para as Famílias Pteropodidae, Hipposideridae e Molossidae. Tenho aproximadamente 500 indivíduos medidos entre essas famílias citadas e pretendo incorporar essas amostras ao banco de dados e avançar com análises de modularidade e estimativas de padrões e magnitudes de integração para essas espécies. 


\section{CONCLUSÕES}

Após um período de diversificação evolutiva de aproximadamente 33.9 milhões de anos, a estrutura fenótipica de variância/covariância se manteve até certo ponto similar entre as espécies de morcegos da Família Phyllostomidae. Enquanto os padrões estruturais das matrizes de correlação e covariação permaneceram relativamente similares, a magnitude geral de integração se mostrou evolutivamente mais plástica entre as espécies. A abordagem dessa métrica quando feita de forma comparativa entre diferentes grupos de mamíferos, sugere para a Família Phyllostomidae a existência de valores baixos que ocupam uma faixa estreita de dispersão. A distinção nos valores de magnitude de integração entre as espécies tem implicações importantes na evolução dos grupos. Os caracteres cranianos que mais divergiram entre as matrizes estão relacionados às regiões do crânio que expressam grande variação morfológica qualitativa e estão diretamente relacionadas aos hábitos alimentares das espécies.

Os resultados sugerem que a seleção direcional, atuando na diversificação da média dos caracteres, pode ter moldado os padrões de covariação, explicando assim o restante das diferenças entre as matrizes que não pode ser atribuída ao erro de amostragem. Este é um ponto ainda não testado diretamente nos filostomídeos (seleção direcional sobre as médias durante a diversificação) mas é uma hipótese bastante razoável neste ponto, dado o grau de modificação qualitativa do crânio observada nestes morcegos e sua associação à dieta. Além disso a hipótese de seleção direcional encontra suporte indireto também nos resultados desta tese já que dieta está correlacionada tanto com a diferencição morfológica média como com as diferenças nas estruturas das matrizes. A independência entre a distância filogenética e a similaridade estrutural das matrizes de variância/covariância indica que as mudanças e as manutenções dos padrões de covariância são, até certo ponto, dissociados da história evolutiva do grupo. Por outro lado, mudanças nas estrutura de correlação e covariância fenotípicas estão associadas à dieta do grupo. Embora dieta e filogenia estejam relacionadas, estes fatores diferem quanto a sua associação (e 
potencial causalidade) com a evolução tanto do fenótipo médio quanto da estrutura de correlação entre os caracteres do crânio. A dieta mostrou um ajuste melhor do que a filogenia para as matrizes de correlação, e para as matrizes de distância morfológica. Além disso os resultados reforçam que não há evidência forte de inércia filogenética já que ao remover a variação na filogenia associada a dieta, esta última mantém sua associação tanto com as distâncias morfológicas como com a similaridade estrutural das matrizes (correlação) enquanto o contrário não ocorreu, ou seja, a relação da filogenia sem dieta com a evolução das médias e da estrutura das matrizes desaparece. Ao que tudo indica, esse cenário parece sugerir que a oportunidade de nichos vagos pode ter levado à diversificação filogenética das espécies, bem como à diversificação na média dos caracteres e na estrutura de covariação. Esses resultados estimulam um teste de hipótese formal de inércia filogenética (ou de sinal filogenético) tanto para a evolução das médias como das matrizes. Além disso, os resultados demonstram que os filostomídeos compartilham padrão de modularidade craniana relacionado à função e desenvolvimento, e corrobora a organização modular encontrada em outras linhagens de mamíferos. Em geral, as subregiões oral, nasal e a abóbada craniana aparecem como módulos dominantes nos crânios destes morcegos, e um olhar para aspectos funcionais e de história evolutiva ajudam a compreender os padrões de integração morfológica desse grupo tão diverso e intrigante. A relação entre magnitude geral de integração e a distinção de módulos foi claramente corroborada nos morcegos filostomídeos, tendo sido observada uma associação negativa significativa entre o $\mathrm{r}^{2}$ em vários dos índices de modularidade (avg+/avg-). Os resultados indicam que quanto maior a magnitude geral de integração, menos evidentes serão os módulos. De forma oposta, um crânio que revela módulos mais distintos apresentará magnitudes de integração mais baixas. Diferentemente do padrão encontrado em outros grupos de mamíferos, nem todas as espécies de filostomídeos estudadas aqui apresentaram variação associada ao tamanho no primeiro componente principal da matriz de covariância, resultado este que difere do padrão encontrado em outros grupos de mamíferos. Mesmo não sendo tamanho, esse componente ainda assim atua como uma força de restrição no 
potencial de mudança evolutiva nos morcegos da Família Phyllostomidae. Esse resultado é evidente nos valores de correlação altos e significativos entre os índices de magnitude geral de integração e o primeiro componente principal, e das correlações entre o primeiro CP e os índices de flexibilidade e restrição. Espécies que apresentaram alta magnitude geral de integração entre os caracteres do crânio possuem menor capacidade de evoluir na direção da seleção, sendo portanto mais restritas evolutivamente. Espécies de filostomídeos que apresentam asssociações mais baixas nos caracteres cranianos apresentam maior flexibilidade evolutiva, ou seja, maior capacidade em responder na direção em que a seleção está atuando. Estes trabalho é um passo inicial para a compreensão da diversificação craniana dos morcegos da Família Phyllostomidae. Estes resultados estimulam outras questões concernentes à evolução do grupo, relacionadas por exemplo: ao papel relativo da seleção natural e deriva genética na geração de diversidade; à detecção de irradiação adaptativa; às linhas de menor resistência evolutiva avaliando suas associções com o ritmo da mudança evolutiva e a magnitude de integração entre os caracteres; às taxas de diversificação e expansão de nichos alimentares em morcegos filostomídeos. 


\section{REFERÊNCIAS BIBLIOGRÁFICAS}

Ackermann, R R, \& Cheverud, J M (2000). Phenotypic covariance structure in tamarins (genus Saguinus): a comparison of variation patterns using matrix correlation and common principal component analysis. American journal of physical anthropology, 111(4), 489-501.

Ackermann, R R, \& Cheverud, J M (2004). Morphological integration in primate evolution. In Phenotypic integration: Studying the ecology and evolution of complex Phenotypes.(Pigliucci \&Preston, eds.) Oxford University Press, Oxford, p 303-319

Ackermann, R R. (2002). Patterns of covariation in the hominoid craniofacial skeleton: implications for paleoanthropological models. Journal of Human Evolution, 43(2), 167-187.

Adams, R., \& Pedersen, S (2000). Ontogeny, functional ecology, and evolution of bats. Cambridge University Press, New York.

Agrawal, A F, \& Stinchcombe, J R (2009). How much do genetic covariances alter the rate of adaptation?. Proceedings of the Royal Society B: Biological Sciences, 276(1659), 1183-1191.

Armbruster, W S, Di Stilio, V S, Tuxill, J D, Flores, T C, \& Runk, J L V (1999). Covariance and decoupling of floral and vegetative traits in nine Neotropical plants: a re-evaluation of Berg's correlation-pleiades concept. American Journal of Botany, 86(1), 39-55.

Arnold, S J (1981). Behavioral variation in natural populations. II. The inheritance of a feeding response in crosses between geographic races of the garter snake, Thamnophis elegans. Evolution, 510-515.

Arnold, S J (1992). Constraints on phenotypic evolution. American Naturalist, S85-S107.

Arnold, S J, Pfrender, M E, \& Jones, A G (2001). The adaptive landscape as a conceptual bridge between micro-and macroevolution. Genetica, 112(1), 9-32.

Arnold, S J, \& Phillips, P C (1999). Hierarchical comparison of genetic variance-covariance matrices. II. Coastal-inland divergence in the garter snake, Thamnophis elegans. Evolution, 1516-1527.

Arroyo-Cabrales, J, Hollander, R R , \& Jones, J K (1987). Choeronycteris mexicana. Mammalian Species, (291), 1-5.

Atchley, W R, Rutledge, J. J., \& Cowley, D. E. (1981). Genetic components of size and shape. II. Multivariate covariance patterns in the rat and mouse skull. Evolution, 35(6), 1037-1055.

Baer, M J, \& Nanda, S. K. (1976). A commentary on the growth and form of the cranial base. Development of the Basicranium, 515-540. 
Baker, R J (1967). Karyotypes of bats of the family Phyllostomidae and their taxonomic implications. The Southwestern Naturalist, 407-428.

Baker, R J (2003). Diversification among New World leaf-nosed bats: an evolutionary hypothesis and classification inferred from digenomic congruence of DNA sequence. Museum of Texas Tech University.

Baker, R J, \& Bass, R A (1979). Evolutionary relationship of the Brachyphyllinae to the glossophagine genera Glossophaga and Monophyllus. Journal of Mammalogy, 364-372.

Baker, R J, Haiduk, M W, Robbins, L W, Cadena, A, \& Koop, B F (1982). Chromosomal studies of South American bats and their systematic implications. Mammalian Biology in South America, 4, 303-327.

Baker, R J, Hood, C S, \& Honeycutt, R L (1989). Phylogenetic relationships and classification of the higher categories of the New World bat family Phyllostomidae. Systematic Biology, 38(3), 228-238.

Baker, R J, Bininda-Emonds, O, Mantilla-Meluk, H., Porter, C A, \& Den, V B (2012). Molecular time scale of diversification of feeding strategy and morphology in New World Leaf-Nosed Bats ( Phyllostomidae ): a phylogenetic perspective. In Evolutionary History of Bats: Fossils, Molecules and Morphology (Cambridge Studies in Morphology and Molecules: New Paradigms in Evolutionary Bio) (1 edition). G. F. Gunnell \& N. B. Simmons (Eds.), Cambridge University Press.

Bégin, M, \& Roff, D (2004). From micro- to macroevolution through quantitative genetic variation: positive evidence from field crickets. Evolution; international journal of organic evolution, 58(10), 2287-304.

Behlfelt, K, Linder-Aronson, S, \& Neander, P (1990). Posture of the head, the hyoid bone, and the tongue in children with and without enlarged tonsils. The European Journal of Orthodontics, 12(4), 458-467.

Bell, G P, \& Fenton, M B (1986). Visual acuity, sensitivity and binocularity in a gleaning insectivorous bat, Macrotus californicus (Chiroptera: Phyllostomidae). Animal Behaviour, 34(2), 409-414.

Berg, R L (1960). The ecological significance of correlation pleiades. Evolution, 171-180.

Bininda-Emonds, O. R., Cardillo, M., Jones, K. E., MacPhee, R. D., Beck, R. M., Grenyer, R., ... $\&$ Purvis, A. (2007). The delayed rise of present-day mammals. Nature, 446(7135), 507-512.

Blackith, R, \& Reyment, R (1971). Multivariate morphometrics. Academic Press: London and New York. p 412. 
Blows, M W, Chenoweth, S F, \& Hine, E (2004). Orientation of the genetic variance-covariance matrix and the fitness surface for multiple male sexually selected traits. The American Naturalist, 163(3), 329-340.

Bonaccorso, F J (1979). Foraging and reproductive ecology in a Panamanian bat community. Florida State Museum of the University of Florida.

van Den Bussche, RA (1992). Restriction-site variation and molecular systematics of New World leaf-nosed bats. Journal of Mammalogy, 29-42.

van Den Bussche, R A, \& Baker, R J (1993). Molecular phylogenetics of the New World bat genus Phyllostomus based on cytochrome b DNA sequence variation. Journal of Mammalogy, 793-802.

van Den Bussche, R A, Hudgeons, J L, \& Baker, R J (1998). Phylogenetic accuracy, stability, and congruence: relationships within and among the New World bat genera Artibeus, Dermanura, and Koopmania. Bat biology and conservation (TH Kunz and PA Racey, eds.). Smithsonian Institution Press, Washington, DC, 59-71.

Carstens, B C, Lundrigan, B L, \& Myers, P (2002). A phylogeny of the neotropical nectar-feeding bats (Chiroptera: Phyllostomidae) based on morphological and molecular data. Journal of Mammalian Evolution, 9(1-2), 23-53.

Chernoff, B, \& Magwene, P M (1999). Morphological integration: forty years later. Morphological integration, 319-353.

Cheverud, J M (1982). Phenotypic, genetic, and environmental morphological integration in the cranium. Evolution, 499-516.

Cheverud, J M (1984). Quantitative genetics and developmental constraints on evolution by selection. Journal of Theoretical Biology, 110(2), 155-171.

Cheverud, J M (1988). A comparison of genetic and phenotypic correlations. Evolution, 958-968.

Cheverud, J M (1989). A comparative analysis of morphological variation patterns in the papionins. Evolution, 1737-1747.

Cheverud, J M (1995). Morphological integration in the saddle-back tamarin (Saguinus fuscicollis) cranium. American Naturalist, 63-89.

Cheverud, J M (1996a). Developmental integration and the evolution of pleiotropy. American Zoologist, 36(1), 44-50.

Cheverud, J. M. (1996). Quantitative genetic analysis of cranial morphology in the cotton-top (Saguinus oedipus) and saddle-back (S. fuscicollis) tamarins. Journal of Evolutionary Biology, 9(1), 5-42. 
Cheverud, JM (2004). Darwinian Evolution by the Natural Selection of Heritable Variation. The origins and nature of sociality.

Cheverud, J M, Dow, M M, \& Leutenegger, W (1985). The quantitative assessment of phylogenetic constraints in comparative analyses: sexual dimorphism in body weight among primates. Evolution, 1335-1351.

Cheverud, J M, \& Marroig, G (2007). Research Article Comparing covariance matrices: random skewers method compared to the common principal components model. Genetics and Molecular Biology, 30(2), 461-469.

Cheverud, J M, \& Routman, E J (1995). Epistasis and its contribution to genetic variance components. Genetics, 139(3), 1455-1461.

Cheverud, J M, Wagner, G P, \& Dow, M M (1989). Methods for the comparative analysis of variation patterns. Systematic Biology, 38(3), 201-213.

Clausen, J, \& Hiesey, W M (1960). The balance between coherence and variation in evolution. Proceedings of the National Academy of Sciences of the United States of America, 46(4), 494.

Datzmann, T., von Helversen, O., \& Mayer, F. (2010). Evolution of nectarivory in phyllostomid bats (Phyllostomidae Gray, 1825, Chiroptera: Mammalia). BMC Evolutionary Biology, 10(1), 165.

De Vienne, D M, Aguileta, G, \& Ollier, S (2011). Euclidean nature of phylogenetic distance matrices. Systematic biology, 60(6), 826-32.

Diniz Filho, J A F (2000). Métodos filogenéticos comparativos. Holos Editora. Riberião Preto.

Draghi, J, \& Wagner, G P (2008). Evolution of evolvability in a developmental model. Evolution, 62(2), 301-315.

Draghi, J, \& Wagner, G P (2009). The evolutionary dynamics of evolvability in a gene network model. Journal of evolutionary biology, 22(3), 599-611.

Dumont, E R (1999). The effect of food hardness on feeding behaviour in frugivorous bats (Phyllostomidae): an experimental study. Journal of Zoology, 248(2), 219-229.

Dumont, E R, Weiblen, G D, \& Winkelmann, J R (2004). Preferences of fig wasps and fruit bats for figs of functionally dioecious Ficus pungens. Journal of Tropical Ecology, 20(2), 233-238.

Dumont, E R, Piccirillo, J, \& Grosse, I R (2005). Finite-element analysis of biting behavior and bone stress in the facial skeletons of bats. The Anatomical Record Part A: Discoveries in Molecular, Cellular, and Evolutionary Biology, 283(2), 319-330. 
Dumont, E R, Grosse, I R, \& Slater, G J (2009). Requirements for comparing the performance of finite element models of biological structures. Journal of Theoretical Biology, 256(1), 96-103.

Dumont, E R (2003). Bats and fruit: an ecomorphological approach. Bat ecology, 398-429.

Dumont, E R, \& Nicolay, C W (2006). Cross-sectional geometry of the dentary in bats. Zoology, 109(1), 66-74.

Dumont, E R, Dávalos, L M, Goldberg, A, Santana, S E, Rex, K, \& Voigt, C C (2012). Morphological innovation, diversification and invasion of a new adaptive zone. Proceedings of the Royal Society B: Biological Sciences, 279(1734), 1797-1805.

Eguiarte, L, \& Búrquez, A (1987). Reproductive ecology of Manfreda brachystachya, an iteroparous species of Agavaceae. The Southwestern Naturalist, 169-178.

Eisenberg, J F, \& Wilson, D E (1978). Relative brain size and feeding strategies in the Chiroptera. Evolution, 740-751.

Espinosa-Soto, C, \& Wagner, A (2010). Specialization can drive the evolution of modularity. PLoS computational biology, 6(3), e1000719.

Evans, S A, \& Evans, H E (1993). Miller's Anatomy of the Dog. Saunders (W.B.) Co Ltd. 1130p.

Ferrarezzi, H, \& Gimenez, E D A (1996). Systematic patterns and the evolution of feeding habits in Chiroptera (Archonta: Mammalia). Journal of Comparative Biology, 1(3/4), 75-94.

Findley, J (1993). Bats: a community perspective Cambridge University Press. New York.

Fleming, T. (1991). The relationship between body size, diet, and habitat use in frugivorous bats, genus Carollia (Phyllostomidae). Journal of Mammalogy, 72(3):493-501.

Freeman, P. (1995). Nectarivorous feeding mechanisms in bats. Biological Journal of the Linnean Society, 56(3), 439-463.

Freeman, P., \& Lemen, C. (2010). Simple predictors of bite force in bats: the good, the better and the better still. Journal of Zoology, 282(4), 284-290.

Freeman, P. (1988). Frugivorous and animalivorous bats (Microchiroptera): dental and cranial adaptations. Biological Journal of the Linnean Society, (33), 249-272.

Freeman, P. (1992). Canine teeth of bats (Microchiroptera): size, shape and role in crack propagation. Biological Journal of the Linnean Society (45), 97-115.

Freeman, P. (2000). Macroevolution in Microchiroptera: Recoupling morphology and ecology with phylogeny. Evolutionary Ecology Research (2), 317-335. 
Freeman, P. (1984). Functional cranial analysis of large animalivorous bats (Microchiroptera). Biological Journal of the Linnean Society, 21(4), 387-408.

Freeman, P. (1998). Form, Function, and Evolution in Skulls and Teeth of Bats.Papers in Natural Resources. Paper 9. http://digitalcommons.unl.edu/natrespapers/9

Freeman, P. (2000). Macroevolution in Microchiroptera: recoupling morphology and ecology with phylogeny. Evolutionary Ecology Research 2 (2000), pp. 317-335.

Freeman, P, \& Weins, W. (1997). Puncturing ability of bat canine teeth: the tip. http://digitalcommons.unl.edu/museummammalogy/9

Game, E. T., \& Caley, M. J. (2006). The stability of P in coral reef fishes.Evolution, 60 (4), 814823.

Gardner, A. L. (1977). Feeding habits. Biology of bats of the New World family Phyllostomatidae, 13 (Part II), 1-364.

Gayon, J. (2000). History of the concept of allometry. American Zoologist,40(5), 748-758.

Giannini, N. P., \& Kalko, E. K. (2004). Trophic structure in a large assemblage of phyllostomid bats in Panama. Oikos, 105(2), 209-220.

Giannini, N. P., Wible, J. R., \& Simmons, N. B. (2006). On the cranial osteology of Chiroptera. I. Pteropus (Megachiroptera: Pteropodidae). Bulletin of the American Museum of Natural History, 1134.

Giannini, N. P., \& Simmons, N. B. (2007). Element homology and the evolution of dental formulae in megachiropteran bats (Mammalia: Chiroptera: Pteropodidae). American Museum Novitates, 1-27.

Gimenez, E. D. A., Ferrarezzi, H., \& Taddei, V. A. (1996). Lingual morphology and cladistic analysis of the New World nectar-feeding bats (Chiroptera: Phyllostomidae). Journal of Comparative Biology, 1(1-2), 41-63.

Griffiths, T. A. (1982). Systematics of the New World nectar-feeding bats (Mammalia, Phyllostomidae), based on the morphology of the hyoid and lingual regions. American Museum novitates; no. 2742.

Goodwin, G. G., \& Greenhall, A. M. (1961). A review of the bats of Trinidad and Tobago: descriptions, rabies infection, and ecology. American Museum of Natural History.

Goswami, A. (2006). Cranial modularity shifts during mammalian evolution. The American Naturalist, 168(2), 270-280. 
Goudy-Trainor, A., \& Freeman, P. W. (2002). Call parameters and facial features in bats: a surprising failure of form following function. Acta Chiropterologica, 4(1), 1-16.

Gregorin, R., \& Ditchfield, A. D. (2005). New genus and species of nectar-feeding bat in the tribe Lonchophyllini (Phyllostomidae: Glossophaginae) from northeastern Brazil. Journal of Mammalogy, 86(2), 403-414. Griffiths, T. (1982). Systematics of the New World nectarfeeding bats (Mammalia, Phyllostomidae), based on the morphology of the hyoid and lingual regions. American Museum.

Griffiths, T. A. (1982). Systematics of the New World nectar-feeding bats (Mammalia, Phyllostomidae), based on the morphology of the hyoid and lingual regions. American Museum novitates; no. 2742, 1-45.

Griffiths, T. A. (1983). On the phylogeny of the Glossophaginae and the proper use of outgroup analysis. Systematic Zoology, 32(3), 283-285.

Grosse, I. R., Dumont, E. R., Coletta, C., \& Tolleson, A. (2007). Techniques for Modeling Muscle-induced Forces in Finite Element Models of Skeletal Structures. The Anatomical Record, 290(9), 1069-1088.

Haiduk, M. W., \& Baker, R. J. (1982). Cladistical analysis of G-banded chromosomes of nectar feeding bats (Glossophaginae: Phyllostomidae).Systematic Biology, 31(3), 252-265.

Haiduk, M. W., \& Baker, R. J. (1984). Scientific method, opinion, phylogenetic reconstruction, and nectar-feeding bats: a response to Griffiths and Warner.Systematic Biology, 33(3), 343-350.

Hallgrímsson, B., Lieberman, D. E., Liu, W., Ford-Hutchinson, A. F., \& Jirik, F. R. (2007). Epigenetic interactions and the structure of phenotypic variation in the cranium. Evolution \& development, 9(1), 76-91.

Hallgrímsson, B., Jamniczky, H., Young, N. M., Rolian, C., Parsons, T. E., Boughner, J. C., \& Marcucio, R. S. (2009). Deciphering the palimpsest: studying the relationship between morphological integration and phenotypic covariation. Evolutionary Biology, 36(4), 355-376.

Hansen, T. F., Carlson, M. L., \& Pélabon, C. (2003). Evolvability and genetic constraint in Dalechampia blossoms: genetic correlations and conditional evolvability. Journal of Experimental Zoology Part B: Molecular and Developmental Evolution, 296(1), 23-39.

Hansen, T., \& Houle, D. (2008). Measuring and comparing evolvability and constraint in multivariate characters. Journal of evolutionary biology, 21(5), 1201-19.

Helms, J. A., Cordero, D., \& Tapadia, M. D. (2005). New insights into craniofacial morphogenesis. Development, 132(5), 851-861.

Von Helversen, O., \& Winter, Y. (2003). Glossophagine bats and their flowers: costs and benefits for plants and pollinators. Bat ecology, 346-397. 
Herrel, A., De Smet, A., Aguirre, L. F., \& Aerts, P. (2008). Morphological and mechanical determinants of bite force in bats: do muscles matter?. Journal of Experimental Biology, 211(1), 86-91.

Hill, J. E., \& Smith, J. D. (1984). Bats: a natural history (No. 877). Austin: University of Texas Press.

Honeycutt, R. L., \& Sarich, V. M. (1987). Albumin evolution and subfamilial relationships among New World leaf-nosed bats (family Phyllostomidae).Journal of Mammalogy, 508-517.

Hoyte, D. A. (1997). Bone remodeling in the craniofacial region. Fundamentals of Craniofacial Growth, CRC Press, New York, 427-442.

Hubbe, A. (2013). Análise morfológica craniana de Xenarthra atuais e extintos: inferências evolutivas e funcionais. Tese de Doutorado, Instituto de Biologia da Universidade de São Paulo. p.267.

Huxley, J. S., \& Teissier, G. (1936). Terminology of relative growth. Nature,137(3471), 780-781.

I.C.V.G.A.N. (2012). International Committee on Veterinary Gross Anatomical Nomenclature. World Association of Veterinary Anatomists, Hannover, Germany[Links].

Jolicoeur, P., Pirlot, P., Baron, G., \& Stephan, H. (1984). Brain structure and correlation patterns in Insectivora, Chiroptera, and Primates. Systematic Biology, 33(1), 14-29.

Jones, K. E., Bininda-Emonds, O. R., \& Gittleman, J. L. (2005). Bats, clocks, and rocks: diversification patterns in Chiroptera. Evolution, 59(10), 2243-2255.

Kelm, D. H., \& von Helversen, O. (2007). How to budget metabolic energy: torpor in a small Neotropical mammal. Journal of Comparative Physiology B,177(6), 667-677.

Kleiman, D. G., \& Davis, T. M. (1979). Ontogeny and maternal care.

Klingenberg, C. P., Mebus, K., \& Auffray, J. C. (2003). Developmental integration in a complex morphological structure: how distinct are the modules in the mouse mandible?. Evolution \& development, 5(5), 522-531.

Kohn, L. A. P., \& Atchley, W. R. (1988). How similar are genetic correlation structures data from mice and rats. Evolution, 467-481.

Kolbe, J. J., Revell, L. J., Szekely, B., Brodie III, E. D., \& Losos, J. B. (2011). Convergent evolution of phenotypic integration and its alignment with morphological diversification in Caribbean Anolis ecomorphs. Evolution, 65(12), 3608-3624.

Krzanowski, W. J. (1979). Between-groups comparison of principal components. Journal of the American Statistical Association, 74(367), 703-707. 
Kunz, T. H., \& Kurta, A. (1987). Size of bats at birth and maternal investment during pregnancy. In Symposia of the Zoological Society of London (Vol. 57, pp. 79-106).

Lande, R. (1979). Quantitative genetic analysis of multivariate evolution, applied to brain: body size allometry. Evolution, 402-416.

Lande, R. (1980). Sexual dimorphism, sexual selection, and adaptation in polygenic characters. Evolution, 292-305.

Lande, R., \& Arnold, S. J. (1983). The measurement of selection on correlated characters. Evolution, 1210-1226.

Lessells, C. M., \& Boag, P. T. (1987). Unrepeatable repeatabilities: a common mistake. The Auk, 116-121.

Luo, Z. X. (2011). Developmental patterns in Mesozoic evolution of mammal ears. Annual Review of Ecology, Evolution, and Systematics, 42, 355-380.

Magwene, P. M. (2001). New tools for studying integration and modularity.Evolution, 55(9), 17341745.

Mancina, C. (2010). Phyllonycteris poeyi (Chiroptera: Phyllostomidae). Mammalian Species, 42(1), $41-$ 48.

Manly, B. F. (1986). Randomization and regression methods for testing for associations with geographical, environmental and biological distances between populations. Researches on Population Ecology, 28(2), 201-218.

Marroig, G., \& Cheverud, J. M. (2005). Size as a line of least evolutionary resistance: diet and adaptive morphological radiation in New World monkeys.Evolution, 59(5), 1128-1142.

Marroig, G, \& Cheverud, J. M. (2001). A comparison of phenotypic variation and covariation patterns and the role of phylogeny, ecology, and ontogeny during cranial evolution of new world monkeys. Evolution, 55(12), 2576-600.

Marroig, G. \& Cheverud, J. (2010). Size as a line of least resistance II: direct selection on size or correlated response due to constraints? Evolution, 64(5), 1470-88.

Marroig, G., Melo, D. a R. \& Garcia, G. (2012). Modularity, noise, and natural selection. Evolution, 66(5), 1506-24.

Marroig, G., Shirai, L. T., Porto, A., Oliveira, F. B., \& Conto, V. (2009). The Evolution of Modularity in the Mammalian Skull II: Evolutionary Consequences. Evolutionary Biology, 36(1), 136-148.

Mayr, E. (1982). The Growth of Biological Thought: Diversity, Evolution, and Inheritance (p. 974). Belknap Press of Harvard University Press. 
Monteiro, L. R., Bonato, V., \& Dos Reis, S. F. (2005). Evolutionary integration and morphological diversification in complex morphological structures: mandible shape divergence in spiny rats (Rodentia, Echimyidae).Evolution \& development, 7(5), 429-439.

Monteiro, L. R., \& Nogueira, M. R. (2010). Adaptive radiations, ecological specialization, and the evolutionary integration of complex morphological structures. Evolution, 64(3), 724-744.

Monteiro, L. R., \& Nogueira, M. R. (2011). Evolutionary patterns and processes in the radiation of phyllostomid bats. BMC evolutionary biology, 11(1), 137.

Moore, W. J. (1981). The mammalian skull (Vol. 8). Cambridge: Cambridge University Press.

Morriss-Kay, G. M., \& Wilkie, A. O. (2005). Growth of the normal skull vault and its alteration in craniosynostosis: insights from human genetics and experimental studies. Journal of anatomy, 207(5), 637-653.

Noden, D. M., \& Trainor, P. A. (2005). Relations and interactions between cranial mesoderm and neural crest populations. Journal of anatomy, 207(5), 575-601.

Nogueira, M. R., Monteiro, L. R., Peracchi, A. L., \& Araújo, A. F. (2005). Ecomorphological analysis of the masticatory apparatus in the seed-eating bats, genus Chiroderma (Chiroptera: Phyllostomidae). Journal of Zoology, 266(4), 355-364.

Nogueira, M. R., Lima, I. P., Peracchi, A. L., \& Simmons, N. B. (2012). New Genus and Species of Nectar-Feeding Bat from the Atlantic Forest of Southeastern Brazil (Chiroptera: Phyllostomidae: Glossophaginae). American Museum Novitates, 3747, 1-30.

Nogueira, M. R., Peracchi, A. L., \& Monteiro, L. R. (2009). Morphological correlates of bite force and diet in the skull and mandible of phyllostomid bats. Functional Ecology, 23(4), 715-723.

O'Higgins, P. (2000). The study of morphological variation in the hominid fossil record: biology, landmarks and geometry. Journal of Anatomy, 197(1), 103-120.

Oliveira, F. B., Porto, A., \& Marroig, G. (2009). Covariance structure in the skull of Catarrhini: a case of pattern stasis and magnitude evolution. Journal of human evolution, 56(4), 417-430.

Oliveira, F. B. (2009). Evolução do crânio dos macacos do Velho Mundo: uma abordagem de genética quantitativa. Tese de Doutorado, Instituto de Biociências da Universidade de São Paulo. 229 p.

Olson, E. C., \& Miller, R. L. (1951). A mathematical model applied to a study of the evolution of species. Evolution, 5(4), 325-338.

Olson, \& Miller. (1958). Morphological Integration (p. 352). University of Chicago Press.

Pavlicev, M., Kenney-Hunt, J. P., Norgard, E. A., Roseman, C. C., Wolf, J. B., \& Cheverud, J. M. (2008). Genetic variation in pleiotropy: differential epistasis as a source of variation in the allometric relationship between long bone lengths and body weight. Evolution, 62(1), 199213. 
Pedersen, S. C. (1993). Cephalometric correlates of echolocation in the Chiroptera. Journal of morphology, 218(1), 85-98.

Pedersen, S. C. (2000). Skull growth and the acoustical axis of the head in bats. Ontogeny, Functional Ecology and Evolution of Bats (ed. RA Adams and SC Pedersen), 174-213.

Pérez-Barbería, F. J., \& Gordon, I. J. (1999). The functional relationship between feeding type and jaw and cranial morphology in ungulates.Oecologia, 118(2), 157-165.

Rinehart, J. B., \& Kunz, T. H. (2006). Rhinophylla pumilio. Mammalian Species, 1-5.

Phillips, C. J. (1971). The dentition of glossophagine bats: development, morphological characteristics, variation, pathology, and evolution (138 p). University of Kansas (Lawrence)

Porter, C. A., Hoofer, S. R., Van Den Bussche, R. A., Lee Jr, T. E., \& Baker, R. J. (2003). Systematics of round-eared bats (Tonatia and Lophostoma) based on nuclear and mitochondrial DNA sequences. Journal of mammalogy,84(3), 791-808.

Porto, A, Shirai, L., Oliveira, F., \& Marroig, G. (2013). Size variation, growth strategies and the evolution of modularity in the mammalian skull. Evolution.

Porto, A., de Oliveira, F. B., Shirai, L. T., De Conto, V., \& Marroig, G. (2009). The evolution of modularity in the mammalian skull I: morphological integration patterns and magnitudes. Evolutionary Biology, 36(1), 118-135.

Prôa, M., O'Higgins, P., \& Monteiro, L. R. (2013). Type I error rates for testing genetic drift with phenotypic covariance matrices: a simulation study. Evolution, 67(1), 185-195.

Redondo, R. a F., Brina, L. P. S., Silva, R. F., Ditchfield, A. D., \& Santos, F. R. (2008). Molecular systematics of the genus Artibeus (Chiroptera: Phyllostomidae). Molecular phylogenetics and evolution, 49(1), 44-58.

Reep, R. L., \& Bhatnagar, K. P. (2000). Brain ontogeny and ecomorphology in bats. Ontogeny, functional ecology, and evolution of bats. Cambridge University Press, Cambridge, 93-136.

Revell, L. J., Johnson, M. A., Schulte, J. A., Kolbe, J. J., \& Losos, J. B. (2007). A phylogenetic test for adaptive convergence in rock-dwelling lizards.Evolution, 61(12), 2898-2912.

Roff, D. A. (1995). The estimation of genetic correlations from phenotypic correlations: a test of Cheverud's conjecture. Heredity, 74(5), 481-490.

Roff, D. A. (1996). The evolution of genetic correlations: an analysis of patterns. Evolution, 13921403.

Roff, D. A., \& Mousseau, T. (2005). The evolution of the phenotypic covariance matrix: evidence for selection and drift in Melanoplus. Journal of evolutionary biology, 18(4), 1104-1114.

Rojas, D., Vale, A., Ferrero, V., \& Navarro, L. (2011). When did plants become important to leafnosed bats? Diversification of feeding habits in the family Phyllostomidae. Molecular ecology, 20(10), 2217-28. 
Rolian, C., \& Willmore, K. E. (2009). Morphological Integration at 50: Patterns and Processes of Integration in Biological Anthropology. Evolutionary Biology, 36(1), 1-4.

Ross, C., \& Henneberg, M. (1995). Basicranial flexion, relative brain size, and facial kyphosis in Homo sapiens and some fossil hominids. American Journal of Physical Anthropology, 98(4), 575593.

Santana, S E, \& Lofgren, S. E. (2013). Does nasal echolocation influence the modularity of the mammal skull? Journal of evolutionary biology, 1-7.

Santana, S. E., Dumont, E. R., \& Davis, J. L. (2010). Mechanics of bite force production and its relationship to diet in bats. Functional Ecology, 24(4), 776-784.

Santana, S. E., Geipel, I., Dumont, E. R., Kalka, M. B., \& Kalko, E. K. (2011). All you can eat: high performance capacity and plasticity in the common big-eared bat, Micronycteris microtis (Chiroptera: Phyllostomidae).PloS one, 6(12), e28584.

Santana, S. E., Grosse, I. R., \& Dumont, E. R. (2012). Dietary hardness, loading behavior, and the evolution of skull form in bats. Evolution, 66(8), 2587-2598.

Schlosser, G., \& Wagner, G. P. (Eds.). (2004). Modularity in development and evolution. University of Chicago Press.

Schluter, D. (1996). Adaptive radiation along genetic lines of least resistance. Evolution, 17661774.

Schluter, D. (2000). The ecology of adaptive radiation. Oxford University Press.

Shaw, F. H., Shaw, R. G., Wilkinson, G. S., \& Turelli, M. (1995). Changes in genetic variances and covariances: G whiz!. Evolution, 49(6), 1260-1267.

Shirai, L. T., \& Marroig, G. (2010). Skull modularity in neotropical marsupials and monkeys: size variation and evolutionary constraint and flexibility. Journal of Experimental Zoology Part B: Molecular and Developmental Evolution, 314(8), 663-683.

Silva, H. S. da. (2010). Evolução morfológica em marsupiais (Mammalia, Didelphimorphia) do Novo Mundo. Tese de doutorado, Instituto de Biociências da Universidade de São Paulo. 223 p.

Simmons, N. (2005). Order chiroptera. In Mammal Species of th world: a taxonomic and geographic reference (D.E. Wilson \& D.M. Reeder, eds.) John Hopkings Press, Washington, p. 312-529.

Smith, J., \& Hood, C. (1984). Genealogy of the New World nectar-feeding bats reexamined: a reply to Griffiths. Systematic zoology. 33(4), 435-460.

Smith, J. M., \& Savage, R. (1959). The mechanics of mammalian jaws. School Sci. Rev. 40, 289-301.

Smith, K. (1997). Comparative patterns of craniofacial development in eutherian and metatherian mammals. Evolution. 51(5), 1663-1678. 
Smith, K., \& Redford, K. (1990). The anatomy and function of the feeding apparatus in two armadillos (Dasypoda): anatomy is not destiny. Journal of Zoology. 222(1), 27-47.

Sokal, R., \& Rohlf, F. (1995). Biometry. WH Freman and company, Nova Iorque. 887 p.

Sperry, T. (1972). Development of the Specialized Craniofacial Complex in Bats of the Genera Mormoops and Chilonycteris (family Mormoopidae). University of Illinois at UrbanaChampaign, $342 \mathrm{p}$.

Steppan, S. (1997). Phylogenetic analysis of phenotypic covariance structure. I. Contrasting results from matrix correlation and common principal component analysis. Evolution. 51(2), 571-586.

Steppan, S., Phillips, P., \& Houle, D. (2002). Comparative quantitative genetics: evolution of the G matrix. Trends in Ecology \& Evolution. 17(7) 320-327.

Swartz, S., Freeman, P., \& Stockwell, E. (2003). Ecomorphology of bats: comparative and experimental approaches relating structural design to ecology. Bat ecology. 257-300.

Tapadia, M., Cordero, D., \& Helms, J. (2005). It's all in your head: new insights into craniofacial development and deformation. Journal of anatomy. 207(5), 461-477.

Tavares, V. D. C. (2008). Revisionary systematics and Phyllogeny of Vampyressa and Stenodermatinae (Chiroptera: Phyllostomidae). Tese de doutorado, City of New York University. 369 p.

Tavares, V. D. C., \& Velazco, P. M. (2010). Platyrrhinus recifinus (Chiroptera: Phyllostomidae). Mammalian Species, 42(1), 119-123.

Teeling, E., Springer, M., \& Madsen, O. (2005). A molecular phylogeny for bats illuminates biogeography and the fossil record. Science. 307(5709), 580-584.

Tukey, J. (1977). Exploratory data analysis. Addison-Wesley Publishing Company. 688 p.

Turelli, M. (1988). Phenotypic evolution, constant covariances, and the maintenance of additive variance. Evolution. 42(6), 1342-1347.

Van Valen, L. (1974). Multivariate structural statistics in natural history. Journal of Theoretical Biology, 45(1), 235-247.

Velazco, P. M. (2005). Morphological phylogeny of the bat genus Platyrrhinus Saussure, 1860 (Chiroptera: Phyllostomidae) with the description of four new species. Fieldiana Zoology, 105. $1-53$.

Velazco, Paúl M, \& Cadenillas, R. (2011). On the identity of Lophostoma silvicolum occidentalis (Davis \& Carter, 1978) (Chiroptera: Phyllostomidae). Zootaxa, 2962, 1-20.

Velazco, Paúl M, \& Patterson, B. D. (2008). Phylogenetics and biogeography of the broad-nosed bats, genus Platyrrhinus (Chiroptera: Phyllostomidae). Molecular phylogenetics and evolution, 49(3), 749-59. 
Velazco, P. M., \& Solari, S. (2003). Taxonomía de Platyrrhinus dorsalis y Platyrrhinus lineatus (Chiroptera: Phyllostomidae) en Perú. Mastozoología Neotropical, 10(2), 303-319.

Velazco, Paúl M., Gardner, A. L., \& Patterson, B. D. (2010). Systematics of the Platyrrhinus helleri species complex (Chiroptera: Phyllostomidae), with descriptions of two new species. Zoological Journal of the Linnean Society, 159(3), 785-812.

Velazco, PaúL M., \& Simmons, N. B. (2011). Systematics and Taxonomy of Great Striped-Faced Bats of the Genus Vampyrodes Thomas, 1900 (Chiroptera: Phyllostomidae). American Museum Novitates, 3710(3710), 1-35.

Venable, D., \& Burquez, A. (1990). Quantitative genetics of size, shape, life-history, and fruit characteristics of the seed heteromorphic composite Heterosperma pinnatum. II. Correlation structure. Evolution. 44(7), 1748-1763.

Voigt, C., \& Speakman, J. (2007). Nectar-feeding bats fuel their high metabolism directly with exogenous carbohydrates. Functional Ecology. 21(5), 913-921.

Wagner, G. P. (1984). On the eigenvalue distribution of genetic and phenotypic dispersion matrices: evidence for a nonrandom organization of quantitative character variation. Journal of Mathematical Biology, 21(1), 77-95.

Wagner, G. (1988). The influence of variation and of developmental constraints on the rate of multivariate phenotypic evolution. Journal of Evolutionary Biology. 1(1), 45-66.

Wagner, G., \& Altenberg, L. (1996). Perspective: Complex adaptations and the evolution of evolvability. Evolution. 50(3), 967-976.

Wagner, G. P., Pavlicev, M., \& Cheverud, J. M. (2007). The road to modularity. Nature reviews. Genetics, 8(12), 921-31.

Waitt, D., \& Levin, D. (1998). Genetic and phenotypic correlations in plants: a botanical test of Cheverud's conjecture. Heredity. 80(3), 310-319.

Warner, R. (1983). Karyotypic megaevolution and phylogenetic analysis: New World nectarfeeding bats revisited. Systematic zoology. 32(3), 279-282.

Webster, M., \& Zelditch, M. L. (2005). Evolutionary modifications of ontogeny: heterochrony and beyond. Paleobiology, 31(3), 354-372.

Wetterer, A. L., Rockman, M. V., \& Simmons, N. B. (2000). Phylogeny of Phyllostomid Bats (Mammalia: Chiroptera): Data From Diverse Morphological Systems, Sex Chromosomes, and Restriction Sites. Bulletin of the American Museum of Natural History, 248(248), 1-200.

Wible, J. R., \& Davis, D. L. (2000). Ontogeny of the chiropteran basicranium, with reference to the Indian false vampire bat, Megaderma lyra. Ontogeny, Functional Ecology, and Evolution of Bats. Cambridge University Press, Cambridge, 214-246.

Winter, Y., \& von Helversen, O. (2003). Operational tongue length in phyllostomid nectarfeeding bats. Journal of mammalogy, 84(3), 886-896. 
Young, N. M., \& HallgrÍmsson, B. (2005). Serial homology and the evolution of mammalian limb covariation structure. Evolution, 59(12), 2691-2704.

Zelditch, M. (1988). Ontogenetic variation in patterns of phenotypic integration in the laboratory rat. Evolution, 42(1), 28-41.

Zelditch, M., \& Carmichael, A. (1989). Ontogenetic variation in patterns of developmental and functional integration in skulls of Sigmodon fulviventer. Evolution, 43(4), 814-824.

Zelditch, M., \& Wood, A. (2008). Modularity of the rodent mandible: integrating bones, muscles, and teeth. Evolution \& development, 10(6), 756-768. 


\section{ANEXOS}

A1 - Apresento a seguir os 21 marcadores anatômicos cranianos utilizados em meu projeto de doutorado, descrevendo detalhadamente os ossos e as suturas que envolvem esses marcadores em morcegos da Família Phyllostomidae.

\section{IS: Intradental superior}

Este ponto se localiza na borda alveolar entre os dois dentes incisivos superiores. É um marcador associado ao osso da pré-maxila. A sutura interincisiva, localizada no corpo da prémaxila, pode ser utilizada como referência na localização e aquisição deste ponto, uma vez que esta sutura percorre a parte anterior do rostro até o alvéolo dos incisivos superiores em sua porção mediana.

\section{PM: Junção pré-maxila-maxila no alvéolo}

PM representa o ponto mais anterior da junção do osso da pré-maxila com a maxila, o qual está normalmente associado ao alvéolo do canino. Este ponto também pode ser tomado usando-se como referência a sutura maxiloincisiva, a qual delimita o processo nasal da pré-maxila e a maxila. Nesse caso, o PM é marcado na porção mais anterior da sutura maxiloincisiva, na borda alveolar do canino. Para este marcador, vale à pena dedicarmos alguma atenção, uma vez que, em trabalho recente, Giannini e Simmons (2007) documentaram a diversidade morfológica da pré-maxila em morcegos, selecionando algumas espécies representantes das famílias atualmente reconhecidas. A pré-maxila é um osso dermal par localizado no ápice do rostro do crânio de vertebrados. Ele normalmente suporta os dentes anteriores, que são os incisivos no caso dos mamíferos, e desempenha um papel funcional importante na aquisição e no processamento dos alimentos. A pré-maxila dos mamíferos, ou também chamado osso incisivo (os incisivum), é composto pelo corpo (corpus ossis incisivi; às vezes chamado de processo alveolar), o 
processo nasal (processus nasalis), e o processo palatino (processus palatinus; Evans, 1993). O corpo da pré-maxila sustenta os alvéolos dos incisivos (Giannini e Simmons, 2007). O processo nasal é uma projeção comprimida do corpo da pré-maxila que forma a parte lateral da abertura nasal externa. O processo palatino constitui a parte mais anterior do palato duro. Cada processo palatino geralmente sustenta um forâmen incisivo que divide o processo palatino em um flange medial (que corre ao longo da linha sagital mediana) e um flange lateral (que corre ao lado da linha alveolar). Muito freqüentemente, a borda caudal de cada forâmen incisivo é delimitada pela maxila. A pré-maxila tem participação em quatro suturas cranianas: a sutura interincisiva, a nasoincisiva, a maxiloincisiva, e a sutura vomeroincisiva. Esse plano básico da pré-maxila de mamíferos tem sido significativamente modificado em muitas linhagens de morcegos, e a ordem Chiroptera como um todo, possui casos de variação não observados na maioria das outras ordens de mamíferos. Alguns aspectos desta diversidade osteológica foram descritas anteriormente (cf. Miller, 1907; Andersen, 1912; Wible e Novacek, 1988, Simmons, 1994); e a pré-maxila em Chiroptera rendeu caracteres de importância filogenética que tem sido utilizado na sistemática de morcegos, em uma variedade de níveis hierárquicos. A morfologia da pré-maxila forneceu sinapomorfias para Chiroptera (por exemplo, Wible e Novacek, 1988; Simmons, 1994) e apoiou hipóteses de relações interfamiliares (por exemplo, Miller, 1907; Koopman, 1994, Simmons, 1998; Simmons e Geisler, 1998). A divisão de Microchiroptera nas duas infraordens Yinochiroptera e Yangochiroptera (Koopman, 1985) foi principalmente baseada nas diferenças da morfologia da pré-maxila. De acordo com Koopman $(1985,1994)$ morcegos yinochiroptera sustentam uma "pré-maxila móvel", frouxamente aderida à maxila. Em contraste, morcegos yangochiroptera apresentam uma pré-maxila solidamente fundida à maxila. Membros da Famíla Phyllsotomidae geralmente apresentam o processo nasal da pré-maxila fusionado à maxila e ao nasal e o corpo direito e esquerdo fusionado um ao outro. A flange medial do processo palatino está presente, então o forâmen incisivo está bem delimitado (Giannini e Simmons, 2007). 


\section{NSL: Nasal}

Os nasais (os nasale) são ossos pares que cobrem o dorso do rostro. Eles têm sua margem rostral livre, e articulam-se um ao outro no plano mediano, formando a sutura reta internasal (sutura internasalis). Este marcador (NSL) representa o ponto mais anterior da sutura internasal, a qual está localizada entre os ossos nasais direito e esquerdo.

\section{NA: Násion}

Cada osso nasal, em sua porção mais caudal, faz contato com o osso frontal, formando a sutura frontonasal (sutura frontonasalis). O NA representa o ponto de encontro da sutura internasal (a qual separa os ossos nasais em direito e esquerdo), com a sutura frontonasal.

\section{BR: Bregma}

O frontal (os frontale) é um osso par que forma a fronte do crânio e a maior parte da parede orbital. O osso parietal (os parietale) por sua vez, é o elemento principal constituindo a cobertura do crânio. O crânio deve a sua forma inflada principalmente devido à curvatura dos parietais. Estes protegem a superfície do cérebro dorsolateralmente e proporcionam uma maior área de fixação para o músculo temporal. Os parietais se contatam um ao outro na margem sagital correspondente através da sutura sagital (sutura sagittalis), e por sua vez cada parietal contata o frontal rostrodorsalmente através da sutura coronal (sutura coronalis). O BR (bregma) é marcado no ponto de junção das suturas coronal e sagital, sendo, portanto o ponto de encontro entre os ossos frontal e parietal. Este ponto é também, juntamente com o PT, um dos mais importantes do ponto de vista anatômico e funcional, pois estão ligados a medidas que descrevem os mais diversos aspectos do neurocrânio (BRPT, BRAPET, BRLD, PTAPET, PTBA, PTTSP, PTEAM, PTAS), ao mesmo tempo em que o interligam com outras regiões funcionais/ontogenéticas cranianas (PTZYGO, NABR). 


\section{PT: Pterion}

O pterion (PT) corresponde ao ponto de encontro dos ossos frontais, parietais e orbitoesfenóide. Nas espécies pertencentes à Família Phyllostomidae, ele é marcado no encontro das suturas esfenofrontal e esfenoparietal. O frontal ocupa grande parte da parede orbital, contatando-se ao osso lacrimal rostrolateralmente, ao palatino ventralmente e ao orbitoesfenóide caudalmente, formando com este último a sutura esfenofrontal (sutura sphenofrontalis). Os ossos parietais por sua vez contatam o osso orbitoesfenóide rostrolateralmente, formando a sutura esfenoparietal (sutura sphenoparietalis). O ptérion é provavelmente o marcador mais importante do ponto de vista anatômico-funcional dentre todos os medidos. É também um dos marcadores que tem o maior número de medidas associadas. Ele funciona como um ponto de referência para diversas medidas neurocranianas (PTBA, PTAPET, PTAS, PTTSP, BRPT, PEAM), integrando suas subregiões (base, calota e órbita), e também as interligando com medidas relacionadas à região facial (PTZYGO). Ele é também um dos marcadores com o maior número de complicações na definição das hipóteses de homologias nos grupos. Isso porque, conjuntamente com o TSP, localiza-se em uma região de encontro de diversos ossos, extremamente variável ao longo dos grupos e até mesmo dentro deles, uma vez que o padrão de conectividade dos ossos só depende de seu crescimento relativo. O ptérion tem, como dito anteriormente, a função de representar diversos aspectos neurocranianos e sua relação com a face, função que é melhor mantida, seguindo-se as suturas fronto-parietais.

\section{ZS: Zigomaxilar superior}

A maxila (os maxilar) é um osso par e juntamente com a pré-maxila, constitui o principal componente do rostro, formando a maxila superior. O processo rostral da maxila contata o jugal posteroventralmente formando a sutura zigomaticomaxilar (sutura sygomaticomaxillaris). O ZS deve ser posicionado na região dorsal dessa sutura. É a sutura que delimita o processo zigomático da maxila (processus aygomaticus) e o osso jugal. 


\section{ZI: Zigomaxilar inferior}

O marcador ZS representa a região ventral da sutura zigomaticomaxilar, a qual delimita o processo zigomático da maxila e o osso jugal.

\section{MT: Tuberosidade do maxilar}

É uma eminência arredondada na parte inferior da superfície infratemporal da maxila, particularmente visível após o crescimento do dente do siso, é áspero em sua lateral para articulação com o processo piramidal do osso palatino e, em alguns casos se articula com a placa pterigóide lateral do esfenóide. Este marcador está ligado a uma região de osso mais poroso, com formato convexo, localizada na região imediatamente posterior à fileira de molares, no final da região ventral da maxila. É também o ponto de ligação de parte da musculatura relacionada à mastigação.

\section{PNS: Espinho nasal posterior}

Esse marcador esta localizado na região mais posterior da sutura interpalatina, a qual divide os ossos do palato em direito e esquerdo.

\section{APET: Região anterior petrosal do temporal}

O osso petrosal (os temporale, pars petrosa) localiza-se na base do crânio, posicionado próximo aos órgãos da audição e do equilíbrio. O APET deve ser marcado no ponto mais extremo da sincondrose esfeno-occipital (synchondrosis sphenoccipitalis), que é uma articulação temporária composta de cartilagem hialina, a qual delimita os ossos basiesfenóide e basioccipital.

\section{BA: Basion}


Este ponto deve ser marcado no limite mais anterior do foramen magnum, localizado no plano sagital.

\section{OPI: Opisthion}

Este ponto deve ser marcado no limite mais posterior do foramen magnum, localizado no plano sagital.

\section{EAM: Meato auditivo externo anterior}

Este ponto deve ser marcado no meato auditivo externo.

\section{PEAM: Meato auditivo externo posterior}

É o ponto localizado no lado oposto do meato auditivo.

\section{ZYGO: Sutura zigo-temporal inferior}

O arco zigomático (arcus sygomaticus, régio sygomatica), é formado pelo processo zigomático da maxila e o pequeno osso jugal, que se articula caudalmente com o processo zigomático do squamosal na região temporal. O ponto ZYGO deve ser marcado ventralmente na sutura temporozigomática, que delimita os ossos jugal e squamosal

\section{TSP: Junção temporo-esfeno-parietal}

Em morcegos da família Phyllostomidae este marcador representa o ponto de encontro entre três ossos: o parietal, o alisfenóide e o esquamosal. $O$ osso parietal contata o orbitoesfenoide rostrolateralmente, formando a sutura esfenoparietal. O parietal contata o alisfenóide anteroventralmente (sendo a continuação da sutura esfenoparietal). O parietal contata o esquamosal ventralmente formando a sutura esquamosa. O ponto deve ser marcado na junção 
das suturas esquamosa e esfenoparietal. As medidas relacionadas a esse marcador se relacionam mais com a base do crânio.

\section{TS: Junção temporo-esfenoidal}

É marcado no ponto mais caudal da sutura temporo-esfenoidal.

\section{JP: Processo jugular}

Localiza-se logo após o foramen jugular, que é um foramen muito conservado em mamíferos por representar o local de passagem de importantes artérias e ramificações nervosas.

\section{LD: Lambda}

Em anatomia, lambda representa o ponto no crânio onde os ossos parietais se encontram com os occipitais. A sutura entre cada osso parietal e occipital é denominada de sutura lambdóide. A denominação lambda é adotada, pois a configuração das suturas do crânio se assemelha a um lambda maiúsculo do alfabeto grego. O interparietal (os interparietale) é um osso que forma a porção mediocaudal do teto do crânio entre os parietais e o supraoccipital. O parietal contata o interparietal mediocaudalmente formando a sutura parietointerparietal (sutura parietointerparietalis). A sutura com o supraoccipital (inexistente no cachorro, pois o interparietal se funde com o supraoccipital no período prénatal; Evans, 1993) é denominada aqui de sutura occipitointerparietal, parte da sutura lambdóide (sutura lambdoidea) na Nomina Anatômica Veterinária. Essa sutura possui três seções: duas porções bilaterais que correm a partir do ponto de articulação do parietal, interparietal e supraoccipital de cada lado, convergendo medianamente e ligeiramente posterior para encontrar a porção central que é essencialmente perpendicular ao eixo longitudinal e um pouco côncavo. Ela é serrilhada, e não há sobreposição significativa entre os dois ossos de contato. A superfície do interparietal é suave e ligeiramente abobadada sobre a porção central da sutura occipitointerparietal, uma característica acentuada nas áreas adjacentes 
do supraoccipital. Em nosso estudo, considerando os morcegos da Família Phillostomidae, a sutura occipitointerparietalis é igualmente denominada de sutura lambdoidea (NAV). Dessa forma, o marcador lambda deve ser tomado na porção central da sutura occipitointerparietal, a qual delimita os ossos interparietal e supraoccipital. Em outros grupos de mamíferos, em que o interparietal não é evidente (fundiu-se ao supraoccipital) a sutura occipitoparietal (Evans, 1993) é também denominada de sutura lambdoidea (NAV).

\section{AS: Asterion}

O parietal contata o supraoccipital laterocaudalmente, formando a sutura occipitoparietal (sutura occipitoparietalis in Evans, 1993). Há um pequeno contato com a exposição do mastóide do petrosal. O ponto se localiza no encontro das suturas temporooccipitais. 
A2 - Crânios de indivíduos jovens em vista dorsal, ventral e lateral ilustrando os marcadores e as suturas aparentes.
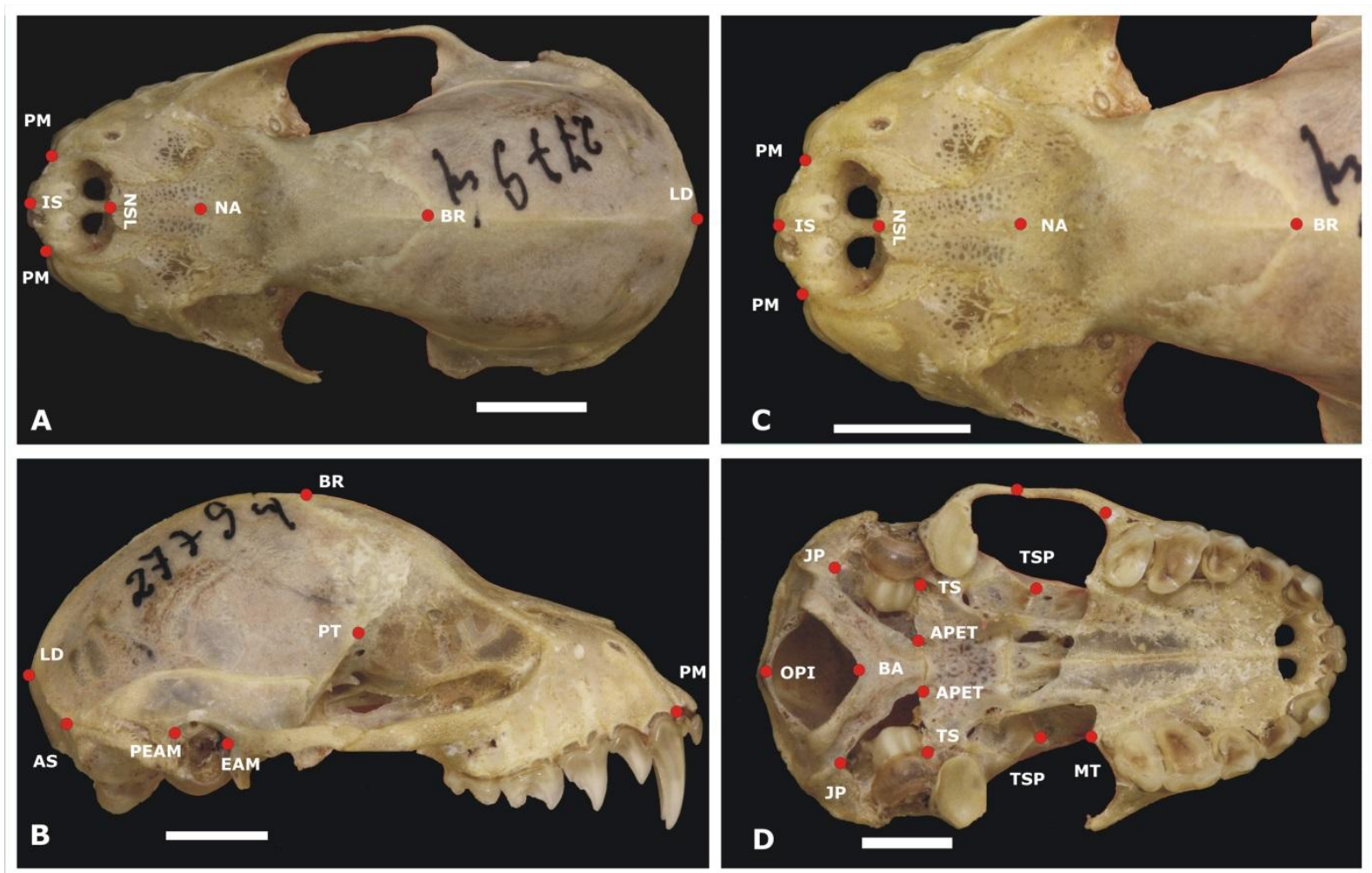

Figura A2 a - Crânio de Artibeus lituratus (MZUSP 27794). Atenção aos ossos e suturas bem definadas em indivíduos jovens. Grupo de dieta: Frugívoro (Kalko \& Handley, 2001). A - vista dorsal. B - vista lateral. C - vista dorsal dos ossos nasal e frontal. D - vista ventral. Escala: $5 \mathrm{~mm}$. Foto: Dani Rossoni. 

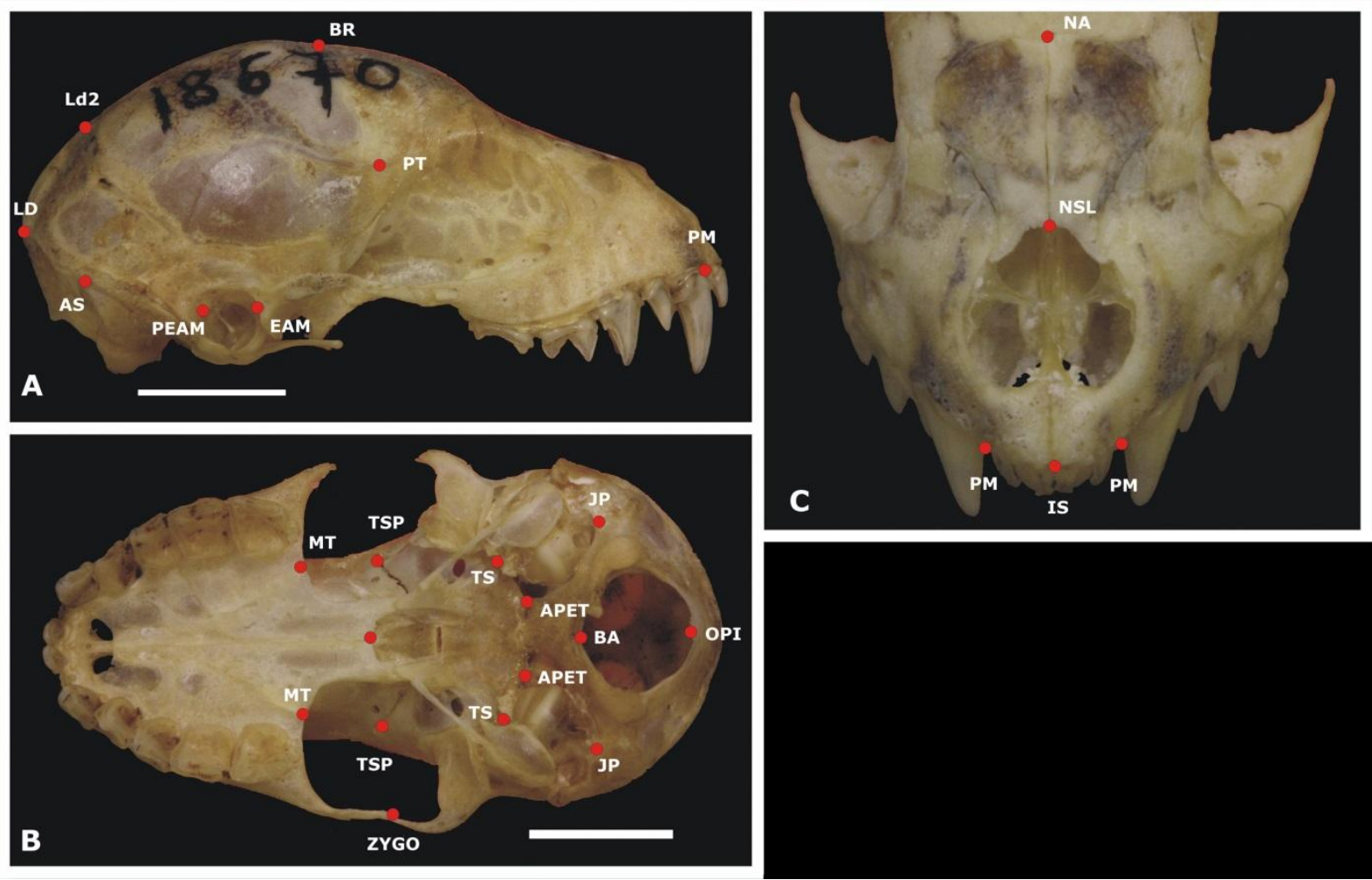

Figura A2 b - Crânio de Platyrrbinus lineatus (MZUSP 18670). Atenção aos ossos e suturas bem definadas em indivíduos jovens. Grupo de dieta: Frugívoro (Kalko \& Handley, 2001). A - vista lateral. B - vista ventral. C - vista rostral. Escala: 5mm. Foto: Dani Rossoni. 
A3 - Matriz de hábitos alimentares para 48 espécies de morcegos da Família Phyllostomidae que compõem o presente estudo. Esta tabela foi adaptada de Rojas et al., (2011).

\section{Dieta}

Taxon

Insetivoria Carnivoria Hematofagia Nectarivoria Frugivoria principal

\begin{tabular}{|c|c|c|c|c|c|c|}
\hline Macrotus californicus & 2 & 0 & 0 & 0 & 1 & 1 \\
\hline Macrotus waterhousii & 2 & 0 & 0 & 0 & 1 & I \\
\hline Micronycteris microtis & 2 & 0 & 0 & 0 & 1 & I \\
\hline Diphylla ecaudata & 0 & 0 & 3 & 0 & 0 & $\mathrm{H}$ \\
\hline Desmodus rotundus & 1 & 0 & 2 & 0 & 0 & $\mathrm{H}$ \\
\hline Diaemus youngi & 0 & 0 & 3 & 0 & 0 & $\mathrm{H}$ \\
\hline Lonchorhina aurita & 2 & 0 & 0 & 0 & 1 & 1 \\
\hline Lonchorhina orinocensis & 2 & 0 & 0 & 0 & 1 & I \\
\hline \multicolumn{7}{|l|}{ Macrophyllum } \\
\hline macrophyllum & 3 & 0 & 0 & 0 & 0 & I \\
\hline Trachops cirrhosus & 2 & 2 & 0 & 0 & 2 & $\mathrm{I}+\mathrm{C}+\mathrm{F}$ \\
\hline Lophostoma silviculum & 2 & 0 & 0 & 1 & 1 & I \\
\hline Tonatia saurophila & 2 & 1 & 0 & 1 & 1 & I \\
\hline Mimon crenulatum & 2 & 0 & 0 & 1 & 1 & 1 \\
\hline Phylloderma stenops & 2 & 0 & 0 & 0 & 2 & $\mathrm{I}+\mathrm{F}$ \\
\hline Phyllostomus hastatus & 2 & 1 & 0 & 2 & 2 & $\mathrm{I}+\mathrm{N}+\mathrm{F}$ \\
\hline Chrotopterus auritus & 1 & 2 & 0 & 0 & 2 & $\mathrm{C}+\mathrm{F}$ \\
\hline Vampyrum spectrum & 1 & 2 & 0 & 0 & 0 & $\mathrm{C}$ \\
\hline Monophyllus redmani & 2 & 0 & 0 & 2 & 1 & $\mathrm{I}+\mathrm{N}$ \\
\hline Glossophaga soricina & 1 & 1 & 0 & 2 & 2 & $\mathrm{~F}+\mathrm{N}$ \\
\hline Leptonycteris curasoae & 1 & 0 & 0 & 2 & 1 & $\mathrm{~N}$ \\
\hline Brachyphylla cavernarum & 1 & 0 & 0 & 2 & 1 & $\mathrm{~N}$ \\
\hline Erophylla sezekorni & 2 & 0 & 0 & 2 & 2 & $\mathrm{I}+\mathrm{N}+\mathrm{F}$ \\
\hline Phyllonycteris poeyi & 1 & 0 & 0 & 2 & 2 & $\mathrm{~N}+\mathrm{F}$ \\
\hline Anoura geoffroyi & 2 & 1 & 0 & 2 & 1 & $\mathrm{I}+\mathrm{N}$ \\
\hline
\end{tabular}


...Continuação A3 - Matriz de hábitos alimentares para 48 espécies de morcegos da Família Phyllostomidae que compõem o presente estudo. Esta tabela foi adaptada de Rojas et al., (2011).

\section{Dieta}

Taxon

Insetivoria Carnivoria Hematofagia Nectarivoria Frugivoria principal

\begin{tabular}{lllllll}
\hline \hline Choeronycteris mexicana & 1 & 0 & 0 & 2 & 1 & $\mathrm{~N}$ \\
Lionycteris spurrelli & 1 & 0 & 0 & 2 & 1 & $\mathrm{~N}$ \\
Lonchophylla robusta & 1 & 0 & 0 & 2 & 1 & $\mathrm{~N}$ \\
Carollia brevicauda & 1 & 0 & 0 & 1 & 2 & $\mathrm{~F}$ \\
Trinycteris nicefori & 2 & 0 & 0 & 0 & 1 & $\mathrm{I}$ \\
Rhinophylla pumilio & 1 & 1 & 0 & 1 & 2 & $\mathrm{~F}$ \\
Chiroderma villosum & 1 & 0 & 0 & 1 & 2 & $\mathrm{~F}$ \\
Vampyriscus bidens & 1 & 0 & 0 & 1 & 2 & $\mathrm{~F}$ \\
Uroderma magnirostrum & 1 & 1 & 0 & 1 & 2 & $\mathrm{~F}$ \\
Vampyressa thyone & 1 & 0 & 0 & 1 & 2 & $\mathrm{~F}$ \\
Mesophylla macconnelli & 1 & 1 & 0 & 1 & 2 & $\mathrm{~F}$ \\
Vampyrodes major & 1 & 0 & 0 & 1 & 2 & $\mathrm{~F}$ \\
Platyrrhinus vittatus & 1 & 0 & 0 & 1 & 2 & $\mathrm{~F}$ \\
Enchisthenes hartii & 0 & 0 & 0 & 0 & 3 & $\mathrm{~F}$ \\
Artibeus fimbriatus & 1 & 0 & 0 & 1 & 2 & $\mathrm{~F}$ \\
Artibeus lituratus & 1 & 0 & 0 & 1 & 2 & $\mathrm{~F}$ \\
Dermanura phaeotis & 1 & 0 & 0 & 0 & 2 & $\mathrm{~F}$ \\
Ariteus flavescens & 0 & 0 & 0 & 0 & 3 & $\mathrm{~F}$ \\
Stenoderma rufum & 0 & 0 & 0 & 0 & 3 & $\mathrm{~F}$ \\
Centurio senex & 0 & 0 & 0 & 0 & 3 & $\mathrm{~F}$ \\
Pygoderma bilabiatum & 0 & 0 & 0 & 0 & 3 & $\mathrm{~F}$ \\
Sphaeronycteris & & & & & 3 & $\mathrm{~F}$ \\
toxophyllum & 0 & 0 & 0 & 0 & 3 & $\mathrm{~F}$ \\
Ametrida centurio & 0 & 0 & 0 & 0 & & $\mathrm{~F}$ \\
Phyllops falcatus & 0 & 0 & 0 & & & \\
\hline \hline
\end{tabular}


A4 - Conjunto de dados obtido de Porto et al., (2009) e Marroig et al., (2009), respresentando (avg+/avg-) paras as hipótese de modularidade, a quantidade de variação no primeiro componente principal (PC1), índices de flexibilidade e restrição evolutivas e o índice de magnitude geral de integração $\left(\mathrm{r}^{2}\right)$ para 21 táxons de mamíferos.

\begin{tabular}{|c|c|c|c|c|c|c|c|c|c|c|c|c|c|}
\hline $\begin{array}{c}\text { Grupo } \\
\text { Taxonômico }\end{array}$ & Face & Nerocrânio & Neuroface & Oral & Nasal & Zigomática & Abóbada & Base & Total & PC1 & Flexibilidade & Restrição & $r^{2}$ \\
\hline Didelphimorphia & 1.18 & 0.82 & 1.01 & 1.20 & 1.26 & 1.18 & 0.90 & 0.73 & 1.04 & 0.68 & 0.30 & 0.89 & 0.35 \\
\hline Paucituberculata & 1.85 & 0.48 & 1.15 & 1.97 & 2.03 & 1.12 & 0.56 & 0.48 & 1.08 & 0.61 & 0.33 & 0.85 & 0.15 \\
\hline Dasyuromorphia & 1.35 & 0.70 & 1.04 & 1.25 & 1.35 & 1.21 & 0.79 & 0.52 & 0.99 & 0.64 & 0.32 & 0.87 & 0.28 \\
\hline Diprotodontia & 1.34 & 0.67 & 1.01 & 1.43 & 1.47 & 1.04 & 0.74 & 0.72 & 1.00 & 0.76 & 0.27 & 0.92 & 0.39 \\
\hline Peramelimorphia & 1.24 & 0.79 & 1.03 & 1.32 & 1.26 & 1.03 & 0.80 & 0.78 & 1.00 & 0.80 & 0.26 & 0.93 & 0.44 \\
\hline Hyracoidea & 1.67 & 0.55 & 1.11 & 1.71 & 1.75 & 1.32 & 0.68 & 0.40 & 1.10 & 0.67 & 0.30 & 0.89 & 0.26 \\
\hline Macroscelidea & 1.74 & 0.66 & 1.27 & 2.63 & 2.02 & 0.64 & 0.87 & 0.01 & 1.24 & 0.30 & 0.49 & 0.65 & 0.07 \\
\hline Cingulata & 1.09 & 0.98 & 1.06 & 1.70 & 1.66 & 0.60 & 1.16 & 0.52 & 1.15 & 0.64 & 0.31 & 0.88 & 0.17 \\
\hline Scandentia & 1.33 & 1.01 & 1.29 & 1.68 & 1.60 & 0.93 & 1.18 & 0.48 & 1.31 & 0.29 & 0.46 & 0.58 & 0.09 \\
\hline Lagomorpha & 1.33 & 0.71 & 1.03 & 1.75 & 1.75 & 0.82 & 0.79 & 0.51 & 1.02 & 0.55 & 0.36 & 0.84 & 0.19 \\
\hline Carnivora & 1.22 & 0.83 & 1.05 & 1.34 & 1.52 & 0.98 & 0.87 & 0.90 & 1.08 & 0.54 & 0.36 & 0.82 & 0.21 \\
\hline Perissodactyla & 1.32 & 0.84 & 1.13 & 2.09 & 1.86 & 0.70 & 1.01 & 0.63 & 1.38 & 0.36 & 0.46 & 0.69 & 0.10 \\
\hline Artiodactyla & 1.13 & 0.96 & 1.08 & 1.97 & 1.36 & 0.55 & 1.28 & 0.09 & 1.35 & 0.41 & 0.42 & 0.74 & 0.11 \\
\hline Rodentia & 1.41 & 0.94 & 1.29 & 1.72 & 2.32 & 0.94 & 1.11 & 0.70 & 1.33 & 0.33 & 0.49 & 0.68 & 0.09 \\
\hline Gorilla & 1.24 & 1.00 & 1.20 & 1.67 & 1.12 & 1.21 & 1.37 & 0.62 & 1.40 & 0.33 & 0.49 & 0.68 & 0.07 \\
\hline Homo & 1.06 & 1.38 & 1.35 & 1.80 & 1.27 & 1.34 & 1.87 & 0.98 & 1.85 & 0.24 & 0.58 & 0.58 & 0.05 \\
\hline Pan & 1.93 & 0.63 & 1.37 & 2.55 & 2.07 & 1.41 & 0.80 & 0.63 & 1.57 & 0.25 & 0.57 & 0.59 & 0.06 \\
\hline Papio & 1.68 & 0.62 & 1.19 & 1.68 & 1.62 & 1.22 & 0.67 & 0.70 & 1.12 & 0.65 & 0.31 & 0.89 & 0.23 \\
\hline Alouatta & 1.47 & 0.76 & 1.17 & 1.82 & 1.33 & 1.21 & 0.93 & 0.61 & 1.24 & 0.42 & 0.43 & 0.77 & 0.15 \\
\hline Cebus & 1.55 & 0.80 & 1.27 & 2.05 & 1.39 & 1.35 & 0.98 & 0.98 & 1.44 & 0.32 & 0.44 & 0.61 & 0.12 \\
\hline Callithrix & 1.18 & 0.99 & 1.15 & 2.20 & 1.43 & 0.98 & 1.19 & 0.72 & 1.50 & 0.23 & 0.54 & 0.55 & 0.07 \\
\hline
\end{tabular}


A5 - Média das réplicas dos dados (primeira e segunda medida por caráter craniano) paras as espécies de morcegos filostomídeos.

\begin{tabular}{|c|c|c|c|c|c|c|c|c|c|c|c|c|c|c|c|c|c|c|c|c|c|c|c|c|c|c|c|c|c|c|c|c|c|c|c|}
\hline écies & & & & & & & & & & & & & $T$ & $T$ & at & n & io & P1 & $z+2+2$ & $\tau z$ & ZIZYGO & PI & MTPNS : & PET & TBA & A APETTS & BAEAM & EAMZYGO & ZYGOTSP & LDAS & BRLD 0 & OPILD & D PTAS & & $S B$ \\
\hline Macrotus californicus & 1.09 & 3.54 & 10.39 & 9.83 & 9.40 & 8.84 & 5.74 & 8.90 & 8.77 & 5.56 & 4.49 & 4.65 & 7.09 & 6.02 & 8.35 & 6.06 & 4.55 & 2.57 & 1.142 & 2.40 & 3.33 & 4.09 & 2.37 & 5.84 & 2.35 & 1.92 & 4.63 & 3.72 & 2.86 & 3.961 & 10.40 & 2.16 & 9.77 & 73.52 & 4.07 \\
\hline Macrotus waterhousii & 1.22 & 3.55 & 10.00 & 9.40 & 8.90 & 8.53 & 5.23 & 8.68 & 8.49 & 5.39 & 4.72 & 4.71 & 7.34 & 5.96 & 8.35 & 6.10 & 4.48 & 2.65 & 1.132 & 2.21 & 3.24 & 4.01 & 2.34 & 5.78 & 2.43 & 1.73 & 4.48 & 3.71 & 2.81 & 4.141 & 10.85 & 2.59 & 9.72 & 23.60 & 3.99 \\
\hline ronycteris microtis & 1.06 & 2.72 & 8.45 & 7.26 & 6.98 & 6.74 & 3.86 & 6.88 & 6.89 & 5.19 & 4.52 & 4.62 & 6.74 & 4.90 & $6768>$ & 4.83 & 3.66 & 2.36 & 1.111 & 1.73 & 2.73 & 3.28 & 319 & & & 167 & $200>$ & & ד & 4.11 & 8.88 & 2.24 & 7.58 & 82.92 & 3.53 \\
\hline ohylla ecaudata & 2.54 & 5.26 & 6.84 & 5.40 & 5.47 & 5.01 & 4.42 & 8.10 & 8.65 & 5.82 & 7.87 & 6.84 & 9.82 & 7.34 & 10.52 & 6.27 & 4.97 & 3.11 & 1.143 & 3.1 & 4.13 & 5.05 & 2.25 & 7.60 & $3.2 \mathrm{r}=\mathrm{s}$ & 1. & 6.8 & & & 6.071 & 11.75 & 3.00 & 10.4 & 04.79 & 5.16 \\
\hline smodus rotundus & 3.21 & 4.67 & 9.30 & 5.23 & 5.47 & 5.30 & 2.93 & 7.67 & 8.24 & 8.09 & 8.19 & 8.19 & 10.96 & 9.26 & 12.91 & 8.62 & 5.96 & 4.96 & 1.093 & 3.03 & .78 & 4.65 & 2.91 & 6.95 & 3.73 & 1.77 & 6.30 & 4.38 & 2.49 & 7.58 & 12.85 & 4.50 & 13.49 & 93.99 & 5.14 \\
\hline aemus youngi & 3.06 & 4.49 & 8.28 & 5.13 & 4.89 & 4.88 & 3.87 & 7.86 & 8.02 & 8.08 & 7.67 & 7.88 & 10.62 & 8.15 & 11.80 & 8.05 & 5.59 & 3.82 & 0.983 & 3.43 & 5.07 & 5.62 & 2.77 & & & .01 & 6.4 & 4.10 & .87 & 7.251 & 12.74 & 4.15 & 12.77 & 75.06 & 5.49 \\
\hline nchorhina aurita & 1.42 & 4.47 & 9.83 & 7.14 & 7.04 & 6.49 & 4.97 & 7.76 & 8.03 & 4.84 & 4.99 & 5.20 & 7.04 & 6.19 & 8.29 & 5.79 & 3.56 & $2.24 \mathrm{C}-2 \mathrm{c}$ & 0.872 & 2.05 & 3.30 & 3.67 & $3.4 \mathrm{C}-\mathrm{r}=\mathrm{s}$ & 4.9 & 2 & 2.50 & 5.27 & & 2 & 4.46 & 8.91 & 2.43 & 9.17 & $7 \quad 3.30$ & 4.08 \\
\hline nchorhina orinocensis & 1.15 & 3.74 & 8.19 & 6.49 & 6.31 & 6.02 & 4.21 & 6.45 & 6.53 & 4.79 & 4.23 & 4.95 & 6.78 & 5.89 & 7.78 & 5.15 & 3.0 & 2.06 & 0.751 & 1.73 & 3.12 & 3.24 & 2.34 & 5.3 & 2.00 & 2.2 & 5.2 & 3. & 82 & .24 & 9.04 & 1.84 & 8.77 & 2.95 & 3.90 \\
\hline acrophyllum macrophy & 1.13 & 3.28 & 6.34 & 6.38 & 6.25 & 5.48 & 2.69 & 6.01 & 6.22 & 4.54 & 3.85 & 4.70 & 6.95 & 4.94 & 6.79 & 4.82 & 3.54 & 1.92 & 0.931 & 1.93 & 2.30 & 3.03 & 2.16 & $A$ & 90 & 1.64 & 3.79 & 10 & 33 & 4.09 & 9.28 & 2.30 & 7.99 & 93.07 & 7.83 \\
\hline Frachops cirrtosus & 1.86 & 4.15 & 11.90 & 10.87 & 10.93 & 10.15 & 4.90 & 10.76 & 11.33 & 8.22 & 6.93 & 7.02 & 10.93 & 8.57 & 11.90 & 8.91 & 7.08 & 4.36 & 1.742 & 2.97 & 4.96 & 5.31 & 3.03 & $7.82 \longrightarrow>$ & 3.36 & 2.55 & 6.09 & 4.13 & 3.75 & 6.261 & 14.48 & 3.89 & 13.23 & 34.33 & $\begin{array}{ll}35.09 \\
\end{array}$ \\
\hline phostoma silvicolum & 1.85 & 4.58 & 12.12 & 10.16 & 9.59 & 9.17 & 4.64 & 9.87 & 9.90 & 7.29 & 7.23 & 6.25 & 10.14 & 7.08 & 9.92 & 7.44 & 6.05 & 3.27 & 1.662 & 2.63 & 4.07 & 5.61 & 3 & 5. & & 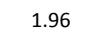 & - & & & 6.241 & 13.42 & 4.46 & & 4.50 & 4.73 \\
\hline natia saurophila & 1.85 & 5.23 & 12.95 & 10.76 & 9.91 & 9.62 & 4.23 & 9.91 & 9.87 & 8.13 & 8.21 & 6.39 & 10.06 & 7.67 & 10.54 & 7.68 & 6.08 & 3.782 & 2.262 & 2.66 & 4.79 & 5.89 & 3.77 & 6. & 92 & 2.49 & 6. & 35 & 70 & 5.81 & 13.91 & 3.90 & 11.95 & 54.16 & 54.66 \\
\hline & 37 & 5.38 & 14.02 & 11.47 & 10.75 & 10.04 & 6.94 & 11.56 & 11.25 & 9.30 & 9.13 & 8.63 & 12.4 & 9.01 & 12.30 & 8.3 & & 4.22 & 1.452 & & & & & & & & & & & 061 & & 9 & & & \\
\hline us & 3.20 & 6.79 & 16.86 & 14.88 & 14.30 & 13.21 & 8.12 & 14.51 & 14.68 & 9.43 & 9.69 & 8.33 & 14.32 & 11.29 & 15.47 & 10.61 & $9.6 \mathrm{C}>\mathrm{C}$ & 5.65 & 2.564 & 4.51 & 5.54 & 7.67 & & 10 & & 2.60 & & & & 8.091 & 18.58 & 4.55 & 16.10 & 05.40 & 6.02 \\
\hline Shrotopterus auritus & 2.26 & 5.98 & 16.63 & 14.32 & 13.23 & 12.83 & 6.45 & 13.41 & 13.26 & 10.04 & 10.25 & 8.46 & 13.88 & 10.80 & 13.87 & 10.46 & 8.35 & 5.112 & 2.704 & 4.11 & 6.50 & 7.64 & 4.34 & $8 . \varepsilon$ & 3.4 & 2.56 & 8.0 & 5.18 & 4.90 & 8.161 & 18.11 & 4.89 & 15.69 & 95.18 & 5.99 \\
\hline & 67 & 8.40 & 25.12 & 21.78 & 21.46 & 20.60 & 12.40 & 18.96 & 19.43 & 11.70 & 12.94 & 10.70 & 16.43 & 13.07 & 17.13 & 13.59 & 11.07 & 6.042 & 2.875 & 5.1. & 8.47 & & & & & & & & & 11.092 & 22.21 & 7.99 & 19.23 & & \\
\hline & 1.34 & 2.99 & 11.66 & 9.12 & 9.08 & 9.11 & 5.93 & 8.51 & 8.53 & 6.10 & 5.32 & 5.25 & 7.2 & 6.60 & 9.45 & 6.25 & 4. & 2.80 & 0.751 & 1.99 & 4.02 & 11 & & & & & & & & 4.17 & 10.19 & 2.26 & 10.75 & 53.58 & 3.96 \\
\hline ga soricina & 1.49 & 2.92 & 11.05 & 7.83 & 7.66 & 7.76 & 5.00 & 7.55 & 7.49 & 4.86 & 5.52 & 4.71 & 7.08 & 5.96 & 8.73 & 5.61 & 4.08 & 2.81 & 0.732 & 2.07 & 3.72 & 3.52 & 2.87 & 3.98 & 2.81 & .24 & 4.5 & $2.6 \varepsilon$ & 88 & 4.37 & 9.87 & 1.86 & 9.58 & 82.93 & $\begin{array}{l}3 \\
4.08\end{array}$ \\
\hline tor & 1.79 & 4.22 & 15.30 & 10.81 & 10.82 & 10.21 & 5.90 & 9.70 & 9.79 & 7.08 & 7.49 & 5.64 & 8.40 & 8.32 & 11.66 & $7.97>-1$ & 5.1. & $3.90 \mathrm{c}$ & 0.591 & 1.93 & 4.87 & 5.1 & 4.9 & $5.7-7>$ & 3.36 & 2. & 5. & & 1.5 & 4.641 & 11.32 & 2.34 & 12.73 & 33.91 & 4.61 \\
\hline & & 5.33 & 13.94 & 12.40 & 12.03 & 11. & 7.35 & 12.45 & 12.40 & 8. & & & & & & & & 52 & 1.134 & & & & & & & & & & & & & & & & \\
\hline oph & 1.88 & 3.24 & 10.42 & 8.63 & 8.56 & 8.13 & 6.11 & 8.65 & 8.62 & 6.72 & 4.48 & 5.68 & 8.53 & 6.88 & 9.70 & 7.1 & 4.3 & 2.95 & 0.431 & 1.70 & 4.25 & 4.3 & 2.83 & 6.79 & 2.99 & 2.02 & 4.6 & 4.2 & 2.16 & 4.77 & 11.39 & 2.67 & 11.18 & 83.64 & $\begin{array}{l}4.20 \\
4\end{array}$ \\
\hline eyi & 2.12 & 3.94 & 10.49 & 8.60 & 8.60 & 8.11 & 6.51 & 8.99 & 9.03 & 6.56 & 5.42 & 5.0 & 8.58 & 7.13 & 9.30 & 6.7 & 4.6 & 2.45 & 0.452 & 2.13 & 5.25 & 4.4 & 2. & 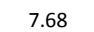 & 2.33 & 1.7 & 4. & 3.4 & 2.62 & 4.54 & 11.20 & 2.72 & 10.83 & 34.02 & 4.66 \\
\hline & & 2.69 & 14.11 & 10.95 & 11.06 & & & 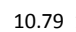 & 10.93 & 6. & & & & & & & & & & & & & & & & & & & & & & & & & \\
\hline mexica & 1.57 & 2.80 & 18.05 & 13.68 & 13.70 & 13.11 & 10.82 & 13.01 & 13.02 & 6.66 & 6.57 & 5.30 & 8.0 & 7.81 & 10.74 & 7.24 & 5.1 & .23 & 0.482 & 2.04 & .77 & 4.7 & 4.6 & $5 . \varepsilon$ & 2.96 & 2.18 & 5. & & 2.19 & 4.25 & 11.31 & 1.90 & 11.73 & 33.69 & .05 \\
\hline & 1.46 & 3.62 & 10.37 & 8.28 & 8.63 & 6.31 & 5.35 & 7.99 & 8.71 & 5.26 & 6. & 5.42 & 8. & 7.01 & 9.72 & & 5. & 2.93 & 1.463 & 3.38 & .93 & 3.6 .625 & & & & 1.7 & & & & 4.87 & 10.68 & 2.65 & 10.03 & 34.12 & 92 \\
\hline Trinycte & 1.11 & 3.90 & 10.41 & 8.08 & 7.78 & 7.41 & 4.19 & 6.89 & 6.87 & 5.27 & 5.7 & 4.49 & 6.6 & 5.62 & 7.97 & 5.6 & 3.8 & 2.27 & 1.051 & 1.76 & .64 & 3.7 & 3. & 4 & 2.3 & 1.9 & 4. & 3.1 & 2.28 & 4.18 & 9.39 & 2.10 & 8.88 & 82.96 & $5 \quad 3.93$ \\
\hline & & 2.91 & 7.98 & 6.63 & 6.64 & 5.09 & 387 & 6.62 & 6.65 & 5.4 & 10 & T. & & & & & & 2.94 & 0.511 & & & & & & & & & & & 4.45 & 9.11 & 2.12 & 51 & 13.05 & \\
\hline & & 4.22 & 12.67 & 9 & 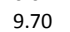 & s & & & 10.09 & 6. & & & & & & & & & 1.763 & 3. & & & & & & & & & & 011 & & & 1 & 14.04 & 4.26 \\
\hline & 4 & 34 & 9.40 & 7.14 & 7. & 0. & 3. $2>3$ & 7.00 & 7.14 & 5 & 6. & 5. & & 6.31 & 8. & 6.3 & 4.5 & $5 \mathrm{c}$ & 0.832 & 2.1 & 3.34 & & & & & 2.0 & 4. & & & 85 & 10.25 & 3.14 & 9 & 3.53 & $\begin{array}{l}3.87 \\
3\end{array}$ \\
\hline strum & 3 & 4.65 & 12.13 & 8.85 & 8.6 & 8.2 & 6. & 9.67 & 9.79 & 6.0 & 8. & 5.84 & 9. & & 10.75 & & 5. & 3.93 & 0.912 & & 4.2 & & 4. & & & 2. & & & & 331 & 11.06 & 2.78 & 1 & 93.58 & 94 \\
\hline & & 3.95 & 8.48 & 6.83 & 6.74 & 6. & 2. & 6.53 & 6.72 & 5. & & & & & 8. & 5 & & 3.04 & 0.832 & $2 . c$ & 2. & & & & & & & & & 32 & 9.09 & 30 & 8 & 83 & 85 \\
\hline nne & 1.24 & 3.77 & 8.07 & 6.73 & 6.60 & 6.0 & 2. & 6. & 6.29 & 4.7 & 4. & 4.41 & & 5 & & & & 2 & 0.861 & 1.8 & 2. & & & & & & & & & .37 & 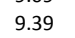 & 2.44 & 54 & 43.14 & $\begin{array}{l}3.78 \\
4\end{array}$ \\
\hline & & 5.19 & 14.05 & 11. & 11.0 & 10. & $-\sigma^{2}+2$ & 11 & 11.25 & 7.6 & & 7.02 & & & 12 & 9. & & 4.68 & 1.993 & & & & & & & & & & & & & 4.25 & 1 & 24 & \\
\hline tyyr & 2 & 6.28 & 16.24 & 14.08 & 13.84 & 12.01 & 6.27 & 13.22 & 13.43 & 9.1 & 9. & 8.23 & 12.02 & 10.10 & 13.46 & 10.51 & 8 & 5.54 & 1.463 & 3. & 5.05 & 6. & & & & 2.9 & & & & 401 & 14.35 & 4.73 & 1 & 4.96 & $\begin{array}{ll}5 & 4.99\end{array}$ \\
\hline & & 0 & - & 7. & 7.6 & 7.2 & & & 7. & & & & & & & & & & & & & & & & & & & & & & & & & & \\
\hline & & 5.52 & 15.60 & 12. & 12.29 & 11. & 5. & 12. & 12. & 9. & & 7. & 12 & 10 & 13 & 10 & & 5 & 1.374 & 4. & & & & & & & & & & 51 & 14.88 & 4.57 & & 65.23 & 56 \\
\hline & 2.74 & 5.65 & 15.30 & 12.49 & 12.11 & 11.61 & 6.16 & 12.20 & 12.36 & 9.2 & 8.7 & 7.90 & 12.47 & 9.91 & 13.65 & 9 & 8. & 5.40 & 1.754 & 4. & 5. & 6.86 & 4.6 & & 3.9 & 2.0 & & & 4.95 & 141 & 8 & 4.53 & 1 & 16 & 64 \\
\hline & 3 & 3.69 & 8.77 & 6.73 & 7.1 & 6.7 & & (c) & 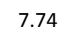 & & & & & & & & & & 1. & 2. & & & & & & & & & & & & 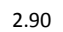 & & & 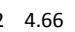 \\
\hline & & & 3. & 6 & 6. & 5. & & 6 . & 6 & & & & & & & & & & & & & & & & & & & & & & & 7 & & & \\
\hline enc & 5 & 5.33 & 4.00 & 7.67 & 7.70 & 6.8 & 2. & 6.91 & 7.36 & 6.8 & 5. & 6. & 9. & 6.96 & 9. & 7 & 5 & 3.48 & 1.163 & 3. & 3. & 5.11 & 4.1 & 10 & 2.5 & 2.7 & 5.2 & & 4.08 & 71 & 6 & 2.87 & 29 & 94.02 & 75 \\
\hline & & 3.31 & 3. & 5.98 & 6.20 & 4.9 & 2. & $700-3$ & 8.61 & 5. & $5:-3>$ & & & & & & & & & & & & & & & & & & & 81 & 10.69 & 4.74 & 4 & 44 & \\
\hline & & & & & & & & & & & & & & & & & & & & & & & & & & & & & & & & & & & \\
\hline$o x c$ & 1.12 & 3.56 & 3.98 & 5.82 & 5.26 & 4.46 & 1. & 6.27 & 6.26 & 6.59 & 4.21 & 6.41 & $8.2-2-3$ & 5.58 & 7.9 & 5.78 & 5. & 3.46 & $1.9 \mathrm{P}>\mathrm{P}$ & 2.53 & 2.77 & $3.28 \mathrm{~s}$ & $2.8<>3$ & 5.6 & 2. & 2. & 4.87 & 3.2 & 3.01 & 4.361. & 10.02 & 2.20 & 8.94 & 3.44 & .60 \\
\hline 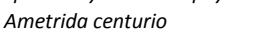 & 1.12 & 3.41 & & & $-\mathrm{cos}$ & 4.5 & $2 . c$ & & $x^{2}+2$ & - & 4.16 & - & & & 6.7 & 4.99 & & 2.69 & & & & & & & & & & & & & 9.70 & .99 & & 11 & \\
\hline & 1.55 & 72 & 4.61 & 0 & 6.23 & 5.8 & 3.6 & 15 & 7.34 & -3 & 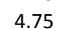 & 5.52 & $8.49>>$ & 6.94 & 9.73 & 7.34 & 57 & 84 & & & .80 & 4.45 & 3.17 & $8.49>>$ & 2.85 & 2.4 & 4.93 & 4.5 & 3.2 & & 1.02 & & & 3.3 & $29-29$ \\
\hline
\end{tabular}


A6 - Desvio padrão das réplicas dos dados (primeira e segunda medida por caráter craniano) paras as espécies de morcegos filostomídeos.

\begin{tabular}{|c|c|c|c|c|c|c|c|c|c|c|c|c|c|c|c|c|c|c|c|c|c|c|c|c|c|c|c|c|c|c|c|c|c|c|}
\hline Espécies & & & & & & & & & & & & & & & & & & & & & & & & & & & & & & & & & & \\
\hline Macrotus californicus & 0.07 & 0.15 & 0.27 & 0.29 & 0.20 & 0.18 & 0.32 & 0.26 & 0.21 & 0.46 & 0.25 & 0.26 & 0.21 & 0.21 & 0.21 & 0.24 & 0.18 & 0.18 & 0.220 .14 & 0.20 & 0.13 & 0.12 & 0.24 & 0.17 & 0.22 & 0.14 & 0.19 & 0.15 & 0.18 & 0.39 & 0.20 & 0.23 & 30.24 & 0.23 \\
\hline Macrotus waterhousii & 0.08 & 0.16 & 0.27 & 0.30 & 0.21 & 0.20 & 0.28 & 0.21 & 0.17 & 0.44 & 0.18 & 0.27 & 0.17 & 0.17 & 0.19 & 0.18 & 0.12 & 0.16 & 0.230 .11 & 0.18 & 0.11 & 0.11 & 0.16 & 0.14 & 0.16 & 0.17 & 0.19 & 0.13 & 0.16 & 0.41 & 0.20 & 0.23 & 30.23 & 30.16 \\
\hline Micronycteris microtis & 0.10 & 0.19 & 0.35 & 0.25 & 0.24 & 0.23 & 0.32 & 0.26 & 0.27 & 0.39 & 0.19 & 0.24 & 0.18 & 0.18 & 0.20 & 0.21 & 0.18 & 0.15 & 0.130 .11 & 0.19 & 0.19 & 0.14 & 0.20 & 0.15 & 0.14 & 0.14 & 0.14 & 0.15 & 0.18 & 0.30 & 0.22 & 0.25 & 50.16 & 0.19 \\
\hline phylla ecaudata & 0.15 & 0.27 & 0.35 & 0.23 & 0.37 & 0.31 & 0.56 & 0.24 & 0.54 & 0.73 & 0.66 & 0.42 & 0.55 & 0.43 & 0.46 & 0.37 & 0.28 & 0.26 & 0.590 .21 & 0.30 & 0.28 & 0.13 & 0.41 & 0.41 & .34 & 0.58 & 0.29 & 24 & 0.29 & 0.68 & 0.33 & 0.41 & 10.28 & 30.46 \\
\hline smodus rotundus & 0.14 & 0.25 & 0.35 & .28 & 0.28 & 0.22 & 0.33 & 0.22 & 0.24 & 0.71 & 0.27 & 0.54 & 0.34 & 0.37 & 0.38 & 0.32 & 0.29 & 0.38 & 0.160 .18 & 0.39 & 0.32 & 0.17 & 0.31 & 0.28 & 0.43 & 0.32 & 0.36 & .21 & 0.38 & 0.61 & 0.34 & 0.38 & 80.27 & $7 \quad 0.24$ \\
\hline nchorhina aurita & 0.09 & 0.23 & 0.21 & 0.22 & 0.17 & 0.16 & 0.37 & 0.20 & 0.23 & 0.65 & 0.18 & 0.48 & 0.24 & 0.19 & 0.21 & 0.20 & 0.24 & 0.20 & 0.120 .10 & 0.17 & 0.12 & 01 & 0.18 & 0.13 & 16 & 0.11 & 20 & 16 & 0.22 & 0.66 & 0.21 & 0.26 & 60.11 & 10.19 \\
\hline nchorhina orinocensis & 0.05 & 0.16 & 0.25 & 0.21 & 0.14 & 0.12 & 0.36 & 0.20 & 0.23 & 0.40 & 0.19 & 0.33 & 0.20 & 0.23 & 0.25 & 0.27 & 0.31 & 0.22 & 0.130 .15 & 0.23 & 0.12 & 0.17 & 0.16 & 0.11 & 0.15 & 0.18 & 0.22 & 0.17 & 0.20 & 0.40 & 0.20 & 0.26 & 60.14 & 0.15 \\
\hline acrophyllum macrophyllum & 0.06 & 0.19 & 0.20 & 0.17 & 0.17 & 0.14 & 0.23 & 0.15 & 0.20 & 0.41 & 0.17 & 0.28 & 0.22 & 0.19 & 0. & 0.21 & 0. & 0.20 & 0.150 .11 & 0.20 & 0.14 & 0.09 & 0.1 & 0.1 & 0.17 & 0.1 & 0.12 & 0.14 & 0.26 & 0.39 & 0.24 & 0.25 & 50.15 & 0.21 \\
\hline achops cirrhosus & 0.09 & 0.16 & 0.38 & 0.29 & 0.27 & 0.23 & 0.35 & 0.29 & 0.26 & 0.52 & 0.29 & 0.36 & 0. & 20 & 0.29 & 0.28 & 0. & 0.25 & 0.230 .21 & 0.28 & 0.21 & 0.21 & 0.30 & 0.19 & 20 & 0.20 & 17 & 18 & 0.29 & 0.54 & 0.33 & 0.35 & 50.18 & $\begin{array}{ll}3 & 0.22\end{array}$ \\
\hline phostoma silvicolum & 0.14 & 0.26 & 0.37 & 0.29 & 0.32 & 0.27 & 0.39 & 0.29 & 0.35 & 0.65 & 0.31 & 0.57 & 0.49 & 0.30 & 0.40 & 0.37 & 0.3 & 0.30 & 0.170 .17 & 0.24 & 0.25 & 0.19 & 0.29 & 0.28 & 0.21 & 0.22 & 0.2 & 25 & 0.41 & 0.73 & 0.45 & 0.39 & 90.24 & 0.20 \\
\hline Tonatia saurophila & 0.09 & 0.29 & 0.50 & 0.56 & 0.39 & 0.38 & 0. & 0.49 & 0.39 & 0.55 & 0.3 & 0.36 & & & & 0.35 & 0. & 0.25 & 0.300 .17 & 0.43 & 0.34 & 0.2 & 0.3 & 0. & 5 & 0.2 & & 20 & 0.27 & 0.46 & 0.35 & & 50.20 & 0.20 \\
\hline ylloderma stenops & 0.17 & 0.34 & 0.80 & 158 & 0.48 & 0.45 & 0.70 & 0.53 & 0.44 & 0.84 & 0.45 & 0.35 & 0.43 & 0.39 & 0.46 & 0.46 & 0.4 & 0.31 & 0.240 .20 & 0.49 & 0.48 & 0.3 & 0.40 & 0.2 & 0.22 & 0.2 & & & 0.25 & 0.68 & 0.38 & 0.53 & $\begin{array}{ll}30.28 \\
\end{array}$ & $\begin{array}{ll}3 & 0.34\end{array}$ \\
\hline IUST & 0.14 & 0.28 & 0.55 & 0.46 & 0.44 & 36 & 0.5 & 0.54 & 0.69 & 0.81 & 0. & 0.62 & & & & 0.54 & & 0.43 & 0.800 .31 & 0.48 & 0.44 & 0. & 0. & 0. & & 0 & & & 0.55 & 0.72 & 0.50 & & 10.40 & 0.32 \\
\hline rotopterus auritus & 0.13 & 0.33 & 0.56 & 0.49 & 0.43 & 0.41 & 0.34 & 0.50 & 0.47 & 0.84 & 0.46 & 0.51 & 0.58 & 0.60 & 0.60 & 0.52 & 0.52 & 0.49 & 0.350 .24 & 0.42 & 0.35 & 0.28 & 0.47 & 0.28 & 0.26 & 0.40 & 34 & 26 & 0.49 & 0.71 & 0.41 & 0.74 & 40.38 & $\begin{array}{ll}3 & 0.32\end{array}$ \\
\hline & 0.15 & 0.49 & 0.90 & 72 & 0.76 & 0.63 & 0.98 & 0.72 & 0.71 & 1.64 & 0.5 & 0.84 & & 0 & & 0.66 & 0.7 & 0.73 & 0.460 .37 & 0.6 & 0.35 & 0.3 & 0. & & 0.3 & 0.4 & & & 0.69 & 1.51 & 0.62 & 0.7 & 40.49 & 0.45 \\
\hline & 0.09 & 0.16 & 0.27 & 0.38 & 0.25 & 0.22 & 0.41 & 0.39 & 0.25 & 0.54 & 0.21 & 0.36 & & & & 0.22 & 0.25 & 0.19 & 0.160 .16 & 0.19 & 0.18 & 0. & 0.2 & & (1) & 0. & & 20 & 0.26 & 0.53 & 0.22 & & $\begin{array}{ll}30.22 \\
\end{array}$ & 0.17 \\
\hline ossophaga soricina & 0.11 & 0.17 & 0.31 & 0.37 & 0.34 & 0.29 & 0.34 & 0.40 & 0.36 & 0.43 & 0.21 & 0.29 & 0.19 & 0.27 & 0.23 & 0.22 & 0.24 & 0.26 & 0.180 .22 & 0.34 & 0.22 & 0.26 & 0.19 & 0.24 & 0.20 & 0.18 & 21 & 18 & 0.28 & 0.39 & 0.22 & 0.26 & $\begin{array}{ll}6 & 0.18\end{array}$ & $\begin{array}{ll}3 & 0.17\end{array}$ \\
\hline & 0.09 & 0.18 & 0.37 & 0.25 & 30 & 0.25 & 0.41 & 0.23 & 0.32 & 0.59 & 0. & 0.31 & & & & 0.3 & & 0.26 & 0.120 & & & & & & & & & & 0.22 & 0.48 & 0.28 & & 10.20 & 18 \\
\hline achyphylla cc & 0.12 & 0.28 & 0.55 & 0.41 & 0.42 & 0.26 & 0.56 & 0.41 & 0.45 & 0.81 & 0.52 & 0.44 & & 0 & 0. & 0.42 & 0.3 & 0.36 & 0.330 .35 & 0.42 & 0.23 & 0.3 & $0 . c^{2}$ & 0. & 0.33 & 0.4 & & 20 & 0.35 & 0.50 & 0.35 & 0.32 & 0.24 & 0.34 \\
\hline sezekorni & 0.12 & 0.15 & 0.30 & 0.30 & 0.19 & 0.16 & 0.32 & 0.33 & 0.25 & 0.41 & 0.19 & 0.28 & 0.25 & 0.25 & 0.2 & 0.25 & 0.3 & 0.21 & 0.140 .12 & 0.23 & 0.16 & 0.1 & 0.2 & 0. & 17 & 0.1 & 0.20 & 23 & 0.21 & 0.35 & 0.26 & 0.30 & $\begin{array}{lll}0 & 0.14\end{array}$ & 0.15 \\
\hline & & 0.20 & 0.23 & 31 & 31 & 1 & & 0.30 & 0.30 & $0-0$ & & 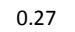 & & & & & & 0.21 & 0.090 & & & & & & & & & & 0 & 0.52 & 26 & & & \\
\hline ieoffroyi & 0.12 & 0.15 & 0.53 & 0.35 & 0.36 & 0.37 & 0. & 0.31 & 0.33 & 0.44 & 0.3 & 0.28 & & 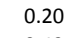 & 0.21 & 0.2 & 0.26 & 0.25 & 0.090 .19 & 0.2 & 0.24 & 0.2 & 0.2 & 0. & 27 & 0. & 0.1 & .18 & 0.27 & 0.36 & 0.22 & 0.30 & $\begin{array}{lll}0 & 0.19\end{array}$ & $\begin{array}{ll}9 & 0.22\end{array}$ \\
\hline cteris mexicana & 0.12 & 0.20 & 0.39 & 0.61 & 0.64 & 0.31 & 0.57 & 0.60 & 0.63 & 0.64 & 0.3 & 0.37 & 0.27 & 0.42 & 0. & 0.46 & 0. & 0.34 & 0.100 .31 & 0.6 & 0.50 & 0.2 & 0.2 & 0. & 30 & 0.1 & 0.2 & 19 & 0.25 & 0.44 & 0.18 & 0.56 & 60.21 & 22 \\
\hline Ila robusta & 0.10 & 0.18 & 0.39 & 26 & 0.27 & 0.30 & 0.45 & 0.27 & 0.30 & 0.52 & 0.36 & 0.30 & 0.2 & 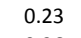 & 0.24 & 0.25 & 0.2 & 0.20 & 0.070 .16 & 0.23 & 0.19 & 0. & 0.2 & 0.22 & 20 & 0.12 & 0.1 & 0.16 & 0.20 & 0.48 & 0.17 & 0.31 & $\begin{array}{ll}1 & 0.17\end{array}$ & 70.17 \\
\hline vicouda & 0.09 & 0.17 & 0.28 & 27 & 0.27 & 0.15 & 0. & 0.2 & 0.27 & 0.42 & 0. & 0.24 & 0.25 & 0.26 & 0.27 & 0.24 & 0. & 0.24 & 0.090 .22 & 0.24 & 0.17 & 0. & 0. & 0.17 & 0.21 & 0.20 & & 0.22 & 0.34 & 0.31 & 0.27 & 0.42 & 20.21 & 23 \\
\hline & & 0.19 & 0.25 & 26 & 0.21 & 0.1 & & 0. & 0.22 & 0. & & & & & & & & & 0.140 & & & & & & & & & & 19 & 0.33 & 0.23 & & & 19 \\
\hline Illa pumilio & 0.11 & 0.18 & 0.37 & 38 & 0.40 & 0.21 & 0.3 & 0.34 & 0.39 & 0.48 & 0.22 & 0.22 & & 0 & 0. & 0.19 & 0. & 0.17 & 0.060 .29 & 0.47 & 29 & $0.2 \mathrm{Z}$ & 0.2 & 0.13 & 0.20 & 0.13 & 0.2 & 0.14 & .23 & 0.32 & 0.22 & 0.30 & $\begin{array}{ll}0 & 0.15\end{array}$ & 0.21 \\
\hline ir & 0.11 & 0.23 & 0.51 & 0.34 & 0.35 & 0.29 & 0.3 & 0.3 & 0.36 & 0.46 & 0. & 0.32 & 0.2 & 0 & 0. & 0.26 & 0 & 0.24 & 0.160 .24 & 0.2 & 24 & 0 & 0. & & 0 & 0.2 & & & 0.31 & 0.46 & 37 & 0.36 & $\begin{array}{ll}6 & 0.20\end{array}$ & 26 \\
\hline & 0 & 0.23 & 0.32 & 2 & .15 & 0.14 & & 0. & 0.20 & 0.3 & & 0. & & & & & & 9 & 0.110 .13 & & & & & & & & & & 23 & 0.37 & 29 & 0 & 15 & 21 \\
\hline magnirc & 0 & 0.21 & 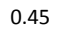 & 0.31 & 0.25 & 0.25 & 0.42 & 0.35 & 4 & 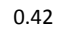 & 0 & 0. & & & & 0. & & 24 & 0.160 .16 & 0. & 23 & 0. & 0.2 & 0.1 & 0.22 & 0.23 & & 0.2 & .29 & 0.43 & 0.28 & 30.44 & $\begin{array}{ll}4 & 0.19\end{array}$ & $\begin{array}{ll}9 & 0.23\end{array}$ \\
\hline & 0 & 0.18 & 0.36 & 0.25 & 0.25 & 0. & 0. & 0. & 0.22 & 0.44 & 0 & 0. & & & & 0. & & & 0.100 .16 & & & & 0.2 & & & & & & 0.26 & 0.41 & 31 & 0.26 & $\begin{array}{ll}6 & 0.16\end{array}$ & 14 \\
\hline & 0 & 0. & 9 & 5 & 23 & 0.22 & 0. & 0.21 & 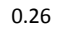 & 0.44 & & 0.23 & & & & & & 8 & 0.090 .11 & & & & & & & & & & .20 & 0.36 & 5 & 50 & 00.15 & 13 \\
\hline & 0 & 0.22 & 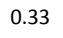 & 1 & 0 & & & & & 0 & 0 & & & & & & & & 0.190. & & & & & & & & & & 8 & 0.60 & 26 & 0.41 & 11 & 24 \\
\hline & 0.12 & 0.23 & 0.39 & 0.34 & 0.31 & 0.2 & 0.3 & 0.2 & 0.27 & 0.50 & 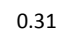 & 0. & & & & & & 0.25 & 0.150 .23 & & & & & & & & & & 30 & 0.40 & 32 & 20 & 19 & $\begin{array}{ll}9 & 0.23\end{array}$ \\
\hline & 0 & 0.19 & 0.36 & 26 & 23 & 0.20 & 0.31 & 0. & 4 & 0.40 & 0. & 0. & & & & 0.3 & & 0 & 0.120 .14 & & 0.21 & & & & & & & & 6 & 0.50 & 0 & 0 & 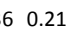 & 20 \\
\hline & & 0. & 0. & 4 & 0 & & & & & & & & & & & & & & 0.2 & & & & & & & & & & 5 & 0.52 & 3 & & & 33 \\
\hline & 0.16 & 0.30 & 0.40 & 0.49 & 0.40 & 0.32 & 0. & 0. & 0.41 & 0. & 0 & 0. & 0. & & 0. & 0. & & 0.34 & 0.270 .23 & 0. & 29 & & 0. & & 0.2 & 0.40 & & 0.28 & .31 & 0.52 & 0.52 & 20 & $18 \quad 0.29$ & 31 \\
\hline & & 0. & 0.30 & 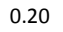 & 0.22 & 0.2 & & 0.18 & 0.22 & 0.3 & & 0.27 & & & & 0.2 & & 9 & 0.10 & & & & & & & & & & 9 & 28 & & & 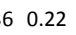 & 21 \\
\hline & & 0. & & & & & & & & & & & & & & & & & & & & & & & & & & & & & & & & \\
\hline ufum & 0.09 & 0.23 & 0.23 & 0.30 & 0.31 & 0.24 & 0. & 0.2 & 0.31 & 0. & 0. & 0.32 & 0. & & - & 0. & & 0.26 & 0.160 .20 & 0. & 20 & 0.17 & 0.36 & 0.17 & 0.23 & 0.18 & 0.2 & 0.20 & 0.25 & 0.38 & 27 & 8 & 17 & 0.19 \\
\hline & & 0. & 0.27 & 26 & 20 & 0.2 & & 0.24 & 0.3 & 0.5 & & 0 & & & & & & & 25 & & & & & & & & & & & & & & & \\
\hline & & 0.24 & 0.3 & & & & & & & & & & & & & & & & & & & & & & & & & & .33 & 47 & 33 & & & \\
\hline phyllum & 0.09 & 0.18 & 0.16 & 0.20 & 0.18 & 0.13 & 0.20 & 0.1 & 0.19 & 0.38 & 0.1 & 0.25 & 0. & 0.19 & 0.22 & 0.18 & 0.19 & 0.19 & 0.140 & 0.16 & 12 & 88 & 20 & 0.21 & 0.20 & 14 & 0.1 & 12 & .22 & 0.35 & 0.23 & & 30.17 & 19 \\
\hline & & 0.25 & 0.2 & 0.32 & . & $0.27 \quad$ & 0.2 & 0 & 0.38 & 0.33 & 0.30 & 20 & & & & & & ( & & & & & & & & & & & & 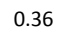 & 26 & & & \\
\hline hyllops falcatu & 0.07 & 0.19 & 0.2 & 0.2 & 0.26 & 0.21 & 0.2 & 0.24 & 0.2 & 0.4 & 0.2 & 0.29 & 0. & 0.28 & 0.25 & 0 & 0.19 & 0.26 & 0.200 .20 & 0.2 & 0.18 & 0.16 & 0. & 0.17 & 0.19 & 0.18 & 0.23 & 0.16 & 0.21 & 0.30 & 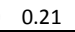 & 26 & 6 & 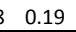 \\
\hline
\end{tabular}


A7 - Razão de divergência dos caracteres cranianos em filostomídeos, obtido pelo método de SRD. A tabela representa as distâncias relacionadas à face e subregiões que a compõem.

\begin{tabular}{|c|c|c|c|c|c|c|c|c|c|c|c|c|c|c|c|c|c|c|}
\hline \multirow{3}{*}{$\begin{array}{l}\text { Subregiões } \\
\text { Espécies }\end{array}$} & \multicolumn{18}{|c|}{ REGIÃO DA FACE } \\
\hline & \multicolumn{6}{|c|}{ ORAL } & \multicolumn{4}{|c|}{ NASAL } & \multicolumn{5}{|c|}{ ZIGOMÁTICA } & \multicolumn{2}{|c|}{ ORAL E NASAL } & \multirow{2}{*}{$\begin{array}{c}\text { ORAL E ZIGO } \\
\text { ZSZI }\end{array}$} \\
\hline & ISPM & PMZS & PMZI & PMMT & ZIMT & MTPNS & ISNSL & NSLNA & NSLZS & NAPNS & PTZYGO & ZIZYGO & ZITSP & EAMZYGO & ZYGOTSP & ISPNS & NSLZI & \\
\hline Macrotus californicus & 46 & 2 & 0 & 0 & 35 & 13 & 19 & 35 & 0 & 14 & 4 & 22 & 35 & 43 & 27 & 2 & 0 & 32 \\
\hline Macrotus waterhousii & 46 & 3 & 3 & 0 & 29 & 9 & 9 & 15 & 2 & 2 & 2 & 18 & 12 & 44 & 12 & 0 & 1 & 31 \\
\hline Micronycteris microtis & 23 & 3 & 5 & 0 & 21 & 17 & 13 & 18 & 1 & 4 & 4 & 29 & 17 & 30 & 11 & 1 & 1 & 28 \\
\hline Diphylla ecaudata & 40 & 2 & 0 & 0 & 14 & 23 & 29 & 19 & 1 & 24 & 2 & 20 & 24 & 25 & 19 & 1 & 1 & 38 \\
\hline Desmodus rotundus & 26 & 6 & 20 & 0 & 34 & 19 & 16 & 28 & 0 & 4 & 1 & 28 & 27 & 43 & 33 & 2 & 1 & 29 \\
\hline Diaemus youngi & 43 & 0 & 0 & 0 & 13 & 32 & 22 & 44 & 9 & 24 & 1 & 20 & 12 & 43 & 11 & 4 & 25 & 42 \\
\hline Lonchorhina aurita & 36 & 1 & 3 & 0 & 16 & 39 & 16 & 35 & 1 & 44 & 25 & 31 & 29 & 22 & 39 & 2 & 0 & 37 \\
\hline Lonchorhina orinocensis & 29 & 13 & 8 & 1 & 42 & 12 & 45 & 25 & 2 & 17 & 2 & 16 & 22 & 39 & 13 & 1 & 0 & 30 \\
\hline Macrophyllum macrophyllum & 24 & 0 & 0 & 1 & 27 & 16 & 42 & 39 & 1 & 15 & 35 & 27 & 12 & 22 & 19 & 4 & 1 & 39 \\
\hline Trachops cirrhosus & 39 & 2 & 2 & 0 & 24 & 16 & 21 & 34 & 0 & 9 & 5 & 20 & 17 & 22 & 7 & 0 & 2 & 47 \\
\hline Lophostoma silvicolum & 21 & 1 & 2 & 0 & 28 & 15 & 15 & 33 & 0 & 13 & 4 & 23 & 17 & 31 & 22 & 3 & 1 & 37 \\
\hline Tonatia saurophila & 37 & 4 & 2 & 0 & 14 & 30 & 10 & 24 & 1 & 8 & 3 & 25 & 18 & 38 & 17 & 1 & 1 & 33 \\
\hline Mimon crenulatum & 23 & 4 & 2 & 0 & 18 & 15 & 34 & 21 & 1 & 9 & 2 & 26 & 18 & 28 & 15 & 2 & 2 & 34 \\
\hline Phylloderma stenops & 42 & 2 & 1 & 0 & 14 & 10 & 10 & 43 & 0 & 9 & 2 & 23 & 12 & 47 & 22 & 3 & 0 & 46 \\
\hline Phyllostomus hastatus & 28 & 1 & 3 & 0 & 26 & 19 & 21 & 27 & 2 & 10 & 3 & 23 & 17 & 27 & 15 & 2 & 1 & 34 \\
\hline Chrotopterus auritus & 20 & 3 & 1 & 0 & 11 & 24 & 14 & 32 & 1 & 4 & 1 & 26 & 17 & 22 & 12 & 2 & 2 & 44 \\
\hline Vampyrum spectrum & 39 & 1 & 1 & 0 & 18 & 36 & 19 & 15 & 0 & 6 & 3 & 22 & 28 & 43 & 31 & 0 & 0 & 32 \\
\hline Monophyllus redmani & 22 & 5 & 0 & 0 & 25 & 9 & 10 & 38 & 7 & 14 & 11 & 27 & 39 & 24 & 30 & 0 & 0 & 41 \\
\hline Glossophaga soricina & 18 & 0 & 0 & 0 & 2 & 45 & 19 & 9 & $\mathrm{o}$ & 9 & 0 & 22 & 35 & 39 & 31 & 1 & 0 & 45 \\
\hline Leptonycteris curasoae & 42 & 0 & 0 & 0 & 25 & 12 & 19 & 30 & 0 & 20 & 1 & 17 & 35 & 17 & 21 & 0 & 0 & 44 \\
\hline Brachyphylla cavernarum & 20 & 4 & 22 & 0 & 14 & 19 & 44 & 8 & 1 & 9 & 2 & 5 & 15 & 24 & 24 & 6 & 8 & 41 \\
\hline Erophylla sezekorni & 43 & 1 & 0 & 0 & 27 & 16 & 46 & 12 & 0 & 14 & 0 & 18 & 12 & 33 & 11 & 3 & 2 & 41 \\
\hline Phyllonycteris poeyi & 31 & 0 & 0 & 0 & 27 & 22 & 27 & 22 & 0 & 14 & 3 & 32 & 33 & 32 & 15 & 2 & 0 & 45 \\
\hline Anoura geoffroyi & 38 & 1 & 0 & 0 & 20 & 14 & 43 & 4 & 1 & 9 & 5 & 9 & 24 & 31 & 45 & 1 & 0 & 39 \\
\hline Choeronycteris mexicana & 16 & 10 & 1 & 1 & 8 & 31 & 45 & 29 & 2 & 21 & 2 & 23 & 36 & 16 & 14 & 0 & 0 & 47 \\
\hline Lionycteris spurrelli & 39 & 0 & 0 & 0 & 15 & 27 & 10 & 20 & 0 & 12 & 1 & 25 & 37 & 45 & 37 & 0 & 0 & 47 \\
\hline Lonchophylla robusta & 21 & 0 & 1 & 0 & 24 & 40 & 38 & 22 & 0 & 21 & 2 & 11 & 9 & 38 & 9 & 0 & 2 & 47 \\
\hline Carollia brevicauda & 26 & 2 & 1 & 0 & 22 & 12 & 23 & 20 & 1 & 9 & 2 & 26 & 36 & 20 & 18 & 2 & 0 & 41 \\
\hline Trinycteris nicefori & 47 & 0 & 2 & 0 & 33 & 17 & 18 & 13 & 0 & 9 & 2 & 25 & 26 & 23 & 21 & 3 & 0 & 44 \\
\hline Rhinophylla pumilio & 23 & 8 & 0 & 0 & 19 & 12 & 16 & 22 & 11 & 23 & 20 & 23 & 37 & 35 & 44 & 0 & 6 & 47 \\
\hline Chiroderma villosum & 32 & 2 & 3 & 0 & 24 & 13 & 19 & 25 & 2 & 10 & 4 & 26 & 16 & 29 & 14 & 2 & 2 & 32 \\
\hline Vampyriscus bidens & 44 & 2 & 2 & 0 & 19 & 14 & 39 & 25 & 2 & 8 & 3 & 16 & 13 & 25 & 21 & 4 & 2 & 47 \\
\hline Uroderma magnirostrum & 22 & 4 & 2 & 0 & 18 & 14 & 16 & 25 & 1 & 4 & 2 & 27 & 12 & 29 & 11 & 0 & 3 & 33 \\
\hline Vampyressa thyone & 24 & 0 & 2 & 0 & 19 & 13 & 20 & 18 & 0 & 6 & 2 & 23 & 16 & 25 & 10 & 0 & 0 & 47 \\
\hline Mesophylla macconnelli & 22 & 1 & 2 & 0 & 20 & 14 & 22 & 18 & 2 & 17 & 2 & 21 & 11 & 25 & 11 & 0 & 2 & 47 \\
\hline Vampyrodes major & 26 & 0 & 2 & 0 & 33 & 13 & 27 & 23 & 0 & 14 & 4 & 25 & 11 & 36 & 28 & 1 & 1 & 35 \\
\hline Platyrrhinus vittatus & 41 & 1 & 2 & 0 & 17 & 21 & 14 & 27 & 0 & 11 & 3 & 29 & 20 & 36 & 16 & 2 & 1 & 46 \\
\hline Enchisthenes hartii & 27 & 0 & 0 & 0 & 18 & 13 & 18 & 35 & 0 & 12 & 7 & 15 & 12 & 24 & 18 & 1 & 2 & 42 \\
\hline Artibeus fimbriatus & 19 & 0 & 1 & 0 & 14 & 30 & 18 & 23 & 0 & 14 & 2 & 13 & 14 & 42 & 12 & 0 & 1 & 42 \\
\hline Artibeus lituratus & 42 & 0 & 0 & 0 & 21 & 16 & 16 & 26 & 0 & 6 & 8 & 19 & 18 & 30 & 18 & 3 & 0 & 47 \\
\hline Dermanura phaeotis & 27 & 5 & 3 & 0 & 43 & 17 & 18 & 14 & 4 & 4 & 1 & 24 & 28 & 44 & 13 & 3 & 2 & 38 \\
\hline Ariteus flavescens & 45 & 0 & 4 & 2 & 19 & 44 & 13 & 18 & 0 & 33 & 4 & 19 & 13 & 41 & 5 & 21 & 1 & 39 \\
\hline Stenoderma rufum & 26 & 0 & 1 & 1 & 13 & 47 & 13 & 38 & 0 & 39 & 2 & 31 & 17 & 24 & 7 & 6 & 1 & 33 \\
\hline Centurio senex & 24 & 3 & 1 & 0 & 6 & 45 & 18 & 20 & 0 & 23 & 1 & 34 & 46 & 40 & 3 & 16 & 1 & 35 \\
\hline Pygoderma bilabiatum & 39 & 10 & 1 & 0 & 13 & 31 & 14 & 44 & 1 & 12 & 10 & 40 & 13 & 17 & 43 & 0 & 1 & 43 \\
\hline Sphaeronycteris toxophyllum & 45 & 3 & 1 & 0 & 9 & 43 & 11 & 38 & 1 & 32 & 1 & 29 & 28 & 45 & 11 & 0 & 0 & 43 \\
\hline Ametrida centurio & 38 & 4 & 2 & 0 & 37 & 19 & 12 & 20 & 2 & 10 & 3 & 19 & 12 & 34 & 15 & 0 & 1 & 25 \\
\hline Phyllops falcatus & 27 & 0 & 1 & 0 & 26 & 44 & 47 & 37 & 0 & 23 & 1 & 12 & 22 & 42 & 29 & 15 & 0 & $203^{2}$ \\
\hline
\end{tabular}


A8 - Razão de divergência dos caracteres cranianos em filostomídeos, obtido pelo método de SRD. A tabela representa as distâncias relacionadas ao neurcrânio e subregiões que o compõem.

REGIÃO DO NEUROCRÂNIO

\begin{tabular}{|c|c|c|c|c|c|c|c|c|c|c|c|c|c|c|c|c|c|}
\hline Subregiões & & & & & ABĆ & BADA & & & & & & & & BASE & & & \\
\hline Espécies & NABR & BRPT & BRAPET & PTAPET & PTBA & PTEAM I & LDAS & BRLD & OPILD & PTAS & JPAS & PNSAPET & APETBA & APETTS & BAEAM & BAOPI & PTTSP \\
\hline Macrotus californicus & 5 & 10 & 5 & 0 & 0 & 1 & 36 & 1 & 29 & 1 & 20 & 29 & 23 & 37 & 7 & 26 & 1 \\
\hline Macrotus waterhousii & 28 & 32 & 4 & 1 & 1 & 1 & 39 & 1 & 31 & 5 & 28 & 14 & 21 & 16 & 4 & 24 & 4 \\
\hline Micronycteris microtis & 14 & 16 & 11 & 0 & 1 & 2 & 25 & 12 & 39 & 2 & 19 & 21 & 21 & 34 & 5 & 31 & 11 \\
\hline Diphylla ecaudata & 22 & 21 & 8 & 2 & 0 & 0 & 29 & 1 & 31 & 0 & 16 & 25 & 34 & 30 & 23 & 37 & 0 \\
\hline Desmodus rotundus & 8 & 11 & 6 & 1 & 0 & 1 & 19 & 7 & 21 & 1 & 18 & 14 & 29 & 35 & 14 & 36 & 4 \\
\hline Diaemus youngi & 2 & 1 & 8 & 0 & 0 & 1 & 19 & 2 & 32 & 0 & 43 & 32 & 18 & 40 & 6 & 27 & 2 \\
\hline Lonchorhina aurita & 7 & 5 & 28 & 0 & 1 & 0 & 14 & 10 & 15 & 0 & 17 & 2 & 29 & 37 & 22 & 13 & 3 \\
\hline Lonchorhina orinocensis & 20 & 26 & 2 & 1 & 0 & 1 & 23 & 0 & 36 & 2 & 14 & 43 & 28 & 32 & 2 & 12 & 2 \\
\hline Macrophyllum macrophyllum & 2 & 16 & 6 & 0 & 0 & 1 & 21 & 1 & 35 & 2 & 35 & 14 & 23 & 38 & 6 & 37 & 26 \\
\hline Trachops cirrhosus & 7 & 23 & 2 & 0 & 0 & 1 & 32 & 1 & 23 & 1 & 40 & 18 & 43 & 31 & 6 & 34 & 10 \\
\hline Lophostoma silvicolum & 18 & 21 & 9 & 0 & 0 & 1 & 30 & 4 & 24 & 1 & 19 & 18 & 30 & 43 & 8 & 28 & 3 \\
\hline Tonatia saurophila & 19 & 24 & 6 & 1 & 1 & 1 & 33 & 22 & 27 & 1 & 17 & 19 & 22 & 32 & 5 & 28 & 4 \\
\hline Mimon crenulatum & 15 & 16 & 8 & 0 & 0 & 1 & 32 & 4 & 41 & 1 & 17 & 10 & 42 & 36 & 10 & 19 & 10 \\
\hline Phylloderma stenops & 13 & 14 & 5 & 1 & 0 & 1 & 14 & 3 & 33 & 36 & 40 & 27 & 34 & 22 & 5 & 47 & 2 \\
\hline Phyllostomus hastatus & 13 & 28 & 2 & 0 & 0 & 1 & 22 & 14 & 30 & 1 & 27 & 18 & 23 & 42 & 6 & 28 & 2 \\
\hline Chrotopterus auritus & 12 & 38 & 0 & 0 & 0 & 1 & 20 & 1 & 19 & 2 & 47 & 13 & 31 & 46 & 6 & 24 & 2 \\
\hline Vampyrum spectrum & 19 & 21 & 12 & 1 & 0 & 2 & 38 & 4 & 31 & 4 & 24 & 34 & 17 & 43 & 9 & 23 & 8 \\
\hline Monophyllus redmani & 1 & 14 & 6 & 0 & 2 & 0 & 39 & 3 & 29 & 9 & 14 & 17 & 37 & 44 & 11 & 37 & 6 \\
\hline Glossophaga soricina & 20 & 30 & 1 & 0 & 0 & 0 & 22 & 0 & 44 & 2 & 45 & 8 & 22 & 30 & 5 & 42 & 0 \\
\hline Leptonycteris curasoae & 4 & 19 & 23 & 0 & 1 & 0 & 37 & 3 & 15 & 1 & 46 & 9 & 18 & 29 & 3 & 47 & 1 \\
\hline Brachyphylla cavernarum & 4 & 3 & 7 & 2 & 12 & 3 & 20 & 3 & 19 & 0 & 19 & 38 & 30 & 42 & 39 & 35 & 4 \\
\hline Erophylla sezekorni & 0 & 4 & 4 & 0 & 0 & 1 & 28 & 3 & 31 & 1 & 38 & 13 & 12 & 41 & 29 & 32 & 1 \\
\hline Phyllonycteris poeyi & 12 & 21 & 8 & 0 & 1 & 1 & 35 & 1 & 28 & 1 & 21 & 13 & 21 & 36 & 3 & 36 & 18 \\
\hline Anoura geoffroyi & 9 & 8 & 27 & 10 & 0 & 1 & 43 & 7 & 22 & 0 & 36 & 23 & 22 & 43 & 31 & 44 & 0 \\
\hline Choeronycteris mexicana & 16 & 23 & 1 & 0 & 1 & 1 & 35 & 0 & 31 & 1 & 16 & 34 & 32 & 30 & 4 & 34 & 1 \\
\hline Lionycteris spurrelli & 16 & 26 & 0 & 0 & 0 & 1 & 44 & 3 & 42 & 1 & 14 & 5 & 21 & 35 & 8 & 19 & 2 \\
\hline Lonchophylla robusta & 7 & 23 & 19 & 1 & 0 & 1 & 31 & 0 & 37 & 2 & 19 & 14 & 8 & 43 & 7 & 29 & 2 \\
\hline Carollia brevicauda & 13 & 20 & 4 & 1 & 0 & 1 & 43 & 14 & 28 & 1 & 23 & 10 & 33 & 31 & 14 & 45 & 2 \\
\hline Trinycteris nicefori & 8 & 21 & 6 & 0 & 0 & 1 & 41 & 6 & 30 & 1 & 16 & 11 & 26 & 34 & 30 & 41 & 3 \\
\hline Rhinophylla pumilio & 8 & 14 & 1 & 0 & 0 & 1 & 21 & 2 & 19 & 0 & 41 & 11 & 33 & 38 & 1 & 18 & 2 \\
\hline Chiroderma villosum & 16 & 15 & 2 & 1 & 1 & 1 & 32 & 4 & 21 & 2 & 19 & 24 & 30 & 29 & 6 & 42 & 4 \\
\hline Vampyriscus bidens & 15 & 14 & 3 & 0 & 0 & 1 & 17 & 2 & 43 & 3 & 28 & 27 & 27 & 23 & 0 & 23 & 3 \\
\hline Uroderma magnirostrum & 17 & 23 & 3 & 0 & 1 & 1 & 36 & 12 & 28 & 1 & 18 & 17 & 36 & 31 & 6 & 23 & 7 \\
\hline Vampyressa thyone & 10 & 15 & 4 & 3 & 1 & 1 & 20 & 26 & 31 & 1 & 46 & 13 & 29 & 32 & 7 & 37 & 8 \\
\hline Mesophylla macconnelli & 16 & 23 & 2 & 1 & 0 & 1 & 39 & 5 & 27 & 1 & 17 & 20 & 19 & 46 & 5 & 29 & 6 \\
\hline Vampyrodes major & 11 & 18 & 3 & 1 & 0 & 1 & 41 & 7 & 36 & 1 & 17 & 12 & 33 & 35 & 10 & 25 & 2 \\
\hline Platyrrhinus vittatus & 13 & 13 & 4 & 1 & 1 & 2 & 34 & 3 & 32 & 1 & 17 & 26 & 17 & 40 & 9 & 21 & 5 \\
\hline Enchisthenes hartii & 15 & 17 & 4 & 1 & 0 & 1 & 27 & 1 & 31 & 1 & 27 & 37 & 22 & 42 & 7 & 44 & 1 \\
\hline Artibeus fimbriatus & 31 & 22 & 10 & 1 & 0 & 1 & 33 & 2 & 40 & 1 & 19 & 14 & 37 & 28 & 26 & 43 & 12 \\
\hline Artibeus lituratus & 9 & 12 & 11 & 0 & 1 & 1 & 32 & 10 & 30 & 0 & 42 & 18 & 24 & 43 & 14 & 44 & 4 \\
\hline Dermanura phaeotis & 23 & 19 & 3 & 0 & 0 & 1 & 38 & 6 & 33 & 1 & 30 & 13 & 25 & 31 & 5 & 35 & 2 \\
\hline Ariteus flavescens & 37 & 29 & 1 & 10 & 0 & 1 & 16 & 11 & 23 & 2 & 31 & 21 & 21 & 21 & 0 & 38 & 10 \\
\hline Stenoderma rufum & 8 & 11 & 12 & 1 & 1 & 1 & 21 & 1 & 30 & 1 & 29 & 14 & 20 & 42 & 5 & 22 & 1 \\
\hline Centurio senex & 17 & 1 & 0 & 1 & 0 & 40 & 13 & 1 & 38 & 5 & 11 & 14 & 25 & 36 & 12 & 23 & 0 \\
\hline Pygoderma bilabiatum & 4 & 20 & 1 & 0 & 0 & 1 & 20 & 5 & 23 & 0 & 12 & 11 & 35 & 25 & 5 & 18 & 0 \\
\hline Sphaeronycteris toxophyllum & 4 & 11 & 9 & 0 & 1 & 1 & 36 & 9 & 33 & 1 & 15 & 12 & 22 & 22 & 6 & 16 & 4 \\
\hline Ametrida centurio & 28 & 34 & 9 & 0 & 0 & 1 & 26 & 10 & 37 & 1 & 44 & 15 & 21 & 37 & 5 & 23 & 3 \\
\hline Phyllops falcatus & 8 & 6 & 12 & 1 & 0 & 0 & 18 & 8 & 20 & 1 & 21 & 11 & 30 & 21 & 5 & 33 & 2 \\
\hline
\end{tabular}


A9 - Gráficos referentes à análise de rarefação para Desmodus rotundus.

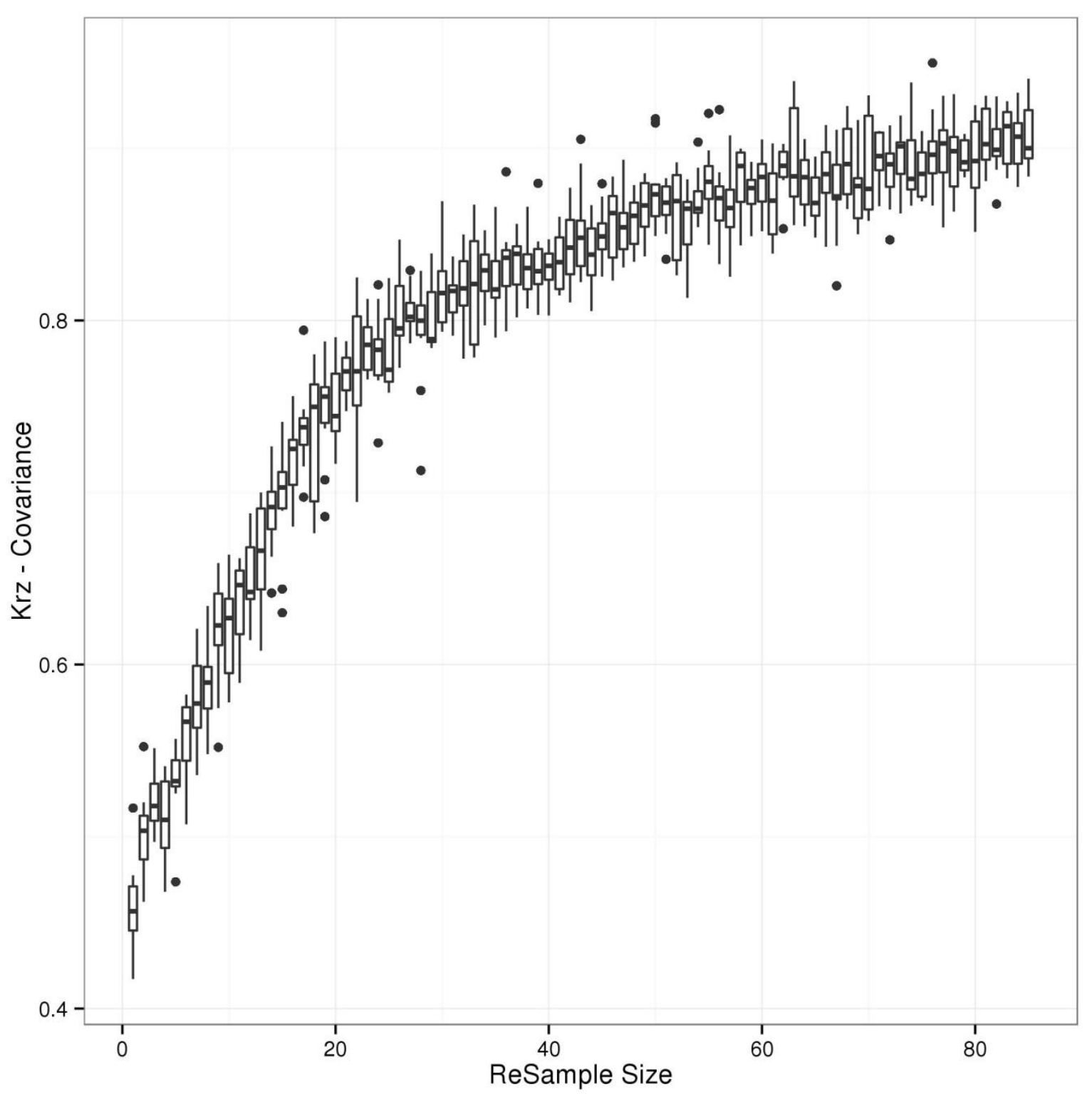

Figura A9a - Gráfico de rarefação para a espécie Desmodus rotundus. No eixo x estão as reamostragens a partir de uma amostra total de 86 indivíduos. No eixo y estão os valores de similaridade para matrizes de covariância estimadas por Kræzanowski. 


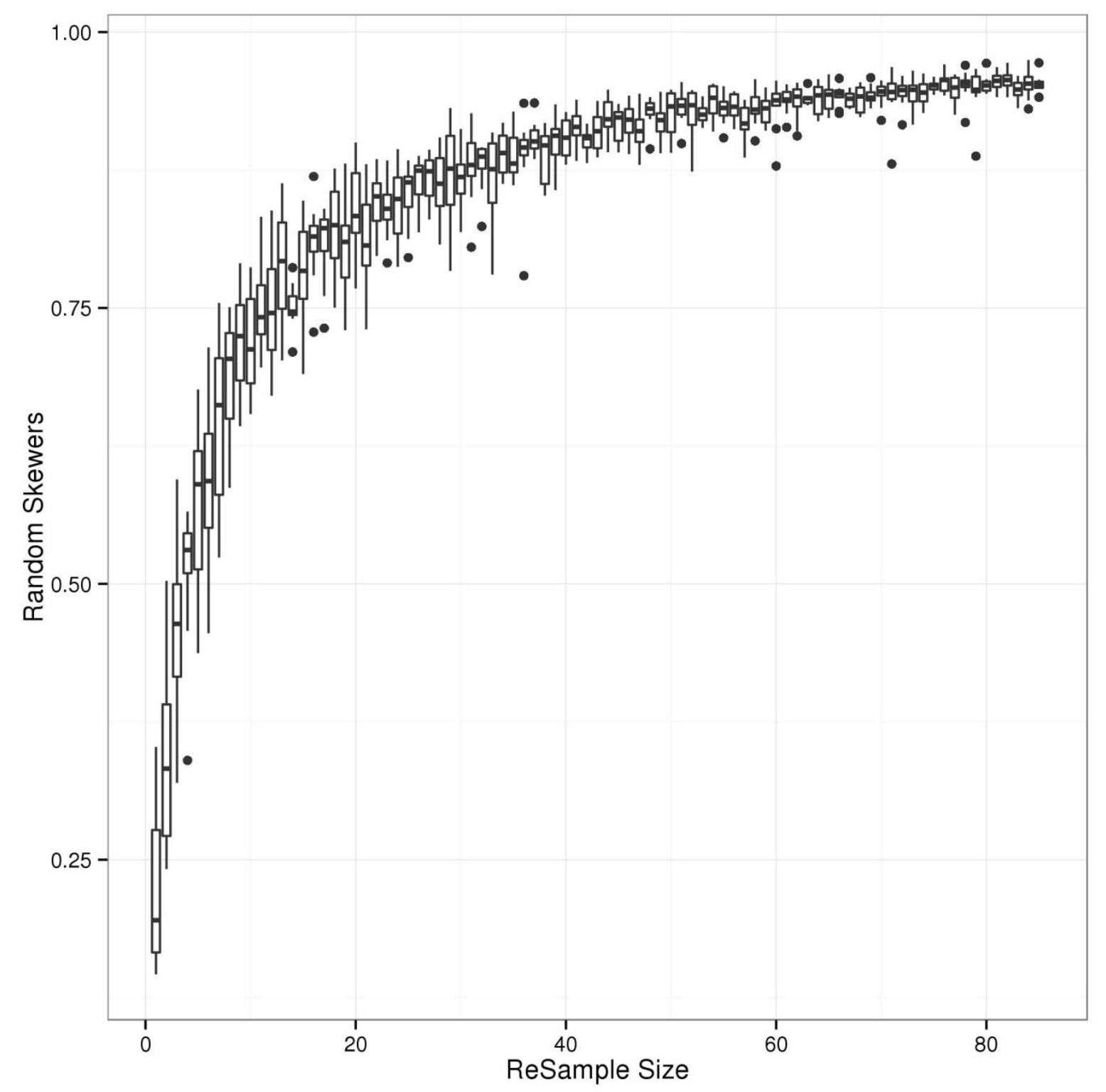

Figura A9b - Gráfico de rarefação para a espécie Desmodus rotundus. No eixo x estão as reamostragens a partir de uma amostra total de 86 indivíduos. No eixo y estão os valores de similaridade para matrizes de covariância estimadas por Random Skewers. 


\section{MATERIAL SUPLEMENTAR}

Lista completa dos espécimes analisados

Sigla das instituições: AMNH-American Museum of Natural History, Nova Iorque; FMNHField Musem of Natural History, Chicago; MN- Museu Nacional, Rio de Janeiro; MVZMuseum of Vertebrate Zoology, Berkeley ; MZUSP- Museu de Zoologia da Universidade de São Paulo, São Paulo; NMNH- National Museum of Natural History, Washington D.C.; SJRPLaboratório de Chiroptera UNESP, São José do Rio Preto; TTU- Texas Tech University, Lubbock.

Ametrida Centurio (N= 48) NMNH $q$ - 370784, 370785, 370786, 370788, 370789, 370796, 387567, 387568, 387576, 387577, 387579, 387600, 387605, 387608, 387609, 387624, 387629, 387630, 387632, 405651, 405652, 405655, 405656, 370783, 372394, 387571, 387572, 387574, 387578, 387613, 387616, 387617, 387628, 387631, 387635, 405654, 409221, 560746; ڤึ- 370783, 372394, 387571, 387572, 387574, 387578, 387613, 387616, 387617, 387628, 387631, 387635, 405654, 409221, 560746, TTU: $+-8766,8772,8773$, $8779,8781,8793,8795,8801,8803 ;$ ふૈ- 8788

Anoura geoffroyi (N= 39), AMNH: 9 - 230222, 230223, 230231, 230233, 230243, 230259, 230261, 230265, 230266, 230269; స̂- 230216, 230225, 230226, 230227, 230228, 230229, 230230, 230234, 230235, 230240, 230241, 230242, 230260, 230263, 230264, 230267, 230268, 230270, 230271, 230272, 230273, 230274, 230275, 230276, 230277, 230278, 233260, 233303; NMNH: $\widehat{\jmath}-195127$ 
Artibeus flavescens (N= 59) NMNH: $q-113926,252771,534909,534911,545167,545170$, 545171, 545172, 545173, 545174, 545176, 545178, 545179, 545180, 545181, 545184, 545185, 546358; ふૈ- 534910, 545168, 545169, 545175, 545177, 545182, 545183; TTU: ㅇ$21720,21721,21724,21725,21726,21727,21728,21730,21731,21732,21733,21734$, $21756,21757,21758,21759,21760,21773,21775,21777,21782,22729$; Љ- 21714, 21715, $21716,21717,21718,21719,21722,21723,21769,21770,21774,21781$

Artibeus fimbriatus (N= 51), SJRP: + - 11643, 11644, 12636, 14929, 15221, 15245, 15246, $15250,15265,15266,15744,15749,15767,15772,15789,16048,16055,16059,16062$ $16063,16067,16070,16127,16128,16132,16166$; Љ-11645, 12634, 12643, 14309, 15217, $15218,15254,15739,15740,15742,15769,15777,15835,16051,16053,16056,16057$, $16065,16133,16139,16141,16150,16151,16162,16167$

Artibeus lituratus (N= 40), SJRP: P- 10426, 10427, 10461, 10464, 10477, 10478, 10482, 10483, 11121, 11993, 11994, 11995, 12186, 13049, 14280, 15743, 16058, 16172, 16190, $16194 ; 0-10428,10436,10480,11126,11141,11142,11991,11992,12187,12200,12237$, $12447,12760,12776,13047,14313,15592,16144,16169,18134$

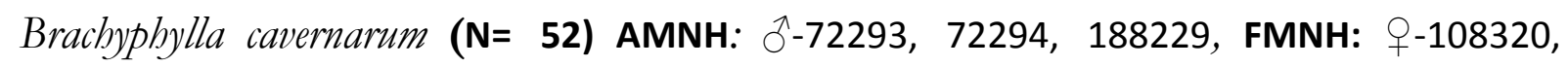
108322, §ิ-91292, 108318, 108319, 108321; NMNH: $+-37394,104060,106006,106010$, 
$106057,106058,106060,106066,106073,113615,113616,113623,123254,123256$, $123263,123265,123276,123286,123288,308680,308683,308686,544828,544831$, 544832, Љ-106011, 106025, 106026, 123250, 123262, 123267, 123270, 308689, 308690, 544829, 544830, 544833, 580677; TTU: $.+31434,31435,31439$, Љ-31425, 31447

Carollia brevicauda (N= 69), FMNH: $q-126875,126877,126878,126879,126880,126881$, $126883,126884,126885,126886,126887,126889,126890,126893,126896,126897$, $126898,126902,126904,126905,126910,126911,126912,126913,126914,126917$, $126918,126920,126925,126926,126928,126929,126932,126933,126938,126940$, $126941,126943,126944,126946$; స-126876, 126882, 126888, 126892, 126894, 126899, $126900,126903,126906,126907,126908,126909,126915,126916,126919,126921$, $126922,126924,126927,126930,126931,126934,126935,126936,126937,126939$, $126942,126945,1268891$

Centurio senex senex (N= 66), FMNH: + - 41795, 41796, 41800, 41804, 41806, 41808, 41810, 41811, 41812, 41813, 41816, 58227, 106819, 127058, 128412, ふ- 41802, 41803, 41805, 41815, 58228, 58581, 58582, 120888, 120889; NMNH: $:-170861,260023,310231,310232$, 310234, 310235, 310237, 310238, 310239, 310245, 310248, 310249, 310250, 310251, 332769, 508827, 511475, 511476, 511477, 511478, 511479, 511481, 511482, 511483, 511485, 511486, 511740, 526244, 559704, 559705, 559706, 565041, 583061; ๙̂- 313194, $503837,511473,511474,511487,511488,511741,514970,565040$ 
Chiroderma villosum (N= 60), NMNH: 9 - 416131, 416133, 416135, 416136, 416138, 416143, 416147, 416154, 416155, 416157, 416158, 416163, 416170, 416171, 416173, 416174, 416177, 416179, 416181, 416192, 416193, 416198, 416200, 416202, 416208, 416211, 416212, 416216, 416220, 416223, 416225, 416226, 416233, 416235, 416243; Љ̂- 416130, 416139, 416150, 416152, 416153, 416162, 416165, 416196, 416215, 416230, 416242, 416245, 416246, 416263, 416264, 416273, 416274, 416281, 416282, 416290, 416300, $416318,416321,416328,416337$

Choeronycteris mexicana (N= 57), AMNH: - 27306, 27309, 27319, 212360, 212362, 212365, 212369, 213003, 237361, 243862; Љ̂-27308, 208229, 212358, 212359, 212361, 212368, 213004, 213762, 237362; Sexo indeterminado- 27366; FMNH: - - 73349, 73350, 73352, 142623, 43773, 43775, 50804, 68239, 329434, 329436, 507121, 511302, 511304, 511305, 531295, 531296, 552744, 554267, 554268, 559560; Љ- 68234, 68235, 375693, 508546, 511303, 556301; Sexo indeterminado- 314688; TTU: + - 6288, 6360, 6447, 36120, 44737, §$24190,36117,36118,82613,82614$

Chrotopterus auritus (N= 58) FMNH: $q-125417,113852,305204,335156,371568,371570$, 388935, 388936, 388939, 388941, 407627, 419249, 460094, 588493, 588494; ふૈ- 31574, 122138, 309372, 311575, 335151, 335152, 335153, 335154, 335155, 335157, 335158, 337976, 337977, 362400, 362401, 370090, 371572, 371573, 385519, 388937, 388938, 388943, 388944, 388945, 391039, 419252, 419253, 444406, 517315, 530910, 549357, 
549358, 564306, 582293, 583010; SJRP: + - 2610, 2611, 2814, 3505, 14908; Љ- 2612, 15604, 16274

Dermanura phaeotis (N= 45) FMNH: $q-127000,127001,127002,127004,127006,127009$, $127010,127011,127020,127025,127026,127029,127030,127031,127036,127038$, 127045, 127048; đ-126994, 126997, 126998, 126999, 127003, 127005, 127007, 127012, $127013,127014,127015,127016,127017,127018,127021,127024,127027,127032$, $127033,127034,127035,127039,127040,127041,127043,127044,127047$

Desmodus rotundus (N= 86), MZUSP: O- 16654, 16655, 16664, 16665, 16669, 16677, 16678, $16679,16680,16681,16682,16698,16699,16700,16702,16703,16704,16706,16712$ $16713,16715,16716,16717,16718,16719,16720,16740,16741,16742,16743,16745$, $16747,16749,16750,16752,16753,16754,16772,16773,16774,16775,16780,16785$; ふ$16656,16657,16658,16659,16660,16662,16663,16667,16670,16675,16676,16683$, $16684,16685,16686,16689,16694,16707,16708,16710,16711,16723,16724,16727$, $16728,16729,16732,16733,16735,16736,16737,16738,16739,16751,16756,16771$, $16778,16779,16781,16782,16783,16784,16788$

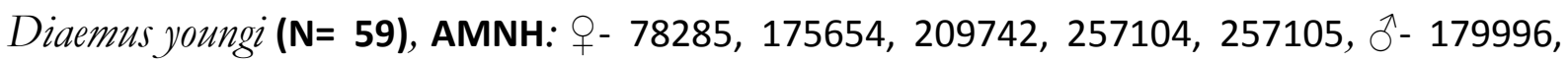
209743, 209744, 209745, 209746, 257103, 266347;NMNH: + - 140769, 393030, 409369, 441629, 536938; đ- 335399, 335400, 361772, 393029, 405768, 405769, 405770, 409367, 409370, 409372, 441628, 555710; SJRP: + - 10697, 10698, 10699, 10701, 10702, 10702, 
$10704,10705,10706,10708,10710,10714,10716,10717,10718,11946,12030,12031$; đ2556, 10700, 10703, 10713, 12087; TTU:ㅇ- 5232, 27591, 62792, 75273; ふぇ- 5233, 5411, 5428

Diphylla ecaudata(N= 56); FMNH: $q-43140,55456,58478,62116,64498,64622,64671$, 64675, 73346, 73347, 73348, 94714, 121071; ڤ̂- 55530, 64623, 64669, 73344, 73345, 89088,

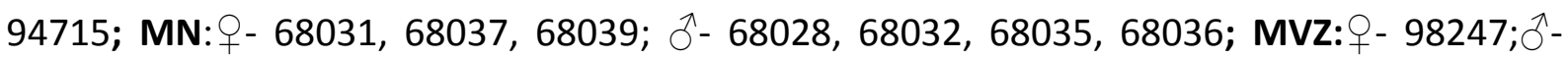
130955; NMNH: $+-14138,177557,335401,338090,338093,391123,391125,405773$, 441630, 549502; §- 238006, 315733, 338091, 338092, 338094, 391124, 391126, 391128, 405772, 548335, 548336, 549503, 556327, 564575; SJRP:ㅇ- 15597, 16147, 16281

Enchisthenes hartii (N= 62), NMNH: $ᄋ-310213,310215,310216,310219,310220,310221$, $310222,310223,310224,310229,323537,323539,323540,323541,338048,338049$, $338052,338053,338054,370729,370734,370735,370737,370745,370748,370756$, 370769, 370773, 387558, 387564, 409220, 441472, 517492, 517493, 517496, 517498, 537601, 562916, 562917; స̂'-310226, 310228, 323542, 338046, 338047, 338058, 370733, $370743,370758,370762,370763,370766,370768,370771,370772,370782,372386$, $387556,387565,409217,517494,517497,539813$

Erophylla sezekorni $(\mathbf{N}=\mathbf{6 0})$,TTU: O- 70371, 70373, 70390, 70392, 70395, 70401, 70409, 70410, 70425, 70430, 70434, 70437, 70441, 70451, 70453, 70454, 70455, 70469, 70481, 70503, 70513, 70514, 70514, 70516, 70516, 70517, 70534, 70542, 70543, 70570;ð- 70363, 70367, 70385, 70398, 70399, 70405, 70417, 70418, 70421, 70431, 70435, 70436, 70444, 
70446, 70449, 70450, 70460, 70463, 70473, 70518, 70519, 70520, 70524, 70528, 70532, 70533, 70536, 70540, 70547, 70548

Glossophaga soricina (N= 35) ,SJRP: $q-2513,2668,2747,2846,3026,3353,3385,3455$, $11888,11935,12164,12165,12208,12223,12225,12227,12228,15894,15906,15957$, 15962, 16242, 16287; ô -2464, 2514, 2744, 2955, 3021, 3098, 3132, 3176, 3362, 12004, 12166,15905

Leptonycteris curasoae (N= 61), NMNH: + - 444973, 444974, 444975, 444976, 444977, 444978, 444979, 444980, 444981, 455063, 455064, 455066, 455071, 455145, 455146, 455148, 455149, 455156, 455159, 455160, 455162, 455163, 455168, 455171, 455174, 455175, 455177; đ-444904, 444908, 444913, 444916, 444921, 444922, 444929, 444931, 444933, 444934, 444935, 444948, 444949, 444952, 444953, 444954, 444961, 444962, 444968, 444970, 444971, 444984, 444985, 444996, 444998, 455006, 455007, 455008, 455009, $455019,455027,455059,455060,455061$

Lionycteris spurrelli $(\mathbf{N}=\mathbf{6 0})$, $\mathbf{N M N H : ~}$ - $-385710,385722,385723,385725,385728,385729$, $385735,385742,385744,385746,389097,389098,407811,407813,407815,407817$, 407821, 407822, 407824, 407826, 407828, 442945, 442946, 442947, 442949, 442951, 444674, 444677, 444678, 444679, 444680, 444682, 444685, 559188; ๙-385698, 385708, 385721, 385724, 385734, 385738, 385739, 385740, 389096, 407810, 407818, 407823, 
407827, 442948, 442952, 444672, 444675, 444676, 444681, 444683, 444693, 444700, $444703,444704,559187,560559$

Lonchopbylla robusta (N= 68), NMNH: $\bigcirc-173851,173852,179624,179625,179626,179627$, 304882, 305237, 306588, 306590, 309394, 311989, 311993, 313747, 315305, 315308, $315309,317594,317598,331255,335183,362541,362564,362569,362571,362572$, 362577, 362582, 362583, 449657, 464622, 464623, 464629; Љ̂-261424, 306586, 306587, 306589, 309390, 311986, 311990, 311995, 311999, 313749, 315304, 315306, 315307, 317599, 331256, 360169, 362543, 362544, 362550, 362551, 362552, 362554, 362566, 362567, 362575, 444616, 464613, 464615, 464617, 464618, 464621, 464624, 464625, 464627,464628

Lonchorbina aurita (N= 39); MVZ: ○-118766, 118767, 118768, 118769; §-118764, 118765, 118770; NMNH: - $-305186,305188,305189,305190,311911,311938,313731,313733$, 315210, 549343, 549344; స̂- 305187, 313729, 311934, 311941, 313100, 313101, 313102, 313103, 313105, 313106, 313728, 313730, 313732, 319252, 499290, 554262, 562755, $562756,562757,562758,562759$

Lonchorbina orinocensis $(\mathbf{N}=40), \mathbf{N M N H : ~}+-373255,373260,373274,373277,373288$, $373294,373296,373297,373298,373417,373429,373468,407268$; ๙- 373257, 373259, $373264,373265,373268,373269,373270,373276,373285,373295,373337,373346$, 
$373347,373354,373359,373360,373372,373383,373388,373394,373402,373416$, $373420,373441,373457,407267,407269$

Lophostoma silviculum (N= 70), AMNH: q-67943, 67948, 71457, 71459, 71466, 73527, 74102, 74374, 75318, 75319, 98733, 230124, 230129; Љ-64026, 64031, 66799, 67938,

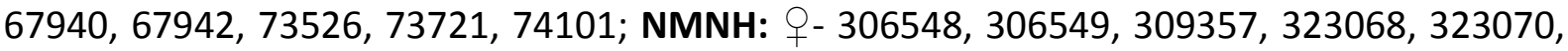
$323071,323072,323073,323075,332045,335111,335114,335117,337975,396400$, 449606, 461096, 461099, 461100, 461101, 520547, 520548, 520549, 522064, 528483, 539805, 575458, 575459; 今̂- 304876, 323074, 323076, 323080, 323082, 335113, 335115, 335116, 362459, 362460, 396401, 449605, 461095, 461097, 519698, 575457, 575460, $575461,575462,575463$

Macrophyllum macrophyllum (N= 51), AMNH: q-97252, 177670, 177671; đ-78416, 94551, 262424; NMNH: - $-311943,311945,312933,312935,312937,312938,312940,312942$, $312943,312947,312948,312956,312958,312959,312960,312965,315213,315214$, 315215, 315216, 335103, 498712, 519699, 554525, 554529; Љ̂-178235, 178236, 306547, 311944, 312932, 312946, 312950, 312951, 312953, 312963, 315212, 315217, 317590, $361504,361505,361506,373478,385448,388741,407270$

Macrotus californicus (N= 59) AMNH: $q-139569,139570,139571,170822,170823,170824$, 170826, 170848; NMNH: ○-99862, 181206, 314678, 314681, Љ̂-99837, 99857, 137001, 137003, 137005, 137006, 137007, 137008, 137009, 137010, 137011, 212213, 212214, 
212215, 212216, 212217, 212218, 212219, 212221, 212222, 314679, 314682, 570793, 570802, 570822, TTU: ㅇ-39908, 39909, 39911, 39912, 39916, 39918, 39920, 39922, 39923, 39924, 39926, 39927, 39929, 39930, 39931, 39932, 39933, 39949, 39950, 39951, 39952, 39955

Macrotus waterhousii (N= 57), NMNH: + $-508487,508488,508489,511286,511287,512193$, 512194, 512195, 512229, 512231, 512232, 512233, 512234, 512235, 512239, 512242, 512247, 512248, 512249, 512250, 512251; శో-511288, 512192, 512197, 512198, 512199, 512200, 512202, 512203, 512204, 512205, 512206, 512207, 512210, 512211, 512212, 512213, 512215, 512224, 512226, 512227, TTU:우-10566, 14228, 14229, 14231, 14242, 14256, 14265, 14266, 14271, 14272; ठో-14220, 14234, 14237, 14251, 14258, 14263

Mesophylla macconnelli (N= 61) AMNH: q $_{-}$48271, 48272, 187223, 208073, 233741, 233745, 233746, 246626, 262540, 266039, 267281; đ- 48269, 172125, 209580, 214368, 233742, 233747, 248887, 262541, 268539, 2675620; NMNH:. - 309978, 331689, 361726, 362922, 405188, 408820, 408822, 408823, 408824, 408852, 460132, 483778, 483779, 499483, 549426, 560608, 560610, 560611, 566547, 574540, 575553, 582327, ○-315564, 331687, 331688, 393715, 408825, 408830, 408846, 408847, 440772, 460133, 530918, 530980, $548244,549427,560609,566546,566548,582869$

Micronycteris microtis, (N= 60), NMNH: + - 296251, 296252, 296257, 304868, 305183, 311890, 311892, 311908, 312914, 312917, 313076, 313077, 313081, 313091, 313098, 313721, 
315200, 315204, 323054, 323056, 331107, 464267, 575449; ふ- 296250, 296254, 296256, 304867, 304869, 306544, 306545, 309356, 311889, 311893, 311904, 312919, 312922, $312922,312924,312925,313083,313085,313086,313173,313173,313722,313723$, 315202, 315203, 315205, 337972, 448354, 448355, 539800, 539801, 539801, 539803, $575444,575446,575451,578983$

Minon crenulatum, (N= 39); AMNH: $\odot$ - 230132, 267437, 267887, 335121; đ- 267177, 267880, 267884, 578146, 582790; MVZ: - 136404, 154777; đ -136405, 157658, 157659, 168856; NMNH: + - 370087, 371473, 371490, 371495, 371503, 371508, 373499, 418975, 418976, 560776; ڤ̂- 371492, 371493, 371494, 371499, 371501, 371507, 373492, 373495, 373497, $373500,385456,385458,385459,388756$

Monophyllus redmani (N= 58) AMNH: $9-45235,45236,45237,45238,45245,45246,45247$, 271525, 271526, 271527, 271530, 271533; ภ̂-45232, 45239, 271522, 271523, 271524, 271528, 271529, 271536, 271539; NMNH:ㅇ- 534893, 534895, 545163; Љో-64480, 534899, 534900, 534903, 534905, 545160, 545161, 545162, 546355; TTU: q-21602, 21603, 21604, 21605, 21606, 21607, 21629, 21631, 21638, 21639, 21641, 21642, 21691; Љ-21608, 21609, 21610, 21611, 21612, 21613, 21614, 21615, 21616, 21617, 21640, 21692

Phylloderma stenops(N= 34) NMNH: $+-506468,361532,371547,388839,388841,388843$, 388848, 407584, 407588, 528488, 564304, 582287, 582289; Љ̂-335142, 335143, 335144, 
373527, 388840, 388846, 388847, 407585, 457937, 519694, 530954, 530955, 575469, 582288; AMNH: $+-126867,126869,267441 ;$ ふ-266077, 267890, 267891; TTU:

Phyllonycteris poeyi $(\mathbf{N}=\mathbf{6 0}), \mathbf{N M N H}$ : $-49565,103548,103550,103551,103553,103554$, $103558,103564,103580,103582,103585,103588,103589,103592,103598,103602$, 103604, 103609, 103610, 103611, 113725, 113726, 113729, 113730, 113731; Љ-49568, 103537, 103541, 103544, 103546, 103547, 103560, 103579, 103581, 103586, 103591, 103597, 103600, 103601, 103603, 103605, 103607, 103608, 113728, 143845; Sexo indeterminado- 103445, 103556, 103557, 103559, 103567, 103568, 103569, 103571, $103572,103573,103574,103575,103576,103577,103578$

Phyllops falcatus (N= 50), NMNH: $+-143662,538317,538318,538337,538338,538340$, 538341, 538343, 538344; ๙ో-538339, 538342, 538345, 542273; TTU: ○-22676, 22677, 22678, 22679, 22680, 22681, 22682, 22683, 22685, 22686, 22687, 22689, 22692, 22693, 22694, 22695, 22696, 22703, 22757; ঐ-22675, 22684, 22691, 22697, 22698, 22699, 22700, 22701, $22712,22713,22714,22715,22716,22717,22718,22719,22720,22733$

Phyllostomus hastatus (N= 64), FMNH: +-24908, 24911, 65752, 68402, 68403, 68404, 68405, $68408,68409,68411,68412,68413,68414,68417,68418,68419,68422,68423,68425$, 68426, 68428, 138868; ठో-24907, 24909, 55450, 62103, 62107, 65829, 68400, 68406, 68415, 68420, 68424 ; SJRP: $q-2342,2887,2888,2956,2957,2977,2988,3066,3171,3554,4053$, 
4204, 4205; đ-2064, 2544, 2558, 2568, 2836, 2892, 2893, 2894, 3065, 3218, 4207, 4208, $11748,11873,11942,11943,11944,11945$

Platyrrbinus vittatus (N= 59) ,NMNH: $+-309692,309693,309694,309696,309697,309698$, 309700, 309701, 309702, 309705, 309713, 309717, 309719, 309720, 309721, 309723, 309724, 309730, 309731, 309732, 309738, 309739, 309740, 309745, 309747, 309752, 309755, 319403, 319495, 331674, 338030, 338034, 338035, 338037, 338039; Љ-309691, 309695, 309703, 309704, 309706, 309707, 309711, 309712, 309714, 309715, 309716, $309725,309735,314244,319400,319401,319402,319494,338029,338031,338032$, $338033,338038,338040$

Pygoderma bilabiatum (N= 57), TTU: + -94136, 94579, 94584, 94626, 94653, 94732, 94760, 94764, 94768, 94769, 94770, 94771, 94777, 94954, 94962, 95103, 95108, 95178, 95203, 95327, 95387, 95417, 95422, 95428, 95486, 95596, 95655, 95668, 95669; Љో-94447, 94509, 94565, 94733, 94755, 94956, 95179, 95205, 95238, 95314, 95342, 95424, 95425, 95674, 95742, 95800, 95814, 96005, 96033, 96045, 96049, 96051, 96062, 96078, 96101, 96205, 96206, 96207

Rhinophylla pumilio (N= 52), NMNH: $q-361636,361637,361639,361640,361643,361646$, 386540, 386541, 386542, 386543, 386544, 386545, 386552, 386555, 389750, 461512, 528331, 530974, 530975, 548123, 548125, 548126, 548127, 560572, 560573, 560779, 560780, 562229, 574531, 574532, 574535; ๙-361645, 386539, 393015, 393673, 393674, 
393675, 393676, 461514, 530911, 530968, 530969, 530971, 530972, 548124, 560571, $560574,560575,574529,574530,574533,574534$

Sphaeronycteris toxophyllum (N= 64) ,NMNH: $9-122785,143657,370797,370798,370802$, $370803,370805,370806,370808,370810,370814,370815,370817,370819,370833$, 370836, 370839, 370840, 370841, 370842, 370843, 370845, 370846, 370849, 372393, 405662, 405663, 405664, 405665, 405666, 405670, 405673, 405674, 405675, 405678, 405684, 409234, 409235, 409238, 441477, 441481, 455933; た̂-370799, 370800, 370801, $370804,370807,370809,370812,370816,370818,370823,370829,370834,370837$, $370838,370847,387637,387639,409233,409239,441480,455934,455938$

Stenoderma rufum (N=60), TTU: q-22352, 22370, 22372, 22373, 22375, 22377, 22378, 22380, 22382, 22385, 22388, 22389, 22392, 43466, 43471, 43474, 43475, 43476, 43481, 43482, 43483, 43484, 43487, 43497, 43498, 43500, 43501, 43502, 43505, 43538, 43546, 46373, 46377, 52900; §ో-8875, 22351, 22361, 22364, 22366, 22367, 22369, 43465, 43468, 43470, 43472, 43486, 43492, 43494, 43503, 43506, 43539, 43541, 43542, 43543, 43544, $43548,46372,46375,56141,57029$

Tonatia saurophila $(\mathbf{N}=\mathbf{5 0})$ AMNH: $+-96964,97226,139443,139444,139445,180262$, 182923, 266047, 267429, 267914; đ-130704, 267430, 267431, 267912, 267915; NMNH: q$306550,361507,361508,361509,371442,373483,388743,388746,448367,448368$, 464562, 528322, 530946, 530947, 539804, 562762, 575456; §-315218, 332044, 371443, 
371444, 418958, 519697, 520546, 526239, 548441, 560555, 560798, 562761, 575454, 582081, 582271, 582272, 588490; TTU: +-84122

Trachops cirrhosus $(\mathbf{N}=60)$ NMNH: -4-419130, 419131, 419148, 419150, 419151, 419154, 419157, 419158, 419166, 419169, 419197, 419199, 419201, 419202, 419210, 419217, 419220, 419226, 419229, 419230, 419232, 419233, 419235, 419242, 419243, 444379, 444383, 444393, 444397, 444398; స-419128, 419136, 419137, 419141, 419145, 419146, 419159, 419160, 419161, 419165, 419168, 419193, 419196, 419204, 419208, 419211, 419212, 419213, 419214, 419218, 419221, 419222, 419224, 419225, 419237, 419239, $419240,419244,444380,444394$

Trinycetris nicefori $(\mathbf{N}=\mathbf{6 1}), \mathbf{N M N H :}$ - $-385294,385317,385319,385323,385326,385343$, $385344,385345,385346,385353,385355,385356,385357,385361,385365,385366$, $385371,385376,385377,385379,385380,385384,385389,385393,385404,385410$, 385415, 385420, 385423, 385439, 385441, 385442, 388729, 560552; ๙ิ-371417, 385295, $385351,385352,385367,385368,385369,385372,385373,385374,385383,385385$, $385392,385400,385403,385417,385422,385436,385437,385438,385443,385444$, $385445,388727,388730,388732,407255$

Uroderma magnirostrum (N= 60), NMNH: q-408398, 408399, 408404, 408406, 415703, 415710, 415711, 415712, 415713, 415714, 415715, 415716, 415717, 415719, 415720, 415722, 415723, 415724, 415725, 415726, 415727, 415729, 415730, 415731, 415735, 
415736, 415743, 415790, 415794, 415796, 415797, 415798, 415801, 415802, 415803, 415804, 415819, 415820, 415827, 415828, 415832, 415833; స-408401, 408402, 408403, 408405, 415702, 415718, 415721, 415733, 415739, 415744, 415745, 415793, 415799, $415800,415806,415818,415839,415844$

Vampyressa thyone (N= 62), NMNH: $q-179622,304902,309864,309865,309866,309876$, $318129,319414,323427,323428,323429,323430,323431,323434,323435,323437$, $323438,335275,335279,335282,338041,339026,440691,440694,440695,440703$, 440713, 440717, 440718, 440719, 440723, 440735, 440736, 443364, 503628, 514966; ○306733, 309863, 318351, 323425, 323432, 331683, 332052, 335277, 335281, 335283, 440698, 440702, 440712, 440720, 440721, 440726, 457953, 503629, 503630, 503633, $503636,514967,518014,520564,520565,536054$

Vampyriscus bidens (N= 48), NMNH: $q-387187,405057,405072,405074,405076,405077$, 405084, 405089, 405092, 405096, 405099, 405101, 405106, 405107, 405109, 405111, 408574, 408576, 408580, 408581, 408595, 415227, 440370; స-387190, 405058, 405061, 405062, 405063, 405069, 405070, 405078, 405079, 405080, 405081, 405083, 405085, 405090, 405097, 405098, 405110, 408577, 408582, 408583, 408594, 408596, 408609, 415225,440433

Vampyrodes major (N= 62), NMNH: $+-304896,304900,306730,306731,309756,309757$, 309759, 309760, 309762, 309764, 309765, 309766, 309768, 309770, 309772, 309773, 
309774, 309780, 309782, 309783, 309790, 309798, 309803, 309808, 309810, 309811, 309812, 309823, 309827, 309829, 309831, 309839, 315546; §-304897, 304898, 304899, 304901, 306729, 309761, 309767, 309775, 309777, 309779, 309781, 309786, 309791, 309795, 309796, 309805, 309813, 309814, 309815, 309817, 309820, 309840, 309841, $309842,309847,309852,309854,309855,315547$

Vampyrum spectrum (N= 41), AMNH: + -256825, 267446; $\widehat{\jmath}-28993,66815,261379 ;$ Sexo indeterminado-7435, 7436; FMNH: ૧-51220, 55402; §ో-58160, 85786; MVZ: †-154780, 154781; NMNH: $+-319373,335160,335161,335162,335163,337312,337313,393007$, 407630, 503833, 528490, 560558, 562766, 564627, 568490, 582294; §-309373, 335159, 337314, 385520, 385521, 396402, 562765, 575471; TTU: ㅇ-5357, 9837; ○̂-9836, 11439 